Cuadernos

de trabajo social

No20 $\cdot 2013$ 
Alternativas. Cuadernos de Trabajo Social

$\mathrm{N}^{\circ}$ 20. Año 2013

\section{Dirección}

Ma Asunción Martínez-Román

masun.martinez@ua.es

Secretaria

Yolanda Domenech López

yolanda.domenech@ua.es

\section{Comité Editorial/Editorial Board}

Antonio Gorri Goñi. Universidad Pública de Navarra

Carmen Alemán Bracho. Universidad Nacional de Educación a Distancia

Carmen Barranco Expósito. Universidad de La Laguna

Jorge Garcés Ferrer. Universitat de València

María Asunción Martínez Román. Universidad de Alicante

Natividad de la Red Vega. Universidad de Valladolid

Víctor M. Giménez Bertomeu. Universidad de Alicante

Yolanda Domenech López. Universidad de Alicante

María Felicidad Tabuenca Cuevas. Universidad de Alicante (editora de inglés)

Consejo Científico Asesor/Advisory board

Clarisa Ramos Feijóo. Universidad de Alicante

Daniel La Parra Casado. Universidad de Alicante

Enrique Pastor Seller. Universidad de Murcia

Esther Villegas Castrillo. Universidad de Alicante

Fernando Casas Mínguez. Universidad de Castilla-La Mancha (Cuenca)

Fernando de Lucas y Murillo de la Cueva. Universidad Complutense

Francisco Javier Domínguez Alonso. Universidad de Alicante

Hortensia Redero Bellido. Universidad de Alicante

José Luis Sarasola-Sánchez Serrano. Universidad Pablo de Olavide. Sevilla

José Manuel Barbero García. Universitat de Girona

Josefina Fernández Barrera. Universidad de Barcelona

Luís Enrique Alonso Benito. Universidad Autónoma de Madrid

María Carmen Pérez Belda. Universidad de Alicante

María Jesús Uriz Pemán. Universidad Pública de Navarra

María Luisa Setién Santamaría. Universidad de Deusto

Marta Llobet Estany. Universidad de Barcelona

Miguel Ángel Mateo Pérez. Universidad de Alicante

Octavio Vázquez Aguado. Universidad de Huelva

Roberto Mohedano Menéndez. Universidad de Alicante

Santa Lázaro Fernández. Universidad Pontificia de Comillas

Consejo Científico Asesor Internacional/International Advisory board

Alberto Acosta Espinosa. Facultad Latinoamericana de Ciencias Sociales, (FLACSO- Ecuador). Quito, Ecuador. Annamaria Campanini. Università degli Studi di Milano-Bicocca. Milán, Italia.

Darja Zavirsek. University of Ljubljana. Ljubljana, Slovenia.

Göran Therborn. Göteborg University. Göteborg, Sweden.

John Gal. Paul Baerwald School of Social Work and Social Welfare. Hebrew University of Jerusalem. Jerusalem, Israel.

Johan Galtung. Transcend. Peace University. A Peace and Development Network.

Jorge M. L. Ferreira. ISCTE-Instituto Universitario de Lisboa. Lisboa, Portugal.

José Paulo Netto. Universidade Federal do Rio de Janeiro. Rio de Janeiro, Brasil.

Mona Fransehn. Göteborg University. Göteborg, Sweden.

Nino Zganec. University of Zagreb. Zagreb, Croatia.

Philip Mendes. Monash University. Melbourne, Australia.

\footnotetext{
* El Comité Editorial tiene las siguientes funciones. Asistir al editor de la revista, especialmente, en el seguimiento de los trabajos: recepción, evaluación, aceptación y decisión final sobre la publicación del trabajo. Asimismo es responsable del estilo, definición de las normas de presentación de trabajos y de establecer la estructura de la revista.
} 


\section{ALTERNATIVAS \\ Cuadernos de Trabajo Social}




\section{BASES DE DATOS}

ISOC. Base de Datos Bibliográficos de Ciencias Sociales y Humanidades del Centro Superior de Investigaciones Científicas (CSIC): http://bddoc.csic.es:8080/

Latindex (Catálogo y directorio). Sistema Regional de Información en Línea para Revistas Científicas de América Latina, el Caribe, España y Portugal: http://www.latindex.unam.mx/

PSICODOC: http://www.psicodoc.org/

DIALNET: http://dialnet.unirioja.es/

COMPLUDOC. Base de datos de artículos de Revistas: http://www.ucm.es/BUCM/complu/menu.htm

\section{PLATAFORMAS DE EVALUACIÓN DE REVISTAS}

DICE. Difusión y calidad editorial de las revistas españolas de Humanidades y Ciencias Sociales y Jurídicas: http://dice.cindoc.csic.es/index.php

CIRC. Clasificación Integrada de Revistas Científicas: http://epuc.cchs.csic.es/circ/

RESH. Revistas Españolas de Ciencias Sociales y Humanas: http://epuc.cchs.csic.es/resh/

MIAR. Matriu d'Informació d'Avaluació de Revistes: http://miar.ub.es/

IN-RECS. Índice de impacto de las revistas españolas de Ciencias Sociales: http://ec3.ugr.es/in-recs/

\section{REPOSITORIOS}

RUA. Repositorio institucional de la Universidad de Alicante: http://rua.ua.es/

Hispana. Directorio y recolector de recursos digitales del Ministerio de Educación: http://hispana.mcu.es/ DRIVER. Digital Repository Infrastructure Vision for European Research: http://search.driver.researchinfrastructures.eu/

OAIster. The OAIster database: http://oaister.worldcat.org/

OpenDOAR. The Directory of Open Access Repositories: http://www.opendoar.org/

RECOLECTA. Recolector de ciencia abierta: http://www.recolecta.net

Scientific Commons. http://en.scientificcommons.org/

Google Académico. http://scholar.google.es/

\section{CATÁLOGOS DE BIBLIOTECAS UNIVERSITARIAS}

Catálogo de la Universidad de Alicante. http://gaudi.ua.es/

Catálogo de la Red de Bibliotecas Universitarias españolas (REBIUN). http://www.rebiun.org/

Catàleg Col-lectiu de les Universitats de Catalunya (CCUC). http://ccuc.cbuc.cat

Catálogo del Consorcio de Bibliotecas Universitarias de Andalucía (CBUA). http://catcbua.cbua.es/

\section{DIRECCIÓN POSTAL}

Alternativas. Cuadernos de Trabajo Social. Universidad de Alicante

Departamento de Trabajo Social y Servicios Sociales. Ap. Correos 99 (03080) Alicante

dtsss@ua.es

Información estadística relativa al No 20. Año 2013

\begin{tabular}{|l|c|}
\hline Número total de trabajos recibidos / Total number of submissions & 16 \\
\hline Número de trabajos aceptados (\%) / Total number of submissions accepted & $10(62,5 \%)$ \\
\hline$\%$ de trabajos rechazados / \% of submissions rejected & $5(31,25 \%)$ \\
\hline Trabajos en proceso de revisión y evaluación (\%) / Submissions in review process (\%) & $1(6,25 \%)$ \\
\hline Número medio de revisores por artículos / Average number or reviewers per article & 2 \\
\hline Demora media recepción-revisión / Average time reception-review & 23,9 \\
\hline Demora media aceptación-publicación / Average time acceptance-publication & 43,3 \\
\hline Demora media recepción-publicación / Average time reception-publication & 179 \\
\hline \% de trabajos que comunican resultados de investigación originales / & $(7 / 10)$ \\
$\%$ works reporting results of original research & $70 \%$ \\
\hline $\begin{array}{l}\% \text { de autores externos al Comité Editorial / } \\
\% \text { of external authors (Editorial Board) }\end{array}$ & $(24 / 24)$ \\
\hline$\%$ de autores externos a la organización editora de la revista / & $100 \%$ \\
\hline of external authors (Publishing Organisation) & $(24 / 24)$ \\
\hline $\begin{array}{l}\% \text { de autores extranjeros / } \\
\% \text { Foreign authors }\end{array}$ & $100 \%$ \\
\hline $\begin{array}{l}\% \text { de trabajos financiados por organismos públicos o privados de investigación / } \\
\% \text { works funded by public/private reseach organisation }\end{array}$ & $(7 / 24)$ \\
\hline
\end{tabular}

El número 20 de la revista Alternativas. Cuadernos de trabajo social, correspondiente a 2013, se editó en diciembre de 2013. 


\section{ALTERNATIVAS \\ Cuadernos de Trabajo Social}

N. ${ }^{\circ}$ 20. Año 2013

DEPARTAMENTO DE TRABAJO SOCIAL Y SERVICIOS SOCIALES

UNIVERSIDAD DE ALICANTE 
La publicación de este número ha sido posible gracias a la obtención de una ayuda del Vicerrectorado de Investigación, Desarrollo e Innovación de la Universidad de Alicante.

TITULO: ALTERNATIVAS. CUADERNOS DE TRABAJO SOCIAL

ISSN: 1133-0473

ISSN electrónico: 1989-9971

EDITOR: Departamento de Trabajo Social y Servicios Sociales. Universidad de Alicante PERIODICIDAD: Anual

FECHA DE INICIO: 1992

WEB: http://dtsss.ua.es/es/alternativascuadernostrabajosocial/

CORREO ELECTRÓNICO: dtsss@ua.es

http://publicaciones.ua.es/publica/revistas.aspx?Cod=11

RUA: http://rua.ua.es/dspace/handle/10045/5269

TITLE: ALTERNATIVAS. CUADERNOS DE TRABAJO SOCIAL

ISSN: 1578-0236

Electronic ISSN: 1989-9971

PUBLISHER: Department of Social Work and Social Services, University of Alicante, Spain

PERIODICITY: Annual

START DATE: 1992

WEB: http://dtsss.ua.es/es/alternativascuadernostrabajosocial/

EMAIL: dtsss@ua.es

http://publicaciones.ua.es/publica/revistas.aspx?Cod=11

RUA: http://rua.ua.es/dspace/handle/10045/5269

Publicaciones de la Universidad de Alicante

Campus de San Vicente s/n

03690 San Vicente del Raspeig

Publicaciones@ua.es

http://publicaciones.ua.es

Teléfono: 965903480

() de la presente edición: Universidad de Alicante

ISSN: 1133-0473

ISSN electrónico: 1989-9971

Depósito legal: M.37.152-1992

Diseño de portada: candela ink

Composición: Marten Kwinkelenberg

Impresión:

Los contenidos están bajo una licencia Creative Commons Reconocimiento 3.0 España.

Los contenidos pueden copiarse, distribuirse o comunicarse públicamente, bajo las siguientes condiciones generales: Reconocimiento. Debe reconocerse los créditos de la obra de la manera especificada por el autor o el licenciador (pero no de una manera que sugiera que tiene su apoyo o apoyan el uso que hace de su obra). Los términos de la licencia disponibles on-line en: http://creativecommons.org/licenses/by-nc/3.0/es/ 


\section{ÍNDICE}

1. El doble estigma de la mujer consumidora de drogas: Estudio cualitativo sobre un Grupo de Auto Apoyo de mujeres con problemas de abuso de sustancias The double stigma of a female drug addict: a qualitative study of a support group of women substance abusers 9

ANTONI Llort SuÁrez, SARA FERrando ESQUerré, Tre Borrás

CABACÉS, IMMA PURROY ARITZETA

2. A community development critique of compulsory income management in Australia

Una crítica del desarrollo comunitario sobre la gestión obligatoria de ingresos en Australia

Philip Mendes, Jacinta Waugh And CATHERINE FlynN

3. Jóvenes que migran solos. Actores y escenarios fuera de los sistemas de protección de menores

Youths who migrate alone. Actors and scenes outside of the children care

systems

CHABIER GIMENO MONTERDE

4. La politica de reeducación en la Comunitat Valenciana. Un analisis de las prácticas educativas de los Centros de justicia juvenil

Re-education policy in the Comunitat Valenciana region. An analysis of educational practices in juvenile justice Centers 57

Francesc XaVier UCEDA I MaZA y José JaVIER NAVARRo PÉREZ

5. Serviço social crítico: da modernidade à contemporaneidade

Critical social work: from modernity to contemporaneity

Helena Belchior Rocha, Paula Marques Ferreira, Teresa Paula

SiLVA, VANDA BRAZ RAMALHO

6. La heterogeneidad conceptual del Tercer Sector

Conceptual heterogeneity of the Non-profit sector....

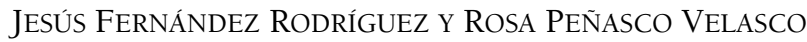

7. Aproximación a la realidad de los desahucios. Perfil y características

de las familias en proceso de desahucios en la ciudad de Málaga

An approach to the reality of evictions. Profile and characteristics of families in the process of eviction in the city of Málaga

RAFAEl ARREDONDO QUIJADA Y MARÍA DE LAS Olas PALMa GARCíA 
8. Impacto de la crisis económica y los cambios en las políticas sociales en el perfil, necesidades y prestaciones de las personas usuarias de los servicios sociales municipales. Análisis de caso local en la Región de Murcia (España)

Economic crisis impact and social policy changes in the profile, needs and benefits of municipal social services' users. A local case study in the region of Murcia (Spain)

ENRIQUe PASTOR SElLER Y MARGarita SÁNCHEZ Millán

9. Aplicación del sistema de promoción de la autonomía personal y atención a personas en situación de dependencia en la Comunitat Valenciana: efectos sobre el ejercicio del derecho social Promotional implementation of the personal autonomy and care for dependent situations in the Valencian Community: effects on the exercise of the social right. 163

CARMEN MONTALBÁ OCAÑA

10. Proceso de selección de los centros de prácticas de trabajo social. Instrumento de sistematización y objetivación

Selection process for centres hosting social work student interns.

Instrument to ensure systematic objective results

Amaia Mosteiro Pascual, Usue BeloKi Marañón,

EMMA SOBREMONTE MENDICUTI

\section{RESEÑAS}

Título: Vivienda y exclusión residencial

Autor: Manuel Hernández Pedreño (coord.)

Edita: Editum. Murcia. 2013. 317 pp.

ISBN: 978-84-15463-72-6

Título: Trabajo Social, Concepto y Metodología

Autora: María José Aguilar Idañez

Edita: Ediciones Paraninfo y Consejo General del Trabajo Social, Madrid, 2013, 435 p.

ISBN: 978-84-283-3485-3

Título: Presente y futuro de la formación en Trabajo Social. III Congreso

Andaluz de Centros Universitarios de Trabajo Social (Málaga, junio de 2011)

Autoras: Gallego Fontalba, C. (Coord.) y Palma García, M.O.

Edita: Colegio Profesional de Trabajo Social de Málaga, 2013

ISBN: 978-84-695-8643-3

Instrucciones para los autores 213

Instructions for the authors 231

Protocolo revisores externos 247

External reviewers' protocol. 


\title{
EL DOBLE ESTIGMA DE LA MUJER CONSUMIDORA DE \\ DROGAS: ESTUDIO CUALITATIVO SOBRE UN GRUPO DE AUTO APOYO DE MUJERES CON PROBLEMAS DE ABUSO DE SUSTANCIAS $^{1}$
}

\author{
The double stigma of a female drug addict: a qualitative study of a \\ support group of women substance abusers
}

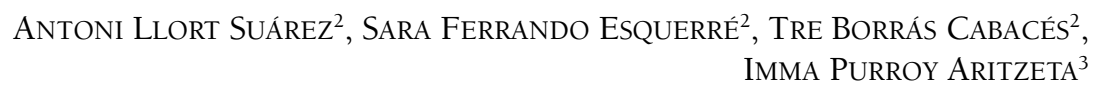

\section{Resumen}

Los estudios sobre género y drogas han sido un campo de la investigación en salud poco desarrollado y difundido y en el que se ha trabajado poco hasta el momento. El texto que se presenta aquí pretende mostrar la investigación desde la perspectiva antropológica sobre un Grupo de Auto Apoyo entre mujeres drogodependientes, visibilizando mediante técnicas cualitativas aspectos biográficos y de relación con las sustancias que permiten señalar diferencias y desigualdades de género en relación a la atención a la salud.

La investigación cualitativa aplicada se ha centrado en el conocimiento de aspectos y significaciones sobre los procesos de salud/enfermedad/atención y consumo de drogas, la búsqueda de elementos que permitan evaluar y mejorar el funcionamiento del propio grupo y por último aspectos específicos desde la perspectiva de género. Para ello se han realizado 8 entrevistas semi estructuradas en profundidad y 2 entrevistas grupales. Algunos de los principales resultados han sido que los factores socio estructurales son tanto o más influyentes en el problema del consumo de sustancias psicoactivas que las propias sustancias o la características individuales de las usuarias, siendo la confluencia de los tres factores el punto de partida de nuestro trabajo. La constatación del doble estigma; uno por romper los roles tradicionales de género y el otro por ser consumidoras de drogas ilegales, la gran influencia de las relaciones con parejas masculinas vinculadas al consumo problemático y la constatación de que los Grupos de Apoyo pueden introducir mejoras importantes en la calidad de vida de las participantes, son algunos de los resultados más destacados.

Palabras clave: drogas, género, desigualdad, Grupo de Apoyo, empoderamiento, investigación cualitativa.
Summary

The main objective of this paper is to present the methodology and first results of a qualitative ethnographic research, applied to a support group of women who use a Service for Drug Dependence and Abuse providing the experience obtained from the dynamic relationship between social intervention and the study of gender and drug use. Eight semi-structured interviews of 25 participants, and two focus groups focused on the gender relationship have been the study sample. The qualitative study has focused on the knowledge of aspects related to the biographical itinerary, implications on health and drug use, search for elements to improve the functioning of the group and specific issues from the perspective of gender. Social and structural factors are more or equally influential on the problem of psychoactive substance abuse than themselves or an individual's characteristics which led to the confluence of these three factors and the starting the point of our work. The realization of a double stigma of being a woman and a drug user, the great influence of male relationships related with problematic consumption and the discovery that support groups can make significant improvements in the quality of life of participants, are some of the most important results.

Keywords: drugs, gender, inequality, support group, empowerment, qualitative research.

1. En 2008-2009 Premio Federica Montseny (Ajuntament de Reus). Trabajo no publicado. Actualización y nuevo trabajo de campo, redacción y análisis: 2010-2012. Hospital Universitari Sant Joan de Reus. Pla d'Accions sobre drogues de Reus.

2. Hospital Universitari Sant Joan de Reus (Drogodependències). Pla d'Accions sobre drogues de Reus. Responsable de la correspondencia: Antoni Llort Suárez. Dir: Av. Josep Laporte 2 CP43204 (Hospital Universitari Sant Joan de Reus. Drogodependències. Pla d'Accions sobre Drogues de Reus. Tlf : 651874836 allort@grupsagessa.com

3. Universitat Oberta de Catalunya (UOC). 


\section{Introducción}

Considerando la salud en su significación más amplia queremos señalar en primera instancia que los procesos relacionados con su atención no sólo son aquellas prácticas terapéuticas que ocurren mayoritariamente en el escenario de una consulta o en un determinado contexto médico, sino que también lo son algunos elementos culturales de referencia, procesos de información y toma de decisiones, de diagnóstico y pronóstico, rehabilitación, prevención y promoción de la salud que nos proporcionan un sentido más amplio de lo que es la atención a la salud. (Haro, 2000:103).

Este tipo de prácticas, proporcionan alternativas o complementariedades a determinadas problemáticas que no pueden ser solventadas en el ámbito de la medicina convencional. Será pues en este espacio entre la auto-atención doméstica (círculos de relación primaria) y los recursos asistenciales propiamente dichos donde situaremos los Grupos de Auto Apoyo a nivel conceptual. Al mismo tiempo este enfoque nos permitirá contextualizar el análisis de su función a través de la experiencia de las participantes de nuestro grupo en cuestión, llamado «Taller de mujeres».

En la actualidad los estudios sobre las desigualdades de género en el área de la salud son un campo en expansión, cada vez resultan más imprescindibles por su necesaria proyección sobre otros ámbitos de estudio como: la accesibilidad a recursos, la diversidad cultural o las desigualdades sociales sin perder de vista la necesidad de interconectarlos. Hasta el momento la gran mayoría de enfoques de las ciencias sociales y estudios epidemiológicos sobre aspectos de salud se han centrado y concebido desde una mirada androcéntrica según Esteban (2006). Un androcentrismo que según la autora-desde una perspectiva antropológica y feminista - se ha reflejado en el plano teórico, en una utilización concreta de conceptos (hogar, familia, parentesco, maternidad, sexualidad, reproducción / producción, doméstico / público) atribuyéndolos a un determinado rol de género. Esto ha implicado una relación jerárquica de diferentes realidades y ha legitimado las desigualdades entre grupos, provocando la supervisibilización de los roles reproductivos de las mujeres y la invisibilización de sus roles de productividad en la esfera pública (Esteban, 2006:11), como por ejemplo el campo del desarrollo profesional, la economía, la política, la cultura, la religión, etc.

Incluir la perspectiva de género en los estudios sobre los usos de drogas supone añadir a los modelos epidemiológicos basados en las diferencias clásicas de sexo, la comprensión de la situación de las mujeres desde los mismos contextos en los que usan y abusan de determinadas drogas (Romo, 2006:244), aportando elementos descriptivos para profundizar en el cómo 
y el porqué determinados procesos se convierten en discriminatorios o determinadas situaciones en desventajosas, con el objetivo de poder cambiar realidades sociales culturalmente perpetuadas que favorecen que esto ocurra, una de las más importantes son las que contribuyen a sustentar la imagen de la consumidora de drogas como la madre que daña a sus bebés, «las malas madres» (Romo, 2004: 72).

Así pues las mujeres que usan drogas ilegales son rechazadas doblemente, por contraponerse a los roles femeninos clásicos y por su relación con la ilegalidad (Romo, 2005:73) y son a la vez objeto de doble penalización moral y social (Martínez, 2009:49) por la misma trasgresión doble.

Desde este punto de partida se ha enfocado el trabajo con el grupo «Taller de mujeres», inspirándose en los principios de la educación entre pares y los Grupos de Ayuda Mutua, los cuales incluso la OMS planteó como una estrategia válida para dar relevancia a un enfoque más social de la salud, ya que vio en ellos, valores y habilidades que es necesario aprovechar para que las personas se auto responsabilicen de sus problemas y los confronten con mayor autonomía (Borràs et al., 2000:23). A sabiendas de las confusiones e imprecisiones sobre la definición y la utilización de los conceptos Grupos de Ayuda Mutua, Grupos de Apoyo, Autoapoyo, Asociaciones de Salud, entre otros, y su compleja y delicada asociación a los términos que la antropología denomina de redistribución y reciprocidad (Canals, 2000), se ha optado por el término Grupo de Apoyo (GA) para definir al «Taller de Mujeres».

Así pues en este estudio el concepto género se convierte en una mirada metodológica, un modo de conocimiento de la realidad social que permite comprender la diferencia y acercarnos y describir situaciones de desigualdad de poder y de accesibilidad a los recursos. Se nos presenta la necesidad según Juliano (2002) de analizar la dicotómica construcción social de los roles asignados a hombres y mujeres y sus consecuencias de discriminación económicas, sociales y de salud.

Entenderemos también que la intervención social, fundamentada en el método científico, se encamina a la resolución de problemas sociales originados la mayoría por una distribución desigual de los recursos materiales y psicológicos (Zimmerman, 2000, en Buelga, 2007:156). Apoyaremos al mismo tiempo nuestra postura ideológica con las teorías contemporáneas del trabajo social crítico que permiten dar prioridad a la estructura social en el análisis del problema del consumo de drogas y despatologizar a los individuos, buscando también el origen de los problemas en la fuerzas u opresiones de tipo social y no sólo en los progresivos enfoques biologicistas (diagnóstico/medicalización) del abordaje de problemas sociales y de salud (Pons, 2012). 
Las mujeres participantes en el «Taller de Mujeres» que son al mismo tiempo usuarias del Servicio de Drogodependencias HUSJ ${ }^{4}$ y del Centro de Acogida La Illeta, presentaban demandas derivadas de una larga trayectoria de consumo y policonsumo de sustancias psicoactivas. Además de un contacto limitado o inestable con los servicios sociosanitarios, también presentan un largo etcétera de problemas de salud, poca adherencia a los procesos de tratamiento, gran disponibilidad de tiempo libre y desvinculación de la realidad sociolaboral, contacto limitado o inexistente con las familias, perdida de las funciones tutelares de sus hijos/as, maltrato o abusos sexuales, dificultad para acceder a recursos formativos, lúdicos o laborales, confluencia con otros problemas asociados a su estilo de vida, problemas judiciales, económicos, de vivienda, y sobre todo una realidad caracterizada por dificultades y por carencias.

En este sentido, O'Mara (2013), señala cómo las mujeres que entran en contacto con centros de tratamiento o rehabilitación tienen pocas oportunidades que se les reconozca como personas individuales con una historia a contar; su experimentación con las sustancias o sus experiencias más íntimas relacionadas con el consumo, como las de expansión de conciencia o incluso encontrar maneras de continuar consumiendo de una manera más segura y moderada son frecuentemente negadas como objeto de discusión ni tratadas como parte de su itinerario terapéutico.

Así pues, el objetivo de esta investigación es la de dar voz a las mujeres participantes del grupo, visibilizando aquellos aspectos biográficos comunes, críticos e importantes, para identificarlos y trabajarlos en el grupo propiciando los cambios necesarios dentro de esta estructura en relación a las desigualdades establecidas en relación al uso de sustancias psicoactivas, la perspectiva de género y la atención a los problemas derivados.

\section{Material y método}

La metodología utilizada en esta investigación es la etnográfico-cualitativa. Se han realizado entrevistas individuales semiestructuradas a 8 de las 25 personas que han participado en el grupo y 2 entrevistas grupales (semiestructuradas), de 6 y 8 participantes respectivamente. Cabe señalar aquí que del total de 25 participantes sólo 10 personas han mantenido una relación y asistencia constante con el grupo. Las demás han mantenido un contacto puntual o

4. El Servicio de Drogodependencias del Hospital Universitario Sant Joan de Reus, es el centro coordinador del Pla d'Accions sobre drogues de Reus, del cual el Centro de Actividades y Acogida La Illeta forma parte. www.infodroguesreus.com 
esporádico al mismo, debido la mayoría de las veces a la difícil situación personal y de consumo que disminuye la adherencia a los servicios asistenciales convencionales y a los tratamientos de manera drástica.

Las entrevistas individuales se realizaron siguiendo un guión que responde a la secuencia vital, desde su inicio de consumo hasta su llegada y participación en el grupo. Se ha puesto especial énfasis en los siguientes fases: Etapa de inicio de consumo, profundizando en las circunstancias y en el contexto, el tipo de sustancias y la vía de consumo, las condiciones, las expectativas, los efectos esperados y percibidos, las creencias alrededor del consumo y la percepción de riesgos. Sobre su modus vivendi, se ha intentado recoger cúales fueron las principales actividades profesionales o alternativas para sustentar el consumo y/o ganarse la vida, tipo de vivienda y núcleo de convivencia, estilo de vida y gestión de la salud/enfermedad, recursos utilizados, gestión del tiempo libre El tipo de relación con las sustancias predominantes de largo recorrido, fijándonos en aspectos como la gestión de la adicción: síndromes de abstinencia, sobredosis, modo de adquisición de la sustancia evolución del consumo, vías de consumo, efectos positivos y negativos, consecuencias no deseadas, riesgos observados y/o daños percibidos. El sistema relacional, observando aspectos evolutivos de relación familiar, ascendente y descendente, redes de amistades, vecinales y comunitarias, relaciones sentimentales, maternidad en sus diferentes etapas relacionadas con los distintos itinerarios de consumo. El acceso a servicios de tratamiento y atención a la salud (básicos y especializados), adherencia a los mismos, percepción de accesibilidad y asistibilidad, descripción de los tratamientos, percepción de su efectividad, percepción y significaciones sobre el concepto de salud/enfermedad/consumo de drogas, experiencias y prácticas de auto cuidado y reducción de riesgos y daños Y por último se han recogido sus vivencias y experiencias en relación a su participación en el grupo de Auto Apoyo; expectativas y consideraciones previas a su integración en el grupo, evaluación de su dinámica y actividades, percepción de utilidad y beneficio personal, valoraciones sobre la convivencia entre pares y sus interrelaciones, aspectos negativos y positivos en relación a su continuidad y propuestas de mejora.

Las entrevistas individuales se realizaron durante 2011 y 2012, en el Centro de Acogida y Actividades La Illeta y en el Servicio de Drogodependencias, garantizando un ambiente reservado, aislado y calmado, realizando dos sesiones de hora y media para cada participante. Las entrevistas individuales fueron realizadas por un antropólogo adjunto del Servicio de Drogodependencias.

Las 2 entrevistas grupales, se llevaron a cabo durante 2012, con 4 meses de diferencia una de la otra con 6 y 8 participantes respectivamente y todas ellas 
también fueron entrevistadas individualmente, posterior o anteriormente. En este caso el trabajo de grupo se centró en la discusión sobre las diferencias de rol de género en los aspectos cotidianos de la vida, el consumo de drogas, la gestión de la salud y la enfermedad (auto atención, acceso y utilización de recursos) y las percepciones sobre el mismo grupo. En todo momento se ha garantizado la confidencialidad de los datos, así como que los mismos puedan utilizarse en algún momento para fines de investigación y docencia, tal y como se acuerda en un documento del Servicio para firmar su consentimiento.

Se ha utilizado también el diario de seguimiento del grupo por parte de la educadora social, quién registra el tipo de actividades, la participación y realiza un análisis para el seguimiento de la evolución del grupo, los acontecimientos y conflictos importantes, para la redacción de los resultados.

Posteriormente se ha procedido al análisis de los datos recogidos, asumiendo una perspectiva hermenéutico-comprensiva reconociendo a ésta como una importante tradición de carácter cualitativo de las ciencias sociales que busca la comprensión del sentido de la acción social en el contexto del mundo de la vida (fenomenología) y de la perspectiva de los participantes (Grup Igia, 2012). Se ha intentando entrelazar la teórica y el documento biográfico empírico, con el objetivo de llegar al núcleo y hacer emerger las «áreas problemáticas»; éstas expuestas naturalmente más a menudo en términos de percepción individual, se asocian a consecuencias de los determinantes del contexto histórico-económico-cultural, de forma tal que evidencian el entrecruzamiento dialéctico -o de «reciprocidad condicionante»-entre individuo, cultura y momento o fase histórica. Lo que significa, tomando en cuenta las historias de vida, el aprehender el nexo entre texto, contexto e intertexto (Ferreroti, 2007).

\section{Resultados}

Modus vivendi o los diferentes estilos de vida e itinerarios biográficos han llevado a las entrevistadas a realizar trabajos de todo tipo para sobrevivir en condiciones adversas, algunas realizando trabajo sexual, tráfico de drogas y otros tal y como hemos apuntado en el capítulo introductorio, relacionados con el mundo del hogar y el cuidado de los demás, evidenciando la perpetuación del rol social de «cuidadoras» que se sigue asignando de manera naturalizada a la mujer y aún más, en los casos donde las participantes han tenido responsabilidades familiares, la sobrecarga de funciones se ve agravada por el consumo de sustancias:

He trabajado de camarera, cuidando niños, ancianos... pero cuando tenía momentos que veía que me hacía falta el dinero, pues iba a hacerlo (trabajo sexual)... 
Ahora hace un año que no lo hago, me hace falta pero no lo hago... (...) Es porque me hacía falta si no, no lo haría... yo quiero mucho a mí pareja. (P-1)

Al tiempo nos propusieron hacer de burras e hicimos de burras un tiempo. Sí, él también traficaba con coca y chocolate y yo hacía viajes a Ámsterdam. Iba y volvía. Yo probaba el material y si el material no nos gustaba, pues no lo bajábamos. (P-3)

El inicio de las relaciones con las diferentes sustancias de consumo son tan diversas como participantes del grupo existen, los principales motivos pueden ser: la simple experimentación, la influencia de las diferentes parejas, la situación de desestructuración social, de sentimiento de soledad y/o abandono o la búsqueda de evasión o supervivencia delante de los problemas y abusos, entre otros muchos, dándose muchas veces simultáneamente:

Total, que yo pregunto qué era eso y me dijeron: ahora lo veras que lo probarás, y yo: «no, no, que yo paso de historias de lo mismo». Pero al final, con la tontería, lo terminé probando. (P-2)

Con 15 años tomaba hachís, con 18 empecé con la cocaína, luego entre en prisión y alli ya conocí todo... heroína, pastillas, todo lo que no conocía lo acabé de conocer. Cuando sali me enganche a la heroína, primero fue heroína vía nasal, esnifada y después ya pasé a la inyectada... primero era heroína sola y luego ya heroina con cocaina. (P-5)

Las primeras drogas fueron pastillas y alcohol a los 14-15 años. Iba al instituto (...) Empecé a probar la heroína a los 24 o25 años. A los 8 o 9 años mis primos me violaban, cuando me dejaron estar, empecé el Instituto pero no me lo podía quitar de la cabeza. Yo quería ser una persona normal pero no podía y empecé a doparme un poquito para tener relaciones normales, relaciones sin presiones. (P-4)

Ni las expectativas del consumo, ni los efectos percibidos tanto positivos como negativos representan lo mismo en cada caso, son los aspectos y momentos biográficos propios de cada participante, la configuración de su entorno, los que significan los usos, instrumentalizaciones y relaciones distintas con las sustancias. Este hecho reafirma la tesis de que no es el consumo de sustancias en sí el factor problematizante al que atender únicamente, sino el conjunto configurado por persona (mujer), contexto y sustancia:

Empecé con el vino blanco, que al principio me tomaba todo de golpe porque no me gustaba... Pero como yo soy también un poco tímida y mi marido era muy extrovertido... pues noté que la bebida me desinhibía, que me ponía más eufórica.... (P-6).

Lo mezclas todo, todo junto. La coca y el caballo. Primero la coca te sube y sientes excitación y después el caballo te relaja, te sientes muy bien. La verdad es que te sientes muy bien. (P-3). 
Salíamos con el coche a fumar ellos empezaban a charlar y yo iba a la naturale$z a$, a coger espárragos. Con el tiempo los efectos de la heroína fueron cambiando, empecé a usarlos porque estaba más preocupada. (P-4).

Las diferentes relaciones de pareja que aparecen en los relatos de las participantes tienen un peso importantísimo en el desarrollo de las historias presentadas tal y como íbamos apuntando, también en el consumo de drogas. En todos los casos y casi como una constante, el consumo problemático de sustancias y la relación o diferentes relaciones de pareja y la relación con los hijos asociadas con estos consumos son dos factores difíciles de separar, los cuales no podemos entender o intentar explicar individualmente:

Yo empecé a consumir con este último chico (...) Claro, no tenía nada, dependía de él. Me hizo dependiente de él con la historia de la coca. Bueno, a ver, yo cuando me fui a vivir con él ya no tenía dinero y mi madre ya se había quedado con mis hijos. Entonces yo entré a vivir con éste, que vivía con tres moros más, que uno vendía chocolate, el otro hacía las bases dobles... ¡Madre mía!.(P-2).

Nos casamos, él fumaba porros, tomaba cervezas, cocaína, esto todo él, yo nada, sólo fumaba cigarros (...) Al final entre él y yo las cosas empezaron a ir mal (...) $Y$ así pues todas estas cosas junto con el sacrificio de la tienda, termine bebiendo hasta Martini... de todo. (P-6)

Con la primera pareja yo siempre estaba cerrada en casa, el que se iba de fiesta era él y a mí eso me frustraba. Yo le esperaba a la hora en el balcón y lo veía pasar con el coche con la gente, de fiesta, debajo de mi casa. (P-4)

La búsqueda y llegada a los servicios de tratamiento con el objetivo de dejar el consumo es un punto de inflexión común en el itinerario biográfico de todas las entrevistadas, podemos apreciar en la mayoría de las participantes resistencias, que explicarían en muchos de los casos la menor presencia de la mujer en los centros de tratamiento. Resistencias que tienen mucho que ver con la gran capacidad de defenderse con los recursos personales propios y otras que tienen que ver con el tipo de control social ejercido sobre las mujeres. La recurrente aparición de la figura/rol de madre, no por casualidad, en muchas de las participantes en el momento de toma de decisiones en relación a acudir a un centro de tratamiento, no deja de ser otro ejemplo de distribución de roles de género:

Porque yo cuando me separé de mi marido fui a vivir con mi madre, y mi madre no es de beber y en su casa no se puede beber. Entonces yo iba al bar y como que bebía poco me entraba la ansiedad... Entonces llegaba a casa y hacía dos vasitos de vino, mi madre se dio cuenta y me dijo que aquello no podía ser, que yo tenía un problema y por eso me hizo ir al médico. (P-6). 
Cuando mi madre se enteró...pobrecita me acuerdo que se ponía las manos en la cabeza y me decía:jesto es ruina!, jesto es ruina!, y yo le decía, mama que no pasa nada, que yo no estoy enganchada...que lo dejo, lo típico, ya verás que mañana me quedo en casa ya verás... y al día siguiente estaba yo pegando unos botes que pa qué... y entonces fue cuando empecé a venir al CAS y a tomar metadona...pero fue ahí que conocí a toda esa «troupe» y fue cuando empecé a tomar metadona....de Guatemala a Guatepeor, y seguía inyectándome y consumiendo metadona y ya fue cuando me metieron presa.... (P-5).

Las diferentes percepciones de salud en relación al uso de sustancias psicoactivas es un punto muy interesante para entender la función del «Taller de mujeres», veremos pues como se aprecia y se significa el proceso de salud / enfermedad desde la perspectiva de género, en personas con itinerarios vitales marcados por el consumo de sustancias, fuertes adversidades sociales y presencia de enfermedades relacionadas:

Yo si estoy enferma, me quejo un rato...me tomo una pastilla o algo me hecho en la cama y ya está...pero el hombre está todo el rato quejándose, todo el rato... las mujeres somos más fuertes que el hombre en muchos sentidos, no en la mano, mucho más fuertes que el hombre y más desarrollo, porqué tiene la casa, tiene la compra, tiene críos, tiene que atenderse a ella, a él... (P-8). Entrevista grupal (1)

Yo creo que a veces tendríamos que aprender a saber estar solas, en los momentos de ansiedad, saber gestionarnos, autoabastecernos sin necesidad de nadie que te diga, tu por aquí, tu por allá....que somos mujeres pero...te puedes tener a ti misma (...) Porque una cosa es la medicina y lo psíquico y otra es equilibrar más lo psíquico y lo físico, porqué ya tienes que desplazarte, salir de casa, el valor de la autoestima, arreglarte, de ir presentable, a gusto contigo misma, sentirte bien...y las mujeres aprendemos unas de las otras y cuando no sabes, pues preguntas... $(P-7)$ Entrevista grupal (1)

Una persona enferma es la que no deja de estar... cuando pasan unos años... si tienes un poco de aquí, te das cuenta que no llegas a ningún lado. Hay que ir por el camino recto... Qué un día te compras medio gramo de coca... un decir... pues bueno... te haces tres o cuatro rayitas y iale! A principio de mes, cuando cobras, que vas un poco más suelta... No te digo todos los meses... porque me salen las facturas por las orejas, pero bueno... con un poco de conocimiento...y ya está bien. Yo a veces también, cuando puedo, me hago un par o tres de rayitas (P-3). Entrevista grupal (1)

Las distintas percepciones sobre la participación en el grupo y los posibles beneficios asociados, son apreciaciones que ayudan a autoevaluar al grupo:

El primer día que fui a la reunión tenía taquicardia, yo no salía de casa, pero al final el Taller ha sido una herramienta más para aprender a moverme por ahí... ha sido una base. (P-7) Entrevista grupal (2) 
A veces te sientes como una mierda y esto aún te hace recaer todavía más (...) $Y$ dices... ¡Coño! Si Ellas pueden yo también, que yo no soy menos que nadie ni nadie es menos que nadie. (P-3) Entrevista grupal (2)

Hoy sí, porque si hoy en día hubiera tenido un hijo, no me lo hubieran tocado, y si hoy en día tengo un marido, tampoco me tocará, porque ahora ya se como hacer para defender el tema de la mujer, ¿ivale?! (P-8) Entrevista grupal (2)

En relación a la observación participante de la educadora social del grupo se han podido recoger y destacar los siguientes resultados:

Cabe destacar la positiva evolución del grupo, registrada en la observación participante y registro de actividades, en relación al número de asistentes, la capacidad para planificar las sesiones de manera participativa y la mejora de la relación entre las participantes, puesto que los conflictos interpersonales, discusiones y las dificultades de convivencia entre ellas, fueron de más a menos en el transcurso de las sesiones y la evolución del grupo. Se ha pasado por ejemplo de actividades de relación, como debates, manualidades, talleres de cocina, costura, etc. a progresivamente actividades más dinámicas relacionadas con sus necesidades, visitas médico ginecológicas en grupo, peluquería, talleres informativos sobre violencia de género, consumo de drogas y reducción de daños y riesgos, higiene del sueño, sexualidad sana, planificación e información sobre recursos socio sanitarios en general. También se ha podido registrar una mayor adherencia a los recursos de tratamiento de drogodependencias. De 2011 a 2012 de las 25 participantes, han pasado a ser de 8 a 5 las que no realizaban tratamiento de ningún tipo y de 9 a 14 las que realizan seguimiento psicoterapéutico actualmente, bajando consecuentemente de 8 a 6 las personas que sólo están en seguimiento en la consulta de enfermería con mínimos objetivos de cambio. Dos participantes en 2012 han iniciado desintoxicaciones relacionadas con el consumo de alcohol, observando que la dinámica del grupo refuerza estos cambios de actitud respecto al consumo. En relación a las visitas ginecológicas en 2012 pasaron 14 participantes, las cuales no habían realizado nunca una visita de este tipo o hacía mucho tiempo, y de las cuales 6 repetían por segundo año consecutivo.

\section{Discusión}

Los diferentes y distintos itinerarios biográficos visibilizan en la mayoría de los casos el doble rechazo o doble penalización social y moral (Romo, 2006; Martínez, 2009; Juliano, 2002) (consumo problemático de drogas y ruptura del rol de género) como un agravante añadido a los problemas de tipo social, relacional y de salud de las diferentes participantes. Por otro lado, el contexto socio familiar y socio económico explica muchas veces las circunstancias por 
las cuales el consumo de sustancias puede ser o ha sido problemático, no pudiendo relacionar la etiología del consumo con una sola causa, ni conformarnos con paradigmas explicativos simplificadores de la realidad que se centren en la sustancia como principal agente problematizador, o sobre el individuo. Dando prioridad a la estructura social, tal y como señala Pons (2012), en el análisis del problema del consumo de drogas y despatologizando a las participantes, conseguimos al menos trabajar desde un punto de partida más cómodo, donde todas ellas puedan expresar y compartir sus experiencias.

La efectividad del grupo pasa la mayoría de las veces por el hecho de sentirse comprendida, escuchada entre iguales. El proceso de comprensión dentro del grupo puede ser más fácil que en las terapias formales ya que se parte de un contexto que permite adaptar el ritmo personal de cada participante, redefiniendo y reconceptualizando los problemas mediante un vocabulario adecuado con una forma de manifestar, adquirida en el mismo grupo, ofreciendo la opción real de verbalizar y expresar aquello que en otro contexto no sería posible como señala Kurtz (1997 en Rivera, 2005:8). El resultado de todo esto se materializa en beneficios para la salud directamente relacionados con el autocuidado y autoapoyo.

La influencia negativa, en casi todos los casos, de los respectivos y diferentes conyugues en los relatos, como factor protagonista en relación al consumo de substancias es una de las principales razones de ser y de utilidad de este grupo, es en el hecho de ser mujer, independientemente de tener pareja o no en la actualidad, de donde proviene la fuente de "poder» por la cual se intenta orientar a las participantes hacía una vida independiente y consciente de sus propias posibilidades y potencialidades. La progresiva concienciación en aspectos de desigualdad de género permite a las participantes ganar un espacio de reivindicación positivo, compartirlo y experimentar que el cambio es posible y sostenible en el tiempo. Es así como se refleja que el grupo cumple al mismo tiempo funciones asistenciales y reivindicativas (Canals, 2002:283).

El proceso de consecución del empoderamiento, es uno de los procesos por los cuales las mujeres que constituyen el grupo pueden llegar a un mayor autocontrol de su situación (Buelga, 2007) y consecuentemente conseguir aquellas metas que el grupo se marca como objetivos de actividad, pequeños cambios que pueden orientar a las participantes hacía una mejora en la calidad de vida en su día a día. Asistir a una cita colectiva para visitarse en una consulta ambulatoria de ginecología, por ejemplo, ha permitido que muchas participantes simplemente pudieran hacerlo después de muchos años de temor o descuido, detectar anomalías y solucionarlas o simplemente lograr llegar a la cita, perdiendo el miedo, concienciarse de la necesidad y ganando 
las ganas de cuidarse. Se cumplirían así los tres niveles de potenciación de recursos, individual, grupal y comunitario, que el «Taller de Mujeres» busca en la consecución del proceso de empoderamiento. En palabras de Martínez (2009): «Trabajar con ellas pasa por romper el no pacto intragénero, la rivalidad entre mujeres», este es un buen ejemplo y un gran objetivo que permite ir a la raíz y trabajar uno de los puntos clave de la desigualdad de género.

La experiencia de la maternidad, cuando ésta se ha visto cuestionada o negada, por haber sido madre consumidora (Romo, 2005), ha resultado ser en la mayoría de los casos uno de los temas más conflictivos en las experiencias de las participantes, siendo uno de los aspectos que mejor reflejan las contradicciones y retos que plantean los estudios de género en mujeres consumidoras de drogas, al mismo tiempo se puede reconvertir y se ha reconvertido en un elemento de cohesión fortísimo y refuerzo de lazos entre las mujeres del grupo.

Tal y como señala Taylor (1993) en un estudio sobre una comunidad de mujeres inyectoras de drogas en Glasgow, estas no quieren ser reconocidas en su carrera de consumo de drogas como un elemento de sumisión ante los hombres, en realidad y como podremos ver también en las historias de vida de las participantes del «Taller de Mujeres», a pesar de presentar muchos problemas sociales y de salud, pero sobretodo problemas ante cónyuges y/o hombres consumidores en general, se auto describen como mujeres independientes y reconocidas socialmente por su subgrupo de consumidores/as a la hora de buscar los recursos necesarios para el consumo, realizando y asumiendo actividades o prácticas de riesgo, rompiendo roles, como por ejemplo traficando, o en la búsqueda intencionada de placer o otras instrumentalizaciones en los efectos de las drogas.

La experiencia en los Grupos de Apoyo y la Educación entre Pares, en este caso permite aportar aspectos evidentes de cuidado de la salud en sentido amplio y mejora de la misma a las participantes, lo que nos debería hacer pensar en la efectividad (coste-beneficio) de algunas de estas intervenciones muchas veces menospreciadas por ser consideradas «profanas» o no efectivas. En las últimas décadas, por ejemplo, usuarias de drogas cómo el éxtasis u otras drogas recreativas, han reclamado su participación en el diseño de políticas públicas y han tomado la iniciativa en la gestión de las intervenciones en algunos colectivos dedicados a la reducción de daños (Romo y Pérez, 2013:242).

Necesitamos, en conclusión, mejorar la accesibilidad a todo tipo de recursos en la comunidad y ser portadores de mensajes positivos y fuente de soporte para las mujeres usuarias de drogas en sus propios contextos. Utilizar de manera eficiente los recursos, sobre todo los basados en el auto apoyo, 
acompañamiento y programas de acercamiento a usuarias poniendo especial énfasis en las mujeres más jóvenes quienes su uso de drogas pudiera escalar hacia la dependencia (O'Mara, 2013).

En este artículo la dimensión de género se presenta como central en la investigación e intervención en drogodependencias; así, se ha querido demostrar cuáles son los procesos o mecanismos que permiten a partir de la participación en este Grupo de Apoyo, empoderar a partir del hecho de ser mujer, al tiempo que mejorar y reconceptualizar un proceso problemático en relación al consumo de drogas investigando desde la concienciación en desigualdades de género y el paradigma de reducción de daños, perspectivas que permiten una mayor permeabilidad y flexibilidad en las intervenciones, desde la horizontalidad y el trabajo en equipo de las personas implicadas.

Este tipo de intervención no tiene que resultar excluyente para la realización de otras específicas para hombres (masculinidades) y/o personas con otras identidades sexuales, todo ello con el interés primordial de generar espacios contenedores del malestar que propicien la expansión de relaciones más coherentes y facilitadoras de la progresión hacia cambios substanciales en la capacidad de decisión de las personas.

\section{Agradecimientos}

A todas las participantes del «Taller de mujeres», sin ellas todo esto carecería de sentido

\section{Bibliografía}

BuElGA, S. (2007). El empowerment: la potenciación del bienestar desde la psicología comunitaria. En Gil, M. (Dir). Psicología Social y Bienestar: una aproximación interdisciplinar (154-173). Zaragoza: Universidad de Zaragoza.

BORRÀs, T. et al. (2000). Asociaciones de usuarios de drogas y grupos afines. Madrid: CREFAT.

CANALS, J. (2002). El regreso de la reciprocidad. Grupos de ayuda mutua y asociaciones de personas afectadas en la crisis del Estado de Bienestar. Tesis doctoral no publicada. Tarragona: Universitat Rovira i Virgili. Departament d'Antropologia, Filosofia i Treball Social.

EStEBAn, M.L. (2006). El estudio de la Salud y el Género: Las ventajas de un Enfoque Antropológico y feminista. Revista Salud Colectiva, 2(1), 9-20.

FERREROTI, F. (2007). Las historias de vida como método. Convergencia. Revista de Ciencias Sociales, 44, 15-40.

Grup Igia (2012). Las familias migrantes frente a las drogas y el alcohol: de la autoatención a la atención especializada. Barcelona: Grup Igia. 
Haro, A. (2000). Cuidados profanos: una dimensión ambigua en la atención de la salud. En Perdiguero, E. y Comelles, J.M. (eds.) Medicina y cultura: Estudios entre la Medicina y la antropología (101-162). Barcelona: Edicions Bellaterra.

JULIANO D. (2002). LA PROSTITUCIÓN: EL ESPEJO OSCURO. BARCELONA: ICARIA EDITORIAL.

MARTínEZ, P. (2009). Extrañándonos de lo «normal». Reflexiones feministas para la intervención con mujeres drogodependientes. Madrid: Ed. Horas y horas.

O'MARA, E. (2013). The History \& Principles of Harm Reduction, Between Public Health E Social Care. France: Médicins du Monde, Agence Française de Développement.

PONS, A. (2012). Interferències. Trabajo social y (Trans)formación de Género. Revista de Treball Social, 195, 109-120.

RiverA, J. (2005). Un análisis de los grupos de ayuda mutua y el movimiento asociativo en el ámbito de la Salud: Adicciones y enfermedades crónicas. Revista de Antropología Experimental, 5. Texto 13.

Romo, N. (2005). Género y uso de drogas: la invisibilidad de las mujeres. Monografías Humanitas, 5, 69-83.

Romo AvilÉs, N. y Gil García, E. (2006). Género y uso de drogas. De la ilegalidad a la legalidad para enfrentar el malestar. Trastornos Adictivos, 8(4), 243-50.

Romo, N. y Pérez, N. (2013). Las chicas también se arriesgan. En Martínez, D.P. y Pallarès, J. (eds.). De riesgos y placeres. Manual para entender las drogas (239250). Barcelona: Ed. Milenio.

TAYLOR, A. (1993). Woman Drug Users. An ethnography of a female injecting community. New York: Oxford.

ANTECEDENTES DE DIFUSIÓN

Presentado parcialmente en la VII Jornada de Treball Social i Universitat «Nexes entre la Intervenció i la Investigació Social» (16 marzo 2012) y Mesa en Pla d'Accions sobre drogues de Reus en el XXXIX Jornades de Socidrogoalcohol, (30 de marzo 2012) 


\title{
A COMMUNITY DEVELOPMENT CRITIQUE OF COMPULSORY INCOME MANAGEMENT IN AUSTRALIA
}

\author{
Una crítica del desarrollo comunitario sobre la gestión obligatoria de \\ ingresos en Australia
}

Philip Mendes ${ }^{1}$, Jacinta Waugh And Catherine Flynn

(Social Inclusion and Social Policy Research Unit, Department of Social Work, Monash University)

The larger project on which this paper is based was funded by Family Care

Shepparton and Berry St Victoria

\begin{abstract}
The introduction of compulsory income management - sometimes called welfare quarantining - for sub-groups of income security recipients within Australia has provoked considerable contention. This paper examines the specific introduction of the Place-Based trial in the rural Victorian region of Greater Shepparton from July 2012. Utilizing key community development principles, we critically analyse processes of implementation and evaluation, and argue that placebased income management has involved a centralized top-down process. In contrast, we recommend a bottom-up approach which would allow the local community to play a key role in defining the problem, and identifying policy solutions.
\end{abstract}

Key words: income management, evaluations, income security, community development, Australia

\section{Resumen}

La introducción de la gestión de ingresos obligatorios -a veces llamada imposición de «cuarentena» a las prestaciones de la asistencia social- para subgrupos de beneficiarios dentro de Australia ha suscitado considerable controversia. Este artículo examina la introducción de una prueba basada en la región rural de Victoria de Gran Shepparton desde julio de 2012. La utilización de los principios fundamentales del desarrollo de la comunidad y el análisis crítico de los procesos de implementación y evaluación, demuestra que la gestión de los ingresos basado en el lugar ha implicado un proceso centralizada de arriba hacia abajo. Por el contrario, se recomienda un enfoque de abajo hacia arriba que permita a la comunidad local a jugar un papel clave en la definición del problema y la identificación del las políticas para crear soluciones.

Palabras clave: Australia, desarrollo de la comunidad, gestión de ingresos, evaluación, seguridad de ingresos.

Recibido: 05/09/2013

Aceptado: 14/10/2013

Publicado: 05/11/2013

1. Department of Social Work, Monash University, PO Box 197, East Caulfield, Victoria, Australia, 3145 - Philip.Mendes@monash.edu 


\section{Introduction}

The introduction of income management - sometimes called welfare quarantining - for sub-groups of Australian income security recipients within the Northern Territory and subsequently a number of other trial sites has provoked considerable contention. Much of this debate has concerned different philosophical approaches, particularly individual versus structural, to addressing chronic disadvantage. There has also been intense discord over the effectiveness of income management programs in achieving their stated aims. In this review, we utilize key community development principles such as social inclusion, empowerment and participation to critically analyse processes of implementation and evaluation. We argue that place-based income management has involved a centralized top-down process. In contrast, we recommend a bottom-up approach which would allow the local community to play a key role in defining the problem, and identifying policy solutions.

Income management (IM) is the quarantining of a set percentage of income security payments (government welfare benefits) - usually somewhere between 50 and 70 per cent - into a special account for the exclusive purchase of pre-determined essential household items such as food, rent, clothing, health care, education and training, child care, public transport and energy bills. The remaining proportion of the payment is paid directly to the recipient to use at their discretion. Income managed funds cannot be used for prohibited items such as drugs, alcohol, cigarettes, gambling and pornography (Buckmaster and Ey, 2012). Income management is not completely new to Australia. There are other existing welfare quarantining schemes such as the Centrepay deduction scheme introduced by the Department of $\mathrm{Hu}$ man Services, and the Food Card schemes established by non-government organisations in the Northern Territory (Buduls, 2013). But those schemes are completely voluntary, whereas most of the new schemes discussed below are compulsory.

There are currently six different versions of Income Management in Australia. They consist of:

1. The Child Protection measure (CPIM) whereby welfare recipients in the Northern Territory and parts of Western Australia are referred by a child protection officer to the Department of Human Services (DHS) to have their income managed. This measure is applied to parents who abuse or neglect their children, or who fail to ensure their school attendance 
2. The Vulnerable Welfare Payment Recipients measure (VWPR) whereby welfare recipients in the Northern Territory are referred for income management by a DHS social worker as a result of poor financial management, family violence, mental health concerns or other factors.

3. The Voluntary Income Management Measure (VIM) whereby people living in the Northern Territory have chosen to be involved in income management arrangements.

4. The School Enrolment and School Attendance Measure (SEAM) applied to parents who fail to ensure their child is enrolled in or regularly attending school.

5. The Queensland Commission (Welfare Reform) measure involving welfare recipients in Cape York whom a statutory body called the Family Responsibilities Commission has ordered should be subject to income management for engaging in dysfunctional behaviour.

6. Place-Based Income Management (PBIM) involving welfare recipients living in one of five targeted communities across Australia who have been referred for Child Protection Income Management (CPIM) or the Vulnerable Welfare Payment Recipients (VWPR) measure, or who choose to participate in Voluntary Income Management (Buckmaster and Ey, 2012; Buckmaster, Ey and Clapdor, 2012).

This article is part of a larger analysis of the government evaluations of income management programs in Australia (Authors, 2013). That analysis examined the key methodologies and limitations of the current frameworks used to evaluate income management in the Northern Territory and other jurisdictions. All seven independent assessments (i.e. those evaluations undertaken independently of government-imposed criteria) of IM published since its introduction (2007 - 2013) were identified. The authors engaged in a content analysis of these papers, to identify key themes, both methodological and in the findings presented in these studies. Such an approach is described by Bryman (2012) to be a useful and appropriate analytic tool to uncover trends and patterns in qualitative data. Given the lack of existing research, a flexible approach was taken with this analysis, with codes and ultimately themes generated from the data, rather than from predetermined categories.

Additionally, given the newness of this issue, we augmented this formal analysis of existing evaluations with informal discussions with two key nongovernment welfare service providers, Family Care and Berry Street Victoria, based in the PBIM site of Shepparton. These stakeholders strongly argued that any effective evaluation needed to consider whether or not local community 
representatives had been substantially consulted in the development and implementation of income management policy (Authors, 2013). That stakeholder critique of the absence of a community development approach has been applied in this article both to the implementation and evaluation of PBIM in Shepparton.

That analysis identified five fundamental themes that were arguably not sufficiently covered in the official evaluations, and formed the basis of an alternative evaluation framework. These themes included choice and control, the quality of decision making, consultation with local community members, structural disadvantage, and economic cost, and are discussed more fully elsewhere (Authors, 2013).

\section{Background and Chronology}

The Coalition Government that headed Australia from 1996-2007 was strongly influenced by neo-liberal philosophy, and imposed an increasing conditionality on the income security system (Billings, 2010; Mendes, 2008). In June 2007, the Government announced the establishment of the Northern Territory Emergency Response (NTER). The NTER was introduced as a result of the Little Children Are Sacred report published by the Northern Territory Board of Inquiry into the Protection of Aboriginal Children from Sexual Abuse. The report found that child sexual abuse was serious, widespread and often unreported. It urged that Aboriginal child sexual abuse in the Northern Territory be designated as an issue of urgent national significance by both the Australian and Northern Territory Governments, and that both governments undertake genuine consultation with Aboriginal people in developing service responses (Wild and Anderson, 2007).

Consequently, the NTER included a range of measures arguably seeking to address such abuse by tackling alcohol abuse, improving school attendance and reforming public housing arrangements. Additionally, 50 per cent of all income support and family assistance payments for Indigenous residents of remote Northern Territory communities would be quarantined via Income Management (IM) to ensure payments were spent on food, school nutrition, rent and other essential items for the care of children and not on alcohol, cigarettes, pornography or gambling. These measures required a suspension of the Racial Discrimination Act so that they could be applied exclusively to Indigenous Australians living in 73 prescribed communities, associated outstations and 10 town camp regions of the Northern Territory. The NTER plan was applied without any consultation with all people living in these 
Indigenous communities regardless of their individual circumstances or capacity (Australian Council of Social Service (ACOSS), 2008).

The Australian Labor Party (ALP) Government elected in November 2007 chose to continue the NTER including IM, but invited an independent Review Board chaired by West Australian Indigenous leader Peter Yu to present a progress report on the intervention. The report of the review, which was released in October 2008, agreed that the intervention had made some positive changes in the Northern Territory in relation to improving housing, health and education. But it called for an end to the compulsory income management system except where child protection or school attendance matters were involved, and urged a reinstatement of the Racial Discrimination Act (Australian Government, 2008).

Despite some identified benefits, the report also exposed widespread discontent with the 'top-down' nature of the program. Instead, Indigenous Australians urged the government to consider an alternative 'bottom-up' approach based on a community development framework that would allow 'local communities to determine and prioritize their needs'. The report defined community development as an approach 'led by the community and partnered by the government'. It emphasized the importance of 'investment in local skills and capacities and leadership', and argued the need for 'a genuine engagement' with Aboriginal communities (Australian Government, 2008:8, 14). This proposal for a program based on community development principles and practice seems, however, to have been largely ignored by the government.

The government introduced a Basics Card in late 2008 which is a personal identification number protected card that enabled participants to use their income managed funds to purchase food and other essential items at authorized stores. The card was initially used only for Indigenous recipients, and has attracted controversy due to the restrictions it places on the consumer choice of IM recipients who are only able to shop at designated retailers. This is of concern given that other stores may be more conveniently located, and sell cheaper and/or better quality products than the large retailers. IM users have also complained of the government's DHS agency failing to make payments on time to utility companies, of difficulties in using the Basics Card to purchase prescription medicines, problems in checking the balance on their Card, and a general sense of shame associated with the use of the Card (ACOSS, 2010; Equality Rights Alliance, 2011; Goulbourn Valley Community Legal Centre Pilot, 2012).

In May 2009, the government released a discussion paper on the NTER which cited various positive impacts of IM in the Northern Territory. The 
paper rejected the recommendations of the earlier review report pertaining to IM, arguing on the basis of some submissions to the NTER Review Board that it had provided benefits for women and children such as increased household expenditure on food and other essential items, less gambling and drinking, and reduced alcohol-fuelled violence. They announced that IM would be extended for at least another 12 months, but they also stated that they would re-draft IM measures via parliamentary legislation to make them comply with the Racial Discrimination Act (Australian Government, 2009).

Further consultations were undertaken with Indigenous participants plus representatives of regional and major Indigenous stakeholder organisations in June and August 2009. But participants were only provided with a choice of two limited options: to continue the existing IM model, or to allow individuals to request exemptions on the basis of demonstrated responsible behaviour. Participants were not given the option of dismantling IM entirely, or transforming it into a voluntary scheme (Australian Government, 2009). The reluctance of the government to engage in genuine consultations to attain community views on whether or not to continue IM was to remain an ongoing concern (ACOSS, 2010; Nicholson, Behrendt, Vivian, Watson and Harris, 2009).

The Social Security and other Legislation Amendment (Welfare Reform and Reinstatement of Racial Discrimination Act) Bill 2009 was passed by Parliament in 2010. In contrast to the NTER income management which affected all residents of prescribed communities, the Bill introduced a new form of income management which applied only to five targeted groups of income security recipients: disengaged young people aged 15-24 years who have been on nominated payments for at least 13 of the past 26 weeks; long-term welfare recipients over 25 years who had received income security payments for more than 52 weeks in the last two years; income security recipients deemed vulnerable by a Centrelink social worker as a result of poor financial management, family violence, mental health concerns or other factors; those individuals referred by child protection authorities, and persons who voluntarily choose income management arrangements. Another action was the reinstatement of the Racial Discrimination Act via amendments to the original NTER measures, and the restoration of appeal and review rights for participants (CALC, 2010). From July 2012, a targeted model of IM called Place-Based Income Management (PBIM) was introduced for a five year trial in five new locations across Australia - one in Victoria (Shepparton), two in Queensland (Logan and Rockhampton), and one each in New South Wales (Bankstown) and South Australia (Playford). 
Concurrently, a welfare reform trial has been taking place in four Cape York communities in far north Queensland since July 2008, based on a partnership between the communities, the Australian Government, the Queensland Government and the Cape York Institute for Policy and Leadership, headed by Aboriginal campaigner Noel Pearson. The aim of the trial, which was recently extended till 2014, is to re-establish positive social norms and reduce passive welfare receipt in these communities. The programs differ from the federal IM in that they are voluntary, income management is only applied as a last resort, and the program planning involved substantial prior consultation with local community leaders (Billings, 2010; Pearson, 2011).

The aims of the range of income management programs vary from the specific to the highly general. The original aim of IM within the NTER was argued to be to protect children from abuse or neglect, and women from financial harassment or 'humbugging' and violence. An associated aim was to focus funds on essential household items such as food and clothing, and reduce or eliminate spending on substance use, gambling and pornography which was seen to be associated with child sexual abuse. IM has also been described as a budgeting tool to assist families, particularly those with alcohol abuse or mental health concerns, to manage their finances (Australian Government, 2013; Deloitte Access Economics, 2013).

But the government has also suggested some much broader objectives of IM involving behavioural change such as reducing welfare dependency, promoting self-reliance and responsibility, improving parenting skills, and increasing the capacity to learn work skills and potentially attain employment (Bray, Gray, Hand, Bradbury, Eastman and Katz, 2012; Macklin, 2010).

All these aims seem to target changes in the individual behaviour of recipients. But these personal deficits are arguably closely related to broader structural and systemic causes of disadvantage. For example, these would include the low level of income security payments and lack of affordable housing, which push many recipients into poverty and associated family breakdown. Additionally, there tends to be minimal education, training and employment opportunities available in many of the targeted communities. Some remote communities lack access to healthy and affordable food, and there is also the intergenerational trauma experienced by many Indigenous Australians due to experiences of racism, dispossession, institutionalization and the removal of children (ACOSS, 2010; Billings, 2010; Cox, 2010; Western Australian Council of Social Service (WACOSS), 2011). However, the income management programs do not appear to recognize or address the broader structural and communal context of individual disadvantage. 


\section{Why Place-Based Income Managememt?}

Place-based programs are intended to address the concentration of disadvantage in specific locations or postcodes. It has been argued that holistic programs which target groups of people with multiple forms of disadvantage in specific neighbourhoods will be more effective than universal programs in promoting opportunities for disadvantaged communities, and preventing inter-generational poverty (Byron, 2010; Green and Zappala, 2000).

The most significant Australian argument in favour of place-based programs was presented by social work academic Tony Vinson. Vinson argues in favour of positive interventions to provide opportunities for the social inclusion of disadvantaged people in local communities (2010). He uses a wide range of indicators to demonstrate spatial inequality and geographic disadvantage. These are:

- Social distress: low family income, rental distress, home purchase distress, lone person's households

- Health: low birth weight, childhood injuries, deficient immunisation, disability/sickness support, mortality (life expectancy), mental health patients treated in hospitals/the community, and suicide

- Community Safety: confirmed child maltreatment, criminal convictions, prison admissions, domestic violence

- Economic: unskilled workers, unemployment, long-term unemployment, dependency ratio, low mean taxable income, limited computer use/internet access

- Education: non-attendance at pre-school, incomplete education (1724 year olds), early school leaving of local population, post-schooling qualifications

- Community engagement: membership of local group, membership of groups that tackle local problems, local volunteering, help from neighbours when needed, feel safe after dark, trust people, attendance at local community events, feel valued by society (Vinson, 2007: 6).

Place-based programs claim to utilize community development principles in addressing social disadvantage. By community development, we refer to the employment of community structures to address social needs and empower groups of people. A community development approach to a social problem such as poverty or limited housing would involve engaging with community members who were poor or homeless, consulting with those community organizations that are involved with and have knowledge of the experiences of 
disadvantaged groups, and ensuring that the local community per se plays a key role in both defining the causes of the problem, and identifying potential policy solutions. Key principles would be the inclusion of all local residents including potentially marginalized groups in the policy development process, and the empowerment of disadvantaged groups by giving them the capacity alongside other community members and organisations to participate in the development and implementation of policy strategies (Kenny, 2011).

The Australian Government seems to have given serious consideration to the introduction of place-based policies aligned with community development. For example, a report by the government's Social Inclusion Board identified the principles underlying effective place based programs as including the enhancement of local capacity and resources, and the devolution of policy development to local groups with local expertise in order to define both problems and solutions. Overall, the Board recommended a decentralized community development approach to policy making (Australian Social Inclusion Board, 2011). An accompanying report noted that the main barrier to facilitating local community control was 'the reluctance of government agencies to give up power to others outside their field of activity' (Australian Social Inclusion Board, 2011: 25).

Australian and UK evaluations of community renewal programs that have applied at least some of these principles suggest a number of positive outcomes including greater resident participation, improvements in social and community cohesion, and better employment outcomes (Fawcett et al, 2010). Similarly, a number of evaluations of welfare services in Indigenous communities have shown that they are most effective when the local community is heavily involved in both the planning and implementation stages (Al-Yaman and Higgins, 2011). Other authors draw specific attention to community development interventions that have worked to enhance school attendance and retention rates for Indigenous children. These programs appear to be most effective when introduced as a result of ongoing consultations between schools and Indigenous parents and communities (Behrendt and McCausland, 2008).

But many place-based programs have not adhered to community development principles. For example, a study of 36 place-focused initiatives in Western Sydney found that projects often narrowly targeted the problems of disadvantaged groups rather than the community or structural context of social problems, and failed to introduce sustainable local outcomes (Randolph, 2004). Another study suggested that too often place-based programs are controlled by centralized government authorities, community consultations are limited, and local knowledge and expertise is marginalized (Morrison, 2008). 
A particular identified concern is that place-based programs can serve to further pathologize excluded groups by targeting changes in individual behaviour, rather than identifying broader community and structural policy reforms (Smyth, 2008). An example of this might be policies which simply aimed to reduce the number of drug users or street sex workers in a particular neighbourhood, rather than introducing strategies that improved outcomes for all community members including those involved in drug use or sex work. Similarly, place-based programs may potentially blame the deficits of the local community for social problems such as drug use or unemployment, rather than identifying broader structural factors which go beyond locality such as inadequate funding of rehabilitation facilities for substance users, or low levels of business and government investment in employment-generating industries.

This emphasis on blaming groups of disadvantaged people seems to be present in the stated aims of PBIM which are to help create financial stability for families by promoting improved budgeting, increase their economic participation, ensure that the priority needs of families including particularly the care, welfare and education of children are met, and address vulnerable circumstances such as homelessness (Australian Government, 2012a; 2012b). These objectives do not seem to be significantly different to those stated for other IM programs. Specifically, there is no mention of addressing the broader structural context of disadvantage. Equally, there is no reference to specific local social and economic factors that may have shaped the nature of disadvantage. Most importantly, it does not appear that any local community groups in Shepparton or the other four trial locations were given the opportunity to shape the core aims and strategies of this program.

Conversely, if the government was true to its stated community development principles, then the following would arguably have happened in relation to the processes and evaluation of place-based income management. Firstly, any consideration regarding the introduction of income management would have involved extensive consultations with representatives of the local community to discuss how and in what way IM measures might benefit the community. This process would have specifically targeted members of three groups: income security recipients that fell into the two key categories of CPIM and VWPR; the key non-government and government agencies ranging from child protection to family support to housing that currently work with these disadvantaged groups; and representatives of Indigenous community groups given that Indigenous Australians are known to be disproportionately represented in income management measures (Bray et al, 2012). 
Secondly, if there was agreement that IM measures might benefit some community members, there would have been extensive consultation as to how these measures might complement existing services and supports that were known to be effectively assisting these groups of people. And finally, extensive consultations with the three groups above would have been incorporated as key components of the planned evaluation framework in order to measure whether or not IM measures lead to better outcomes for disadvantaged groups and the local community as a whole. However, as we shall see this is not what happened.

\section{Why Greater Shepparton?}

According to the Australian government, the five PBIM locations were chosen on the basis of statistical indicators of disadvantage such as high levels of unemployment, youth unemployment, the numbers of people on income security payments and the length of time of being on payments (FaHCSIA, 2012). However, it is noticeable that none of the five trial sites chosen for PBIM feature in Tony Vinson's list of Australia's most disadvantaged or next most disadvantaged postcodes, except for Playford, SA. Vinson's list is widely regarded as an accepted typology/measure of disadvantaged areas (Vinson, 2007: 26-47).

The particular focus of this study is on the rural Victorian location of Greater Shepparton which does appear to be a relatively disadvantaged area. The Community Services Minister, Jenny Macklin, has stated that Shepparton was chosen because of a relatively high rate of disadvantage including significant numbers of teenage parents, and jobless families with young children (Macklin cited in Doherty and Johnston, 2011).

Shepparton has a population of over 63,000 people. Other key population characteristics include the following: $8.7 \%$ of the workforce are unemployed compared to the national average of $5.6 \%, 18.3 \%$ of the working age population are reliant on income support compared to 12.4 per cent nationally, 66.5 per cent of those receiving unemployment benefits have done so for more than a year compared to 60.1 per cent nationally, one in five of those aged 15-19 years are not engaged in work or further education or training, 3.2 per cent or 2080 people are Indigenous which is higher than the one per cent of Indigenous residents state-wide, 11.7 per cent or 8000 people were born overseas, 10.4 per cent speak a language other than English at home, and 1.9 or 1750 people have poor proficiency in English. Over the past five years, more than 500 humanitarian migrants have settled in the Greater Shepparton area. The three groups in Greater Shepparton that appear to be most 
at risk of unemployment are Indigenous people, humanitarian migrants, and people without post-school qualifications. There is some evidence of major social problems including family violence, crime, substance use, and teenage pregnancy, but arguably no worse than many other areas not targeted for income management trials (Deloitte Access Economics, 2013: 32; Department of Education, Employment and Workplace Relations, 2012: 2; Department of Planning and Community Development, 2011: 32; Greater Shepparton City Council, 2011; Munro, 2012).

\section{The PBIM implementation process in Greater Shepparton}

The PBIM implementation process appears to have followed a strictly topdown model. The Federal Government does not appear to have consulted with any community groups in these locations to clarify whether the introduction of IM programs was warranted, or how they might complement existing support programs (ACOSS, 2012; Lewis, 2012; Tennant, 2012).

The government announced in the Federal Budget of May 2011 that Shepparton would host an income management trial from July 2012. The announcement stated that PBIM would involve a similar approach to the child protection (CPIM) model already trialled in Western Australia (W.A.) which had involved the withholding of up to 70 per cent of parents' income support and family payments to ensure that the needs of their children were met (Macklin, 2011). This was arguably significant given that the W.A. trial had no community development content whatsoever, and merely involved the application of particular IM measures to two specific locations (ORIMA Research, 2010).

The timing of the announcement was arguably problematic in that it focused media attention on the implied weaknesses rather than strengths of the selected communities. Additionally, it was only a number of weeks later that a rationale was released by the government for targeting Shepparton. The first meeting between the Commonwealth departments involved and local community agencies was not held till the end of August 2011 (Tennant, 2012).

The only implied suggestion of the application of a community development framework in Shepparton was a promise to 'give communities a say' in identifying programs relevant to income management recipients in their community (Macklin, 2011: 4). This seemed, however, to be mere rhetoric given the entire trial had been announced in a top-down fashion. An online survey of local welfare agencies in Shepparton found that the great majority of participants (26/33) believed there had been an inadequate level of government consultation with the community (GVCLCP, 2012). Similarly, a meeting 
of a local community forum reported that none of the existing welfare agencies had been directly consulted with by the federal government prior to or following the announcement of Shepparton as a trial site in the May 2011 budget. Particular concern was expressed that the government had 'undervalued and overlooked local expertise and local knowledge of the community' (Shepparton Community Forum on Income Management, 2012, p.2).

To be sure, the government announced the establishment of Local Advisory Groups (LAGs) in the five trial sites in March 2012 to assist in the introduction of income management. Specifically, the LAGs were expected to advise the government on the allocation of money from a Local Solutions Fund aimed at providing additional financial support services and parental support services in Shepparton. These were intended to assist recipients of income management to improve their budgeting skills, work readiness, and their care of children (Greater Shepparton Local Advisory Group, 2013).

In principle, the LAGs could have provided an opportunity for at least a partial bottom-up framework. The stated aims included: engaging local experts, seeking the advice of local communities to identify local employment training priorities, and generally working with the local community to promote participation in the community (GSLAG, 2013; Macklin, 2011). But there is no evidence that the LAGs have served as a serious forum for local input into policy development and decision making around income management. And the funded support services, whilst potentially helpful to the targeted groups, were not introduced as a result of a genuine consultation processes with the local community. The CEO of a major local welfare agency, Goulbourn Valley Family Care, concluded disappointingly that 'At the time of writing it is 14 months since the trial was announced and local engagement is only just beginning. Unless it becomes a central focus soon, Shepparton will not be part of a place-based trial, it will just be a place required to host a trial for the Commonwealth' (Tennant, 2012:7).

\section{The evaluation process in Shepparton}

The official evaluations have played a significant role in the policy debate around income management. In particular, the government has consistently asserted that the evaluation reports demonstrate the effectiveness of income management even though the evidence seems to be highly contested and a number of significant methodological flaws have been identified in these evaluations (Authors, 2013). This lead one academic commentator to argue that 'evaluation itself is not a tool for objectively measuring success or failure, but rather forms a part of the policy process' (Altman and Russell, 2012: 14). 
The government appointed the private sector consultants Deloitte Access Economics to conduct the evaluation of PBIM in the five trial sites including Shepparton. Deloitte stated that they would be undertaking interviews and focus groups with key stakeholders in each PBIM site. However, the proposed consultations, which are not as yet concluded, targeted almost exclusively employees from federal or state government departments (covering child protection, housing and income security) in these regions. The only reference to community or non-government organisations was to discussions with representatives of the Communities for Children program which is actually a federal government program aimed at enhancing parenting skills (Deloitte Access Economics, 2013).

Absent from the proposed consultations are the large number of non-government organisations (covering key areas such as mental health, housing, family violence, emergency relief, drug and alcohol, family support and Indigenous community and culture) which already work with, and often have, extensive knowledge of the lives of income management recipients. Nor is there any stated intention to interview representatives of elected local governments who might be able to comment on the local communal factors that impact on chronic disadvantage. Nor is the evaluation intended to examine what consultation processes good or bad were originally used for the implementation of PBIM in the five trial sites.

\section{Conclusion}

The introduction of PBIM arguably had the potential to introduce a significant community development framework into the application of income management programs. This would have enabled a range of local community stakeholders including service users, community welfare organisations, and representatives of Indigenous organisations to consider how and why IM measures might complement existing community services in order to benefit income security recipients and the local community more generally. The positives of utilizing such a bottom-up approach to policy development and delivery were specifically endorsed by a number of government reports.

But our overview of both the implementation and evaluation processes in the trial site of Shepparton suggests that this potential was mostly ignored. Both processes involved centralized policies being imposed top-down by distant politicians and bureaucrats on a particular location. There is little evidence that the introduction of PBIM in Shepparton utilized local knowledge and expertise regarding the causes of, and potential solutions to, social disadvantage. Little if any contact was made with existing local networks of service 
providers. No attention was given to research evidence confirming the efficacy of place-based programs based on community development principles. Instead, PBIM in Shepparton merely involved the introduction of stigmatizing programs focused narrowly on the individual behaviour of income security recipients in a particular location.

\section{References}

Altman, J., Russell, S. (2012). Too much Dreaming: Evaluations of the Northern Territory National Emergency Response Intervention 2007-2012. Evidence Base, 3, 1-24.

AL-YAMAN, F. and Higgins, D. (2011). What works to overcome Indigenous disadvantage: key learnings and gaps in the evidence. Canberra: Australian Government.

Australian Council of Social Service (2008). Submission to the Department of Families, Housing, Community Services and Indigenous Affairs: NT Emergency Response Review. Sydney: ACOSS.

Australian Council of Social Service (2010). Submission to Senate Community Affairs Legislation Committee: Inquiry into Social Security and other legislation amendment (Welfare Reform and Reinstatement of Racial Discrimination Act) Bill 2009 and related bills. Sydney: ACOSS.

Australian Council of Social Service (2012). Submission to Senate Community Affairs Committee: Social Security Legislation Amendment Bill 2011. Sydney: ACOSS.

Australian Government (2008). Northern Territory emergency responses: Report of the NTER Review Board. Canberra: Commonwealth of Australia.

Australian Government (2009). Future Directions for the Northern Territory Emergency Response. Canberra: Commonwealth of Australia.

Australian Government (2012a). Helping vulnerable families: targeted income management. Canberra: Australian Government.

Australian Government (2012b). Place Based Income Management in Greater Shepparton. Canberra: Australian Government.

Australian Government (2013). Changes to the Vulnerable Welfare Payment Recipient measure of income management. Canberra: Australian Government.

Australian Social Inclusion Board (2010). Annual Report 2010. Canberra: Commonwealth of Australia.

Australian Social Inclusion Board (2011). Governance models for location based initiatives. Canberra: Commonwealth of Australia.

Authors (2013). The Place-based Income Management Trial in Shepparton: A best practice model for evaluation. Melbourne: Social Inclusion and Social Policy Research Unit, Monash University. 
BEHRENDT L. and MCCAUSLAND R. (2008). Welfare payments and school attendance: An analysis of experimental policy in Indigenous education. Sydney: University of Technology.

Billings, P. (2010). Social welfare experiments in Australia: more trials for Aboriginal communities. Journal of Social Security Law, 17(3), 164-195.

Bray J.R., Gray M., Hand, K., Bradbury, B., EAstman, C. and Katz, I. (2012). Evaluating New Income Management in the Northern Territory: First Evaluation Report. Sydney: Social Policy Research Centre \& Australian National University.

Bryman, A. (2012). Social research methods. (4th ed.). South Melbourne: Oxford University Press.

Buduls, A. (2013). Report of the Independent Review of Centrepay. Canberra: Department of Human Services.

BuCKMASTER, L. and Ey, C. (2012). Is income management working. Canberra: Parliamentary Library.

Buckmaster, L., Ey, C. and Clapdor, M. (2012) Income Management: An overview. Canberra: Parliamentary Library.

BYron, I. (2010). Place-based approaches to addressing disadvantage. Family Matters, 84, 20-27.

Cox, E. (2010). It started with the Intervention. New Matilda, 1 November.

Deloitte Access Economics (2013). Evaluation Framework - Place Based Income Management. Melbourne: Deloitte Access Economics.

Department of Education, Employment and Workplace Relations (DEEWR) (2012). Greater Shepparton Local Government Area: Survey of Employers' Recruitment Experiences. Canberra: Australian Government.

Department of Families, Housing, Community Services and Indigenous Affairs (FaHCSIA) (2012). Families and Children: Place-based income management. Canberra: Australian Government.

Department of Planning and Community Development (2011). Change and disadvantage in the Hume Region, Victoria. Melbourne: State Government Victoria.

DOHERTY, E., JOHNSTON, M. (2011). Cuts in welfare to pay the rent. Herald Sun, 29 October.

Equality Rights Alliance (2011). Women's Experience of Income Management in the Northern Territory. Canberra: Equality Rights Alliance.

Fawcett, B., Goodwin, S., Meagher, G. and Phillips, R. (2010). Social Policy for Social Change. Melbourne: Palgrave Macmillan.

Goulbourn Valley Community Legal Centre Pilot (2012). Shepparton Income Management Survey Report. Bendigo: GVCLCP.

Greater Shepparton City Council (2011), Overseas Arrivals, (http://profile.id.com. au/shepparton/overseas-arrivals? WebID=10, accessed on 22/02/2013). 
Greater Shepparton Local Advisory Group (2013). Better Futures, Local Solutions. http://www.sheppartonlag.com.au, accessed on 31/7/13.

GREEN, V., and ZAPPALA, G. (2000). From welfare to place management: Challenges and developments for service delivery in the community sector. Research and Advocacy Briefing Paper. Sydney: The Smith Family.

Kenny, S. (2011). Developing Communities for the Future. Melbourne: Cengage.

LEWIS, J. (2012). Income control trial concern. Shepparton News, 1 February.

MACKLIN, J. (2010). Income management is improving lives in Western Australia. Media Release, 8 October.

MACKLIN, J. (2011). New approaches to address disadvantage in targeted communities. Media Release, 10 May.

Mendes, P. (2008). Australia's Welfare Wars Revisited. Sydney: UNSW Press.

MORRISON, Z. (2008, June). Place, social inclusion and cultural justice. Presentation given at the Brotherhood of St Laurence and the Department of Planning and Community Development Social Inclusion and Place Based Disadvantage Workshop. Melbourne: BSL.

Munro, P. (2012). Rolling with the punches. Sunday Age, 16 September.

Nicholson, A., Behrendt, L., Vivian, A., Watson, N., and Harris, M. (2009). Will they be heard? A response to the NTER Consultations. Sydney: Jumbunna Indigenous House of Learning.

Orima Research (2010). Evaluation of the child protection scheme of Income Management and Voluntary Income Management Measures in Western Australia. Canberra: Department of Families, Housing, Community Services and Indigenous Affairs.

PEARson, N. (2011). Ineffectual bipartisanship ruins social policy. The Australian, 26 March.

RANDOLPH, B. (2004). Social Inclusion and Place-Focused Initiatives in Western Sydney: A review of current practice. Australian Journal of Social Issues, 39(1), 63-78.

Shepparton Community Forum on Income Management (2012). Minutes of Forum, 24 January.

SMYTH, P. (2008, June). Place based policy at the crossroads. Presentation given at the Brotherhood of St Laurence and the Department of Planning and Community Development Social Inclusion and Place Based Disadvantage Workshop, Melbourne: BSL.

TEnnAnt, D (2012). How 'place' fares in place-based solutions. Victorian Council of Social Service Insight, 7, 34-35.

VINSON T. (2007). Dropping off the edge: the distribution of disadvantage in Australia. Melbourne: Jesuit Social Services.

VINSON, T. (2010). Moving from the Edge: Stories of achieving greater social inclusion. Melbourne: Jesuit Social Services. 
Western Australian Council of Social Service (2011). WACOSS analysis of the ORIMA Research Evaluation of the Child Protection Scheme of Income Management and Voluntary Income Management Measures in Western Australia. Perth: WACOSS.

Wild, R. and ANDERSON, P. (2007). Little Children are Sacred. Darwin, Northern Territory Board Of Inquiry Into The Protection Of Aboriginal Children From Sexual Abuse. 


\section{JÓVENES QUE MIGRAN SOLOS. ACTORES Y ESCENARIOS FUERA DE LOS SISTEMAS DE PROTECCIÓN DE MENORES}

\section{Youths who migrate alone. Actors and scenes outside of the children care systems}

Chabier Gimeno Monterde ${ }^{1}$

\section{Resumen}

Este artículo nace de una investigación más amplia en torno a los menores migrantes no acompañados que fueron tutelados por el Servicio de Protección de Menores del Gobierno de Aragón entre los años 2000 y 2010. Se ha accedido a los casi trescientos expedientes de tutela administrativa del periodo, que se han analizado estadísticamente. Los resultados muestran un colectivo de adolescentes magrebíes (78'5\%) y subsaharianos ( $\left.17^{\prime} 4 \%\right)$, del que apenas un 4'4 son niñas. Y para el que se han establecido varios periodos en el flujo migratorio, así como posibles pautas de su comportamiento frente a la acogida institucional, en relación con el sexo, el origen y la edad. Entre 2007 y 2012, las entrevistas a menores tutelados y extutelados, a técnicos de entidades públicas y privadas, así como la observación participante durante nuestra práctica profesional en proyectos educativos para jóvenes migrantes, han conformado el trabajo de campo en las tres provincias aragonesas. Entre otros análisis, concluimos que el itinerario de inserción social que los Servicios de Protección plantean a estos jóvenes a través de la tutela administrativa es sólo uno más de los múltiples itinerarios que, en paralelo, los menores recorren acompañados por actores a menudo ocultos a la Administración como los familiares en España y Europa y las redes de iguales; o en escenarios donde los Servicios Sociales tienen dificultades para actuar, como la infracción jurídica, la prostitución y las redes de explotación. Entender esta heterogeneidad de itinerarios creemos que evitará algunas situaciones graves de desprotección.

Palabras clave: menores no acompañados, migración irregular, transnacionalismo, protección de menores.

\begin{abstract}
This article stems from a larger research on unaccompanied migrant children who were protected by the Child Protection Service of the Government of Aragon between 2000 and 2010. The researcher obtained access to the almost three hundred cases under administrative supervision during that period. These cases were analyzed statistically. The results showed a group composed of young North Africans (78.5\%) and subSaharan youngters $(17.4 \%)$, of which barely a $4.4 \%$ are girls. Several periods in the migration flow and possible patterns of their behaviours in the host institution, in relation to sex, origin and age were established. Between 2007 and 2012, interviews with protected and former protected children and with technicians from public and private entities, as well as the participant observation during our professional practice in educational projects for young migrants defined the fieldwork in the three Aragonese provinces. Among other analyses, we concluded that the social integration schedule that Protection Services offers to these young people through administrative protection is just one of the many itineraries that these children go through in parallel: accompanied by actors often unknown to the Administration, such as relatives in Spain and Europe and peer networks; or in scenarios where Social Services find it difficult to intervene such as legal infringement, prostitution and exploitation networks. Understanding this heterogeneity of itineraries will avoid, we think, some serious situations of lack of protection.
\end{abstract}

Keywords: unaccompanied minors, irregular migration, transnationalism, child protection. 


\section{Introducción}

Los denominados «menores extranjeros no acompañados» son aquellos jóvenes menores de edad que migran solos e irregularmente de las áreas pobres del Planeta a las más ricas. La legislación internacional, al igual que la española, ampara su acogida en los sistemas de protección de menores hasta que alcanzan la edad adulta (Quiroga, 2005).

Recientemente, y tras la migración de miles de menores por esta vía alternativa a la migración adulta (Jiménez, 2011: 104), esta acogida institucionalizada es de nuevo objeto de debate. Hasta el punto de cuestionar si las Comunidades Autónomas no habrán recibido competencias explícitas e implícitas en la política migratoria española. Explícitamente se les reclamaría que protegiera a estos jóvenes, mientras implícitamente se les responsabilizaría de evitar el efecto llamada que dicha acogida supone (Gimeno, 2013: 146).

Diversos informes emitidos por instituciones públicas que tutelan a estos menores o que velan por sus derechos, se refieren a menudo a un grupo homogéneo de jóvenes que son «conscientes» de su estatus legal de desamparo, y que han emigrado a Europa "para ser atendidos» por las administraciones locales (Justicia de Aragón, 2007: 122). Sin embargo, aquí nos planteamos un grupo de menores mucho más heterogéneo. Pues entendemos que, más allá de los adolescentes acogidos por las instituciones, hay otras vías de migración que permanecen ocultas, por voluntad de sus actores o, en ocasiones, por negligencia del Estado. De manera que el itinerario estandarizado por los Servicios de Protección autonómicos para atender a los menores no acompañados es sólo uno de los recorridos por éstos.

A continuación queremos evidenciar, por un lado, la existencia de estos otros itinerarios migratorios que, aunque discurren en paralelo, en ocasiones se cruzan con el institucional. Y por otro, los conflictos técnicos y éticos que esta heterogeneidad provoca en el Trabajo Social.

\section{Material y metodología}

Este texto surge de una de las líneas de trabajo de la investigación doctoral «Como una bolisma. Menores que migran solos a Aragón $»^{2}$, desarrollada en las tres capitales provinciales aragonesas, donde estos menores han sido acogidos por el gobierno autónomo.

2. Dirigida por los profesores Carlos Gómez Bahillo y Aurora López Azcona, de la Universidad de Zaragoza 
Entre 2007 y 2012 hemos realizado un trabajo de campo que ha incluido dieciséis entrevistas semiestructuradas a jóvenes migrantes y trenta y nueve a técnicos de administraciones públicas o entidades privadas. En este periodo el autor, trabajador social, ha realizado también observación participante en los proyectos educativos en los que contactaba con estos menores, además de en otros espacios urbanos donde concurren jóvenes migrantes.

Nuestro análisis documental sobre esta migración ha incluido los informes anuales sobre menores realizados por el defensor del pueblo autonómico (Justicia de Aragón), así como otros emitidos por o para el Instituto Aragonés de Servicios Sociales (responsable del Servicio de Protección de Menores) y por entidades sociales que trabajan con jóvenes migrantes.

Y, finalmente, el IASS nos ha facilitado información anonimizada sobre los 298 expedientes de tutela administrativa de los menores no acompañados acogidos entre enero de 2000 y diciembre de 2010. Estos datos se han tratado estadísticamente, con el programa SPSS, y los resultados se publicarán próximamente por el gobierno autónomo ${ }^{3}$.

Tabla 1: Técnicas y variables

\begin{tabular}{|l|l|}
\hline Técnica & Variables \\
\hline Entrevistas semiestructuradas a menores & $\begin{array}{l}\text { Contexto de origen. Trayectoria } \\
\text { migratoria. Detección. Acogida } \\
\text { institucional. Tensiones en la acogida. } \\
\text { Emancipación. }\end{array}$ \\
\hline Entrevistas semiestructuradas a técnicos & idem \\
\hline Análisis estadístico de expedientes & $\begin{array}{l}\text { Datos demográficos. Inicio y cierre del } \\
\text { expediente. Notificante. Motivo del } \\
\text { cierre. Modalidad residencial. }\end{array}$ \\
\hline Observación participante & $\begin{array}{l}\text { Relaciones entre iguales, con jóvenes } \\
\text { nativos, con el Servicio de Protección y } \\
\text { otros técnicos. }\end{array}$ \\
\hline
\end{tabular}

\section{Itinerarios paralelos}

Aunque lejos de la realidad de Cataluña o Madrid, donde ha sido evidente la presencia de menores no acompañados que vivían en la calle (Quiroga, 2009:

3. Una breve descripción de los primeros resultados nos permite hablar de un colectivo de adolescentes, entre 15 y 17 años de edad, procedentes del Magreb en un 78'5 \% y del África Occidental en un $17^{\prime} 4 \%$. De entre ellos apenas un $4^{\prime} 4 \%$ son niñas. 
201), lo observado durante el comienzo de siglo por los profesionales del Trabajo Social entrevistados en Aragón permite intuir que, también en esta Comunidad, ha habido otras vías por donde los menores no acompañados han migrado, al margen de la acogida institucional.

Para explicar esta dualidad (protección/desprotección), que implica que los menores que migran solos atraviesan diversas circunstancias jurídicas hasta la mayoría de edad, Liliana Suárez (2006: 13) habla de un «itinerario intermitente»: que busca la regularización, al mismo tiempo que conservar la autonomía del menor frente a la Administración. Para esta antropóloga, el «uso meramente instrumental» de dicho sistema se corresponde con estrategias mixtas, no siempre preconcebidas, que dificultan la conducción de los menores hacia la estandarización que buscan los Sistemas de Protección de Menores, con los consiguientes conflictos con sus profesionales ${ }^{4}$.

Nuestra investigación propone llevar más lejos estos análisis, animando a los técnicos implicados a valorar si los menores que están fuera de la protección, o entran y salen de ésta, no estarían sino en una fase más de un itinerario de múltiples vías. Este planteamiento explicaría por qué tantos itinerarios paralelos al de la acogida incluyen, con frecuencia, la desinstitucionalización pasiva (fugas de los menores) ${ }^{5}$. Y, en cualquier caso, aclara por qué el periodo de institucionalización no es necesariamente la etapa definitiva de sus trayectorias migratorias.

Reforzando esta propuesta, durante la observación participante de la investigación hemos detectado diversos itinerarios migratorios que han estado al margen de o entrando y saliendo de la protección. Dadas las características de esta migración clandestina, existirán otros itinerarios que no nos habrán sido accesibles, ni como profesionales ni como investigadores ${ }^{6}$; pero, aun así, nos servirán para informarnos de la heterogeneidad de esta migración.

Así, al perfil del menor detectado por el Sistema de Protección y que llega a la mayoría de edad cumpliendo los objetivos de inserción que el itinerario estandarizado por los protocolos de acogida le marca, podemos añadir otros itinerarios observados:

4. Nuestro cuaderno de campo (2009-2010) señala la estrategia «dentro y fuera» de menores solos que hacen un uso instrumental de un recurso, donde se les apoya desde el área de Trabajo Social de acuerdo a su «victimización» (López Riopedre, 2011). Mientras, continúan su vida en la calle, que incluye infracciones frecuentes. Esta conjunción («y») es ajena al planteamiento excluyente del Trabajo Social ( «o») y la subvierte.

5. Por oposición a la desinstitucionalización activa (la repatriación al lugar de origen).

6. Insistiendo en una línea que vertebra nuestra metodología: reconocer que siempre hay más «socius» del que percibimos, y que este reconocimiento no nos impide «intuir» a través de lo que sí hemos podido percibir (Bergua, 2011: 199). 
a. Itinerario de menor magrebí que llega con pasaporte falso de adulto para ser acogido por la familia extensa en destino. La familia posteriormente rechaza su compromiso de acogida, por lo que el menor deambula itinerante por la península, «guiado» por compatriotas adultos. Su paso por la calle lo vincula ocasionalmente a la prostitución masculina. Llega a la edad adulta sin regularizar su residencia y con fuertes nexos con la infracción y el «lumpemproletariado».

b. Itinerario de menores subsaharianas que llegan a destino adoptadas por la familia extensa. Ésta las fuerza a la prostitución, por lo que piden ayuda y son derivadas al Sistema de Protección.

c. Itinerario de menores magrebís acogidos por su familia extensa (o nuclear) en destino. Ésta, conocedora del Sistema de Protección, insta al menor a presentarse para ser acogido por éste. Una vez llegado a la mayoría de edad, el menor vuelve a ser acogido por la misma red familiar.

d. Itinerario de menores magrebís que conocen del Sistema de Protección a través de las redes de iguales (jóvenes compatriotas, tutelados o no). Acceden al sistema por éstas y al terminar la tutela vuelven a integrarse en las mismas redes, que les continúan acompañando como adultos clandestinos o regulares.

e. Itinerario de menores magrebís que entran y salen de la protección mediante «fugas», constando varias fechas de apertura y cierre en sus expedientes de tutela. A la ausencia de un proyecto migratorio acorde a las expectativas del Sistema de Protección se une, a menudo, el contacto con las infracciones.

f. Itinerario de menores europeas del Este que llegan a destino tratadas ${ }^{7}$ por su familia o por una red mafiosa. Al detectarse su presencia ejerciendo la prostitución se les deriva al Sistema de Protección. Habitualmente las menores abandonan el centro de acogida en pocas horas y vuelven con los adultos que las prostituyen, cambiando de provincia de residencia. En pocas ocasiones, las menores completan el itinerario de protección.

7. La diferencia entre «trata»y «tráfico de personas» reside en que el «traficking» busca el lucro de las redes por cruzar las fronteras entre Estados, mientras la trata se basa en el engaño y en la explotación de las víctimas, dentro o fuera del Estado de origen (Defensor del Pueblo, 2012). 


\section{Actores y escenarios fuera de la protección}

Para llegar a entender la complejidad de estos itinerarios paralelos, los Sistemas de Protección necesitan reconocer que el itinerario lineal de sus protocolos, el que va del desamparo a la protección, no se ajusta a la realidad. Al contrario, la protección no es sino una más de las etapas posibles en la migración de menores solos. Y esto es así porque este movimiento migratorio abarca más allá en el tiempo (no sólo lo acotado por la mayoría o minoría de edad) y el espacio (no sólo lo delimitado territorialmente por un Servicio de Protección); así como en los actores intervinientes y los escenarios donde se desarrolla.

La presencia de actores migratorios no insertados en los protocolos del Sistema de Protección, como pueden ser las redes de iguales y la familia nuclear o extensa, ha sido una constante en la investigación, así como en el acervo profesional acumulado en nuestra praxis. Estos actores, junto a los escenarios que interseccionan con la acogida institucional, como son la infracción y la prostitución, deben ser analizados como elementos centrales en la configuración de los «otros itinerarios».

\subsection{Redes de iguales}

Si la migración de los menores llamados «no acompañados» tiene una característica, esa es la heterogeneidad y la inestabilidad (Gimeno, 2010: 57). La mayoría de los términos que intentan definirla, esto es, situarla en un contexto estable, acaban sucumbiendo a la realidad. Algo que ha sido reconocido por los profesionales del Trabajo Social sin apenas resistencia durante las entrevistas. Esto es evidente al hablar de menores «desamparados», «solos» o «no acompañados». Cuando en el discurso institucional ${ }^{8}$ y en las entrevistas con profesionales la presencia continua de actores migratorios que acompañan a muchos de los menores es algo explicitado sin rubor.

Las redes de iguales, esto es, los jóvenes compatriotas de los menores que migran, apoyan a éstos para llegar al destino, para permanecer en él (generalmente en el Sistema de Protección) y para seguir el viaje (a nuevos destinos o intentando establecerse al terminar la acogida institucional).

Al igual que quienes han estudiado esta migración (Suárez, 2006: 22), los profesionales del IASS son conscientes de este acompañamiento entre iguales ${ }^{9}$ y de que la lógica de las redes que apoyan e informan no hace sino reducir los

8. Véanse Ararteko (2005: 205 y 211) y Quiroga (2009: 160 y 204).

9. Las entrevistas a técnicos y otros profesionales se reseñan como P1, P2, etc. Las entrevistas a menores, como M1, M2, etc. 
riesgos y los costes personales del proyecto migratorio. De ahí que racionalicen la presencia de este actor ajeno a la acogida.

Se presentan ellos mismos, muchos vienen con la dirección aprendida (...) Vente ahora, que ahora hay plaza, se avisaban (...) Si, porque se lo pasan de uno a otro (P1).

Yo pienso que esto fue como un bulo, que entre ellos habia una fama de que en [ciudad] era fácil conseguir la documentación, porque había menos afluencia de gente, y fue de no tener ninguno a tener un montón de gente. Entre ellos mismos decían, lo verbalizaban, aquí es una ciudad tranquila, es más fácil. (...) Es que yo tengo un amigo, que me ha dicho que aquí es más fácil conseguir los papeles y conseguir trabajo (P37).

Por lo que el aparente «no querer saber» de la Administración, que sí es consciente de que no hay tal soledad migratoria generalizada, responde sobre todo a la «invisibilización» de las redes de iguales. Las redes están, pero no son tangibles en términos burocráticos. Algo que en el juego de burla y astucia propio de los menores migrantes (Bergua, 2005: 44) es tenido en cuenta, al menos para «no declararse ganadores mientras están en el campo del equipo contrario».

En el COA [Centro de Observación y Acogida] encuentro gente conocida, pero sin decir que los conozco, si no dirán que nos están trayendo a gente (M10).

Las redes de iguales, al constituir un modelo de solidaridad edataria, tienen un papel relevante en muchos de los itinerarios migratorios observados, así como en casi todas las fases de los mismos. El momento y la forma en que participan en la trayectoria migratoria varía según el origen geográfico de los menores. En el caso magrebí, en las redes tienen mayor presencia las nuevas tecnologías. Y en el caso subsahariano el peso del vínculo local previo entre los menores es mayor.

Cuando las redes intervienen al inicio del proyecto migratorio, en origen, el boca a boca transmite entre los jóvenes la presencia de los corredores o vías institucionalizadas de llegar a Europa. O bien es Messenger o el teléfono el canal que traslada de destino a origen esa información entre iguales.

Sí, aquí [Aragón] hay centro de menores, puedes estudiar, puedes salir más adelante. No como aquí [Marruecos] con diploma y parado en casa... Sabía que iba a venir a un centro y nada más... Sólo sabia decir centro, centro, (M12).

Hablamos por Messenger.. Que si quieres venir, que están bien. Porque es normal tener miedo, pero cuando te cuentan que están bien,... Uno que llevaba ya un año, los demás seis meses, en pisos, que están bien ... Si no, no voy a venir (M10). 
Una vez iniciado el viaje, las redes intervienen especialmente cuando se llega al Estado de destino. Si el menor conocía la vía de la institucionalización, los iguales pueden, en ocasiones, hacer una primera acogida, orientando sobre los pasos para introducirse en el itinerario de la protección. Y si el menor no conocía previamente el Sistema de Protección, los iguales pueden aconsejarle sobre la idoneidad de esa vía para acceder a la regularización administrativa y otros objetivos de esta etapa migratoria.

Nos hemos encontrado gente de un centro [de menores] y nos han dicho que vayamos a la policía... Me llevó uno de un centro (M12).

Me dijeron que sin papeles era muy chungo, no podría trabajar, y me mandaron unos chavales al centro de menores de Zaragoza (M14).

Por último, estas mismas redes intervienen en la trayectoria migratoria cuando esta se dirige hacia nuevos destinos. Durante la etapa de la protección, a través de las nuevas tecnologías de la información, los iguales informan a los menores tutelados de las opciones existentes, tanto en otras Comunidades Autónomas como al otro lado de los Pirineos. De forma que, cuando la protección termina al llegar a la edad adulta o agotar los recursos institucionales para los nuevos adultos ${ }^{10}$, las redes transnacionales acogen a los ex-tutelados en Francia, Bélgica, País Vasco, Andalucía, etc. O bien en Aragón, compartiendo pisos alquilados entre varios ex-tutelados.

Si conoces a alguien es más fácil moverse a otro país (M8).

Los mismos chavales que han salido del centro y no tienen dinero se han juntado en una misma casa, compartiendo (P37).

En su papel de «colchón social» frente a la incertidumbre, las redes contienen en su interior una multiplicidad de opciones frente a la precariedad y el riesgo. En ellas cabe no sólo la coordinación transnacional, sino también la espontaneidad y, en no pocas ocasiones, la empatía con los perdedores frente al Sistema de Protección o la legislación de extranjería. Junto a estas reacciones ante la fragilidad de la protección, en varias entrevistas ha surgido también el fracaso como algo que las redes transmiten como un riesgo muy presente. De hecho, técnicos y menores han coincidido en señalar la presencia de ex-tutelados y de algún menor no detectado en infraviviendas o kharbas ${ }^{11}$. Último escalón residencial en el fracaso del proyecto migratorio.

10. Recursos de emancipación para ex-tutelados y servicios sociales que ofrecen alternativas residenciales.

11. Kharba o خ غربة es una palabra coloquial usada en todo Marruecos, que describe un sitio abandonado o destruido. 
Hay gente [extutelados] que está sin casa, los subo a mi piso [de acogida], si me ve el jefe, me dirá lárgate... Gente que ha estado en el albergue... olía mal ... hemos compartido cama... No me gusta que le pase eso a la gente (M1).

A buscarse la vida, durmiendo en la calle, en el río, debajo del puente (M3).

Hasta a vivir en casas de campo, como ocupas, hasta que les han pillado robando un bolso (P37).

\subsection{Familia de origen y en Europa}

En el caso de la familia, extensa o nuclear, estamos ante un actor al que podemos adscribir (casi) las mismas intervenciones que a las redes de iguales, pero que cuenta con otras variables propias y plantea otros «retos» al Sistema de Protección, que ha percibido también la debilidad de la categoría «no acompañado» cuando se usa para uniformizar el papel de la familia en esta migración. Como ejemplo, en los informes del Justicia de Aragón la presencia de las familias es algo evidente ${ }^{12}$, aunque en ellos no se perciba si no una parte de la diversidad de intervenciones familiares en la migración de los tutelados.

Analizando la intervención de las familias en las diferentes fases de la migración, su papel en el diseño del proyecto migratorio en origen es diferente al de las redes. En este caso nos encontramos, como señala abundantemente la literatura (Quiroga, 2005: 72), ante familias que pueden compartir o no el proyecto del menor, así como que pueden facilitar o dificultar el mismo. Por tanto, el discurso uniforme en torno a familias con «desapego» por los menores que migran está, como todo lo homogéneo, lejos de la realidad observada.

Algo similar ocurre cuando la familia intenta minimizar el riesgo migratorio desde el destino, bien desde otras Comunidades Autónomas o bien desde otros Estados europeos (como Francia o Italia), que pueden servir de etapa intermedia en su viaje hasta Aragón. La visión territorial de los Sistemas de Protección, de nuevo, no permite ver con distancia y claridad la dimensión transnacional de la familia, muy superior al marco estatal ${ }^{13}$. La mayor capacidad

12. «Apareciendo cada vez más menores inmigrantes marroquíes teóricamente no acompañados pero de los que se sospecha que sí lo están, que si bien sus padres permanecen en Marruecos aquí tienen familia (tíos, hermanos mayores...) y dada la imposibilidad de reagruparse, utilizan este recurso para la atención y cuidado de los menores y, a ser posible, su regularización, pervirtiendo así el sistema de protección pues se parte de la base de que el menor estará mejor con su familia que en un centro» (Justicia de Aragón, 2007: 122).

13. Las entrevistas recogen varios itinerarios con etapas europeas. M4 llega de Argelia a Murcia y de ahí a Francia, de donde viene a Zaragoza animado por otro compatriota tutelado. Otros menores han pedido a la investigación que no demos ninguna referencia («si apagas eso sí») que pueda ligarlos a su paso previo por Francia, donde estaban acogidos por la familia extensa. Todos ellos reflejan una movilidad que se adapta a la 
de las familias para situar la acogida institucional en un escenario global, donde el acceso a los servicios sociales se contempla dentro de las estrategias de migración transnacional, permite a éstas hacer un consumo estratégico de dichas acogidas, difícil de rechazar desde la lógica burocrática del desamparo. El ocultamiento y la complejidad del diseño migratorio, así como el acompañamiento consiguiente durante la tutela reflejan los múltiples matices de algo difícil de asumir desde un Sistema de Protección diseñado inicialmente para menores «regulares».

Mi hermano estaba aquí [España] y un día llamó a mi tío [Francia] y le contó eso... que un chico vino y lo tutelaron en un piso, le dieron los papeles y estudió... Me pasaron a mí, ¿si vienes, vas a estudiar...? Yo dije sí... Me llevaron a un autobús, que cogía pasajeros de Francia a Marruecos... con un hermano de amigo de mi hermano... Llegamos por la noche aquí [Zaragoza]... al día siguiente me acompañó un amigo de... estuvo en Francia también... Él me llevó a la comisaría, a la central... Yo tenía miedo... entendí que le dijo que vine debajo de un autobús... Si te pregunta cualquier cosa, tú dile que sí... cuântos años... Luego llegamos al COA (M13).

También hemos constatado la existencia de familias que, una vez el menor está en el Estado de destino, o bien «dicen no poder» o bien no pueden hacerse cargo de los menores, por su situación económica o administrativa como unidad familiar en precario, pasando el Servicio de Protección a ser una vía para asegurar o bien la estabilidad económica del joven o bien la regularización del mismo.

Estas cosas son bastante dificiles de hablar con ellos... Ya la madre llorando y tal, hijo mío, buena suerte, te doy los teléfonos de tus tíos, que están en España, habla con ellos,... Él llama a sus tíos, que estaban aquí, cogieron sus tíos y bajaron a buscarlo. Una vez aquí, los tíos creen que no pueden afrontarlo... y hablan con el IASS (P13).

Aunque en otras muchas ocasiones los servicios de acogida sí que acaban detectando la presencia de las familias en destino, especialmente al acabar la tutela con la mayoría de edad y pasar el menor a vivir con dicha familia extensa, posible interfaz de la familia nuclear (Justicia de Aragón, 2007: 147). En nuestro cuaderno de campo registramos en mayo de 2010: "[Menor] me enseña en el móvil las fotos de su hermano. Vive en [España]. Cuando salga del centro, ira con él a vivir. Él le dijo que viniera a un centro, porque tiene mujer e hijos y no puede pagar sus gastos».

legislación durante el itinerario, igual que se adapta a los cambios de ésta (Jiménez, 2011: 279). 
Aun así, el Sistema de Protección sigue sin poder asumir al «consumidor de» la acogida (Gimeno, 2010: 66) en que se convierte el menor apoyado por la familia. Esta idea, anteriormente citada, de «perversión» de la tutela al sustituir ésta a la familia, se expresa en los informes institucionales junto a la clave de esta trayectoria migratoria: la imposibilidad de reagruparse familiarmente, que ha generado estrategias familiares híbridas, donde la subversión del Orden migratorio supera lo admisible por éste (Gimeno, 2011: 859).

Ahora bien, mientras que las redes de iguales eran «invisibles» burocráticamente, el Sistema de Protección sí que ha visualizado a algunas familias, lo que le ha permitido reposicionarse. $\mathrm{Y}$ esta es una variable que diferencia claramente familias e iguales: la invisibilidad de las familias es más frágil. La presencia de las mismas es algo que la Administración rastrea e intenta detectar desde el comienzo mismo del itinerario de acogida. Esta praxis es una reacción frente a la internacionalización del uso de la protección, pero también una herramienta de control sobre el menor, como hemos observado en los menores infractores. Aun así, durante la investigación no hemos detectado acciones de represalia frente a las familias nucleares en destino que utilizan la protección, algo que se ha empezado a producir en otras Comunidades Autónomas con mayor volumen de migración de menores ${ }^{14}$.

Se pasaron un montón de tiempo pidiendo que les dé el número de teléfono de mi padre, y no lo consiguieron (M13).

[Servicio de Protección de Menores] ha hablado con mi familia. Yo no he dicho nada, cuando acabe esto prefiero decirles que yo no soy ese cabrón que dicen [que está en centro de reforma]... Ha hablado un traductor y la coordinadora, no estaba yo delante, han hablado con mi hermano, por suerte, no lo sabe mi madre,.... ¿Por qué han hablado?, ¿para joderme? La familia saben que estoy aquí y estoy haciendo papeles,... no saben lo que está pasando (M12).

Otra variable que diferencia a las redes y a las familias como actores transnacionales es la capacidad evaluadora de la migración de los menores que éstas tienen. La familia está presente casi siempre, se encuentre en destino o en origen. Para los profesionales es la conciencia (o superego) del menor, en unas ocasiones, o la cogestora migratoria, en otras. En cualquier caso, la intervención en clave de evaluación es una constante en el discurso de la mayoría de los menores entrevistados.

14. «Andalucía detecta casos de niños marroquíes en falso desamparo», en http://elpais. com/diario/2011/10/27/sociedad/1319666403_850215.html. 
Sí, claro... Depende, cada semana, cada día, depende,... Ellos quieren verte bien, con tus papeles, con tu todo, sin problemas, con tu familia, quieren ver sólo bien. Te quieren ver mejor que ellos (M3).

Y, finalmente, hemos de plasmar la relación que ha existido entre la protección como sistema y la familia como actor visibilizado por éste. En este caso, la realidad de la gestión de esta migración desde el Sistema de Protección se define por lo que no es: no es transnacional. Frente a las propuestas teóricas (Esteban, 2010) o prácticas (Manzani, 2012) que preconizan una protección que cuente con las familias en origen, la praxis de acogida en Aragón, como en otras Comunidades, ha mantenido una relación instrumental con las familias de los menores. Esto es, se ha relacionado con las mismas para gestionar la regularización del menor, en los casos en que éste se adecuaba al perfil del itinerario estandarizado, o para influir en su «uso» del sistema ${ }^{15}$.

Así, los principales protagonistas del contacto del sistema de acogida con las familias han sido los propios menores. El Servicio de Protección ha asumido universalmente el derecho al contacto periódico, generalmente por teléfono ${ }^{16}$, del menor con su familia nuclear; asignando una dotación económica a tal efecto, que no ha sido retirada en función de sanciones u otras incidencias. Y, al mismo tiempo, ha externalizado a los menores la responsabilidad de aligerar los trámites de documentación y otros tendentes a su regularización. Si bien desde algunos recursos se ha trabajado en estas tareas, la inexistencia de enlaces estables en origen ha puesto en manos del menor gran parte de la responsabilidad de transmitir a su familia la información sobre los trámites precisos en el Estado originario.

¿Por qué no se ha realizado esta coordinación transnacional? Lo evidente es que existe un discurso institucional sobre el «efecto llamada» que estas buenas prácticas implicarían (Gimeno, 2013: 144). Asumiendo así algunas praxis de Trabajo Social con menores solos un nacionalismo metodológico claramente contradictorio con su ética profesional.

15. A este «uso» y a sus diversas variantes se refiere el Trabajo Social como «comportamiento», partiendo de un asistencialismo opuesto al menor como «consumidor de» la protección.

16. «Cuando vienen se les da una tarjeta para llamar a su casa,... Se recarga una vez al mes,... Depende de cómo están llaman o no» (P6). También hay ocasiones en que los menores utilizan los medios telemáticos del centro de acogida para contactar con sus familias: «O por internet, Messenger, con voz y con imagen, te presentan, mira mi madre, mi hermano, desde su propia casa o desde casa del vecino» (P36). 


\subsection{Escenarios fuera de la Protección}

Además de estos actores externos al Sistema de Protección, los trabajadores sociales asumimos que hay, al menos, dos escenarios con los que no sabemos, no podemos o no queremos intervenir: la infracción jurídica y las redes de explotación y/o prostitución.

En el caso de la infracción, la investigación ha desarrollado más ampliamente el análisis de ésta en otro texto ${ }^{17}$, por lo que aquí sólo insistiremos en que evidencia una tendencia a la desinstitucionalización, un rechazo a los itinerarios estandarizados, que no coinciden con las expectativas migratorias de algunos menores solos. La infracción es, en definitiva, una confrontación más entre la homogeneidad de resultados esperada por el Sistema de Protección y el imaginario migratorio de los menores solos. El imaginario de unos jóvenes globales que, aun dentro de la acogida institucional, ansían ser Primer Mundo (consumismo, hedonismo, etc), desarrollando para ello una heterogeneidad de procedimientos, unas veces dentro y otras fuera de la ley.

El otro escenario al margen de la protección es el transitado por los menores, especialmente, las menores que llegan a Aragón mal acompañadas por redes de explotación, dirigidas por adultos. Dentro o al margen de estas redes, la prostitución suele estar vinculada a la mayoría de estas trayectorias migratorias, diferenciadas para niños ${ }^{18} \mathrm{y}$ para niñas.

Se trata de los itinerarios menos conocidos por el Trabajo Social, que hemos explorado a través de las entrevistas a profesionales, especialmente de entidades sociales que atienden específicamente a trabajadoras sexuales. En estas entrevistas se señala la presencia de menores prostituidas, que provienen casi siempre del África Subsahariana y de Europa del Este ${ }^{19}$. En algunos casos, las menores subsaharianas están vinculadas a la trata de personas, pero aquí bajo redes familiares: menores ecuatoguineanas tratadas mediante «adopciones» que se han usado para burlar los controles migratorios. Algunas de estas menores han llegado a la edad adulta tras una trayectoria migratoria de invisibilización durante varios años.

Hace poco nos vino una chica con dieciocho, nigeriana, que había estado desde menor, en un piso por [Casco Viejo], lo llevaba una senegalesa (P11).

17. «Menores solos e infracción en Aragón» (Gimeno, 2012).

18. Los casos conocidos por este investigador de menores que se prostituyen, habitualmente fuera de redes de explotación, coinciden en su perfil con lo descrito por Ainhoa Rodríguez (2008).

19. La investigación de Ariadna Alonso (2008 y 2010) sobre menores del Este europeo prostituidas en Cataluña es una buena introducción a este escenario. 
En el caso de las europeas, casi siempre rumanas, aun habiendo más expedientes de protección, al convertirse este siglo en miembros de la Unión Europea las pautas migratorias son diferentes. El paso de los menores rumanos y rumanas por los centros de primera acogida ha sido siempre fugaz (Justicia de Aragón, 2008: 82), siguiendo una pauta extendida por nuestro entorno europeo (Senovilla, 2007: 49; TdH, 2009: 31). Lo más grave es que, muy a menudo, las menores del Este vinculadas a la prostitución se fugan de los centros o son recuperadas de éstos por redes familiares o mafiosas que las reintegran de nuevo en la actividad del comercio sexual. En estos casos, los técnicos públicos y privados coinciden en la inadecuación de las intervenciones que se desarrollan con estas menores, que deberían ser acogidas como víctimas de trata, eliminando el contacto con su «familia extensa» (Alonso, 2008: 142).

\section{Discusión}

A la vista de las estrategias migratorias presentadas, podemos concluir que las Comunidades Autónomas han recibido competencias explícitas e implícitas en la política migratoria española sobre menores no acompañados. Explícitamente se les reclama que los protejan, mientras implícitamente se les responsabiliza de evitar el efecto llamada que dicha acogida supone.

Con todo, los intentos de abordar la presencia de otros actores y escenarios, desde una acogida institucional posicionada como herramienta de control migratorio, se encuentran siempre con nuevas estrategias que los desbordan, generando nuevos itinerarios paralelos al de la protección. Por lo que parece necesario que los Servicios de Protección de Menores implementen praxis que, a través de la mediación, abarquen el entorno social transnacional de estos adolescentes.

Y, por último, el escenario reseñado de prostitución de menores nos invita a debatir como técnicos sobre la necesidad y urgencia de la modificación de algunas prácticas administrativas en la detección y acogida de las menores solas. Especialmente para evitar la fuga de los centros, presionadas por unas redes que las desplazan contra su voluntad por la geografía del Estado.

\section{Bibliografía}

Alonso, A. (2008). En terra de ningú. Una aproximació a la prostitució en els projectes migratoris de menors no acompanyades de l'Europa de l'Est a Catalunya. Tesina de Máster, Universitat Autònoma de Barcelona.

Alonso, A. (2010). En tierra de nadie. Migración y prostitución entre adolescentes no acompañadas de Europa del Este en Cataluña. Educación Social, 45, 65-77. 
ARARTEKo (2005). Situación de los menores extranjeros no acompañados en la CAPV. Vitoria: Ararteko.

Bergua, J.A. (2005). Lo social instituyente y la imaginación. Culturales, 1, 29-56. BERGUA, J.A. (2007). Lo social instituyente. Materiales para una sociología no clásica. Zaragoza: Prensas Universitarias.

Bergua, J.A. (2011). Estilos de la investigación social. Técnicas, epistemología, algo de anarquía y una pizca de sociosofía. Zaragoza: Prensas Universitarias.

Defensor del Pueblo (2012). Trata de seres humanos en España: víctimas invisibles. Madrid: Defensor del Pueblo.

Esteban, G. (2010). Propuestas para la creación de un sistema transnacional de protección de menores (entre España y Marruecos, en el marco de la Estrategia Europea sobre los Derechos de la Infancia). Propuestas para la actuación conjunta hispano-marroquí en el ámbito de la infancia: Colección Estudios e Informes sobre Inmigración $n^{\circ}$ 2. Granada: Editorial Comares.

GIMENO, Ch. (2010). Menores extranjeros no acompañados: una cuestión compleja para las políticas públicas y sociales. Revista de Derecho Migratorio y Extranjería, 25, 55-72.

GIMENO, Ch (2011). El orden y la gente: los menores migrantes no acompañados. En S. Giménez, y A. García, (coord.), Innovaciones en la sociedad del riesgo. Asociación Castellano Manchega de Sociología.

GIMENO, Ch (2012). Menores que migran solos e infracción en Aragón. Revista de Derecho Migratorio y Extranjería, 29, 263-283.

GIMENO, Ch. (2013). Expectativas de acogida en el imaginario de los menores que migran solos. REID, 9, 142-158.

JiMÉNEZ, M. (2011). Intrusos en la fortaleza. Menores marroquíes migrantes en la Frontera Sur de Europa. Tesis doctoral, Universidad Autónoma de Madrid.

Justicia de Aragón (2000 a 2010). Informes sobre la situación de los menores en Aragón. Zaragoza: Justicia de Aragón.

LÓPEZ RIOPEDRE, J. (2011, octubre). El proceso de victimización de la trabajadora sexual migrante. Comunicación en la International Conference on Negotiating Identity in Migration Processes. Madrid: CSIC. Pendiente de publicación.

MANZANI, L. et alter (2012, abril). La medicación transnacional para la mejora de la intervención socioeducativa con menores y jóvenes extranjeros sin referente familiar adulto en las sociedades receptoras. Póster en el Congreso sobre las Migraciones Internacionales en España. Bilbao.

Quiroga, V. (coord.) (2005) Rutas de pequeños sueños. Los menores migrantes no acompañados en Europa [Informe comparativo]. Barcelona: Fundación Pere Tarrés.

Quiroga, V. (coord.) (2009), Somnis de butxaca. Nois i noies menors migrants no acompanyats a Catalunya. Barcelona: Fundació Jaume Bofill. 
RODRíguez, A. (2008). Reacciones y relaciones de menores y jóvenes marroquíes ante la protección y la exclusión. E-migrinter, 2. Universidad de Poitiers (Francia).

SEnovilla, D. (2007). Situación y tratamiento de los menores extranjeros no acompañados en Europa. Bruselas: Observatorio Internacional de Justicia Juvenil.

SuÁREZ, L. (2006). Un nuevo actor migratorio: jóvenes, rutas y ritos juveniles transnacionales. En F. Checa, A. Arjona y J.C. Checa (Eds.), Menores tras la frontera. Otra inmigración que aguarda. Barcelona: Icaria.

TERRE DES HOMMES - TDH (2009). DisAPPEARING, departing, running away. A surfeit of children in Europe? Laussane (Suiza): TdH.

ANTECEDENTES DE DIFUSIÓN

Presentado un avance como comunicación a la International Conference Unprotected unaccompanied children in Europe: Which reasons lead to their lack of protection? Poitiers, Francia, celebrado el 22-24 de octubre de 2012.

Alternativas, 20, 2013, pp. 41-56 - ISSN 1133-0473 - DOI: 10.14198/ALTERN2013.20.03 
LA POLITICA DE REEDUCACIÓN EN LA COMUNITAT VALENCIANA. UN ANALISIS DE LAS PRÁCTICAS EDUCATIVAS DE LOS CENTROS DE JUSTICIA JUVENIL ${ }^{1}$

\author{
RE-EDUCATION POLICY IN THE COMUNITAT VALENCIANA \\ REGION. AN ANALYSIS OF EDUCATIONAL PRACTICES IN JUVENILE \\ JUSTICE CENTERS
}

Francesc Xavier Uceda i MaZA² Y José JaVier NaVArro PÉReZ ${ }^{3}$

\begin{abstract}
Resumen
En el presente artículo se analizan aspectos que definen la política de reeducación de la Comunitat Valenciana. Se examina el papel de los Centros de Reeducación y sus prácticas educativas, para ello se toma como indicadores: los mecanismos de coordinación con el medio abierto, las relaciones con la comunidad, la proporción del gasto e inversión que la administración pública realiza sobre el sistema de justicia juvenil, el compromiso de las políticas públicas con la integración de los Adolescentes en Conflicto con la Ley, etc. La investigación es fundamentalmente cualitativa, basada en el análisis de entrevistas en profundidad de profesionales y de relatos de vida de adolescentes complementándose con datos documentales que ofrecen información de contexto. La principal conclusión apunta a que la política de reeducación se aproxima a un modelo de gestión de riesgos, distanciándose de las recomendaciones internacionales, y específicamente de aquellas que hacen referencia a un modelo basado en la comunidad. Asimismo se hallan evidencias para anunciar la inexistencia de una hoja de ruta establecida por la entidad autonómica que asume las competencias en esta materia, produciéndose divergencias absolutas entre los centros, predominando un modelo punitivo-sancionador frente a un modelo educativo - inclusivo (sólo presente en uno de los centros investigados). Todo ello, amparado ante un único marco jurídico normativo y en una misma política pública de reeducación.
\end{abstract}

Palabras clave: Justicia Juvenil, Responsabilidad Pública, Modelos de Intervención, Comunidad.

\begin{abstract}
This article discusses aspects that define the policy of rehabilitation regarding juvenile justice in the Valencian region. It examines the role of rehabilitation centers and educational practices, and the following are taken as indicators: coordination mechanisms with the open environment, community relations, the share of investment and spending by the public administration on the juvenile justice system, the public policy commitment towards the integration of Adolescents in Conflict with the Law, etc. The research is mainly qualitative, based on in-depth analysis of professional and life stories of teens complemented by documentary evidence which offers background information. The main conclusion suggests that rehabilitation policy approaches a risk management model, distancing itself from international recommendations, specifically those that refer to a community-based model. The article tries to identify the possible absence of an established juvenile justice model within public services. The results from the analysis defined the absence of a roadmap in the Communidad, that is unable to plan the direction of juvenile justice model that is also accompanied by serious discrepancies in management: a punitive model against an educational - inclusive model (which was only present in one centre) This is based on the same normative legal framework and on the same public policy for reeducation.
\end{abstract}

Keywords: Juvenile Justice, Public Responsability, Intervention Models, Community.

Recibido: 26/02/2013

Aceptado: 25/09/2013

Publicado: 05/11/2013

1. El presente artículo constituye una extensión al proyecto de investigación que lleva por título El sistema de Servicios Sociales ante la crisis económica. Retos, desafíos y territorio: el caso de la provincia de Valencia Ref./ UV-INV-PRECOMP12-82190.

2. Departamento de Trabajo Social y Servicios Sociales, Facultad de Ciencias Sociales de la Universitat de València; Avenida de los Naranjos, $n^{\circ}$ 4-B, 46071. Valencia. España. Telf: (00-34) 963828180; fax: (00-34).963828188. Email: Francesc.Uceda@uv.es

3. Instituto Interuniversitario de Desarrollo Local. Departamento de Trabajo Social y Servicios Sociales. Universitat de València. 


\section{Introducción}

En el contexto europeo, e incluso en el global - mundial, subyace una cuestión fundamental en el diseño de prácticamente todos los sistemas de justicia juvenil. Hay en el ambiente una constante sobre la cual, las diferentes administraciones públicas se cuestionan qué modelo de justicia juvenil se desea implementar, bajo qué postulados y con qué finalidad, para así comprender la coherencia e integración de todos los elementos y factores que lo definen. En este caso, al abrigo de nuestra sociedad, las administraciones optan cada vez más por la judicialización como forma de resolver los conflictos de la vida cotidiana y de índole netamente social (Uceda, 2012).

El escenario social y judicial responde cada vez más a un modelo de gestión de riesgos que se apoya fundamentalmente en el valor de la seguridad. Su premisa básica parte de la igualdad radical de oportunidades para todos, y en este sentido, percibe al menor/joven como un actor racional, libre y dueño de su destino, y también de sus actos (Bernuz y Fernández, 2008). El discurso general sobre la seguridad de las personas, la antisocialidad, la peligrosidad de los adolescentes y jóvenes, el interés por las víctimas, etc. formulados desde el paradigma de la Tolerancia Cero se ha abierto camino en nuestras políticas, instituciones y metodologías de intervención (De Giorgio, 2005) exigiendo garantías de seguridad desde la opción de una justicia juvenil retributiva y selectiva.

Nuestro marco jurídico de atención a los Adolescentes en conflicto con la ley ${ }^{3}$ se sustenta en las recomendaciones internacionales (Reglas de Beijing, Directrices de Riad, Reglas de la Habana y Reglas de Tokio) asumidas por el estado español. Con su firma se reconoce la delincuencia juvenil como un fenómeno global que requiere una regulación en su prevención y tratamiento; así como la orientación hacia un modelo de justicia juvenil garantista tanto en el plano jurídico como en el procesal, "sustentado en la despenalización y la desjudicialización como variables proyectivas del medio abierto que además posibilitan la participación e inserción delen la comunidad» (González-Tascón, 2010: 98).

El ámbito comunitario constituye un marco extraordinario para aprovechar las sinergias pues en el territorio confluyen las personas y los grupos, las administraciones públicas con sus diferentes políticas, servicios y programas, las instituciones sociales privadas (sin y con ánimo de lucro), las empresas, los espacios de ocio, etc.; y es en el mismo donde se promueve la convivencia

3. En adelante ACL. 
y la integración garantizando la seguridad, pues los problemas sociales son problemas espaciales (Hamzaoui, 2005).

La ley 5/2000, reguladora de la responsabilidad penal de los menores ${ }^{4}$, pivota sobre tres ejes: interés superior del menor, responsabilidad ante los hechos y la fijación de una edad mínima para ser penalmente imputable. Para la consecución de la finalidad se arbitran medidas privativas de libertad y no privativas.

La Comunitat Valenciana, mediante la ley 12/2008, de protección integral de la infancia y la adolescencia, define que el sistema de reeducación de menores es el conjunto de acciones orientadas a procurar el desarrollo integral y la inserción social y familiar del menor infractor. Asimismo, la ejecución de medidas privativas de libertad se realizará en centros específicos denominados de reeducación o socioeducativos que deberán disponer de un Proyecto Global que recoja la identidad del centro, el proyecto técnico de actuación y las normas de funcionamiento y convivencia.

Así pues, partimos de la premisa que garantizar el interés superior del menor, así como los aspectos educativos, no sólo depende del tipo de medida y de los tratamientos terapéuticos individualizados que se apliquen sino también del tipo de programa educativo global al que está sujeto. Morente et al. (2009) clasifica los programas socioeducativos de los centros de reeducación en tres perfiles tipológicos:

a. La eficacia, caracterizada por la búsqueda de la coerción, disciplina, control del comportamiento y estimulación conductista, para lo que su ideal es la rehabilitación (cambiar al individuo), donde el papel del educador es coercitivo para orientar la desviación del educando (desconoce las reglas sociales) y se ubica en un modelo neo-correccionalista del riesgo.

b. La educación moral, amparado en un modelo de asistencia social y reinserción moral donde el educando es un ser incompleto.

c. La relación democrática y enseñanza activa, cuyas características son, libertad y desarrollo de la individualidad, el derecho a la expresión y participación, donde el educador adquiere un rol fundamental en el entrenamiento de la reflexión del educando a través del diálogo y el acompañamiento.

Existe literatura científica que enmarca en el tercer perfil tipológico las intervenciones con éxito, por ejemplo, los trabajos de Bowlby (1971) relativos al

4. En adelante LORPM. 
desarrollo de las teorías del apego que inciden en la importancia del afecto y la comunicación participativa del menor en su proceso socializador; los postulados de Howe (1987), sostienen la importancia de la intervención socioeducativa a través de la teoría del vínculo afectivo. Respecto a las investigaciones con ACL, Serra (1993) destaca que los agentes institucionales involucrados en la atención residencial de menores deben de ser percibidos desde el apoyo y el afecto; Vives (2001), incide en el interés de una aproximación afectiva a través de la presencia constante y el acompañamiento del educador; Valverde (2002) proyecta que es necesaria una relación afectivo-terapéutica con el joven internado para que éste identifique el apoyo percibido que ayude a incentivar su crecimiento y desarrollo positivo; y Camps y Cano (2006) señalan que la mejora socio-cognitiva de los menores delincuentes internados, facilita su adaptación a la estancia residencial y colabora en el compromiso con la evolución positiva de su internamiento. Por su parte, Navarro y Puig (2010) plantean que recibir estímulos instructivos y afectivos por parte del personal educativo de los centros, ayuda a potenciar sus capacidades e implica dotar al menor de mayores y mejores estrategias para afrontar su situación y el proceso que se deriva del internamiento.

\section{Material y métodos}

Constituyen elementos esenciales para desvelar la ideología de una determinada política pública, la forma y el modo de gestión. Junto a ello, desvelar las prácticas educativas tanto oficiales como aquellas que se derivan del currículum oculto son indicadores claves de su concepción (Apple, 1986). En este sentido los objetivos de la investigación son:

- Mostrar la relevancia adquirida por el medio cerrado en la política reeducativa valenciana, siendo pilar básico del actual modelo de justicia juvenil.

- Conocer el grado de privatización en la gestión del sistema.

- Identificar los programas educativos de los centros y la opinión de sus principales actores, es decir, tanto de los profesionales como de los ACL internos.

- Describir los programas socioeducativos desarrollados en el ámbito territorial de la Comunitat Valenciana y clasificarlos atendiendo a su tipología.

- Conocer la coordinación entre el medio cerrado y el abierto en la ejecución de las medidas judiciales como indicador básico de la concepción comunitaria. 
Para acceder a los resultados de la investigación, se utilizaron diversas técnicas concebidas desde la complementariedad metodológica, pues la dificultad del objeto así lo aconsejaba. Se inició con el análisis documental, ya que la explotación de datos secundarios puede considerarse posiblemente como una de las técnicas más extendidas en cualquier investigación social (Almarcha, De Miguel y Romero, 1969). Se dispuso de datos facilitados por la Conselleria de Gobernación y Justicia de la Generalitat Valenciana, Fiscalía de menores de la provincia de València y de datos recogidos directamente del Diari Oficial de la Comunitat Valencianas.

En una segunda fase se complementó con dos técnicas cualitativas: las entrevistas focalizadas a profesionales de la justicia juvenil (juzgados de menores, centros de reeducación y equipos de medio abierto) y, los relatos de vida de los $\mathrm{ACL}^{6}$ que estuvieron internados en diferentes centros siendo objeto de diversas medidas y grados de libertad.

En las entrevistas focalizadas se siguieron las orientaciones del modelo de Patton (1990), es decir, basadas en un guión y caracterizadas por la preparación previa de los temas a tratar y la libertad del entrevistador para formular las preguntas. Se realizaron 32 entrevistas a informantes clave con una trayectoria superior a cinco años en la atención a ACL siguiendo además, «criterios de inclusión que respondieran a la heterogeneidad, accesibilidad y representación,» de acuerdo con Vallés (1999: 89).

Tabla 1. Relación de informantes claves: ámbito, perfil profesional y codificación

\begin{tabular}{|l|l|l|}
\hline \multicolumn{1}{|c|}{ ÁMBITO } & \multicolumn{1}{|c|}{$\begin{array}{c}\text { PERFIL } \\
\text { PROFESIONAL }\end{array}$} & CODIFICACIÓN \\
\hline \multirow{5}{*}{$\begin{array}{l}\text { ESCENARIO JUDICIAL: AMBITO } \\
\text { JURIDICO }\end{array}$} & Abogado & Entrevista/EAB1 \\
\cline { 2 - 3 } & Abogado & Entrevista/EAB2 \\
\cline { 2 - 3 } & Abogado & Entrevista/EAB3 \\
\cline { 2 - 3 } & Jueza & Entrevista/EJ1 \\
\cline { 2 - 3 } & Juez & Entrevista/EJ2 \\
\cline { 2 - 3 } & Juez & Entrevista/EJ3 \\
\hline & Fiscala & Entrevista/EFIS1 \\
\hline & Fiscala & Entrevista/EFIS2 \\
\hline & Fiscala & Entrevista/EFIS3 \\
\hline
\end{tabular}

5. En el DOCV se publican las licitaciones, concursos públicos, subvenciones, convenios, etc.; en este caso los precios de licitación de los Centros de Reeducación.

6. Los datos derivados de las entrevistas tanto de los informantes clave como de los ACL se obtuvieron a través del preceptivo consentimiento. 


\begin{tabular}{|c|c|c|}
\hline \multirow{7}{*}{$\begin{array}{l}\text { ESCENARIO JUDICIAL: AMBITO PSICO- } \\
\text { SOCIAL (EQUIPO TÉCNICO) }\end{array}$} & $\begin{array}{l}\text { Téc. Esp. Menor } \\
\text { (Pedagogo) }\end{array}$ & Entrevista/EETTM1 \\
\hline & $\begin{array}{l}\text { Téc. Esp. Menor } \\
\text { (Maestra) }\end{array}$ & Entrevista/EETTM2 \\
\hline & Trabajadora social & Entrevista/EETTS1 \\
\hline & Trabajadora social & Entrevista/EETTS2 \\
\hline & Psicóloga & Entrevista/EETP1 \\
\hline & Psicóloga & Entrevista/EETP2 \\
\hline & Psicóloga & Entrevista/EETP3 \\
\hline \multirow{4}{*}{$\begin{array}{l}\text { ESCENARIO JUDICIAL AMBITO PSICO- } \\
\text { SOCIAL MEDIO ABIERTO }\end{array}$} & Educador social & Entrevista/EMAE1 \\
\hline & Educador social & Entrevista/EMAE2 \\
\hline & Educador Social & Entrevista/EMAE3 \\
\hline & Educador Social & Entrevista/EMAE4 \\
\hline \multirow{7}{*}{$\begin{array}{l}\text { ESCENARIO JUDICIAL AMBITO PSICO- } \\
\text { SOCIAL MEDIO CERRADO }\end{array}$} & Educador & Entrevista/ECOLE1 \\
\hline & Educadora & Entrevista/ECOLE2 \\
\hline & Educadora & Entrevista/ECOLE3 \\
\hline & Educador & Entrevista/EDIAE1 \\
\hline & Educador & Entrevista/EDIAE2 \\
\hline & Trabajador social & Entrevista/ECOLTS \\
\hline & Psicóloga & Entrevista/ECOLP1 \\
\hline \multirow{3}{*}{$\begin{array}{l}\text { ESCENARIO JUDICIAL-AMBITO } \\
\text { EJECUCION UNIDAD DOCENTE }\end{array}$} & Profesora & Entrevista/EMEST1 \\
\hline & Profesora & Entrevista/EMEST2 \\
\hline & Profesora & Entrevista/EMEST3 \\
\hline \multirow[b]{2}{*}{ ESCENARIO POLICIAL } & Inspectora & Entrevista/EGRUME \\
\hline & Subinspector & Entrevista/EPN \\
\hline
\end{tabular}

Fuente: Elaboración propia.

Los relatos autobiográficos son una construcción de la realidad social (Stanley, 1992). Vallés (1999) los denomina relatos de vida, pues permiten reconstruir trayectorias vitales a partir de elementos biográficos significativos, en este caso, la estancia en los centros por parte de los ACL. Su percepción nos ayudó a desvelar prácticas educativas y modelos de intervención. Fue de interés disponer de una base heterogénea donde poder hallar diferentes variables de análisis (edad, genero, $\mathrm{n}^{\mathrm{o}}$ de ingresos en centros, procedencia, tipología penal, situación en el momento de la entrevista...). Lo vemos, de manera gráfica en la siguiente tabla: 
Tabla 2. Relación de entrevistas a ACL y relatos autobiográficos

\begin{tabular}{|l|l|l|l|l|l|}
\hline \multicolumn{1}{|c|}{ SEXO } & EDAD & ORIGEN & $\begin{array}{c}\text { SITUACIÓN } \\
\text { ACTUAL }\end{array}$ & CENTROS & CODIFICACIÓN* \\
\hline Mujer & 24 & Paterna & Prisión & 3 & Saray \\
\hline Varón & 23 & Gandía & Prisión & 4 & Javi \\
\hline Varón & 25 & Elche & Prisión & 4 & Pepón \\
\hline Mujer & 23 & Alicante & Libertad & 1 & Raquel \\
\hline Mujer & 23 & Valencia & Libertad & 3 & Álexia \\
\hline Varón & 17 & Villareal & C. Reeducación & 2 & Lolo \\
\hline Varón & 19 & Chiva & Libertad & 3 & Dani \\
\hline Varón & 18 & Elda & C. Reeducación & 3 & Carlos \\
\hline Varón & 27 & Burjassot & Prisión & 3 & Andrés \\
\hline Varón & 21 & Castellón & Libertad & 3 & Christian \\
\hline Varón & 22 & Alicante & Libertad & 2 & Sergio \\
\hline Mujer & 23 & Sagunto & Libertad & 2 & Eva \\
\hline Varón & 19 & Catarroja & C. Reeducación & 2 & Kevin \\
\hline Varón & 20 & Sax & Libertad & 2 & Samuel \\
\hline Varón & 21 & Valencia & Prisión & 3 & Jonny \\
\hline Mujer & 19 & Valencia & Prisión & 3 & Carla \\
\hline
\end{tabular}

* Así es como los jóvenes entrevistados quisieron identificarse. Un nombre ficticio con el que ocultar su identidad y a través del cual, reconocerse a sí mismos.

Fuente: Elaboración propia

El tratamiento cualitativo se efectuó mediante el programa informático MAXqda 2007. La utilización de un programa informático facilita la manejabilidad de los testimonios obtenidos, especialmente el proceso de codificación.

\section{Resultados}

Estructuraremos los resultados en dos niveles, en función de los objetivos planteados:

Nivel 1: Asociando los resultados obtenidos al modelo de justicia juvenil.

Nivel 2: Describiendo las prácticas educativas de los diferentes centros de justicia juvenil de la Comunitat Valenciana.

\subsection{Nivel 1: Modelo de Justicia Juvenil}

El primer gran efecto que salta a la vista se da en la gran diferencia existente entre el presupuesto destinado a los centros de reeducación frente a 
los equipos educativos de medio abierto, que denota la potenciación de uno frente al otro.

A partir de estos datos, se sistematizaron los hallazgos en dos categorías:

Categoría A: Refiere el crecimiento de las plazas en centros de internamiento frente al escaso incremento de recursos humanos para el medio abierto.

El 13 de enero de 2001 se implantó operativamente la LORPM. En ese momento, la Comunitat Valenciana tenía disponible 155 plazas, repartidas en tres centros de reeducación (C.R. Pi Gros de Castelló, con 40 plazas, C.R. La Villa con 50 plazas en Alicante y el C.R. Colonia San Vicente Ferrer con 65 plazas en València). A fecha actual de 2013, para la ejecución de medidas privativas de libertad hay un total de 416 plazas repartidas en ocho centros:

- 132 plazas en Alicante (C.R. La Villa con 62 plazas y C.R. Els Reiets con 70 plazas),

- 47 en Castelló (C.R. Pi Gros),

- 237 en València (60 plazas en C.R. Mariano Ribera, 20 en C.R. Pi i Margall, 82 en C.R. Colonia San Vicente Ferrer, 25 en C.R. Cabanyal y 50 en C.R. Jaume I).

La gestión de los centros realizada por entidades privadas es prácticamente del 100\% (Fundación Amigó gestiona un centro en Valencia de reciente creación ${ }^{7}$, Fundación Diagrama cinco y Fundación Los Arcos uno); únicamente las 82 plazas de la Colonia San Vicente Ferrer son de gestión mixta entre la Generalitat y la congregación religiosa de los Terciarios Capuchinos.

Con todo ello, queremos referenciar que las plazas de estancia en centros se han incrementado un $268 \%$ respecto a los datos de 2001 . Todo ello requiere la preceptiva explicación de que todos los ACL sujetos a una medida de internamiento han de cumplir, a la finalización de la misma, un periodo de libertad vigilada tal como refleja el artículo $7.2^{8}$ de la LORPM.

7. El C.R. Cabanyal, que tradicionalmente había atendido menores de protección, le fueron modificadas sus competencias para la atención y tratamiento de jóvenes sujetos a medidas judiciales de internamiento e inició su nueva andadura en reeducación el pasado 1 de mayo de 2012.

8. El articulo 7.2 de la Ley señala lo siguiente: «Las medidas de internamiento constarán de dos períodos: el primero se llevará a cabo en el centro correspondiente, conforme a la descripción efectuada en el apartado anterior de este artículo, el segundo se llevará a cabo en régimen de libertad vigilada, en la modalidad elegida por el Juez». 
Fig. 1. Evolución de las plazas en los centros de reeducación de la C.

Valenciana (2001-2013)

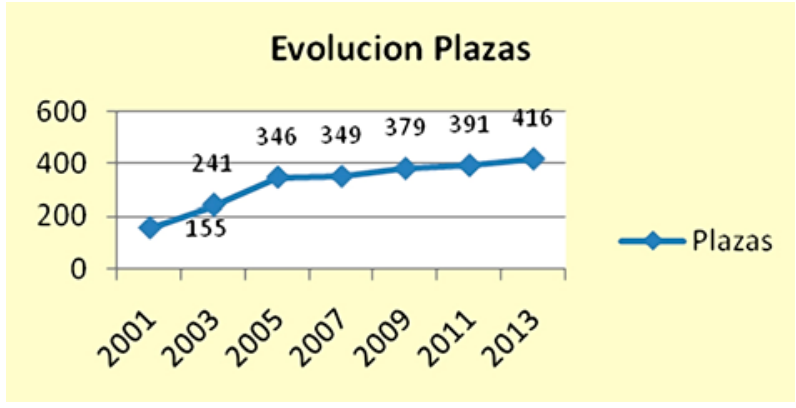

Fuente: elaboración propia a partir de datos de D.G. de Justicia y Menor. Generalitat Valenciana.

Fig. 2. Titularidad de las plazas en la Comunitat Valenciana

\section{Titularidad de Plazas}

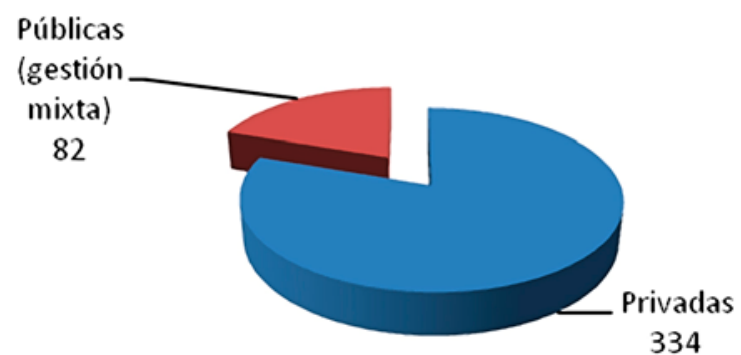

Fuente: elaboración propia a partir de datos de D.G. de Justicia y Menor. Generalitat Valenciana.

Con respecto al medio abierto, la Generalitat Valenciana otorga subvenciones para la gestión del servicio a ayuntamientos (preferentemente) o a entidades sin ánimo de lucro. En el periodo 2001 a 2013, el número de técnicos de medio abierto se incrementó de 57 a 76 en toda la Comunitat. Las cifras muestran un diferente trato entre medio abierto y medio cerrado, ya que la inversión en recursos humanos para el medio abierto tan sólo ha crecido un $21 \%$, es decir, un porcentaje trece veces inferior que el crecimiento mostrado por el medio cerrado. Podríamos, con estos datos, incidir en las ratios educador/menor, ya que si en los centros hay una proporción aproximada de 1 
educador para 3 menores, el medio abierto proyecta unas cifras de 1 educador para 38 menores.

Fig. 3. Evolución número de técnicos de medio abierto en la Comunitat Valenciana (2001-2013)

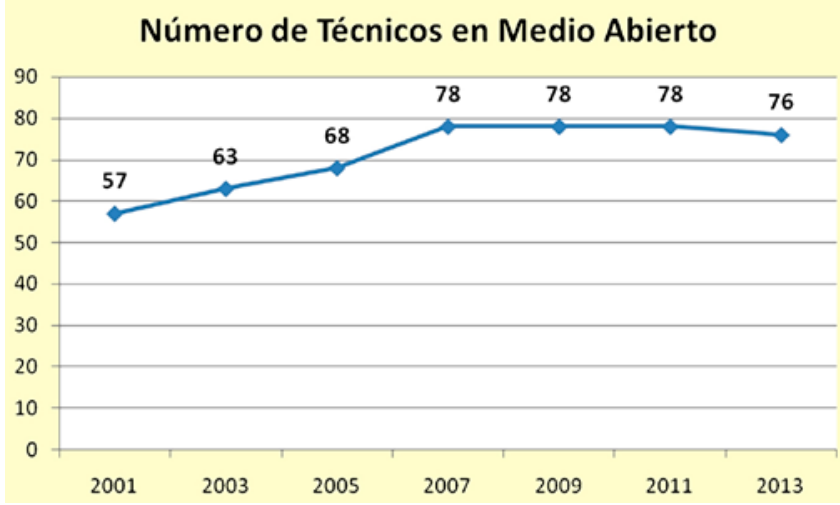

Fuente: elaboración propia a partir de datos de D.G. de Justicia y Menor. Generalitat Valenciana.

Respecto a los recursos destinados a la ejecución de medidas judiciales, las administraciones públicas, principalmente la Generalitat, destina el 95\% para la ejecución de las medidas privativas de libertad frente al 5\% para las medidas de medio abierto.

Fig. 4. Recursos destinados por las diferentes admón. públicas

Financiación M. Cerrado-M. Abierto

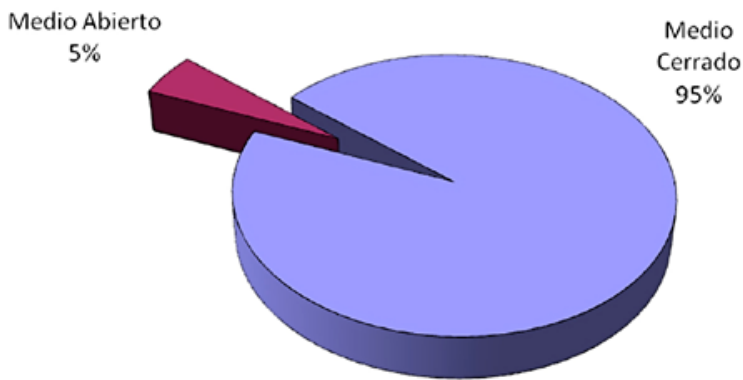

Fuente: elaboración propia a partir de datos de la Generalitat Valenciana y la Secretaria de Estado de Política Social. 
Para acabar de completar este análisis y cerrar el círculo entre administraciones públicas, entidades gestoras de la ejecución y cumplimiento de medidas y la propia administración de justicia juvenil, hacemos referencia a las Memorias de la Fiscalia de Menores de Valencia para los años 2009, 2010, 2011 y 2012 y así observar con detenimiento el estado de la representatividad en la imposición de medidas judiciales.

Tabla 3. Medidas impuestas los años 2009 a 2012 por la Fiscalía de Menores de Valencia

\begin{tabular}{|l|c|c|c|c|}
\hline \multicolumn{1}{|c|}{ MEDIDAS IMPUESTAS } & 2009 & 2010 & 2011 & 2012 \\
\hline Internamiento cerrado & 31 & 36 & 27 & 14 \\
\hline Internamiento semiabierto & 216 & 174 & 200 & 202 \\
\hline Internamiento abierto & 1 & 3 & 2 & 2 \\
\hline Internamiento terapéutico & 22 & 21 & 14 & 17 \\
\hline Asistencia a centro de día & 7 & 4 & 6 & 4 \\
\hline Tratamiento ambulatorio & 21 & 16 & 20 & 13 \\
\hline Permanencia de fin de semana & 54 & 57 & 34 & 19 \\
\hline Libertad vigilada & 695 & 677 & 571 & 551 \\
\hline Convivencia con grupo educativo & 59 & 55 & 55 & 68 \\
\hline Tareas socio educativas & 343 & 324 & 290 & 303 \\
\hline $\begin{array}{l}\text { Prestaciones en } \\
\text { beneficio de la comunidad }\end{array}$ & 193 & 248 & 240 & 310 \\
\hline Privación permisos y licencias & 38 & 24 & No datos & No datos \\
\hline Amonestaciones & 111 & 89 & 99 & 90 \\
\hline $\begin{array}{l}\text { Prohibición de aproximación y } \\
\text { comunicación }\end{array}$ & 14 & 20 & 25 & 5 \\
\hline Otras & 105 & 8 & 14 & 7 \\
\hline Total Medidas Impuestas & 1910 & 1756 & 1597 & 1603 \\
\hline
\end{tabular}

\begin{tabular}{|l|c|c|c|c|}
\hline \multicolumn{1}{|c|}{$\begin{array}{c}\text { MEDIDAS IMPUESTAS EN } \\
\text { MEDIO ABIERTO }\end{array}$} & 2009 & 2010 & 2011 & 2012 \\
\hline Asistencia a centro de día & 7 & 4 & 6 & 4 \\
\hline Tratamiento ambulatorio & 21 & 16 & 20 & 13 \\
\hline Permanencia de fin de semana & 54 & 57 & 34 & 19 \\
\hline Libertad vigilada & 695 & 677 & 571 & 551 \\
\hline Convivencia con grupo educativo & 59 & 55 & 55 & 68 \\
\hline Tareas socio educativas & 343 & 324 & 290 & 303 \\
\hline $\begin{array}{l}\text { Prestaciones en } \\
\text { beneficio de la comunidad }\end{array}$ & 193 & 248 & 240 & 310 \\
\hline Privación permisos y licencias & 38 & 24 & No datos & No datos \\
\hline
\end{tabular}




\begin{tabular}{|l|c|c|c|c|}
\hline Amonestaciones & 111 & 89 & 99 & 90 \\
\hline Prohibición de aproximación y & & & & \\
comunicación & 14 & 20 & 25 & 5 \\
\hline & 1535 & 1514 & 1340 & 1363 \\
Total Medidas en Medio Abierto & $80,3 \%$ & $86,2 \%$ & $83,9 \%$ & $85 \%$ \\
\hline
\end{tabular}

\begin{tabular}{|l|c|c|c|c|}
\hline $\begin{array}{c}\text { MEDIDAS IMPUESTAS EN } \\
\text { MEDIO CERRADO }\end{array}$ & 2009 & 2010 & 2011 & 2012 \\
\hline Internamiento cerrado & 31 & 36 & 27 & 14 \\
\hline Internamiento semiabierto & 216 & 174 & 200 & 202 \\
\hline Internamiento abierto & 1 & 3 & 2 & 2 \\
\hline Internamiento terapéutico & 22 & 21 & 14 & 17 \\
\hline & 270 & 234 & 243 & 235 \\
Total Medidas en Medio cerrado & $19,7 \%$ & $13,8 \%$ & $16,1 \%$ & $15 \%$ \\
\hline
\end{tabular}

Fuente: Elaboración propia a partir de las Memorias de la Fiscalía de Menores de Valencia.

Las cifras reflejan cómo en todos estos años, el número de medidas impuestas en medio abierto supera hasta en cuatro y casi cinco veces a las medidas impuestas en medio residencial o cerrado. Las evidencias nos informan cómo la imposición de medidas del medio abierto para el año 2009, supusieron un $80,3 \%$ mientras que para el medio cerrado un 19,7\%; sin embargo, la horquilla para 2012 crece todavía más, al representar el medio abierto un $85 \%$, mientras que el medio cerrado asumió tan solo un $15 \%$ del total de medidas impuestas.

Categoría B: La apuesta por la privatización y monopolio del modelo respecto la gestión mixta o pública.

En cuanto al presupuesto destinado a centros ${ }^{9}$, tomando como referencia el Centro de Reeducación Els Reiets, cuya gestión del servicio integral salió a concurso por 3 años, 7 meses y 15 días $^{10}$, con un valor de licitación ${ }^{11}$ de 28.041.310,50€, se dividió éste por el número de días, obteniendo:

9. Se han realizado los cálculos a partir de las publicaciones aparecidas en el Diari Oficial de la Comunitat Valenciana ya que no fue facilitado por la Dirección General.

10. Resolución de 27 de mayo de 2009, de la Conselleria de Justicia y Administraciones Públicas, por la que se hace pública convocatoria de licitación por procedimiento restringido, mediante pluralidad de criterios, del contrato del servicio de atención integral del Centro de Reeducación de Menores Els Reiets (Alicante). Diari Oficial de la Comunitat Valenciana núm. 6027 con fecha del 03/06/2009.

11. La licitación indica el precio por el que la administración pública audita la gestión para el citado recurso. Ello no implica que la entidad que asume la gestión concurse por una 
Tabla 4. Presupuesto para la gestión educativa del C.R. Els Reiets (Alicante)

28.041.310,50 €/1320 días * $=21.243,42 €$ (presupuesto/total días del centro)

$21.243,42 € \times 365$ días $=7.753 .848,3 €$ (presupuesto año centro)

7.753.848,3€/70 plazas del centro: $110.769,2 €$ (plaza/año).

$110.769,2 € / 365$ días $=302,3 €($ plaza/dia $)$

* Los días se calcularon de la siguiente forma: 3 años (1095 días), 7 meses (210 días) y se le sumó los 15 días, por lo que el total son: 1.320 días.

Fuente: elaboración propia a partir de datos del DOGV.

Los profesionales entrevistados señalan que se ha seguido una política de privatización de la gestión, inicialmente en los centros de internamiento pero extendiéndose al medio abierto:

En la Comunidad Valenciana existe un monopolio en la privatización, pues hay una entidad que gestiona prácticamente todo el sistema y ha ido abriendo centros y ahora el medio abierto; se está privatizando todo y es preocupante. (EMAE-3);

Y de potenciación del medio cerrado frente al medio abierto:

No se ha fomentado el medio abierto; el medio cerrado va aumentando en profesionales, plazas, etc. y el medio abierto no, cada vez la ratio por educador y ACL es mayor. (EMAE-2).

Al inicio se estuvo con un ratio de 12-13, ahora con 28-30, y sería adecuado no más de 15 (...) Yo creo que el chip viene de la justicia de adultos, basada en el castigo más que en la reinserción de la gente (...) Y lo más definible de esto es el internamiento que por otra parte es lo más caro. (EMAE-3).

La administración de justicia juega un importante papel en la orientación educativa y resocializadora de los chavales y en la política de planificación y gestión de recursos que desarrollan las administraciones:

Ahi pintan mucho los jueces y fiscales [...] Los juzgados exigen mucho a la Conselleria que es la que se encarga de organizar la red de centros, las plazas y todo eso. Los politicos tienen miedo a que los juzgados enroquen con que no hay medios para encerrar a los chavales con la alarma que eso provocaría. El político vive de su imagen pública y al deteriorarse por estas cosas, ninguno quiere que le toque la china. (EMAE-4).

El político lo que quiere es cero problemas y lo que hacen en algunos centros es ponerles la alfombra roja y claro, se dejan querer. Así pueden salir todos los días en el Canal 9 repartiendo sonrisas, ya sabes, ¿no?. (EADIE-1).

cantidad inferior, que sea finalmente la efectiva. 
3.2. Nivel 2: Resultados atendiendo a las prácticas educativas de los centros

El primer resultado es la amplia discrecionalidad de los centros para el diseño de los proyectos globales educativos, no existiendo en la ley ni en los concursos convocados por la Generalitat más referencias que las generalidades señaladas.

Sistematicemos a continuación los hallazgos en tres categorías que justifican la afirmación anterior: coordinación entre medio cerrado y abierto, modelos institucionales de intervención pedagógica y resocializadora, y finalmente, las relaciones educativas entre educadores y educandos de estos recursos. Veamos pues:

\section{Coordinación entre medio cerrado y abierto}

No cabe duda que la estancia en el centro es algo temporal y hay que preparar al ACL para volver a su espacio natural. Los equipos de medio abierto podrán cumplir las medidas que tengan asociadas simultáneamente al internamiento o a su finalización.

Así pues, por lo que a la conexión de ambos medios y equipos educativos (abierto y residencial o cerrado) se refiere, la colaboración mutua, transparencia, mediación y negociación con el programa socio-educativo y los recursos del espacio natural del menor, la formalidad de los procesos, los canales de intercambio... es decir, todo ello habría de ser una evidencia lógica, organizada y protocolizada incluso a petición de la administración pública autonómica encargada de custodiar estas garantías pseudoburocráticas, para evitar que todo dependa del nivel de compromiso, responsabilidad asumida o entendimiento, tanto de los profesionales que ejecutan la medida como de los centros encargados de asumir la atención de los menores.

En este sentido, los informantes (en este caso de los equipos de medio abierto) señalan que la comunicación y coordinación con los centros es dispar; cuando es fluida, no se rompe la relación socioeducativa que ya se mantiene con el menor, y por el contrario, cuando es trabada se rompe el proceso.

En el C.R.-412 entras cuando quieres y jamás han puesto ninguna objeción; pero en el C.R.-3 o en C.R.-1 lo primero que te piden es el DNI y luego te pasan la paleta, después la información no fluye y te preguntas por qué si vamos todos en el mismo barco. Ellos no ven más allá del centro. Pero a ver, yo tengo un chaval que va a salir dentro de dos meses y cuando entró se planteó unos objetivos con

12. Las referencias explícitas a los Centros de Reeducación y demás entidades de atención socio-educativa han sido codificadas, a efectos de reservar tanto la intimidad de los informantes como de los argumentos expresados. 
él, pero cuando salga no va a tener una escuela, ni una formación y el chaval está mosqueado, y es normal. Y nosotros un poco también, porque yo me siento responsable de todo este proyecto (EADIE-1).

Aqui depende de cómo quieran gestionarlo los centros; ellos manda y si tienes suerte que el chaval cae en el C.R.-2, que la directora es muy bonica, pues afortunado... pero si te toca en el C.R.-3 o C.R.-,1 mala suerte. (EMAE-2).

\section{El modelo intervención}

Respecto a la metodología y los modelos de atención, las respuestas de los profesionales se diferencian en los llevados a cabo en dos entidades, en ambos se incide en la modificación de la conducta pero por ejemplo, en el C.R.-4 desde un trabajo cognitivo y empático, fundamentado en la relación socio-educativa:

Nosotros tenemos una perspectiva cognitivo-conductual de intervención (...) primero adaptación al centro, asimilación y aceptación de las normas y medida, y una vez que los sitúas comienzas la intervención cognitiva (...) es muy personal, va en función del chaval. De hecho, con casi todos tenemos una relación bastante buena, a medio plazo (...) la empatía con ellos es muy buena, es algo que le sorprendería a mucha gente que no conoce el funcionamiento de un centro. (ECOLE-3).

Sin embargo, los propios trabajadores de otra de las entidades que asume la mayor parte de centros de reeducación valencianos, inciden en una metodología centrada en un modelo conductista, normativo, jerárquico y disciplinario; la observación es permanente y disciplinaria, tal y como ya describió Goffman (1984). A este respecto, los informantes refieren:

Conductistas absolutamente, que por un lado está bien, pero tiene un límite. Los chavales no interiorizan nada. Además, el aprender por miedo, hago esto porque sino obtengo algo negativo, un castigo (...) no hay un aprendizaje donde el niño entienda que ese comportamiento está bien o no. Sabe que tiene que hacer esa actividad y hacerla bien (...). (EADIE-1).

Seguir el horario que te marca la dirección del centro, es decir, si hay matemáticas, matemáticas, si hay fútbol, futbol, dormir, pues se duerme, etc. Y en cada una de las actividades estar controlando al 100\% todo lo que se maneja, todo lo que se utiliza, lo que se habla, lo que se mira. (EADIE-2).

Ahondando en lo expuesto anteriormente vemos la incidencia del relato de los hoy jóvenes sobre la experiencia en los centros. Hallamos coincidencias entre informantes clave educadores y los ACL ex - internos. Sirva como ejemplo, 
el relato de vida de Andrés ${ }^{13}$ refiriendo su experiencia derivada de la estancia en centros:

En la C.R.-4, te tratan bien, ahí estás bien, sala de televisión todos juntos con películas, tu tabaco, tus actividades (...) hablabas, tenías tu trato con los educadores y el director (...) pero en el C.R.-3 todo estaba prohibido, enseguida a piñón fijo. (Andrés).

Javi y Christian, jóvenes internados en varios centros, valoraron su estancia en ellos:

De los centros que yo he estao, el C.R.-4 un paraíso, un lujo, se come que flipas, buen trato si lo llevas bien, al mes permiso, qué más quieres; $y$ en el otro que hay al lao, tienes que ser un mariconcillo, no puedes hacer na, decir na, pues normal que te fugues, 5 ó 6 veces (...) Es todo muy estricto, (...) Quieras o no, si estás dos años sin salir, te acostumbras a ser un tonto, de la mentalidad de las normas. Y por la mañana te haces tu cama y to, pero da igual, luego estás en la calle y vuelves a lo tuyo. (Javi).

En el C.R.-4 te ayudan a que pienses en lo que has hecho y en la vida que quieres dar a tu gente y quieras o no te comes la bola... En el C.R.-6 da igual si fuera eres un hijo puta, mientras en el centro cumplas, pues de lujo. En el C.R.-1 siempre te están controlando todo y a la minima te meten un tiempo. Al final achantas, pero cuando vuelves a las movidas de tu barrio no has aprendio ná.... (Christian).

III. La relación socioeducativa establecida entre los ACL y sus educadores

Los centros de justicia juvenil se convierten en espacios donde la relación humana constituye un importante elemento que favorece el intercambio y el aprendizaje de nuevos ritmos y estrategias de ajuste social. Por ello, la relación educativa cercana y humana que el ACL genere con el personal educador, le ayudará a serenarse y mirar su proceso bajo una perspectiva de cambio.

En este sentido, Saray, ingresó en diferentes centros de reeducación. En relación a su experiencia propia, reflexionaba sobre la divergencia de trato en cada uno de ellos, diferenciando dónde se sintió bien tratada y dónde echó en falta lazos afectivos:

En C.R.-4, 2 abiertos y 2 cerraos (...) me dieron libertad vigilada, y incluso me llevaban para que me sacara el permiso de conducir de la moto (...) ya en el C.R.1, te acuerdas del C.R.-4, porque alli te dan cariño y te cuidan (...) y el C.R.-1 es una cárcel, bueno ahora estoy en la cárcel y aquello es peor. Yo prefiero estar aqui que allí. Alli te pegan, te maltratan, te pinchan pa meterte tiempos (...) Yo prefiero estar aquí. Y las educadoras no hablaban contigo, no te apoyan (...) Y el

13. Al igual que el resto de ACL, nombre ficticio que le fue asignado en el proceso de codificación. 
C.R.-3 era igual que el C.R.-1, es que es una cárcel (...) no puedes hablar ni de tu familia, sólo puedes hablar de lo que haces ahi y yo eso no lo entendía. No es como el C.R.-4 que hablas de cosas, que te hablan, te ríes, no sé, tampoco es que te dejen hablar de robos y eso, pero puedes hablar de las cosas, de la familia, con la educadora; ella saca temas y jugabas con los educadores, una partida de parchís, cartas, le contabas cosas de tu familia. (Saray).

Los diferentes discursos producen una narrativa lineal de hechos que entre si se ajustan a la realidad que describe la investigación.

\section{Discusión de los resultados y conclusiones}

A partir de las evidencias empíricas de la investigación es posible advertir que prima una política de gestión de riesgos en aras de mantener niveles de seguridad y que se traduce en destinar el presupuesto público fundamentalmente para la gestión del medio cerrado en detrimento del medio abierto. Asimismo, existen grandes diferencias en las prácticas educativas, en los estilos y en la concepción de los programas socioeducativos, en el papel del equipo técnico, de la relación con la comunidad, etc., primando en todos los centros a excepción de uno, cuestiones vinculadas a la gestión de riesgos y no a la promoción del ACL.

La privatización de servicios públicos tan sensibles como la seguridad y reinserción de ACL ha de debatirse, evaluarse y supervisarse muy estrechamente, ya que es una responsabilidad pública. La gestión privada no puede realizarse en monopolio desde una entidad, pues se produce una ausencia real de competencia, y en este sentido el modelo de privatización desarrollado por la Generalitat Valenciana minimiza la supervisión a la justificación económica y administrativa, lo que implica «abrir un abanico de modalidades de orientación y gestión tan diverso como son los idearios de las agencias que los desarrollan» (Morente, et al., 2008:160). Ante esta situación, el Síndic de Greuges (defensor del pueblo autonómico) ya sugirió a la Generalitat Valenciana que «no debe desistir de sus funciones de inspección y de control periódico con las entidades privadas con las que convenía la ejecución» (2005:48). En realidad lo que se produce por parte de la Generalitat mediante este modelo es una desresponsabilización de la función pública de organizar y planificar el sistema.

La Generalitat invierte el 95\% de su presupuesto en la ejecución de medidas privativas y sólo el $5 \%$ en las medidas no privativas de libertad; el esfuerzo institucional se dirige a la ejecución de medidas de internamiento, deteriorándose cada vez más la calidad de la intervención en el medio abierto al incrementarse la ratio en los equipos. No es algo nuevo, ya Cea d'Ancona (1992) y Tapias (2009) en diferentes periodos, denuncian la carencia de los 
delegados de libertad vigilada y la orientación del sistema hacia el medio cerrado. El Síndic de Greuges (2005) recomendó a la Generalitat el aumento de profesionales del medio abierto por cuanto se ha incrementado el volumen de ACL y de medidas sin que se hayan incrementado los recursos económicos y de personal durante los últimos años. Invertir en medio abierto implica invertir en prevención y con ello mejorar las condiciones de vida del ACL en su propio territorio que a su vez es parte substancial de su contexto socializador de referencia (Bueno y Moya, 1998).

Los datos de la Fiscalía de Menores de Valencia permiten comparar analíticamente el abismo que separa el medio abierto respecto el medio residencial cuando la realidad de las medidas dejan al descubierto que la desproporción presupuestaria y de recursos, no se debe a una mayor asunción de medidas. El incremento de unos respecto otros no es fortuito o accidental y tampoco se debe a causas motivadas por la administración de justicia que garanticen las ejecuciones. A la vista de todos queda pues, como jueces y fiscales instrumentalizan más aquellos recursos del medio abierto que los propios del medio cerrado, cuestión que tampoco explica las elevadas diferencias en la distribución presupuestaria para asumir ratios, actividades de inclusión y socialización educativa, supervisión controlada de las libertades operativas... etc., que el medio abierto ha de asumir.

Desde nuestros hallazgos coincidimos con Morente et al (2009), y de hecho así se advierte en los relatos de los ACL, donde la entidad que ostenta la mayoría de la gestión de centros se aproximaría al modelo de eficacia, y la Colonia San Vicente al modelo basado en la relación democrática y enseñanza activa. El resto de centros con menor recorrido (C.R. Jaume I y C.R. Cabanyal) no podemos establecer con exactitud un patrón de funcionamiento, ya que la trayectoria de gestión en ambos casos es reciente. El tiempo, las experiencias y nuevos trabajos de investigación dictaminarán su bagaje.

Por otro lado, existen extremos del discurso de los informantes que demuestran una mejor vinculación de los ACL ante procesos reeducativos que combinan normas y límites con prácticas educativas y afectivas. Por otro lado, ante instituciones marcadas por la punición y la conducta, los ACL se vinculan artificialmente atendiendo a las consecuencias negativas, obviando los aprendizajes positivos que de ellas se pudieran derivar.

Se producen diferencias abismales en el funcionamiento entre los centros, ya que a partir de las declaraciones genéricas y vagas de contenido sobre el interés del menor, su derecho a la resocialización, etc. cada entidad, centro y equipo efectúa su propio reglamento y/o curriculum oculto. Hemos evaluado 
la existencia de centros ${ }^{14}$ donde su funcionamiento se basa en modelos conductistas, normativizados y disciplinarios, caracterizados por el control y la seguridad, donde el ACL es desposeído de la concepción de sujeto y los educadores de la relación socioeducativa. Para la administración pública prima el aspecto sancionador frente al socializador e integrador. El interés superior del menor es una responsabilidad social, pública y ha de ser garantizada por las administraciones a partir de la supervisión efectiva de las medidas educativas, de la gestión de los centros y de sus proyectos educativos.

Los datos desprenden la inexistencia de un modelo de justicia juvenil sobre el que construir desarrollos pedagógicos, socializadores e inclusivos a largo plazo. Se trata más bien de un modelo que funciona mediante sonadas incongruencias y dando prioridad al medio cerrado, pero que en ausencia de protocolos y de una planificación constructiva, permite dilucidar un horizonte muy difuso.

Los procesos de desinstitucionalización son muy complejos y ninguno de los centros analizados aporta datos exactos $\mathrm{u}$ objetivos sobre los niveles de éxito que representan las intervenciones en medio cerrado para justificar la elevadísima y desproporcionada inversión de la administración. En este sentido, el tipo y naturaleza del recurso condiciona la eficacia de los resultados. Si lo que se plantea es que los ACL puedan reintegrase de nuevo en la sociedad, habrá que contar con ella y con los espacios y recursos comunitarios para que el proceso reeducativo y la resocialización positiva sea posible.

\section{Bibliografía}

Almarcha, A., De Miguel, A., De Miguel, J. y Romero, J.L. (1969). La documentación y organización de datos en la investigación sociológica. Madrid: Fondo para la Investigación Económica y Social de la Confederación Española de Cajas de Ahorro.

APPLE, M. (1986). Ideología y currículo. Madrid: Akal.

Bernuz, Ma J. y FernÁndez-Molina, E. (2008). La gestión de la delincuencia juvenil como riesgo. Indicadores de un nuevo modelo. Revista electrónica de ciencia penal y criminología. 10-13, 1-20. http://criminet.ugr.es/recpc/10/recpc10-13.pdf [23 Jan. 2013]

BowlbY, J. (1971). El vínculo afectivo. Buenos Aires: Paidós.

14. A pesar de la insistencia en la solicitud de los proyectos educativos y normativas de régimen interno de los diferentes centros, solamente la Colonia San Vicente Ferrer nos permitió acceder tanto a su reglamento como al propio proyecto educativo de centro. El primero, constaba con la aprobación de los Juzgados de Menores y el segundo con el visado de la entidad pública. 
BOURDIEU, P. (1999). La miseria del mundo. Madrid: Akal.

Bueno, A. y Moya, C. (1998). La delincuencia juvenil como síntoma: perspectivas de intervención psicosocial. Alternativas. Cuadernos de Trabajo Social. 6 , 151-159.

CAMPS, J. y CANO, A. (2006). Incidència de l'aplicació d'un programa de control de la conducta violenta en joves infractors. Avaluació de l' impacte de la intervenció i resultats de l'aplicació de tres programes en centres educatius i dos programes de medi obert. Barcelona: Centre d' Estudis Jurídics i Formació Especialitzada.

CANO, M.A. (2006). El futuro del Derecho penal juvenil europeo. Un estudio comparado del Derecho penal juvenil en Alemania y España. Barcelona: Atelier.

CeA D'Ancona, Ma A. (1992). La justicia de menores en España. Madrid: Centro de investigaciones sociológicas y Siglo XXI.

De Giongio, A. (2005). Tolerancia Cero. Estrategias y prácticas de la sociedad del control. Barcelona: Virus.

DENZIN, N. (1978). The research act. A theoretichal introduction to sociological methods. New York: McGraw-Hill.

GOFFMAN, E. (1984). Internados. Ensayos sobre la situación social de los enfermos mentales. Buenos Aires: Amorrortu.

González-Tascón, M.M. (2010). El tratamiento de la delincuencia juvenil en la Unión Europea. Hacia una futura política común. Valladolid: Lex Nova.

Hamzaoui, M. (2005). El trabajo social territorializado. Las transformaciones de la acción pública en la intervención social. València: Universitat de València y Nau Llibres.

Howe, D. (1997). La teoría del vínculo afectivo para la práctica del trabajo social. Barcelona: Paidós.

Informe Síndic de Greuges de la Comunitat Valenciana (2005). La implantación de los medios para hacer efectivas las medidas de reforma que prevé la Ley Orgánica 5/2000. Alacant: Síndic de Greuges de la Comunitat Valenciana.

Morente, F., Barroso, I. y Morente, V. (2009). Los estilos educativos en la tarea resocializadora de menores infractores. Revista de Servicios Sociales y Política Social, 87, 109-130.

NAVARRo, J.J. y Puig, M. (2010). El valor de la educación afectiva con niños en situación de vulnerabilidad acogidos en instituciones de protección: un modelo de trabajo social basado en la cotidianidad. Revista de Servicios Sociales y Política Social, 90, 65-84.

PATTON, M. (1990). Qualitative evaluation and research methods. Beverly Hills, CA: Sage.

SERRA, I. (1993). La construcción social de la marginación del menor. Un análisis cualitativo. Madrid: Universidad Complutense de Madrid.

STANLEY, L. (1992). The autobiographical I: The theory and practice of feminist autobiography. Machester: Maschester University Press. 
TAPIAS, F. (2009). El trabajo con adolescentes desde la obligatoriedad judicial. Revista de Servicios Sociales y Política Social, 87, 131-142

UCEDA, F. X. (2012). Adolescentes en conflicto con la ley. Una aproximación comunitaria: trayectorias, escenarios e itinerarios. València: Universitat de València.

VALLÉS, M.S. (1999). Técnicas cualitativas de investigación social. Reflexión metodológica y práctica profesional. Madrid: Síntesis Sociologia.

VALVERDE, J. (2002). El diálogo terapéutico en exclusión social. Madrid: Narcea.

VIVES, J.A. (2001). Identidad amigoniana en acción. Valencia: Martin Impresores. 



\title{
SERVIÇO SOCIAL CRÍTICO: DA MODERNIDADE À CONTEMPORANEIDADE
}

\author{
Critical social work: from modernity to contemporaneity \\ Helena Belchior Rocha ${ }^{1}$, Paula Marques Ferreira ${ }^{2}$, Teresa Paula Silva ${ }^{3}$, \\ VANDA BRAZ RAMALHO ${ }^{3}$
}

\section{Resumo}

O Século XXI e o desafio da contemporaneidade, implicam para o Serviço Social diferentes horizontes teóricos e diferentes abordagens de prática, no enfrentamento da «questão social» e na promoção de conceções de mudança social. Com o objetivo de entender o imanente e o explícito no questionamento dos fundamentos normativos e dos fundamentos que sustentam a crítica no Serviço Social, e ainda de localizar no amplo debate da Teoria Social Contemporânea as influências dos pensadores, da Teoria Social clássica, da Escola de Frankfurt e mais recentemente pelas teorias pós estruturalistas, as reflexões do presente artigo abarcam do contexto de surgimento das teorias críticas ao Serviço Social crítico contemporâneo, seus princípios e fundamentos e por fim a teoria crítica pósmoderna na sua dimensão ontológica, epistemológica e metodológica.

Palavras chave: Serviço Social, Teoria Crítica, Pós-modernismo

\begin{abstract}
The XXI Century and the challenge of contemporaneity implies for Social Work different horizons and different theoretical approaches of its practice in combating the «social issue» and promoting conceptions of social change. In order to understand the inherent and explicit in questioning the normative foundations and fundamentals that underpin critical in social work, and even to locate the broad debate of Contemporary Social Theory influences of its thinkers, Classical Social Theory, Frankfurt School and more recently the post structuralist theories, the reflections of this article cover the context of the emergence of critical theories to critical contemporary Social Work, its principles and foundations and finally postmodern critical theory in its ontological, epistemological and methodological dimensions.
\end{abstract}

Keywords: Social Work, Critical Theory,

Postmodernism

1. Centro de Investigaçao e Estudos de Sociologia (CIES).

2. Responsable de la correspondencia. Centro de Investigação e Estudos de Sociologia (CIES). Edifício ISCTE. Av. das Forças Armadas. 1649-026 Lisboa (Portugal). +351 960073849

3. Centro Lusíada de investigação em Serviço Social e Intervenção Social. Universidade Lusíada de Lisboa. Instituto Superior de Serviço Social, Lisboa, Portugal. 


\section{Introdução}

O seguinte artigo pretende reflectir sobre tendências e perspectivas da produção do conhecimento do Serviço Social num mundo globalizado - da teoria normativa à teoria crítica.

O Século XXI, sendo um século de «descentramentos» (Restrepo, 2003: 7), onde propostas de modelos se (re)estruturam e se (re)desenham, exigem do Serviço Social a necessidade de reflectir sobre o sentido histórico e epistemológico dos sistemas teóricos que os fundamentam a fim de estabelecer quebras e rupturas com discursos, conceitos, métodos e práticas que no passado foram considerados como definitivos.

Por esta ordem de razão, o imaginário e a visão do Serviço Social estão marcados por interpretações restritivas do processo de modernidade e pela assunção de modelos teóricos que dificultam a compreensão das sociedades complexas contemporâneas (Restrepo, 2003). Impõe-se ao Serviço Social contemporâneo o desafio de estabelecer categorias teóricas e metodologias que ampliem o seu horizonte interdisciplinar e estimulem a concepção do ser humano como construtor da sua própria realidade.

Em Teoria Social, a questão da «base normativa» ou dos fundamentos que sustentam a crítica tem vindo a ganhar um interesse crescente. Enquanto as teorias sociais empíricas podem deixar com maior facilidade a sua fonte normativa num estado implícito, pois visam mais a explicação do que a avaliação, o mesmo não acontece com as teorias críticas, que se posicionam como guias para a acção humana, pois sendo reflexivas, visam esclarecer e emancipar os agentes de coerções, muitas vezes, auto impostas (Geuss, 1988: 8).

Habermas, que provém da tradição crítica alemã em teoria social, tornou a questão da justificação imanente completamente explícita, adoptando um critério transcendente de racionalidade para criticar o capitalismo, passando a olhar com desconfiança para os seus fundamentos normativos (Habermas, 1987: 347-402). Para abordar estas questões parte-se neste trabalho para a abordagem de aspectos centrais da teoria crítica: contexto do seu surgimento, princípios e fundamentos, e teoria crítica pós-moderna.

\section{Enquadramento da Teoria Crítica: contexto de surgimento}

Num contexto marcado pelos movimentos sociais e pelo despontar das teorias sociais críticas, assiste-se, no início dos anos 70 do séc. XX, no Serviço Social, aquilo que se pode designar por uma reorientação crítica da teoria da prática.

Marcados pela oposição ao carácter individualista das teorias ortodoxas do Serviço Social, em especial as psicanalíticas que vigoravam desde a década 
de 20, os assistentes sociais procuraram o questionamento reflexivo das generalizações modernas e da visão conservadora dos antepassados da profissão (Adams, 1961; Parker, 1961; Reynolds, 1963; Kravetz, 1976; Franklin, 1986; Van Krieken, 1992, in Healy, 2001).

Contudo, e apesar dos múltiplos contributos que este questionamento trouxe para a profissão, ainda hoje, esta prática crítica carece, segundo Rojek (in Healy, 2001), em grande medida, de enquadramento teórico.

Esta situação deriva, segundo Howe, da subjetividade e complexidade com a qual têm de lidar as ciências sociais e humanas, às quais não escapa o Serviço Social contemporâneo. Como refere o autor, «the social and psychological sciences therefore have to deal with subjective experience as well as objective reality - what people think, fell, and believe as well as what they say and do. This is why language and the quality of the relationship are so important in the conduct of Social Work» (Howe, 2009: 4).

Assim, assistimos, segundo Payne (2002), a um debate epistemológico do Serviço Social centrado em duas visões: - a visão moderna ou positivista (Cristopher Bryant, 1985; Saint-Simon; Durkheim; Weber e Habermas] e a visão pós-moderna da teoria do Serviço Social (Foucault, 1972; Chambon e Irving, 1994; Howe, 1994; Pardeck e Parton, 1994).

Para o autor, numa visão positivista ou moderna a teoria do Serviço Social consiste «numa aplicação estrita do método científico (...) uma afirmação geral sobre o mundo real» (Payne, 2002: 59). Já nas visões pós-modernistas, Payne reconhece um significado mais amplo para o entendimento das teorias do Serviço Social, que são entendidas quer como um sistema de classificação que permite explicações sistemáticas, quer como um enquadramento ou disciplina ou ainda como teoria explanatória de uma determinada acção (Payne, 2002).

Para Healy, os antecedentes intelectuais do Serviço Social crítico contemporâneo são diversificados e recorrem a um amplo conjunto de teorias sociais críticas, que vão desde as teorias feministas, ao marxismo, ao desenvolvimento comunitário, à teoria radical da educação de Paulo Freire (1970), à antipsiquiatria, à sociologia radical, à teologia da libertação, etc., que por sua vez deram lugar a diferentes modelos que podem ser considerados críticos: serviço social anti-racista e multicultural, anti-opressor e anti-discriminativo, feminista e serviço social radical (Healy, 2001).

A teoria crítica do Serviço Social absorveu uma concepção geral das ideias da ciência social crítica acerca da natureza do mundo social e da existência humana, tentando compreender o mundo de forma a poder transformá-lo, patente no objectivo de mudança social, que trespassa, hoje, a profissão. 
Nos antecendentes da ciência social crítica contemporânea, que se encontram na base do Serviço Social crítico, encontramos, num primeiro momento, as influências de Hegel (1770-1831) e Marx (1818-1883) no que concerne à sua insistência na capacidade humana de, mediante uma acção consciente e colectiva, transformar a sociedade, fazendo vingar uma visão emancipadora, livre da dominação.

Contudo, no entender desta autora, tratam-se de influências que se revelam incapazes ou insuficientes para dar resposta aos desafios resultantes das mutações sociais da contemporaneidade.

Surgem também como relevantes os contributos pós-estruturalistas, sob a influência de Foulcault (1926-1984) e dos movimentos feministas radicais (Healy, 2001).

Adams, Dominelli e Payne (2009) identificam 3 grandes grupos comumente referidos como teorias sociais críticas:

- Marxismo: «Marxists would say that conventional Social Work practices support and extend the oppressive power of social institutions in capitalist states» (Adams, Dominelli \& Payne, 2009: 10);

- Escola de sociologia de Frankfurt: (Horkheimer (1978); Adorno (1979) e Marcuse (1964): "The Frankfurt theorists argue that we treat our cultural and ideological heritage as given, whereas these elements of society are crucial elements in how we may be dominated by a capitalist, authoritarian state.» (Ibidem).

- Sucessores da escola de Frankfurt, como Habermas (1984, 1987): «Habermas distinguishes between the system and the lifeworld, wich interact and some extent conflict with each other» (Ibidem).

Recentemente, abordagens alternativas do Serviço Social crítico apoiam-se nas teorias pós-modernas (como Fook e Gardner, 2002-2007), cujo foco é feito "on the way in which understanding of the world reflects personal experience and social and historical context» (Adams et al., 2009: 11).

Segundo estes autores, o Serviço Social crítico contemporâneo, permeado pelo contributo das teorias pós-estruturalistas, permite orientar uma prática crítica, reflexiva, com cariz de intencionalidade, participação, permitindo, ainda, a extensão da intersubjectividade na compreensão da realidade social. Com efeito, nas palavras destes, "reflective practice and critical reflection are methods of interpreting social knowledge, professional and social values and agency and policy aims into practice actions. The reflective cycle and processes of critical reflection enable practitioners to use ideas from practice theories to develop and renew their practice» (Adams et al., 2009: 91). 
Apesar de algumas reticências da profissão em integrar os contributos recentes das teorias pós-modernas, é importante, reconhecer que estes apelam à adopção de uma postura crítica reflexiva sobre os efeitos negativos de alguns ideais utópicos do Serviço Social crítico activista, que acabou por não conseguir romper com a tradição assistencial na profissão.

As correntes pós-modernas, e dentro destas as teorias pós-estruturais, desafiam o Serviço Social a centrar-se em propostas locais e contextuais, a reexaminar os seus problemas práticos relacionando-os com os problemas locais de poder, identidade e mudança, tendo em vista a qualificação da sua prática para responder aos novos problemas sociais (Healy, 2001; Fook, 2001).

\section{A Teoria Crítica: princípios e fundamentos}

Influenciada pela Teoria Social Clássica (com destaque para as obras de Marx e Hegel), pela moderna Escola Crítica de Frankfurt e, recentemente (década de 90), pelas teorias pós-estruturalistas, a teoria crítica social do século XX apresenta-se como uma nova forma de estar, de pensar e de conhecer a realidade social.

As suas repercussões ao nível do Serviço Social são notórias, conduzindo ao surgimento de um corpo diferenciado de teorias práticas críticas e que vêm pôr em causa a auto e hetero imagem ocupacional e assistencial da profissão (Rojek, 1988 e Sarri e Sarri, 1992 in Healy, 2001).

Com efeito, um ponto-chave da teoria crítica social que influenciou o Serviço Social é o seu enfoque em compreender o mundo para transformá-lo e a importância da razão e da acção humanas para a configuração da sociedade (Healy, 2001).

Segundo Howe, "critical theorists examine the socially constructed character of society. They show how ruling and powerful social groups are able to justify injustice and inequality by their control of the language, media, education, political agenda and terms of debate» (Howe, 2009: 130).

Neste ponto, a influência da dialéctica materialista de Hegel e Marx é clara. Insistindo na relação dialéctica entre pensamento e realidade, o sujeito assume-se como agente que transforma o objecto que observa. É a razão autoconsciente que capacita os humanos para reconhecer a sua relação dialéctica com o mundo (Fay, 1987 in Healy, 2001), sendo nesta relação com a totalidade social que todos os acontecimentos e a experiência se produzem (Hegel, 1910).

Neste processo de transformação, a consciencialização e a acção colectiva sobre as estruturas sociais revelam-se fundamentais, segundo Marx que 
considera que a libertação humana de uma relação de dominação requer a transformação da realidade material.

Analisando o desenvolvimento da Teoria Crítica no Séc. XX, podemos observar os enormes contributos da Escola de Frankfurt com as obras de Horkeimer (1895-1973), Adorno (1903-1969), Marcuse (1898-1979) e Habermas (1929). A escola de Frankfurt afirma que as relações de dominação se introduziram nas formas culturais modernas. Horkeimer e Adorno defendem que a razão ficou comprometida ao incorporar-se na estrutura da sociedade capitalista, advogando um pensamento que não seja puramente abstracto e que permita uma crítica emancipatória (Kellner, 1989 in Healy, 2001).

Habermas, defende ao contrário de outros autores da escola Frankfurt, a modernidade como ideal inacabado ao invés de um projeto irrealizável (Lechte, 1994 in Healy, 2001).

A sua obra, centrada numa teoria crítica e emancipatória, procura responder às questões, desafios, projectos e contradições da contemporaneidade, sendo conhecido pelo estudo persistente dos problemas da natureza da comunicação, da autoconsciência, do seu papel causal na acção social e pela sua proposta de uma teoria do agir comunicativo, como alternativa de explicação e construção da sociedade.

Habermas dedica-se, assim ao estudo da acção comunicativa, investigando as limitações da comunicação racional e promovendo a compreensão intersubjectiva. Para o autor, a transformação social parte da promoção do debate público e do consenso sobre as questões relativas às necessidades humanas.

O problema central das sociedades contemporâneas, para Habermas, não é a compreensão de como é mantida a ordem social, mas sim como criar condições para o que chama de «acção comunicativa».

Tal como Parsons, Habermas considera que as sociedades exigem a integração, mas como os neo-marxistas, advoga que as sociedades que denomina de capitalismo avançado, se encontram num profundo processo de crise, de legitimação das instituições sociais e do Estado e de motivação, no que concerne à identificação de sentido para a existência humana, reduzindo a função integradora do núcleo de comunicação. O núcleo da sua Teoria do Agir Comunicativo consiste em descrever esta crise societal como colonização do mundo da vida pelos sistemas (Habermas, 1987, 1990).

Nas palavras de Ahlert, este novo paradigma, «centrado na linguagem intersubjetiva de diferentes sujeitos, possibilita a retomada para a comunidade das questões da justiça, do dever, da verdade e da liberdade.» Com efeito, podemos verificar como Habermas propõe que, "para além do elemento 
cognitivo-instrumental a racionalidade comunicativa permite integrar também os elementos prático-moral e estético-expressivo» (Ahlert, s.d.: 5).

Verifica-se uma dupla proposta no pensamento de Habermas, quando este nos fala de uma teoria do agir comunicativo, como teoria social: o modelo do 'sistema', que se refere à 'reprodução material', regido pela lógica instrumental, de relações de poder e o modelo do 'mundo da vida', que por sua vez se refere ao campo da 'reprodução simbólica', ou seja, dos significados que compõem uma visão de mundo.

Assim, ao propor uma teoria do agir comunicativo, Habermas desejaria encontrar uma solução em prol da integração social democrática, que levasse ao exercício de uma cidadania plena e à resolução de conflitos sociais, através do consenso comunicacional e discursivo para a justiça.

Destes contributos destacam-se algumas características relevantes para o Serviço Social crítico:

- A reflexão racional que proporciona uma base vital para a acção radical. Compreensão da sociedade como totalidade (Wearing, 1986).

- A estrutura social global que ordena o sentido fundamental das relações sociais, nos níveis institucionais e individuais. As experiências locais surgem como efeitos de uma estrutura social global, na qual a posição de oprimido e opressor se encontra determinada pela estrutura social (Balibar, 1977).

- Relevam a dimensão do poder, da luta dialéctica entre grupos sociais opostos (Mullaly, 1993).

- Os humanos produzem e são produto da sociedade. Os seres humanos são configurados pela estrutura social, mas são também capazes de alterá-la.

- Promoção do pensamento racional, autoconsciente no processo de emancipação pessoal e social (Corrigan e Leonard, 1978).

- Capacitação dos sujeitos para transformar a ordem social. Insiste na capacidade dos sujeitos para transformar a sociedade (Fay, 1987).

Segundo Healy, nas correntes críticas as estratégias de conciencialização individual e coletiva são importantes como meio de compreender, reflexivamente, a organização da estrutura social, levando ao questionamento das visões do mundo naturalizadas e auto-limitadoras, interiorizadas pelos oprimidos. Com efeito, a consciencialização é fundamental e precursora da acção social radical (Healy, 2001).

Não havendo uma abordagem única, é, sobretudo, uma visão da sociedade como totalidade, uma valorização da estrutura social global, como factor 
de organização das relações sociais, a indiferenciação entre poder e dominação e a consciencialização dos 'oprimidos' para processos de emancipação e mudança estrutural, que une estas diferentes correntes teóricas.

A estas, Healy acrescenta as teorias pós-estruturalistas, onde se incluem as obras de Foucault e do feminismo radical, como referências centrais na construção da teoria crítica pós-estruturalista do Serviço Social. Estas novas perspectivas têm em vista a compreensão da importância da linguagem na explicação e produção da realidade social, da diversidade das práticas sociais e locais e dos seus efeitos, numa perspectiva indutiva de análise, que valoriza a compreensão da diversidade das identidades culturais e a aceitação das representações sociais como parcelares e provisórias (Healy, 2001).

Surgidas com mais relevância nos anos 90, as teorias pós-estruturalistas apresentam 3 orientações importantes para o Serviço Social crítico contemporâneo (Foulcault, 1981; Leonard, 1994; Scott, 1992 in Healy, 2001):

- Risco de incerteza e ambiguidade para guiar a prática; dificuldades em definir os limites teóricos da diferença;

- A prática crítica passa a estar enquadrada nos contextos históricos e locais em que se encontram imersas as práticas do Serviço Social;

- Oportunidade para transcender pressupostos racionalistas modernos na prática profissional.

Ao centrar-se nas representações da prática, a teoria pós-estruturalista dirige, sobretudo, a sua atenção para os discursos mediante os quais se produz o Serviço Social crítico, aumentando a reflexividade dos profissionais, questionando sobre a forma como se constroem as relações locais de poder, desconstruindo as oposições identitárias dualistas e reconhecendo a importância da diversidade e dos contextos específicos de acção na operacionalização da mudança social, promovendo novas concepções de mudança, focadas em aspectos mais irracionais e emocionais do saber.

Desta forma, o pós-estruturalismo afirma-se como um contributo teórico -prático que "puede contribuir al establecimiento de unas formas nuevas y más respetuosas de afrontar las diferencias» (Healy, 2001: 85).

\section{A teoria crítica pós-moderna}

Numa reviravolta pós-moderna surgem, nos últimos anos novas abordagens de cariz pós-estruturalista no seio das teorias críticas do Serviço Social. Nesta nova abordagem, «modernity's grand views are replaced by relative truths, more local explanations and multiple perspectives. The postmodern world is more fluid, 
more open to interpretation, more tolerant of diversity, more self-made, and less certain. Postmodernists see no absolute truths» (Howe, 2009: 132).

Contudo, há que manter em mente que pese embora a influência destas perspectivas pós-modernas no Serviço Social, tal não resulta exclusivo desta área de saber mas do reconhecimento de um amplo debate no seio da própria teoria social contemporânea face às diversas transformações sociais.

Hay (2002) vai mais longe nesta organização do pensamento pós-moderno e identifica três dimensões que considera integrarem os principais atributos do pós-modernismo: a dimensão ontológica, epistemológica e metodológica. Deste modo, identifica como característica fulcral das correntes pós-modernas a instauração de uma ontologia da diferença, cujas premissas fundamentais são "o mundo é experimentado de formas diferentes por diferentes observadores; essas experiências possuem especificidade histórica e cultural; essas experiências são únicas e singulares e não são a expressão de processos genéricos» (Hay, 2002: 207).

Por outro lado, revela-nos o cepticismo epistemológico, como segunda característica do pensamento pós-moderno, fundado nas seguintes afirmações: «diferentes posições do sujeito implicam diferentes reivindicações do conhecimento; o conhecimento depende do contexto e da perspectiva adoptada, as reivindicações de verdade não podem ser validadas empiricamente e são dogmáticas e potencialmente totalitárias» (Ibidem).

Por último, Hay fala-nos da adopção de uma metodologia desconstrutivista por parte dos cientistas pós-modernos, que se baseia nas ideias de que " 0 cepticismo epistemológico silencia reivindicações substantivas do conhecimento; as perspectivas modernistas continuam a pressupor um acesso privilegiado à realidade, que é insustentável e potencialmente totalitário em seus efeitos; as técnicas desconstrucionistas podem confrontar essas metanarrativas, chamando à atenção para outras linguagens, que, de outra forma, ficariam marginalizadas" (Ibidem).

Ligadas ao desconstrutivismo proposto por Michel Foucault (1926-1984), Jacques Derrida (1930-2004) e Roland Barthes (1915-1980), as perspetivas pós-modernas vêm promover um corte no corpo do estruturalismo e interrogar criticamente as noções dominantes até então e que perderam o seu sentido na contemporaneidade e nos seus discursos da prática.

Desenvolve-se, neste âmbito, uma prática reflexiva que, mais do que visar a constituição de um conhecimento estabilizado, pretende o desenvolvimento das capacidades de reflexividade e de acção, tendo em vista o engajamento entre «as nossas 'verdades', 'histórias' e 'construções' e as dos outros» (Parton et al., 1998: 248). 
A importância deste tipo de prática constitui, segundo Howe, «(...) the basis of a well-articulated approach to social work, that blends elements of postmodernism, post structuralism, critical social work, reflective practice and reflexivity» (Howe, 2009: 171).

Para Howe, o processo de reflexão crítica é realizado em dois momentos: análise e mudança «the stage of analysis is one of deconstructtion, of critical reflection. The worker and user become aware of other people's use and miss-use of power. The change stage is one of re-construction. It is at this point in the relationship that service users begin to re-value themselves. (...) Reflection, then, is one of the process through which clients participate in social work» (Howe, 2009: 172-173).

Também para Payne a importância da reflexividade constitui uma característica das teorias mais modernas do trabalho social que reconhece a necessidade de estar em constante mudança para responder às construções práticas dos sujeitos, não podendo, portanto gerar reconhecimentos universais (Payne, 2002: 45).

Tal reconhecimento implica, uma alteração do enfoque. Se no pensamento moderno encontramos um enfoque dedutivo, adoptado pelo Serviço Social crítico durante ao século XX, Foulcault, numa perspectiva crítica pós-estrutural insiste numa visão ascendente de análise (indutiva), defendendo uma investigação que tenha início nos contextos específicos da prática social (Foulcault, 1978 e 1991 in Healy, 2001) e que parte do reconhecimento do uso e importância da intuição e arte na prática profissional (Fook, 2001). Tudo isto numa abordagem holista e feita a partir de abordagens experimentais e não-positivistas.

Ao aplicar esta perspectiva reflexiva à prática profissional, ela assume-se por uma intervenção na qual: «Reflective practitioners are those who can situate themselves in the context of the situation and can factor this understanding into the ways in which they practise» (Fook, 2001: 40). Trata-se de um processo on going de reflexão e que permite aos interventores desenvolverem a sua teoria directamente a partir da sua experiência. Para além disso, permite 'adaptar' a sua intervenção a cada contexto específico, recorrendo para tal a um leque de competências e perspectivas não pré-definidas (como nos métodos mais tradicionais).

Neste sentido, e conforme nos propõe Fook (2001), a teoria é redefinida e assume-se como um conjunto de ferramentas intelectuais que prevêem um quadro inicial de referência a partir da qual é possível dar sentido a novas situações. Ao fazer isso, ela liberta a teoria da prática da noção de esta ser um conjunto normativo de regras (que raramente são aplicados na prática), para 
passar a ser um processo que permite aos assistentes sociais pensar no que eles precisam de saber para levar a cabo a sua prática diária.

O contributo deste tipo de ideias para abordagem crítica e pós moderna do Serviço Social é claro: reconhece múltiplas e diversas construções; o conhecimento é construído de forma inclusiva, integrando quer a experiência quer o processo reflexivo sobre esta; a comunicação e o diálogo constituem importantes processos de negociação das próprias estruturas e relações.

\section{Conclusão}

Apesar da vitalidade do marxismo como paradigma de análise e compreensão da realidade e apesar da manutenção da hegemonia do projecto profissional caracterizado pela ruptura com o conservadorismo que caracterizou a trajectória do Serviço Social, permanecem neste início do século XXI questões, em torno dos paradigmas clássicos e a busca de construção de novos paradigmas que se colocam pela apropriação do pensamento de autores contemporâneos de diversas tendências teórico-metodológicas como Anthony Giddens, Hannah Arendt, Pierre Bourdieu, Michel Foucault, Jurgen Habermas, Edgar Morin, Boaventura Souza Santos, Eric Hobsbawm, E.P. Thompson e tantos outros.

Efectivamente, coloca-se como desafio à profissão ao longo neste início de milénio a consolidação do projecto ético político, teórico metodológico e operativo que vem construindo particularmente sob a influência da tradição marxista, «mas incorporando valores auridos noutras fontes e vertentes $e$, pois sem vincos estreitos ou sectários, aquelas matrizes estão directamente conectadas ao ideal de socialidade colocado pelo programa da modernidade - neste sentido, tais matrizes não são 'marxistas' nem dizem respeito apenas aos marxistas, mas remetem a um largo rol de conquistas da civilização e, do ponto de vista profissional, concretizam um avanço que é pertinente a todos os profissionais que, na luta contra o conservadorismo, não abrem mão daquilo que o velho Lukács chamava de 'herança cultural'.» (Netto, 1996: 117).

\section{Bibliografia}

Adams, R., Dominelli, L., \& Payne, M. (2009). Critical Pratice in Social Work. New York: Palgrave Macmillan.

Adams, R., Dominelli, L., \& Payne, M. (Eds.). (2002). Social Work. Themes, Issues and Critical Debates. 2. ${ }^{a}$ ed. New York: Palgrave Macmillan.

AHLERT, A. (s.d.). A teoria da ação comunicativa como paradigma para a formação ética. IEPG/EST. RS: Brasil. 
Coulshed, V. (1991). Social Work Practice: An Introduction. London: Basingstoke Macmillan - now Palgrave Macmillan.

Dominelli, L. (1997). Sociology for Social Work. London: Basingstoke Macmillan - now Palgrave Macmillan.

Fook, J. (2001). Social Work: Critical Theory and Practice. London: Sage.

Freire, P. (1970). Pedagogy of the Opressed. New York: The Continuum Publhing Company.

Guess, R. (1988) Teoria Crítica: Habermas e a Escola de Frankfurt. Campinas: Papirus.

Habermas, J. (1990). O discurso filosófico da modernidade. Lisboa: Dom Quixote.

HABERMAS, J. (1998). Between Facts and Norms: Contributions to a Discourse Theory of Law and Democracy. Trans. W. Rehg. Cambridge, MA: MIT Press.

HABERMAS, J. (1987). Teoría de la acción comunicativa I: racionalidad de la acción y racionalización social. $4^{\mathrm{a}}$ ed. Madrid: Taurus.

HaY, C. (2002). Political Analysis. A critical introduction. New York: Palgrave Macmillan.

HoRkHEIMER, M., \& AdORNO, T. W. (1995). Dialéctica do esclarecimento: fragmentos filosóficos. Rio de Janeiro: Jorge Zahar Ed.

HowE, D. (2009). A brief introduction to social work theory. New York: Palgrave Macmillan.

Howe, D. (2008). The Emotionally Intelligent Social Worker. New York: Palgrave Macmillan.

HeALY, K. (2001). Trabajo Social: perspectivas contemporâneas. Madrid: Ediciones Morata. Fundación Paideia.

NetTo, J. P. (1996). «Transformações Societárias e Serviço Social - notas para uma análise prospectiva da profissão no Brasil». In: Serviço Social e Sociedade n. 50. São Paulo: Cortez. Abril.

PARTON, N. (2004). Constructive social work - towards a new practice. London: Macmillen Press.

Payne, M. (2002). Teoria do Trabalho Social Moderno. Coimbra: Quarteto.

PARSLOE, P. (1996). Pathways to Empowerment, Birmingham: Venture.

Restrepo, O. (2003). Reconfigurando el Trabajo Social. Perspectivas y Tendencias Contemporáneas. Buenos Aires: Espacio Editorial. 


\title{
LA HETEROGENEIDAD CONCEPTUAL DEL TERCER SECTOR
}

\author{
Conceptual heterogeneity of the non-profit sector \\ JESÚs FERnÁNDEZ RodRígueZ ${ }^{1}$ y Rosa PEÑAsCo VELASCO ${ }^{2}$
}

\section{Resumen}

El conocido como Tercer Sector, ha sido y es el protagonista de cientos de libros, obras, y artículos en todo el mundo. Decenas de autores prestigiosos han analizado la irrupción de esta figura en las diferentes sociedades, así como su esencia, características, funciones, tipología y consecuencias en ámbitos geográficos determinados. Sin embargo, resulta cuanto menos curioso, observar cómo en pleno s. XXI, en realidad no existe una verdadera definición de Tercer Sector, sino un conjunto de operaciones que, unas veces por exclusión, deducción o análisis de las Entidades y otros elementos que lo componen, nos sitúan y aproximan a esta importante realidad. Llegar a la conclusión de que no existe una definición del Tercer Sector, puede resultar desalentador al principio. Si bien, en su no definición reside, precisamente, la grandeza del propio Tercer Sector, ya que encuadrarlo en un concepto rígido y hermético, atentaría contra su movilidad, extensión, eclecticismo y necesaria heterogeneidad: la misma heterogeneidad que podremos observar, tanto en lo que se refiere al concepto como a las funciones, tipología y características del Tercer Sector.

Palabras clave: Tercer Sector, heterogeneidad, diversidad, acción social, bienestar social, Entidad no lucrativa, Sector Público. Mercado, Asociación.

\begin{abstract}
The Third sector, known by everyone as the nonprofit Sector, is the protagonist of hundreds of books, plays, and articles throughout the word. Lots of prestigious authors have analyzed the emergence of this figure in different societies. The features, functions and its impacts in particular geographical contexts have been examined.

However, there is no agreement, on the definition of the nonprofit Sector in the $21^{\text {st }}$ century, but rather a set of practices which by exclusion, deduction or analysis regarding the practices of the Entities show us the relevant reality. At first, the non-definition of the nonprofit Sector could be discouraging. However, this phenomenon the shows us the grandiosity of the nonprofit Sector because if it were limited to a static and rigid concept, this might threaten its nobility, its extension, eclecticism and its necessary heterogeneity. The same heterogeneity that is included in the monographic concept, functions, typology and characteristics of the nonprofit Sector.
\end{abstract}

Keywords: Non-profit Sector, heterogeneity, diversity, social action, social welfare, non-profit entity, public sector, market, association.

Recibido: 10/04/2013

Aceptado: 13/06/2013

Publicado: 05/11/2013

1. Responsable de la correspondencia. Departamento de Servicios Sociales y Fundamentos Histórico-Jurídicos. Facultad de Derecho UNED. C/ Obispo Trejo S/N. 28040 Madrid. Profesor de Servicios Sociales y Fundamentos Histórico-Jurídicos. Grado de Trabajo Social. Facultad de Derecho. Uned. Correo: jfernandez@der.uned.es Telf.: 913987015

2. Profesora de Servicios Sociales y Fundamentos Histórico-Jurídicos. Grado de Trabajo Social. Facultad de Derecho. Uned. Correo: rosap@der.uned.es Telf. 913988929 


\section{Definición y características del Tercer Sector}

Hasta llegar al desarrollo del Estado de bienestar, tal y como lo entendemos en las sociedades democráticas contemporáneas, han existido una serie de antecedentes importantes a lo largo de la historia. De entre ellos destacan, especialmente, ciertas acciones que para algunos autores, no son más que los indicios del conocido como Tercer Sector. En este sentido, resulta crucial la investigación realizada por la Comisión Filer en Estados Unidos (1973) que, para muchos autores, entre ellos Pérez-Díaz y López Novo (2003)33 jugó un papel fundamental en el nacimiento del Tercer Sector.

Pero el Informe Filer, no se limitó a analizar las aportaciones mencionadas, ya que si hoy en día, prácticamente existe unanimidad en considerarlo como un detonante definitivo en el nacimiento de la realidad que conocemos como Tercer Sector, tal vez sea porque también resultó pionero a la hora de denunciar el desconocimiento de este Sector y las dificultades de cuantificación, o porque diferenció las Organizaciones no lucrativas, del resto de Instituciones que trabajaban dentro del ámbito social.

De otro lado, el carácter innovador, denunciador y solidario de tal Informe, en ningún momento debería hacernos creer que facilitó la conceptualización o una definición exacta del Tercer Sector. Todo lo contrario: ni en el Informe Filer, ni en las obras de investigadores expertos en la materia, existe unanimidad al respecto.

Y así, no es extraño que en cuanto se pretenda definir el Tercer Sector, nos encontremos con una batería de autores que, de una forma u otra, en vez de proporcionar un concepto, como punto de partida harán hincapié en la confusión o dificultad de llevar a cabo aquella conceptualización. Sin ir más lejos, Antonio Ariño $(2008)^{4}$, hace constar cómo pese a la pluralidad de personas que se han ocupado de investigar sobre el Tercer Sector, nos hallamos ante un fenómeno difícil de definir. La misma idea parece compartir Rodríguez

3. Pérez Díaz, V. López Novo, J.P. (2003). El tercer sector social en España. Madrid. Ed. Ministerio de Trabajo y Asuntos Sociales. Subdirección general de publicaciones, p.30-32: «El informe de la Comisión Filer, analizó la aportación que realizaban las organizaciones no lucrativas a sectores como la sanidad, la educación, los servicios sociales y la cultura, así como su contribución a la vida política del país y la magnitud del empleo que generaban. Propuso por primera vez, la idea de que la organizaciones no lucrativas, constituían un sector diferenciado y relativamente autónomo, y también llamó la atención sobre lo poco que se conocía del sector y lo difícil que era realizar una estimación realista de su magnitud, ya que la contabilidad nacional, no caracterizaba adecuadamente al sector».

4. Antonio Ariño (2008), Articulación del Tercer Sector en España, en Revista Española del Tercer Sector, número 10. Ejemplar dedicado a Tendencias de Cambio en el Tercer Sector Social. Madrid. Fundación Luis Vives. p.107-132 
Cabrero (2003), pero incidiendo en las dificultades para delimitar la extensión del Tercer Sector, así como en las dispares formas de medirlo.

Si bien y tal y como resaltan autores como García Delgado (2004) o Ruiz Olabúenaga (2006), la confusión y hasta el hecho de que muchas veces resulte inadecuada una conceptualización, jamás debería constituir un obstáculo que nos impida hablar del Tercer Sector como una realidad social relativamente acotada.

Es posible que la dificultad para concretar un concepto de Tercer Sector, guarde también relación con determinados hechos que tuvieron lugar, justo en el momento de su nacimiento. Porque es inevitable reparar en que cuando afloró esta realidad, hoy conocida como Tercer Sector, cobraban auge todas las consecuencias generadas por la crisis económica de la década de los años 70 , profundamente marcada por los shocks petrolíferos. A su vez, es seguro que estos hechos, habrán influido en que, desde que tuvieron lugar, se abandonara la clásica concepción bisectorial estado-mercado que se había dado en las sociedades hasta ese momento, para entrar, por primera vez y gracias a la aparición de los dos factores citados más arriba, en una concepción trisectorial, compuesta por mercado, Estado y Tercer Sector.

En este sentido y siguiendo a Pérez Díaz y López Novo (2003), dicha concepción trisectorial permite que adquiera protagonismo una sociedad civil, hasta entonces prácticamente ensombrecida y con ella, parece inevitable que surjan una serie de concatenaciones, tales como la irrupción de las redes sociales, el peso específico de determinados aspectos de las familias, las asociaciones voluntarias, las organizaciones no lucrativas, las empresas y el mercado.

En otro orden de cosas, es posible que la dificultad para proporcionar un concepto acotado de Tercer Sector, también venga dada por su propia esencia, pues se caracteriza, entre otros aspectos, precisamente por la heterogeneidad y por el sinfín de diferentes Entidades que lo conforman. Además y visto lo visto, no es descabellado indicar que quizás sea más correcto asumir aquella heterogeneidad conceptual, puesto que el Tercer Sector en sí mismo, es de por sí una realidad cambiante y heterogénea.

Y tal afirmación viene dada, entre otras razones, porque autores como Antonio Ariño (2008) y Antonio Gutiérrez Resa (2010), sin olvidar en ningún momento la identidad del Tercer Sector, comienzan realizando una definición del mismo «por deducción», es decir, partiendo de su diferenciación de todo aquello que no es sector público y mundo empresarial. 
De otro lado y aunque pudiera parecer más concreta la definición realizada por Pérez Díaz y López Novo $(2003)^{5}$, en realidad tampoco sería correcto afirmar que se trata de una definición en sí misma, sino de un intento de conceptualizar el Tercer Sector, no por deducción, pero sí en base a las organizaciones que lo componen.

De esta definición, se desprende, en primer lugar, una marcada tendencia de complementariedad entre los diferentes sectores. A su vez, dicha complementariedad, también está teñida de una interrelación de aspectos positivos y enriquecedores de la intervención social, al constituir una alternativa a las demandas de los ciudadanos. Sin embargo, junto al criterio de la deducción o de la composición/configuración ${ }^{6}$, otros autores optan por utilizar un criterio de exclusión ${ }^{7}$.

En una línea similar, Gutiérrez Resa (2010), también diferencia el Estado, considerado como el primer sector, del mundo de la empresa-mercado que constituye el segundo sector. A su vez y sin olvidar las aportaciones de las familias, distingue y diferencia, tanto de uno como de otro caso, el conocido como Tercer Sector ${ }^{8}$.

5. Pérez Díaz, V. López Novo, J.P. (2003). Óp. cit. p. 53: «El Tercer Sector social comprende las organizaciones voluntarias y no lucrativas que prestan atención social a colectivos que se supone necesitados de la misma; y por ello de manera complementaria o concurrente con el estado y el mercado, bien porque se piense que tales organizaciones realizan sus prestaciones mejor que el Estado y el mercado, bien porque se suponga que atienden a necesidades que no son atendidas (o no lo son adecuadamente) por las políticas sociales públicas ni por el mercado».

6. Cabra de Luna, M.A. De Lorenzo García, R. (1993) «La constelación de las entidades no lucrativas: el tercer sector», p.29: partiendo de la base de que el Tercer Sector no pertenece ni al sector público, ni al sector privado o mercantil, indican, desde el punto de vista de exclusión, que «se tiende a decir que el Tercer Sector es todo lo que no es mercado o Estado, es decir, se encuadra a una organización o a una entidad dentro de este sector por exclusión».

7. Rodríguez Piñero y Bravo Ferrer, M y otros (1993) El Sector no lucrativo en España. Madrid. Ed. Escuela Libre Editorial, p. 29: «Así y para indicar su diferencia con el mercado (business) se habla de entidades no lucrativas (non profit) y para diferenciarlo del Estado (goverment) sus organizaciones reciben del nombre de no gubernamentales (O.N.G.)».

8. Gutiérrez Resa, A. (2010). Tercer sector e intervención social. Madrid. Ed. Académicas. p. 23-24: «Es muy heterogéneo y lo constituyen tanto asociaciones como fundaciones, mutualidades, cooperativas, clubes, colegios profesionales y otro tipo de entidades. Son organizaciones de la sociedad civil sin fines de lucro porque no distribuyen beneficios. También se les denomina Organizaciones No Gubernamentales (Naciones Unidas) que en el caso de España han tenido una fuerte vinculación con la atención social-intervención social». Es evidente que el autor introduce un marco definitorio más universal, especificando que en el caso de España, este sector viene asociado a una fuerte vinculación con la intervención social y con el desarrollo de los Servicios Sociales. Además, amplía 
También pueden observarse otras maneras de definir el Tercer Sector, desde la perspectiva de Entidades que participan y trabajan en este campo, tales como las Entidades no lucrativas, organizaciones no gubernamentales, asociaciones voluntarias y la propia sociedad civil. Sin embargo, es necesario indicar que si bien todas ellas comparten y reúnen una serie de características, también quedan diferenciadas por distintas líneas de actuación que definen su identidad. A su vez, partiendo de este criterio, Salomón y Anheier (1992) analizan las cinco características de estas Instituciones que permitirán considerarlas como un sector:

- Están organizadas formalmente o ha de tratarse de organizaciones formalmente constituidas ${ }^{10}$.

- Son privadas y están separadas de la Administración del Estado ${ }^{11}$.

- No reparten beneficios entre los propietarios y los administradores porque las organizaciones carecen de intereses mercantiles ${ }^{12}$.

- Son autónomas y controlan, en esencia, sus propias actividades ${ }^{13}$.

el marco definitorio al considerar que el Tercer Sector lo constituyen también el tejido social formado por redes sociales de diversa procedencia, como la familia, la amistad, los movimientos sociales.

9. Salamon, L. Anheeier, H.K. (1992). «In search of the nonprofit sector I: The questions of definitions» en Revista internacional de Organizaciones Voluntarias y sin Fines de Lucro. Vol.3, no 2. Berlin. Ed. Springer. p.125-131.

10. No obstante, hay que indicar que han de estar dotadas de una estructuración interna (órgano representativo y órgano de gestión), estabilidad relativa a los objetos formales y distinción cualitativa entre socios y no socios, aunque este punto de la definición deja fuera un grupo importante en el que se encuadran aquellos grupos carentes de una estructura organizada y reconocida por la Administración, que participan del resto de los caracteres.

11. Aunque en la actualidad este requisito se nos muestra poco aséptico, es muy frecuente que el Estado cree Fundaciones o bien participe a gran o pequeña escala en Fundaciones Privadas. Inclusive la alteración es mayor, cuando el Estado transfiere la realización de algunos servicios a Entidades Semipúblicas.

12. Ahora bien: el que carezcan de intereses comerciales, no les priva de la obtención de beneficios, con la condición esencial que han de ser reinvertidos en función de la misión corporativa de la propia organización y no entre sus administradores o directivos. Este principio está sometido a una serie de matizaciones, basadas en el peso que comienzan a tener estas organizaciones que demandan e implican un grado de profesionalización que ha de retribuirse. Y por otro lado, es normal que los servicios que prestan estas organizaciones comiencen a remunerarse, hecho que les proporciona un perfil similar al de las empresas.

13. Sin embargo, no hay que perder de vista el hecho de que, conforme van creciendo y participando de iniciativas o recursos provenientes del Estado, también se efectúa un mayor control público sobre las mismas. Un claro ejemplo, lo representan las auditorías a las que se someten los proyectos de cooperación al desarrollo puestos en marcha 
- Tienen participación voluntaria y sus miembros participan de las actividades, desde su libre voluntad y no por obligaciones legales ${ }^{14}$.

Ahora bien: pese a este mosaico de particularidades que nos permiten identificar a las Entidades que trabajan dentro del Tercer Sector, también debe tenerse sobre todo en cuenta, la forma de entender la característica de «no lucratividad». En este sentido, existen dos enfoques que permiten completar el marco definitorio de estas Organizaciones: por un lado, el de la economía social y, por otro, el enfoque de la «no lucratividad». Además, existen otras características que permiten singularizar al Tercer Sector ${ }^{15}$, del resto de sectores que intervienen en acción social. Por ejemplo, la diversidad que se perfila como uno de los aspectos claves de la identidad de este sector, ya que siempre presenta un grupo de Organizaciones distintas, aunque dichas Entidades, pese a su diversidad, comparten aspectos como objetivos, tamaños y aspectos jurídicos.

Desde el punto de vista de la diversidad, autores como Gutiérrez Resa (2010) y Olabuénaga (2006), hacen hincapié en cómo el factor determinante de la diversidad entre las Organizaciones en el seno del Tercer Sector, puede observarse, fundamentalmente, en sus objetivos y en las diferentes formas jurídicas con las que se constituyen. Pero además de dichas formas jurídicas diversas, podemos encontrar otras características destacables que nos permiten apreciar la pluralidad del Tercer Sector. Y así, autores como Olabuénaga (2006) y García Delgado (2005), optan por resaltar su minifundismo o la cantidad mayor o menor de Instituciones que conforman el Tercer Sector, sin dejar de apreciar cómo gran parte de ellas, pueden presentar un tamaño pequeño o mediano, frente a la escasa presencia de Instituciones de grandes dimensiones y finalizar manifestando, cómo el tamaño de las Instituciones es un dato sumamente significativo, ya que se trata de uno de los factores que condiciona su independencia económica.

por las Organizaciones No Gubernamentales y financiados por las Administraciones Públicas.

14. Lorenzo García R. Cabra de Luna, M.A. Comos Tovar, C. Martí Sánchez de León, J.J. Muñoz Sánchez, C. Pindado, F. Sanjurjo González, T. (2003). Tejido Asociativo Español y Tercer Sector. Madrid. Ed. Centros de Estudios Ramón Areces S.A., p. 6.

15. Porque una vez analizados los caracteres que parecen desprenderse de tal clasificación, podemos deducir que estas Instituciones están dotadas, tanto de una organización formal como de una estructuración interna. A su vez, no hay que olvidar que pertenecen al ámbito privado, pues se encuentran claramente separadas de la administración del Estado. De otro lado, tampoco reparten los beneficios obtenidos entre los propietarios, hecho que no les impide necesitar de un control de actividades, sin perder de vista su carácter autónomo. 
Por último, es necesario hacer constar que también podría caracterizarse al Tercer Sector, por ejemplo teniendo en cuenta su madurez o grado de institucionalización, así como el peso de la dimensión europea en la planificación de políticas nacionales que efectúa una división de organizaciones voluntarias. Y así, mientras el norte de Europa, manifiesta la madurez de su Tercer Sector, los países del sur se encuentran en un nivel totalmente emergente de institucionalización. Ahora bien: entre la madurez y la emergencia del Tercer Sector, puede encontrarse un término medio en los casos de Italia y España pues, según Rodríguez Cabrero (2003), en los últimos años han casi completado la regulación del sector, ya que son países que si bien se acercan a la madurez institucional, aún tienen pendiente su consolidación ${ }^{16}$.

De los diferentes criterios que cada autor utiliza con ánimo de definir el Tercer Sector, bien deductivos o excluyentes, de análisis de las Entidades que lo componen, de las connotaciones de aquéllas y hasta de las zonas geográficas en las que operan, surge una primera deducción que nos lleva a afirmar cómo la heterogeneidad que indudablemente lo caracteriza, hace que, al menos en principio, no sea aconsejable delimitarlo, constreñirlo y asfixiarlo en un concepto hermético, quizás porque, precisamente su grandeza, reside en la diversidad que también forma parte de su esencia. Además, no debe olvidarse que «la no definición» también es aconsejable, si tenemos en cuenta que todas las Organizaciones pertenecientes al Tercer Sector que operan dentro de nuestra sociedad, han dejado de considerarse como un fenómeno emergente y residual, desde el momento en que han quedado perfectamente consolidadas como una fuerza social y como un referente en el proceso de acción de una sociedad en crisis, en la que no deja de cuestionarse el Sistema de bienestar ${ }^{17}$.

16. Rodríguez Cabrero, G. (Coord.) (2003) Op. cit. p. 82.

17. De hecho, tras observar las distintas acepciones que los diferentes autores proporcionan, más que un concepto hermético que impida su desarrollo, quizás sea recomendable establecer algunos aspectos esenciales referidos al Tercer Sector de acción social: A) El Tercer Sector atañe a un área de intervención formada por Entidades privadas. B) Estas Entidades no persiguen ningún ánimo de lucro y no pertenecen a ninguna institución gubernamental. C) Poseen un carácter voluntario. D) Precisamente por su carácter voluntario, funcionan de forma autónoma y solidaria. E) A su vez, potencian el reconocimiento de los derechos sociales. F) Las Entidades que conforman el Tercer Sector, fomentan la recuperación social y activa de las personas en todos sus ámbitos, incidiendo en aquellos grupos sociales que son más vulnerables, al encuadrarse en procesos de exclusión social. 


\section{Tipología y funciones del Tercer Sector}

Como enseguida se comprobará, tampoco será sencillo establecer una sola corriente que sirva para determinar las tipologías referidas al Tercer Sector, ya que a la hora de llevar a cabo una clasificación, algunos autores se basan en criterios tan dispares como el tipo de relación existente entre las Instituciones y los gobiernos, en tanto que otros, prefieren resaltar su capacidad de innovación. Por si fuera poco, no existe una única tipología, ya que de entre los variopintos sistemas existentes, destacan varios modelos que, con sus peculiaridades, operan en zonas geográficas diferentes. Así, en los países escandinavos, en donde las Asociaciones se convierten en un canal de transmisión de las demandas sociales y de incentivación de los servicios públicos del Estado, resalta el modelo universalista. Por el contrario, el modelo Liberal, característico del Reino Unido, abandona otras áreas de la política social en manos del sector privado, permitiendo una intervención residual de asistencia social, con la salvedad de que en ciertos ámbitos como la ayuda a domicilio, servicios para la infancia o integración social, el tradicional sector voluntario se ve reemplazado por empresas de economía social, tipo cooperativa, a la vez que se produce un desarrollo de organizaciones voluntarias de padres, que pone de manifiesto la evolución del Tercer Sector social como respuesta a las necesidades no cubiertas por el Estado de bienestar, desde una sociedad civil activa. En cambio, en los países del sur de Europa, destaca el modelo dual, caracterizado por una debilidad en la oferta de servicios, en favor de prestaciones económicas, aunque esta oferta tiene peso relativo en áreas como la atención a las personas mayores y la discapacidad ${ }^{18}$.

Un cuarto y último modelo ideal es el corporativo, con un papel muy significativo del Tercer Sector y en donde los Servicios Sociales se hallan, en gran medida, financiados por el Estado. Los casos de Alemania, Holanda, Bélgica y Francia son ejemplo de este modelo y las relaciones entre Estado y Tercer Sector son muy sólidas en áreas como sanidad y servicios sociales. Es por ello que autores como Rodríguez Cabrero (2003), argumentan que este tipo de tipología potencia la innovación del propio Tercer Sector, al desarrollar nuevas formas de participación cívica o manifestación del espacio público, mediante Entidades sociales.

18. En España, gracias a la ley de Cooperativas de 1999, se pone en marcha la articulación de cooperativas de servicios sociales, educación y sanidad así como de integración social. Además, los distintos programas de rentas mínimas de las CCAA potenciarán directa o indirectamente el desarrollo de empresas sociales. 
Los diferentes modelos, una vez más sirven para mostrar la heterogeneidad como singularidad del Tercer Sector, aunque en lo tocante a su tipología, dicha diversidad guarde una relación directa con variables tan diferentes como su capacidad de innovación, su relación con los gobiernos y el grado de institucionalización.

De otro lado, no se pueden analizar los diferentes modelos del Tercer Sector y su relación con los múltiples matices que dan lugar a este universo de intervención, sin conjugarse con una serie de objetivos o funciones, siempre tendentes a buscar el desarrollo y el bienestar de la sociedad. Es más: tampoco podemos pasar por alto, cómo estas funciones pueden agruparse en cinco categorías, según diferentes autores:

- La provisión de servicios. Pérez-Díaz y López Novo (2003) afirman que estos servicios van orientados a contrarrestar los efectos de la exclusión social y evitar que determinados colectivos caigan por debajo de un nivel mínimo de calidad de vida. La provisión de servicios se considera la apuesta fuerte de este Sector dentro de la intervención social, al proteger un espacio de acción donde ni el Estado, ni las empresas pueden llegar de forma adecuada. Por el contrario, para Ruiz Olabúenaga (2000) esta prestación de servicios se puede realizar en mejores condiciones, atendiendo al pluralismo, diversidad, flexibilidad, mejor equidad y mayor claridad a menor costo, atendiendo a la especificad del servicio, la agilidad y el arraigo popular.

- Defender los intereses sociales. La defensa social debe ser entendida como garantía de los derechos de las personas a nivel individual y grupal. Así, Cabra de Luna (2003) recoge la defensa de los principios democráticos de la protección de los intereses de las minorías, de la necesidad de satisfacer las carencias de los débiles y de trabajar en pro de la cooperación al desarrollo a favor de las sociedades más desfavorecidas.

- Proceso de concienciación. Este objetivo de trabajo se erige para Balas Lara como uno de los principales cometidos del Tercer Sector, ante las sociedades contemporáneas ${ }^{19}$.

19. Balas Lara, M. (2011), La gestión de la comunicación en el tercer sector: cómo mejorar la imagen de las ONG. (Madrid). Ed. ESIC. p. 42: "La sensibilización de la sociedad acerca de los colectivos en riesgo de exclusión, por poner un ejemplo, copa gran parte de la actividad de numerosas organizaciones del Tercer Sector que persiguen derribar barreras mentales para obtener el cambio de actividades negativas en positivas que cristalicen conductas favorable para tales colectivos o causas sociales». 
- Desarrollo comunitario. El Tercer Sector también participa en el desarrollo, difusión e intercambio de ideas políticas y sociales, pues se configura como un canal de comunicación entre las esferas privadas y públicas y entre las personas y la sociedad.

- Función económica. Para Ruiz Olabúenaga (2000), el Tercer Sector siempre se configura como innovador ${ }^{20}$, al posibilitar respuestas alternativas ${ }^{21}$.

\section{La heterogeneidad como característica del Tercer Sector}

Visto lo visto, parece que la heterogeneidad aflora, inevitablemente, en cuanto se analiza cualquier aspecto del Tercer Sector y en cualquiera de sus ámbitos: concepto, funciones, características, tipología y etc. Precisamente partiendo de esta heterogeneidad, no es descabellado incidir en la idea de la diversidad, tanto desde los factores institucionales ${ }^{22}$ como no institucionales ${ }^{23}$ que operan dentro del Tercer Sector.

20. De hecho, ofrece una oferta de servicios atendiendo a necesidades nuevas con ideas e iniciativas también nuevas, con modos de gestión vanguardistas, aplicados a campos de actuación, con flexibilidad y rapidez frente a la rigidez y burocratización de la administración estatal.

21. Por último, al presentar las características funcionales del Tercer Sector, hay que tener presente que también existen voces como las de Pérez-Díaz y López Novo (2003), que en cuanto a las Organizaciones del Tercer Sector, si bien reconocen cómo pueden favorecer el desarrollo de una sociedad, también hacen hincapié en cómo pueden llegar a fomentar la desconfianza respecto a la democracia liberal y la economía del mercado, al ocupar un espacio público con un discurso simplificador y victimista, que potencien el desarrollo de personalidades dogmáticas.

22. De hecho, la característica de la heterogeneidad vuelve a manifestarse con insolencia, hasta cuando se estudian las diferentes Entidades de acción social que configuran el Tercer Sector, aunque, en esta ocasión, sea tanto por lo diferentes que resultan en sí mismas las asociaciones, fundaciones, entidades religiosas y cajas de ahorro, como por las también diferentes normas jurídicas que sirven para poder constituir cada una de ellas. La diferenciación entre asociaciones y fundaciones viene determinada por el orden y las normas jurídicas con las que se constituyen, así como por los objetivos de cada una de ellas, ya que no es igual la fidelidad necesaria a la voluntad del fundador en el caso de las fundaciones, que la voluntad conjunta de los socios en el caso de las asociaciones. Por otro lado, las entidades religiosas son producto del peso institucional y social que responde a la atención prestada a los sectores sociales desfavorecidos, en tanto que las cajas de ahorro, además de ser producto de un mandato legal, operan como entidades que siempre han de proteger a los más desfavorecidos, aunque desde el punto de vista crediticio.

23. En lo que respecta a los conocidos como factores no institucionales, hay que indicar que, lejos de denotar homogeneidad, en realidad no hacen sino manifestar, aún más, la diversidad de las Entidades de acción social. Y así, Pérez Díaz, V. López Novo, J.P. (2003) Óp. Cit. p. 156, indican que «entre estos factores de subespeciación no 
Además, la diversidad que presentan estas Instituciones, también parece configurarse como uno de los factores para su consolidación dentro de la acción social al poder trabajar desde la individualidad, sin olvidar funciones básicas que consensuan el trabajo y los fines de las Instituciones ${ }^{24}$.

Si es evidente que la ya recurrente connotación de heterogeneidad también se observa cuando analizamos la tipológica de las Entidades, no es menos innegable que asimismo se pone de manifiesto, tanto al analizar el campo de acción en el que desarrollan su intervención como en las diversas teorías que estudian su clasificación e identificación. De hecho, una primera clasificación, se encuentra en un informe de Lord Beveridge (1948), que realiza una diversificación entre aquellas instituciones que define como mutualistas porque trabajan en la búsqueda de la satisfacción de las necesidades de sus integrantes, y aquellas que dan satisfacción a los grupos desfavorecidos o Entidades altruistas ${ }^{25}$.

Por su parte, Gutierrez Resa (2010) ${ }^{26}$, siguiendo el criterio antaño utilizado por Ascoli (1987), vuelve a proponer una clasificación del Tercer Sector

institucionales, hay que mencionar el ámbito territorial, la edad y el tamaño de las entidades de acción social. Estos tres factores tienen, sin embargo, una fuerza desigual como fuentes de diferenciación de las entidades de acción social».

24. Aunque podrían enumerarse muchas otras, quizás y respecto a estas finalidades, destacan especialmente, las siguientes: 1) La cohesión social, no solo a nivel interno, sino también externo, con otras organizaciones del Tercer Sector. 2) La participación democrática en la toma de decisiones, dando voz y voto a sus socios e implicando a todas las personas afectadas en la toma de decisiones. 3) La generación de valores, que impulsan su actividad y permiten adaptarse a los cambios que se producen en la sociedad. 4) Son prestadores de servicios que permiten cubrir las necesidades y dar oportunidades de participación y recuperación social.

25. Jornadas de Estudio y Planificación de la Acción Social (1989 Valladolid). Bienestar social y desarrollo de los derechos sociales / Jornadas de Estudio y Planificación de la Acción Social, Valladolid 27-30 de Septiembre de 1989. Valladolid. Ed. Salamanca. p. 428-429. En dichas jornadas, se recogieron las aportaciones de Hoekendijk (1986), basadas en la clasificación de Beveridge. En estas aportaciones, el autor mostró una estructuración de las Entidades del Tercer Sector, según el trabajo voluntario a favor de otros, distinguiendo entre las asociaciones tradicionales de voluntarios, acciones alternativas y críticas, redes informales y los grupos de mentalización. A su vez, Hoekendijk, también resalta el trabajo voluntario a favor del propio grupo, los grupos de auto-ayuda y ayuda mutua, los grupos de colectivos diversos con intereses concretos-comunes y hasta las asociaciones de vecinos.

26. Gutiérrez Ressa, A. (2010). Op. Cit. p. 98, diferencia entre los siguientes grupos: 1) Organizaciones religiosas. 2) Organizaciones relacionadas con el trabajo (sindicatos, organizaciones profesionales). 3) Organizaciones relacionadas con la educación. 4) Fundaciones. 5) Organizaciones culturales (bibliotecas y museos). 6) Organizaciones de servicios (servicios sociales). 7) Organizaciones sociales (deportivas o étnicas). 8) Organizaciones relacionadas con la sanidad. 9) Organizaciones benéficas. 10) Organizaciones políticas. 11) Movimientos de masas organizados. 
en la que combina criterios tan diversos como actividades, organización, dependencias y estructura del Tercer Sector. Sin duda, esta categorización puede verse complementada con las aportaciones que realiza Demetrio Casado ${ }^{27}$ sobre las Organizaciones del Tercer Sector, pues prestan sus servicios a ciudadanos de forma desinteresada, mediante la participación social.

Pero aún podemos llegar más lejos, ya que desde el punto de vista de la sociología de acción, destaca la posición del Alain Touraine (1990), pues analiza los movimientos sociales de hoy a través de la técnica de la Intervención sociológica, permitiendo la aparición del actor social detrás de las reacciones que, a su vez, pueden ser ante todo interpretadas como signos de funcionamiento del sistema ${ }^{28}$.

En la actualidad, quizás una de las clasificaciones que parece tener más adeptos, se encuentra recogida en la categorización internacional de entidades no lucrativas ${ }^{29}$, basada en los trabajos de la clasificación de estándares internacionales industriales de las Naciones Unidas (1990), o en las estadísticas europeas de clasificación de actividades económicas e industriales (Eurostat,

27. Casado, D. (1989). Las organizaciones sociovoluntarias, en Álvarez, J.J. Organizaciones voluntarias e intervención social. Madrid. Ed. Acebedo. p. 18-50. Del análisis realizado por el autor, puede desprenderse cómo posiciona a diferentes sectores de la intervención social como actores claves para entender el Tercer Sector: los grupos y relaciones solidarias de carácter primario, el mercado, las entidades voluntarios y el Estado. Además de estos actores, el autor no olvida a la familia, ya que la posiciona como un elemento vertebrador de la sociedad, que forma parte esencial en el proceso de integración social y de solidaridad. Además, el autor realiza una catalogación de las Instituciones sociovoluntarias, entre las que se encuentra la iglesia, las obras sociales de patrocinio público o privado, las asociaciones de vecinos y afectados, las coordinadoras y colectivos de acción cívica y las fundaciones culturales, educativas y asistenciales. Junto a estas, el autor menciona otras cuatro clases de entidades no gubernamentales: colegios profesionales, sindicatos, asociaciones empresariales y partidos políticos.

28. Cabra de Luna, M.A. De Lorenzo García, R. (1993). Op. Cit. p. 29-31, indican cómo el autor ha realizado estudios «sobre el movimiento obrero desde el punto de vista del miedo a la catástrofe o el movimiento de las mujeres, a través de la simple llamada a la igualdad de derechos y por tanto a la desaparición del status por el sexo, etc. Sin duda, todos estos movimientos sociales de hoy, también forman parte del Tercer Sector».

29. Esta clasificación, de influencia múltiple y tan heterodoxa como heterodoxa es la esencia del Tercer Sector, pueden distinguirse los siguientes grupos: 1) De cultura y ocio. 2) De educación e investigación. 3) De salud. 4) De servicios sociales. 5) De medio ambiente. 6) De desarrollo económico y de vivienda. 7) De protección y promoción de los derechos civiles. 8) De servicios relacionados con la justicia. 9) De derechos reconocidos por la ley (consumidores). 10) De organizaciones políticas (partidos). 11) De filantropía y promoción del voluntariado (entre las que destaca las fundaciones). 12) De actividades internacionales, incluida la cooperación al desarrollo. 13) De actividades religiosas. 14) De actividades económicas, profesionales y sindicales. 15) Sin clasificación (donde se integran las no contempladas anteriormente). 
1985) y en la taxonomía nacional de actividades exentas (Centro Nacional de Estadísticas de Entidades no lucrativas de Estados Unidos).

Además, también pueden observarse otras clasificaciones, si atendemos a criterios relativos a los sistemas de financiación y gestión, pero con la salvedad de que este tipo de estructuración puede resultar contradictoria, ya que muchas de las Instituciones que trabajan dentro del Tercer Sector, no se rigen por un sistema único de financiación, ya que tienen un carácter mixto ${ }^{30}$.

En lo que respecta a nuestro país, la mayor representación de Instituciones del Tercer Sector se encuentra en las Asociaciones y las Fundaciones, sin olvidar las Entidades como Cruz Roja, ONCE y Cáritas que, por tamaño y regímenes especiales, representan una singularidad dentro de un sector muy heterogéneo, cuyos elementos y características que lo configuran, pueden llegar a tener más rasgos diferenciadores que comunes ${ }^{31}$.

Una vez más e independientemente del ámbito que se analice, el criterio de diversidad se observa en el estudio de cualquier elemento, característica, tipología o funciones del Tercer Sector, quizás porque, también una vez más, la heterogeneidad vuelve a ponerse de manifiesto como cualidad inherente a aquél.

\section{El avance y la consolidación del Tercer Sector en España}

Es necesario destacar que, en el caso concreto de España, la configuración del Tercer Sector, guarda una estrecha relación con el papel que ha desempeñado el Estado y la sociedad civil, así como por la propia evolución histórica de un sector que ha experimentado un gran desarrollo en estos últimos años, al sustituir al Estado en la prestación de servicios e incidir en aquellos sectores de población más vulnerables o en procesos de exclusión social.

En consecuencia, para poder comprender el desarrollo y la posterior consolidación del Tercer Sector, se hace necesario indagar sobre los factores que hayan podido condicionar su aparición y posterior consolidación. Y,

30. Por su parte, puede observarse una estructuración de las Instituciones más rígida, si se lleva a cabo una clasificación atendiendo a sus niveles, teniendo en cuenta que en el primer nivel se encuentran las Asociaciones, en el segundo nivel, las Federaciones y en el tercer nivel, las Confederaciones.

31. Pérez Díaz, V, López Novo, J.P. (2003) Óp. cit. p. 159-160, «las fundaciones suelen ser una expresión de la filantropía privada de los sectores sociales económicamente pudientes; las asociaciones suelen ser una expresión del activismo cívico de la ciudadanía. Las fundaciones son una suerte de extensiones de la personalidad (individual o corporativa) de sus fundadores, que establecen su misión y definen su identidad; las asociaciones, en cambio, son entidades colectivas y sus outputs son el producto de procesos de participación y decisión colectiva». 
nuevamente, parece que la diversidad vuelve a mostrarse como una constante, sobre todo en lo tocante al estudio de unas Entidades que conjugan sus singularidades con un mismo marco de intervención social, contribuyendo a la consolidación de este sector. En este sentido, Rafael de Lorenzo ${ }^{32}$, enumera una serie de elementos esenciales, tanto en la aparición del propio Tercer Sector como en su posterior consolidación, pero con la salvedad de que cada uno de los factores, resulta determinante en lo que respecta al proceso de consolidación del Tercer Sector. Porque si bien factores históricos y el marco legal utilizado, inciden directamente en el desarrollo social de un país, también podemos observar, una vez más, que la heterogeneidad se configura como el rasgo característico de este sector, pues condiciona en todo momento el nivel de desarrollo de la Entidades y el peso que adquieren de cara a la sociedad.

No obstante, sería una imprudencia pensar en consolidación, sin tener en cuenta un importante suceso que, sin lugar a dudas, condicionó la expansión del Tercer Sector, concretamente a finales de los años noventa ${ }^{33}$ o cuando se inició un marcado proceso de externalización de servicios públicos ${ }^{34}$.

32. Lorenzo García, R. (Coord.), (2003). Op. cit. p. 129-130: 1) La Heterogeneidad: a mayor heterogeneidad en un país, más limitaciones del sector público y del mercado para cubrir las demandas de la población. 2) Mientras más se expanda el Estado de bienestar en un país, menor será el sector no lucrativo. 3) A mayor nivel de desarrollo económico en un país, más fortaleza cobrará el Tercer Sector. 4) Marco Legal: en países regidos por el Rule of Law (Derecho Común) se consolidan más fácilmente las organizaciones no lucrativas, frente a los países de régimen administrativo, típicos de continentales de Europa, en los que como la tipología institucional del Tercer Sector suele estar regulada legalmente, se hace necesario, en múltiples ocasiones, un reconocimiento público previo para comenzar a actuar, configurándose, unas veces, como un reconocimiento genérico, limitado por disposiciones normativas a través de un registro constitutivo y, otras, como un reconocimiento específico o acto administrativo de concesión. 5) Las tradiciones históricas y religiosas inciden en la creación de entidades no lucrativas: así, el principio de subsidiariedad, tan extendido en Alemania, sin duda ha estimulado al Tercer Sector. Por el contrario, las teorías jacobinas en Francia, han impedido un florecimiento de aquél.

33. Altares Consulting. (2011). Modelos europeos en la evolución del Tercer Sector Social. Fundación Luis Vives, p. 206, incide en cómo este hecho: «ha generado nuevas oportunidades para el Tercer Sector, que ha sido visto por las administraciones como un socio natural en la prestación de servicios sociales y, a veces, como una estrategia para poder atender una demanda creciente de servicios públicos a un menor coste».

34. Además, la estrecha colaboración de las instituciones del Tercer Sector con las administraciones, ha ido acrecentándose en la misma medida en que ha podido observarse cómo los diversos organismos, han supuesto un beneficio tanto para el ciudadano a quien han proporcionado los recursos necesarios, como para el Estado, que podido reducir el gasto público, sin dejar de prestar servicios, hecho que, sin duda, ha contribuido en que la externalización de servicios, se haya seguido por la mayoría de las administraciones públicas. 
Sea como sea ${ }^{35}$, parece inevitable que una vez más vuelva a ponerse de manifiesto, cómo la heterogeneidad de Tercer Sector es uno de los elementos claves que lo diferencian del resto de sectores, al tiempo que juega un papel clave en el proceso de consolidación. Porque la diversidad ha ido creciendo durante estos últimos años, al igual que su profesionalización, su consolidación en la creación de empleo y su eficacia en los servicios prestados ${ }^{36}$.

En este sentido ${ }^{37}$, el Tercer Sector aporta un equilibrio entre el sector público y el mercado ${ }^{38}$, al ofertar alternativas de intervención pública y frenar la imposición de la actividad privada, aunque también actúa de forma muy valiosa, trasladando al Estado, la información que recogen de su actividad social ${ }^{39}$. Por último, es evidente que contribuye al bienestar social, al posicionarse

35. De otro lado, conviene recordar que el proceso de externalización, parece coincidir con la descentralización de la administración central hacia las autonómicas. Porque mientras la regulación del Tercer Sector depende del Estado central, las competencias en materia social corren a cargo de las distintas Comunidades Autónomas, produciendo una dispersión competencial sobre áreas de trabajo específicas del Tercer Sector que, en un principio, ha podido distorsionar la visión que podía tenerse de este sector y de las Instituciones.

36. Altares Consulting. (2011). Op. Cit. p. 209, indica que es preciso potenciar esta diversidad en lo tocante a la gestión de sus recursos humanos, su participación y su incidencia en el ámbito de la vida política y social porque: «la mejora de la capacidad de incidencia política, las plataformas de tercer nivel y las redes europeas aparecen como aspectos clave del Tercer Sector Social a corto plazo».

37. No debemos olvidar que la relación del Tercer Sector con la Administración pública, sigue condicionando, al menos por el momento, su posicionamiento social, pues la dependencia financiera se considera un obstáculo a la hora de plantear nuevos campos de trabajo. Sin duda, las Entidades que trabajan dentro el Tercer Sector, deben buscar nuevas propuestas, encaminadas a diseñar nuevos modelos económicos que consigan cortar la dependencia que estas Instituciones tienen del Estado.

38. Sánchez Hernández, F. (2011). Sociedad civil: informes sobre el Tercer Sector y el voluntariado en España, en Documentación Social. Revista de estudios sociales y de la sociología aplicada. Enero-Marzo 2011. Madrid. Ed. Cáritas Española. p. 287: «Pero además, el sector de la Acción Social, como espacio paralelo y a la vez complementario del ámbito público y empresarial, cumple una importante misión, desde la acción por la promoción de los derechos y la igualdad».

39. En otro orden de cosas, es necesario tener presente que el desarrollo de las Organizaciones del Tercer Sector en nuestro país, se produce a raíz de una serie de factores claves, de entre los que destaca la ejecución de las subvenciones del IRPF para fines de interés social a finales de los años 80 , así como la puesta en marcha de una serie de propuestas que va a incidir en la mejora del Tercer Sector de ámbito social o la aparición del libro blanco sobre este sector. Junto a estas medidas de ámbito institucional, aparecen otros condicionantes, definidos por algunos autores como los nuevos riesgos sociales, que sin duda van a potenciar el crecimiento de estas Instituciones, tales como la inmigración, el envejecimiento de la población, la desigualdad de género, la segmentación laboral y los cambios en la estructura familiar. 
como portavoz de la expresión de la sociedad civil y al mantener una relación directa con los otros dos sectores de acción social ${ }^{40}$.

En el caso de nuestro país, el avance del Tercer Sector se ha producido en los años 90, coincidiendo con la consolidación del Estado de bienestar. Este progreso, que se ha materializado mediante la prestación y externalización de los servicios por parte de la administración pública, ha ido acompañado por una transformación en la profesionalización y especialización de las Instituciones que conforman el Tercer Sector y por los distintos mecanismos de financiación ${ }^{41}$. Dichos mecanismos van a ser una constante dentro del desarrollo del Tercer Sector en nuestro país. Sin embargo, la dependencia institucional financiera, ha dado lugar a que se haya puesto de manifiesto la insuficiencia de este sistema de financiación, ante un sector de intervención social que intenta dar respuestas a las necesidades de los grupos sociales más desfavorecidos.

Es esencial, por tanto, plantear nuevos modelos de financiación ${ }^{42}$, acordes a una sociedad en la que el Estado se aleja de la implicación social, los mercados cobran más protagonismo y las familias se erigen como principales valedores de la ayuda social ${ }^{43}$. Además, este proceso de independencia

40. Sánchez Hernández, F. (2011). Óp. cit. p. 286-287: «A lo largo de las dos últimas décadas, el Tercer Sector de Acción Social (TSAS) español ha experimentado un gran avance, que ha estado ligado a la democratización, a la revitalización de la sociedad civil y a la evolución del Estado de Bienestar. En nuestros días, se trata de un sector maduro y consolidado, con un importante papel, tanto social como económico. Como parte del Tercer Sector, las entidades de Acción Social son una expresión específica de la sociedad civil y, por tanto, canalizan la dinámica de la solidaridad voluntaria de las sociedades. En nuestro país, más de la mitad de las organizaciones existentes (56,5\%) ha sido promovida por la iniciativa ciudadana».

41. Castro Sanz, M (2011), «El Tercer Sector demanda una financiación sostenible» Revista Española del Tercer Sector, Madrid, No 19 (Septiembre-Diciembre 2011), p. 63: «El esquema básico de financiación de este sector, es $61.3 \%$ de sus ingresos provienen de los poderes públicos, el $23.90 \%$ de recursos privados y el $14,80 \%$ de fuentes propias».

42. Santibáñez Gruber, R. Setien Santamaría M. L. (Coord.) (2004). Las necesidades de formación del tercer sector: su medición y programación desde la perspectiva europea. Bilbao. Ed. Universidad de Deusto. p. 45: «Para asegurar su independencia del sector público y del mercado, el Tercer Sector español debe esforzarse por aumentar su financiación a través de donaciones privadas. En este sentido, el Tercer Sector debe aprender a tratar con los nuevos poderes supranacionales (Unión Europea, por ejemplo). El impacto social de las actividades que se desarrollan en el Tercer Sector es tan importante que éste no puede funcionar sin ser, al mismo tiempo, un socio fundamental del sector público».

43. Castro Sanz, M (2011), Op. cit. p. 77-78: «Por lo que cobra especial relevancia la acción nacida desde la solidaridad social, donde los grupos de personas que desean otro mundo más acorde con la equidad y cohesión, que se definió en los documentos institucionales, se comprometen en tareas que los Estados han relegado. No es, pues, la 
financiera debe ir unido a una revitalización de la sociedad civil ${ }^{44}$, con una mayor implicación de la ciudadanía y de las Instituciones del Tercer Sector en los Servicios Sociales ${ }^{45}$.

Pese a esta escasa representatividad, el Tercer Sector ha conjugado su evolución con factores políticos y sociales e incluso económicos de nuestro país y ha contribuido al desarrollo democrático y a la cohesión social, mediante la asunción de actividades a las que no llegan otros sectores. En este sentido y desde la actual distribución de competencias de los Servicios Sociales en las Comunidades Autónomas, llama la atención el incipiente protagonismo que está cobrando el sector mercantil ${ }^{46}$, a su vez condicionado por las restricciones presupuestarias y por las políticas sociales ${ }^{47}$.

\section{Conclusión}

En un principio, puede resultar desalentador no encontrar una definición de la realidad conocida como Tercer Sector, ya que los que aparecen como

demanda de un mecanismo financiador de estas acciones una demanda cuestionable, o no debería serlo, sino necesaria, si se desea tener una sociedad cohesionada, y su puesta en práctica es imprescindible».

44. Con todo, no debería deducirse que el Tercer Sector de Acción Social en España, se limita a un mero ámbito de prestación de servicios. Más bien al contrario: la experiencia demuestra que la realidad social, no hace más que demandar nuevas necesidades que conllevan la aparición de también nuevos grupos de atención social.

45. Gutiérrez Resa, A. (2010). Op. cit. p. 165, en lo referente a las encuestas y barómetros de CIS (CIS, 2006, 2007, 2008, 2009), pone de manifiesto cómo «entre los años 2006 y 2009 , una media del $85 \%$ de los españoles mayores de edad, nunca han pertenecido a asociaciones y organizaciones de voluntariado, frente al 7\% que sí y al 7,5 que sigue perteneciendo».

46. Rodríguez Cabrero, G. (2000), La economía política de las organizaciones no lucrativas, en «Economía del Tercer Sector. ${ }^{\circ}$ 83». Madrid. Ed. Colegio de Economistas de Madrid. p. 16: «De algún modo, y sin que ello constituya una ley general, parece que cuando las entidades sociales desarrollan actividades productivas y están más alejados de la influencia del Estado sus beneficios son superiores a los costes en términos de viabilidad e independencia. Por el contrario, cuando desarrollan actividades de servicios y están dependen de los recursos públicos los beneficios o éxitos de las entidades tienden a ser inferiores a los costes en términos, igualmente, de viabilidad organizativa e independencia».

47. Quizás el Tercer Sector, debería plantearse nuevos retos orientados a fortalecer su presencia en la sociedad. Estos desafíos pueden abarcar aspectos tan amplios e incluso aparentemente tan dispares como su financiación, la diversidad o su representatividad, etc. La experiencia ha demostrado que los puntos débiles de las Entidades que trabajan dentro del Tercer Sector en nuestro país, reside en la dependencia económica del Estado y en la elevada fragmentación. Por tanto estas Organizaciones, tal vez deberían plantearse -y más en tiempos de crisis- cómo conseguir mayor independencia económica, con ánimo de alcanzar un modelo de gestión autosuficiente. 
conceptos en las obras de grandes expertos en la materia, en realidad son enunciados a los que parece llegarse, tras aplicar una serie de fórmulas. Fórmulas basadas en la exclusión, la deducción o la integración porque permiten aproximarnos al Tercer Sector, bien descartándolo de otras realidades, bien analizando las entidades que lo componen o bien excluyéndolo del ámbito de acción de «otros sectores».

Por suerte, no es difícil deducir que «el no concepto del concepto del Tercer Sector», no es un asunto baladí, ya que la heterogeneidad cobra tal importancia en la esencia del propio Tercer Sector que un concepto hermético, acotado y rígido, no haría sino atentar contra dicha heterogeneidad y, por tanto, contra la propia esencia del Tercer Sector.

El refuerzo de la identidad del Tercer Sector, no puede alcanzarse sin respetar su diversidad, ya que dicha diversidad es uno de los elementos claves para poder lograr su consolidación dentro de nuestra sociedad. Además, esta heterogeneidad del Tercer Sector, es compatible con la defensa de unas funciones marco que permitan seguir presentándose como el exponente de una sociedad civil, que pretende seguir luchando contra los nuevos riesgos sociales, mediante la defensa y articulación de la solidaridad.

La sociedad del siglo XXI, demanda Instituciones variopintas porque diversas son las necesidades sociales, aunque en base a esta diversidad, debamos ensalzar la heterogeneidad como elemento esencial de una realidad que jamás debería acotarse, y sí definirse, proporcionando un «no concepto, del concepto del Tercer Sector».

\section{Bibliografía}

Alemán Bracho, A. Alonso Seco, J.M, García Serrano, M. (2011). Sistema Público de Servicios Sociales. Madrid. Ed. Tecnos UNED.

Alemán Bracho, C. y García Serrano M. (2008). Los Servicios Sociales Especializados en España. Madrid. Ed. Universitaria Ramón Areces.

Alemán Bracho, A. Trinidad Requena, A. (2012). Evaluación de Servicios Sociales. Pamplona. Ed. Thomson-Reuters.

Altares Consulting. (2011). Modelos europeos en la evolución del Tercer Sector Social. Fundación Luis Vives.

Anuario del Tercer Sector de Acción Social en España (2010). Las personas en el Tercer Sector de Acción Social. Madrid. Fundación Luis Vives.

ARIÑO, A (Dir. (2007). Asociacionismo y Voluntariado en España. Una perspectiva general. Valencia. Ed. Tirant lo Blanch.

ARIÑO, A (2008) «Articulación del Tercer Sector en España», Revista Española del Tercer Sector, número 10. pp. 107-132. 
ARNANZ Villalta, E. (2011), «Voluntariado y participación». Revista Española del Tercer Sector, No 18 (Mayo-Agosto 2011).

AzUA, P. (1995). Informe sobre Asociaciones de objeto social en España, en Casado, D. Organizaciones Voluntarias en España. Barcelona: Ed. Hacer. pp. 113-169.

BALAS LARA, M. (2011), La gestión de la comunicación en el tercer sector: cómo mejorar la imagen de las ONG. (Madrid): Ed. ESIC.

BAREA, J. (2000). El marco conceptual de las Instituciones sin fines de lucro en Economía del Tercer Sector, $n^{\circ} 83$, p. 30-34.

BENito Ruiz, L. (1995). Informe sobre las fundaciones en España, en CASADO, D (Coord.). Organizaciones voluntarias en España. Barcelona: Ed. Hacer. pp. 171-264.

CABRA DE LUNA, M.A. (1998). El tercer sector y las fundaciones de España hacia el nuevo milenio: enfoque económico, sociológico y jurídico. Madrid: Ed. Escuela Libre.

Cabra de Luna, M.A, DE Lorenzo García, R. (1993) La constelación de las entidades no lucrativas: el tercer sector, en Rodríguez-Piñero y Bravo Ferrer, et. alt. El Sector no lucrativo en España. Madrid: Ed. Escuela Libre Editorial, p. 25-52.

CASAdO, D. (1989). Las organizaciones sociovoluntarias, en ÁlvAREZ, J.J. Organizaciones voluntarias e intervención social. Madrid: Ed. Acebedo. pp. 18-50.

CASADO, D. (1999). Introducción a los servicios sociales. Madrid: Ed. Acebedo.

CASADO, D. (2000). «Organizaciones voluntarias de objeto social en España», en Economía del Tercer Sector, $n^{\circ} 83$, p. 46-61.

CAstro SANZ, M (2011), «El Tercer Sector demanda una financiación sostenible», en Revista Española del Tercer Sector, $N^{o} 19$ (Septiembre-Diciembre 2011), p.61-86.

EDIS (2012), Anuario del Tercer Sector de Acción Social en España. Madrid: Ed. Fundación Luis Vives.

FANTOVA AzCOAA, F. (2001). La gestión de organizaciones no lucrativas. Herramientas para la intervención social. Madrid: Ed. CCS.

GARCía Delgado, J.L. (2005). La economía social en España: un enfoque económico del Tercer Sector. Madrid: Ed. Fundación ONCE.

GÓMEz GIL, C. (2005) Las ONG en España de la apariencia a la realidad. Madrid: Ed.Catarata.

GómEz GómEz. F. (2004). «Los cambios relacionales en los recursos humanos de las organizaciones», en Revista de Trabajo y Seguridad Social. Comentarios, casos prácticos: recursos humanos, $n^{\circ} 259$, pp. 155-224.

GUTIÉRREZ RESA, A. (1997). Acción social no gubernamental, análisis y reflexiones sobre las organizaciones voluntarias. Valencia: Ed. Tirant lo Blanch. 
GUTIÉRREZ RESA, A. (2010). Tercer sector e intervención social. Madrid: Ed. Académicas.

HOMS I FERRET, O. (Coord.) (2009). Los retos del tercer sector ante la crisis: Madrid. Fundación Luis Vives.

Jornadas de Estudio y Planificación de la Acción Social (1989 Valladolid). Bienestar social y desarrollo de los derechos sociales / Jornadas de Estudio y Planificación de la Acción Social, Valladolid 27-30 de Septiembre de 1989. Valladolid: Ed. Salamanca. p. 428-429

Johnson, N. (1990) El Estado de bienestar en transición. La teoría y la práctica del pluralismo de bienestar. Madrid: Ministerio de Trabajo y Seguridad Social.

LÓPEZ REY, J.A. (2006). El tercer sector y el mercado: conflictos institucionales en España. Madrid: Centro de Investigaciones Sociológicas.

Lorenzo García R. Cabra de Luna, M.A. Comos Tovar, C. Martí Sánchez de LeÓn, J.J. Muñoz SÁnchez, C. Pindado, F. Sanjurjo González, T. (2003). Tejido Asociativo Español y Tercer Sector. Madrid: Ed. Centros de Estudios Ramón Areces S.A.

MontSERRAT Codorniu, J. (2006). Incidencia en la financiación y en el presupuesto, en Ruiz Olabuénaga, J.I. (Dir.) El sector no lucrativo español. Una visión reciente. Bilbao: Ed. Fundación BBV. pp. 173-206.

NAVARRO, J. LORENTE, S. (1985). «Una aproximación empírica al estudio del Voluntariado en España», en Cuaderno de Acción Social. Voluntariado Social, $n^{o}$ 17, pp. 7-45.

Observatorio del Tercer Sector. (2007). Buenas prácticas en la gestión del voluntariado: Barcelona. Obra Social Fundación La Caixa.

PÉRez DíAz, V. LóPez Novo, J.P. (2003). El tercer sector social en España. Madrid: Ed. Ministerio de Trabajo y Asuntos Sociales. Subdirección general de publicaciones.

RodríGuez CABrero, G. (2006). El gobierno de las organizaciones no lucrativas, en RUIZ OlABUÉNAGA, J.I. El sector no lucrativo en España. Una visión reciente. Bilbao: Ed. Fundación BBVA. pp. 85-125.

Rodríguez CABrero, G. (Coord.) (2003) Las entidades voluntarias de acción social en España. Madrid: Ed. Fundación FOESSA.

Rodríguez CABrero, G. (2000), «La economía política de las organizaciones no lucrativas», en Economía del Tercer Sector. $n^{\circ}$ 83, p. 6-16

Rodríguez CABrero, G. (Coord.) (2005). Las entidades voluntarias de acción social en España. Informe general. Madrid: Ed. Fundación FOESSA.

RODRíGUEz MEZA, R. (2009), Estudios sobre seguridad social. Barranquilla (Colombia): Ed. Ediciones Uninorte.

Rodríguez Piñero y Bravo Ferre, M. (Coord.) (1993). El Sector no lucrativo en España. Madrid: Ed. Escuela Libre. 
ROSSEl OdRIOZOLA, C. (2008). Tercer Sector y co-gestión de políticas en España y Uruguay: ¿un matrimonio por conveniencia? Madrid: Ed. Instituto nacional de Administración Pública (INAP).

Ruiz Olabuénaga, J.I., Casado, D. Jiménez, A. Orellana, J.L. Mancisidor, M. La, C. Oiarzabal, M.A. Soto, S. Fernández, A. (2000). El Sector no lucrativo en España. Bilbao: Ed. Fundación BBV.

RUIZ OlABUÉNAGA, J.I. (2006). El sector no lucrativo en España. una visión reciente. Bilbao: Ed. Fundación BBVA.

SALAMÓN, L. Anheier, H.K. (1992). «In search of the nonprofit sector I: The questions of definitions» en Revista internacional de Organizaciones Voluntarias y sin Fines de Lucro. Voluntas 3, $n^{\circ} 2$, pp.125-131.

SÁNCHEZ HERnÁNDEZ, F. (2011). «Sociedad civil: informes sobre el Tercer Sector y el voluntariado en España», en Documentación Social. Revista de estudios sociales y de la sociología aplicada. Enero-Marzo 2011, pp. 287-301.

SAntibáñez Gruber, R. Setien SAntamaría, M.L. (Coord.) (2004). Las necesidades de formación del tercer sector: su medición y programación desde la perspectiva europea. Bilbao: Ed. Universidad de Deusto.

Vernis, A., Iglesias, M., Sanz, B., Solernos, M., Urgell, J., Vidal, P. (2004). La gestión de las organizaciones no lucrativas. Bilbao: Ed. Ediciones Deusto.

VERNIS, A. (2004). Los retos en la gestión de las organizaciones no lucrativas: claves para el fortalecimiento institucional del tercer sector. Barcelona: Ed. Granica.

Voluntariado, Tercer Sector y Movimiento Sindical (2011). Madrid: Ed. Confederación Sindical de Comisiones Obreras. 



\title{
APROXIMACIÓN A LA REALIDAD DE LOS DESAHUCIOS. PERFIL Y CARACTERÍSTICAS DE LAS FAMILIAS EN PROCESO DE DESAHUCIOS EN LA CIUDAD DE MÁLAGA
}

\author{
An approach to the reality of evictions. Profile and characteristics of \\ families in the process of eviction in the city of Málaga
}

\author{
RAFAel ARredondo Quijada ${ }^{1}$ y María de las Olas Palma García ${ }^{2}$
}

\section{Resumen}

El incremento de familias que se encuentran en situación de vulnerabilidad y/o riesgo social ante la pérdida de su vivienda se presenta en la actualidad como realidad emergente para la intervención social. Con el objetivo de acercarnos a dicha realidad, el presente artículo recoge los resultados de una investigación desarrollada en el marco del Master de Investigación e Intervención Social y Comunitaria de la Universidad de Málaga, en la que se analizan los hechos ocurridos en los últimos años, como posibles explicaciones de los actuales desahucios y las características de las familias que los sufren. En el estudio participan 110 sujetos, identificados de forma aleatoria a partir de las familias que acuden a los diferentes recursos de atención a la realidad de los desahucios en la ciudad de Málaga, principalmente a través de la Plataforma de Afectados por la Hipoteca (PAH). A los participantes se les aplica un cuestionario específico diseñado para esta investigación que explora el perfil de las familias afectadas por los desahucios y las circunstancias que presentan ante el impago de sus hipotecas. Los resultados muestran el desempleo como principal causa de dicho impago, a la vez que se describen como posibles consecuencias, efectos directos sobre el bienestar psicosocial de las familias implicadas. A partir de los resultados, se realizan propuestas para la intervención con dichas familias y su entorno, así como con las entidades financieras, tales como la necesidad de abordar el desempleo como circunstancia fundamental que está originando los impagos hipotecarios, la utilización de la mediación como instrumento de resolución del conflicto y la necesidad de que se realicen las modificaciones legislativas correspondientes a fin de que la vivienda se considere un derecho fundamental. Se concluye sobre la necesidad de seguir con esta línea de investigación ante la escasez de estudios que aborden esta problemática

Palabras clave: Desahucio, hipoteca, vivienda, vulnerabilidad, Plataforma de Afectados por la Hipoteca (PAH).

\section{Abstract}

The increase in families who are vulnerable and / or at social risk at the loss of their home is presented today as emerging reality for social intervention. In order to approach this reality, this article presents the results of a research project developed within the framework of the Master of Research and Social Intervention and Community at the University of Málaga, which discusses the events of recent years, as possible explanations for the current evictions and the characteristics of families who suffer. The study involved 110 subjects, randomly identified from the families that use the different resources for attention about the reality of eviction in the city of Málaga, primarily through the Platform of People Affected by Mortgages (PAH). Participants are given a specific questionnaire designed for this research that explores the profile of the families affected by the evictions and the circumstances that present themselves defaulting on their mortgages. The results show unemployment as the main cause of such failure, while described as potential consequences, direct effects on psychosocial well-being of the families involved. From the results, proposals are made for intervention with these families and their environment, as well as financial institutions, such as the need to tackle unemployment as fundamental circumstance that is causing mortgage defaults, the use of mediation as instrument of conflict resolution and the need for legislative changes to be made so that appropriate housing is considered a basic right. We conclude on the need to continue this line of research due to the scarcity of studies addressing this problem.

Keywords: Eviction, mortgage, housing, vulnerability, Platform of People Affected by Mortgages (PAH).

1. Asociación Cívica para la Prevención (ACP), Málaga, España. Responsable de la correspondencia. C/ Alfeizar núm. 1. 29130 Alhaurín de la Torre. Málaga, España. E-mail: rafael.arredondo. quijada@cgtrabajosocial.es

2. Universidad de Málaga. Departamento de Psicología Social, Antropología Social, Trabajo Social y Servicios Sociales. Facultad de Estudios Sociales y del Trabajo. Málaga, España 


\section{Introducción}

Hablar en la actualidad del problema de vivienda nos lleva de lleno a tratar la situación de las personas que ante la imposibilidad de hacer frente a su hipoteca, se ven inmersas en un proceso de cambio en el que tienen que afrontar nuevas situaciones y roles, que en muchos de los casos, termina con el desahucio de su vivienda. Es este un contexto emergente para la intervención social, en el que de acuerdo con Navarro (2005) se ha de considerar «la privación de una vivienda digna como una de las manifestaciones más visibles de la pobreza y la exclusión social» (p.175). De ahí que cuando se interviene en procesos de exclusión, la vivienda es un elemento que junto al empleo, la formación o el acompañamiento social, se consideran fundamentales. (Concurso de Buenas Prácticas. Dubai 1996).

Ante este nuevo escenario, actualmente constituido en uno de los dramas más difíciles y preocupantes para miles de familias en el conjunto de nuestra sociedad, es necesario desarrollar «estudios que proporcionen criterios para la construcción de índices que permitan no sólo conocer la extensión de la pobreza y la exclusión, sino también sus factores determinantes» (Navarro, 2005, p.175).

La revisión bibliográfica realizada en el marco de esta investigación ha puesto de manifiesto la falta de estudios específicos sobre esta problemática, como posible consecuencia de que hasta ahora esta realidad no se había visibilizado suficientemente, ni había afectado de una manera tan contundente como está ocurriendo en los últimos años, sobre todo desde el 2007 a raíz de la crisis financiera y del estallido de la llamada burbuja inmobiliaria.

No es hasta noviembre de 2012, cinco años después del inicio de la crisis, cuando el Centro de Investigaciones Sociológicas (CIS) incorpora en sus encuestas el concepto desahucios, a la hora de preguntar por los tres principales problemas en España. En base a ello, según el barómetro de abril de 2013, los desahucios se convierten en el sexto problema más importante indicado por los españoles, por delante incluso de problemas como la educación, los recortes, la inmigración, las pensiones, el fraude fiscal o el terrorismo.

Da la sensación de que los desalojos que se producen a cientos de familias, ha cogido al conjunto de la sociedad, y sobre todo a los sistemas de protección, desconcertados y sin capacidad para encontrar soluciones que den respuestas concretas e inmediatas a una emergencia como tal. Dichos desalojos conllevan no sólo «la vergüenza, el estigma y el miedo asociado al proceso» (Colau y Alemany, 2012, p. 16), sino todo un conjunto de problemas colaterales, que quedan solapados por la inmediatez de dar respuesta a la búsqueda de una nueva vivienda o lugar de alojamiento transitorio. 
Esos problemas colaterales son en sí mismos situaciones multiproblemáticas que se encuentran en la base de la intervención social. Elementos como el absentismo escolar, en caso de que haya menores, efectos sobre la salud física y psíquica, conflictos en las relaciones familiares, falta de empleo o precarización en la contratación, etc., «son agravantes en cuanto a costes sociales que incidirán en la vulnerabilidad para iniciar un proceso de exclusión social» (Laparra, et al., 2007, p. 45).

Todo este escenario de vulnerabilidad social, según el reciente Catálogo de Referencia de Servicios Sociales ${ }^{3}$, sigue siendo objeto de análisis e intervención para los profesionales del Trabajo Social como profesionales de referencia, lo que plantea nuevos retos para la disciplina ante la realidad de los desahucios. Es necesario reflexionar sobre si hubiera sido posible haber evitado, o en todo caso, haber pronosticado las consecuencias que ahora están manifestándose. A ello quiere contribuir el presente artículo, aportando un primer acercamiento ante la realidad de los desahucios que ofrezca alternativas de intervención, y líneas futuras de investigación.

\section{La realidad de los desahucios: pasado y presente}

\section{Perfil del mercado inmobiliario en España}

El desenlace de esta situación, que afecta a familias con nombres y apellidos, tiene su origen en circunstancias que se han venido produciendo históricamente, tales como el incremento y fomento de la compra sobre el alquiler de manera espectacular por parte de los ciudadanos españoles.

El Plan Estatal de fomento del alquiler de vivienda, la rehabilitación edificatoria, y la regeneración y renovación urbanas, 2013-2016, establece que el alquiler significa en España el 17\% frente al 83\% del mercado de la vivienda en propiedad, mientras que en Europa, en porcentajes medios, el mercado de la vivienda principal en alquiler representa el 38\%, frente al 62\% de vivienda en propiedad.

Estos datos reflejan una tendencia a la propiedad en las últimas décadas, que no siempre ha estado presente en nuestro país. De hecho, en 1950 el 51\% de la población vivía de alquiler y la cifra superaba el $90 \%$ en grandes ciudades como Madrid o Barcelona (Colau y Alemany, 2012). Aun así, parafraseando al primer ministro de la vivienda en 1957 José Luis Arrese, esto no respondía a los intereses de gobierno, ya que se quería «un país de propietarios no de proletarios, dado que el hombre, cuando no tiene hogar, se apodera de la

3. BOE 117 de 16 de mayo 2013 
calle, y perseguido por su mal humor, se vuelve subversivo, agrio, violento...» (Citado por Colau y Alemany, 2012 p. 34).

En paralelo se ha producido un incremento espectacular en la construcción de vivienda de promoción libre frente a la vivienda de protección. Según el Instituto Nacional de Estadísticas (INE) ${ }^{4}$, en el período 1997 a 2012, se iniciaron 6.977 .176 viviendas, de las que el $85,6 \%$ son de protección y el 14,2\% son de promoción libre. Tal como se observa en el cuadro 1, desglosado este periodo con referencia al comienzo de la crisis financiera, se produce un descenso en la construcción de viviendas, finalizando con ello el llamado boom inmobiliario.

Cuadro I. Viviendas iniciadas según tipo, período 1997 - 2012

\begin{tabular}{|l|c|c|c|c|}
\hline \multirow{2}{*}{ Viviendas iniciadas } & \multicolumn{2}{|c|}{ Período 1997-2006 } & \multicolumn{2}{c|}{ Período 2007-2012 } \\
\cline { 2 - 5 } & & $\%$ sobre total & & $\%$ sobre total \\
\hline Protección & 631.796 & $11,23 \%$ & 365.748 & $27,08 \%$ \\
\hline Promoción libre & 4.994 .516 & $88,77 \%$ & 985.116 & $72,92 \%$ \\
\hline Total & 5.626 .312 & $100,00 \%$ & 1.350 .864 & $100,00 \%$ \\
\hline
\end{tabular}

Elaboración propia. Fuente: Instituto Nacional de Estadística

Según el Censo de población y viviendas de 2011 del INE ${ }^{5}$, España dispone de 25.208 .623 viviendas, de ellas el $13,66 \%$ se encuentran vacías.

\section{Perfil del mercado hipotecario}

Como consecuencia de este incremento de construcción de viviendas de promoción libre, las entidades financieras (Cajas de Ahorros y Bancos) han hecho de los productos hipotecarios su principal negocio. De acuerdo con Trabada (2012, p.177), «que los créditos hipotecarios pasasen a ser el negocio principal para las entidades financieras derivó en un abandono de $<<$ buenas prácticas hipotecarias $>>$, como que la cuota a pagar no se elevase por encima del umbral de un tercio de los ingresos del hogar endeudado, y que la cantidad económica del préstamo no superase el $80 \%$ del valor de tasación de la vivienda hipotecada.»

\footnotetext{
4. http://www.ine.es/jaxi/tabla.do? path=/t38/bme2/t07/a081/10/\&file=1300007. px\&type $=$ pcaxis\& $\&=0$

5. http://www.ine.es/prensa/np775.pdf
} 
En este escenario, según los datos del Registro de la Propiedad ${ }^{6}$, en los últimos diez años se ha producido en España una media anual de más de 870.000 operaciones de hipotecas constituidas. Según la Encuesta de Condiciones de $\mathrm{Vida}^{7}$ correspondiente al año 2012, el 29,9\% de los hogares posee vivienda en propiedad pero con una hipoteca pendiente. Ante este dato, el Banco de España ${ }^{8}$ indica en su informe del 10 de mayo de 2013, que a fecha del 31 de diciembre de 2012 de las viviendas hipotecadas, el 90,7\% correspondía a la vivienda habitual, y sólo un 9,2\%, a hipotecas sobre otras viviendas.

No sólo las entidades financieras generaron ante las hipotecas un negocio sin reservas y precauciones, sino que también los ayuntamientos vieron una gran oportunidad de obtención de ingresos financieros a través del conjunto de la actividad relacionada con el mercado inmobiliario: licencias y convenios urbanísticos, tasas e impuestos sobre construcciones, instalaciones y obras, enajenación de suelo público, etc. Tomando como ejemplo el Ayuntamiento

Cuadro II. Ingresos relacionados al ámbito inmobiliario según presupuesto Ayuntamiento de Málaga 2006 y 2013

\begin{tabular}{|l|r|r|}
\hline Concepto & $\begin{array}{c}\text { Presupuesto año 2006 } \\
\text { (euros) }\end{array}$ & $\begin{array}{c}\text { Presupuesto año 2013 } \\
\text { (euros) }\end{array}$ \\
\hline Licencias urbanísticas & $14.000 .000,00$ & $5.642 .473,92$ \\
\hline Convenios urbanísticos & $93.722 .059,00$ & 0,00 \\
\hline Construcciones, instalaciones y obras & $20.203 .300,00$ & $4.478 .230,00$ \\
\hline Enajenación de parcelas vía pública & $28.148 .642,00$ & $30.000,00$ \\
\hline Enajenación de otros terrenos & $75.000,00$ & $1.525 .000,00$ \\
\hline $\begin{array}{l}\text { Enajenación de viviendas y locales de } \\
\text { negocio }\end{array}$ & $16.792 .309,78$ & $1.789 .337,11$ \\
\hline Enajenación de otras inversiones reales & $38.238 .769,42$ & $1.438 .563,12$ \\
\hline Total ingresos ámbito inmobiliario & $211.180 .080,20$ & $\mathbf{1 4 . 9 0 3 . 6 0 4 , 1 5}$ \\
\hline Ingresos totales previstos & $958.036 .278,52$ & $685.132 .295,78$ \\
\hline $\begin{array}{l}\text { \% Ingresos ámbito inmobiliario sobre el } \\
\text { total }\end{array}$ & $\mathbf{2 2 , 0 4 \%}$ & $\mathbf{2 , 1 8 \%}$ \\
\hline
\end{tabular}

Elaboración propia. Fuente: Presupuestos Ayuntamiento de Málaga

6. http://www.registradores.org/get?DS=6\&file=/Estadisticas/Panorama_registral_ de_impagos_hipotecarios_de_vivienda_en_2012.pdf

7. http://www.ine.es/prensa/np740.pdf

8. http://www.bde.es/f/webbde/GAP/Secciones/SalaPrensa/NotasInformativas/Briefing_notes/es/notabe10-05-13.pdf 
de Málaga ${ }^{9}$, según se observa en el cuadro 2, en el presupuesto para el año 2006 , previo a la crisis financiera, el 22,04\% de los ingresos previstos provenían de los conceptos anteriormente indicados, mientras que para el presupuesto del año 2013 en los mismos ítems, la previsión de ingreso sobre el total sólo representaba el 2,18\%, un 92,94 menos.

\section{Capacidad de endeudamiento de las familias y vulnerabilidad económica}

La privación de una vivienda puede situar a una familia en las puertas de la vulnerabilidad, y a un paso de la exclusión social (Navarro, 2005). Esta circunstancia ha sido el elemento utilizado, tanto por la administración central como por parte de los gobiernos autonómicos, a la hora de aprobar normativas para intervenir sobre las personas que se ven afectadas por un desahucio. En concreto, las últimas normativas aprobadas sobre medidas ante deudores hipotecarios, hacen explícitos los indicadores de riesgo que se tienen en cuenta para considerar a una familia en el umbral de la exclusión social, como colectivo especialmente vulnerable, o como persona en una situación de emergencia o exclusión social (ver cuadro 3).

Con esta delimitación de familias y otras muchas, que aun no encontrándose entre los parámetros aquí expuestos, también pueden presentar dificultades para hacer frente a la cuota hipotecaria, se establece el punto de partida para que la entidad financiera decida interponer una demanda vía judicial de reclamación de pagos pendiente, iniciándose con ello una ejecución hipotecaria. Este proceso dará pie a una posterior subasta de la vivienda si no se han satisfecho las deudas reclamadas, y al denominado lanzamiento, acto por el que la familia es sacada a la fuerza, en caso necesario, de la que ha sido su vivienda.

En paralelo, como consecuencia del estallido de la burbuja inmobiliaria a raíz de la crisis financiera, se están produciendo cifras de paro jamás registradas. En el primer trimestre de 2007, inicio de la crisis, se situaba en 413.300 los hogares del conjunto del estado que tenían todos sus miembros en paro. Seis años después, en el primer trimestre de 2013 alcanza la cifra de 1.906 .100 hogares, lo que supone un incremento del 461,19\%, según la Encuesta de Población Activa (EPA) ${ }^{10}$.

9. http://presupuestos2013.malaga.eu/export/sites/default/economia/presupuestos2013/ portal/menu/seccion_0001/documentos/estado_consolidado.pdf

10. http://www.ine.es/jaxi/menu.do? L=0\&type=pcaxis\&path=\% $2 \mathrm{Ft} 22 \% 2$ Fe308_mnu\&file=inebase 
Cuadro III. Perfil de deudores hipotecarios en riesgo según normativas

\begin{tabular}{|c|c|}
\hline Normativa & Requisitos beneficiarios \\
\hline $\begin{array}{l}\text { Real Decreto-ley } 6 / 2012 \text {, de } 9 \\
\text { de marzo, de medidas urgentes } \\
\text { de protección de deudores } \\
\text { hipotecarios sin recursos } \\
\text { (Gobierno central) } \\
\text { Referido a deudores en el } \\
\text { umbral de exclusión }\end{array}$ & $\begin{array}{l}\text { a. Vivienda habitual } \\
\text { b. Inexistencia de otra vivienda } \\
\text { c. Miembros de la unidad familiar sin rentas } \\
\text { d. Cuota hipotecaria superior al } 60 \% \text { de los ingresos } \\
\text { netos del conjunto de la unidad familiar } \\
\text { e. Miembros de la unidad familiar sin otros bienes } \\
\text { o derechos patrimoniales suficientes con los que } \\
\text { hacer frente a la deuda }\end{array}$ \\
\hline $\begin{array}{l}\text { Ley } 1 / 2013, \text { de } 14 \text { de mayo, } \\
\text { de medidas para reforzar la } \\
\text { protección a los deudores } \\
\text { hipotecarios, reestructuración } \\
\text { de deuda y alquiler social } \\
\text { (Gobierno central) } \\
\text { Real Decreto-ley } 27 / 2012 \text {, de } \\
15 \text { de noviembre, de medidas } \\
\text { urgentes para reforzar la } \\
\text { protección a los deudores } \\
\text { hipotecarios } \\
\text { (Gobierno central) } \\
\text { Referidos a colectivos } \\
\text { especialmente vulnerables }\end{array}$ & $\begin{array}{l}\text { a. Familia numerosa } \\
\text { b. Unidad familiar monoparental con dos hijos a cargo } \\
\text { c. Unidad familiar con un menor de tres años } \\
\text { d. Unidad familiar con algún miembro con } \\
\text { discapacidad (mayor 33\%), dependencia o } \\
\text { enfermedad. O que conviva en la misma vivienda } \\
\text { con el titular de la hipoteca o su cónyuge por } \\
\text { vínculo de parentesco hasta el tercer grado de } \\
\text { consaguinidad o afinidad } \\
\text { e. Deudor hipotecario desempleado y sin prestaciones } \\
\text { f. Unidad familiar con víctima de violencia de género } \\
\text { g. Ingresos de la unidad familiar no superen } 3 \text { veces } \\
\text { el IPREM } \\
\text { h. En los cuatro años anteriores a la solicitud la } \\
\text { unidad familiar haya sufrido una alteración } \\
\text { significativa de sus circunstancias económicas en } \\
\text { términos de esfuerzo de acceso a la vivienda } \\
\text { i. Cuota hipotecaria superior al } 50 \% \text { de los ingresos } \\
\text { netos del conjunto de la unidad familiar } \\
\text { j. Disponer de una sola vivienda } \\
\text { k. La carga hipotecaria sobre la renta familiar se haya } \\
\text { multiplicado por al menos } 1,5\end{array}$ \\
\hline $\begin{array}{l}\text { Decreto-ley } 6 / 2013 \text {, de } 9 \text { de } \\
\text { abril, de medidas para asegurar } \\
\text { el cumplimiento de la Función } \\
\text { Social de la Vivienda (Junta de } \\
\text { Andalucía) } \\
\text { Referido a personas en situación } \\
\text { de emergencia o exclusión social }\end{array}$ & $\begin{array}{l}\text { a. La carga hipotecaria sobre la renta familiar se haya } \\
\text { multiplicado por, al menos, 1,5 y suponga más de } \\
\text { un tercio de los ingresos familiares. } \\
\text { b. Ingresos de la unidad familiar no supere } 3 \text { veces el } \\
\text { IPREM } \\
\text { c. Informe de los Servicios Sociales Comunitarios } \\
\text { sobre la situación de emergencia o exclusión social } \\
\text { en que puede quedar el beneficiario en caso de } \\
\text { lanzamiento }\end{array}$ \\
\hline
\end{tabular}

Elaboración propia. Fuente: Boletín Oficial del Estado y Boletín Oficial de la Junta de Andalucía 
No podemos olvidar que la tasa de riesgo de pobreza según las diferentes Encuestas de Condiciones de Vida del INE ${ }^{11}$, recogidas desde 2004 hasta 2012, ha experimentado un crecimiento del 1,2\%, pasando del 19,9\% en el año 2004 a un $21,1 \%$ en el año 2012, generándose una cada vez mayor bolsa de familias con dificultades para hacer frente de manera puntual, a los compromisos contraídos con las entidades financieras.

Por último, y según los datos facilitados por Cáritas en su VIII Informe del Observatorio de la Realidad Social (2013), «las principales causas de empeoramiento de la situación económica son, por este orden, el desempleo y la precarización de las condiciones laborales; y el endeudamiento de los hogares (especialmente hipotecas de vivienda)». Ante ello, la ayuda más habitual de apoyo desde las familias, está relacionada con ayudas económicas para la vivienda.

\section{Proceso de ejecución hipotecaria}

Todas estas circunstancias empiezan a estar visibilizadas a nivel estadístico, principalmente por el informe que cada tres meses elabora el Consejo General del Poder Judicial, titulado «Datos sobre el efecto de la crisis en los órganos judiciales», en el que dedica una serie de apartados a las ejecuciones hipotecarias y lanzamientos ${ }^{12}$. En él se refleja cómo se ha producido desde el año 2008 hasta finales de 2012, un total de 415.117 ejecuciones hipotecarias, y 236.973 lanzamientos en el conjunto del Estado. A su vez, el propio Consejo General del Poder Judicial en su memoria anual «La justicia dato a dato», viene recogiendo desde el año 2008, el número de lanzamientos sobre los recibidos que son realizados de manera positiva ${ }^{13}$ (ver cuadro 4 ).

Tal como refleja el cuadro 4, se mantiene un incremento en cuanto a los lanzamientos cumplimentados positivamente año tras año, en un 166,21\% más del año 2008 al 2012. Aunque no existen datos sobre qué circusntancias

11. http://www.ine.es/jaxi/tabla.do?path=/t25/p453/provi/lo/\&file=0 1002 . px\&type $=$ pcaxis $\& L=0$

12. Ejecuciones hipotecarias: Procedimientos tramitados en los Juzgados de Primera Instancia, que permiten exigir el pago de las deudas garantizadas por prenda o hipoteca al acreedor con escritura de hipoteca a su favor.

Lanzamientos: Diligencias practicadas por la comisión judicial que habitualmente implica el desplazamiento de funcionarios a las viviendas para el desalojo. Sólo se contabilizan los realizados por los servicios comunes de notificaciones y embargos y no los realizados directamente por los juzgados en las localidades en las que no existen dichos servicios.

13. Lanzamientos con cumplimiento positivo: Lanzamientos en los que se ha podido practicar el lanzamiento acordado por el juzgado. 
Cuadro IV. Ejecuciones hipotecarias, lanzamientos recibidos y lanzamientos cumplimentados positivamente en el Estado 2008-2012

\begin{tabular}{|c|c|c|c|c|}
\hline Año & $\begin{array}{c}\text { Ejecuciones } \\
\text { hipotecarias }\end{array}$ & $\begin{array}{c}\text { Lanzamientos } \\
\text { recibidos }\end{array}$ & $\begin{array}{c}\text { Lanzamientos } \\
\text { cumplimentados } \\
\text { positivamente }\end{array}$ & $\begin{array}{c}\text { \% lanzamientos } \\
\text { cumplimentados } \\
\text { positivamente sobre los } \\
\text { recibidos }\end{array}$ \\
\hline 2008 & 58.686 & 26.748 & 17.433 & $65,17 \%$ \\
\hline 2009 & 93.319 & 33.918 & 22.493 & $66.32 \%$ \\
\hline 2010 & 93.636 & 47.809 & 32.689 & $68,37 \%$ \\
\hline 2011 & 77.854 & 58.241 & 40.740 & $69,95 \%$ \\
\hline 2012 & 91.622 & 70.257 & 46.408 & $66,05 \%$ \\
\hline
\end{tabular}

Elaboración propia. Fuente Consejo General del Poder Judicial

son las que han impedido la realización de estos lanzamientos en su totalidad, es conocido que cada vez se están produciendo más actos ciudadanos para llegar a su paralización o retraso.

Recientemente, en abril y en mayo de 2013, se han publicado dos nuevos documentos referentes a información estadística sobre esta problemática. El primero de ellos corresponde al Colegio de Registradores de la Propiedad, Bienes Muebles y Mercantiles de España, bajo el título «Panorama Registral impagos hipotecarios de vivienda 2012». Dicho informe indica que durante el año 2012 se han registrado 38.976 adjudicaciones por ejecución hipotecaria sobre vivienda, ${ }^{14}$ relativos a titulares personas físicas. Estas adjudicaciones suponen el final del proceso de ejecución hipotecaria, que se inicia con la certificación registral.

El segundo documento corresponde a la nota hecha pública por el Banco de España con fecha del 10 de mayo, en el que se indica que el número total de entrega de viviendas ocurrido en el año 2012 ha sido de 39.167, de ellas, 32.490 vivienda habitual. En el $83 \%$ de los casos de entrega judicial de viviendas habituales, la vivienda estaba vacía, por lo que en un $17 \%$ de ellos, en el momento de dicha entrega había una familia ocupándola.

Tanto el Relator Especial de Naciones Unidas, Sr. Miloon Kothari, con su informe «Promoción y protección de todos los derechos humanos, civiles,

14. Adjudicaciones como consecuencia de procedimiento de ejecución hipotecaria relativas exclusivamente a vivienda: Operaciones que inscriben el cambio de titularidad como consecuencia del impago de la hipoteca. Pueden llegar con demora al Registro de la Propiedad por el retraso de las entidades financieras para evitar los gastos inherentes en tanto no venden a un tercero la vivienda, aprovechando en ese momento para hacer ambas inscripciones, adjudicación y venta. 
políticos, económicos, sociales y culturales incluido el derecho al desarrollo» del año 2008, como el informe «El derecho a una vivienda adecuada», presentado en la Asamblea General de las Naciones Unidas en el año 2012, han planteado que la vivienda es un derecho recogido no sólo a nivel constitucional, como es el caso español, sino también en el derecho internacional incorporado en la Declaración Universal de los Derechos Humanos. Se ha indicado, además, que urge una protección de aquellos sectores más vulnerables para que puedan acceder a una vivienda digna y habitable, en condiciones económicas posibles y viables. Por ello, cualquier acto de violencia y/o presión que se realiza para desalojar a una familia de su vivienda, debe desaparecer e incluso ser penalizado. Se defiende con ello, un rechazo a modelos en donde la corrupción y la especulación urbanística sitúe a la vivienda no como un derecho humano, sino como un instrumento de intercambio comercial para obtener beneficios empresariales, sobre todo con aquellas familias que tienen la necesidad de acceder a lo que consideramos como vivienda habitual.

A su vez el dictamen emitido por la abogada general del Tribunal de Justicia de la UE, Juliane Kokott, el 8 de noviembre de 2012, a raiz de una demanda de Mohamed Aziz contra CatalunyaCaixa, donde se recoge la incompatibilidad que se ha estado realizando respecto a la Directiva 93/13, indicando que: «Un sistema de ejecución de títulos notariales sobre bienes hipotecados o pignorados en el que las posibilidades de oposición frente a la ejecución se encuentran restringidas es incompatible con la Directiva 93/13/CEE del Consejo, de 5 de abril de 1993, sobre las cláusulas abusivas en los contratos celebrados con consumidores, cuando el consumidor, ni en el propio procedimiento ejecutivo ni en un procedimiento judicial separado, puede obtener una tutela jurídica efectiva para ejercitar los derechos reconocidos en dicha Directiva, por ejemplo mediante una resolución judicial que suspenda provisionalmente la ejecución forzosa.» Este dictamen ha significado un ante y un después en los procedimientos hipotecarios, obligando a la administración de justicia y al propio Estado español, a una revisión y modificación en cuanto a este tipo de procedimiento.

Ante toda esta serie de circunstancias, se hace necesaria la intervención de los estados en una política de vivienda amplia y coordinada, en donde se favorezca y se facilite el acceso a aquellos sectores con mayor dificultad por cuestiones económicas, de accesibilidad, cultural, etc., para que la falta de una vivienda no se sitúe como factor que potencie un proceso de exclusión, sino por el contrario sea un instrumento preventivo y de refuerzo de 
cara a los ciudadanos en su proyecto de vida. «La vivienda es un espacio vital, imprescindible para la socialización, para ser parte de una sociedad, es decir, es un factor de inclusión social de primer orden». (Alguacil, et al., 2013, p. 4)

Al objeto de evitar que la vivienda sea utilizada como mera mercancía para la especulación, se propone partir de una regulación rígida de cara al mercado inmobiliario, respecto a las viviendas de primer uso para familias y/o personas a nivel individual, que inician un proceso de desarrollo personal, en donde la vivienda sea una de las herramientas que les facilita no sólo habitabilidad sino también seguridad, protección y espacio vital. La Declaración Universal de Derechos Humanos, como ya se ha indicado, establece el derecho a una vivienda digna, ya que este es uno de los componentes importantes para alcanzar un nivel de vida adecuado. (Mira, 2001).

Desde este planteamiento, se hace necesario acercarnos a la realidad de los desahucios, explorando las circunstancias previas y actuales que en ella se están produciendo, y su influencia en el proceso de desarrollo personal de las familias afectadas. Precisamente, esta es la finalidad de la presente investigación, con la que ha sido posible conocer y profundizar en las circunstancias que están originando el que las familias no puedan hacer frente al pago de su hipoteca, a la vez que, definir cuál es el perfil de éstas personas y/o familias.

\section{Material y Método}

\section{Participantes}

La muestra de participantes se ha diseñado a partir del informe sobre «Panorama registral Impagos hipotecarios de vivienda 2012», del Colegio de Registradores de la Propiedad, Bienes Muebles y Mercantiles de España, referenciado a la provincia de Málaga, en la que durante el año 2012 se han producido 2.268 adjudicaciones por ejecución hipotecaria. De todas estas adjudicaciones, el $77,06 \%$ corresponde a primera vivienda, lo que supone un total de 1.748. Sobre este dato se ha calculado el tamaño de la muestra para universos finitos con un nivel de confianza del $95 \%$ y un error del $\pm 9 \%$, resultando un total de 110 sujetos a quienes se les ha identificado de forma aleatoria, a partir de las personas que acuden a los diferentes recursos existentes en Málaga, para obtener información y/o asesoramiento sobre desahucios. 


\section{Instrumentos}

Se ha elaborado un cuestionario ${ }^{15}$ específico para la presente investigación, de 27 ítems, en los que a partir de preguntas tanto abiertas como cerradas se ha obtenido información sobre datos relativos a la composición y relaciones de la unidad familiar, datos económicos, sociodemográficos, de salud y afrontamiento del problema, respecto al cómo y dónde actuar para encontrar una salida, de relación con la entidad bancaria y situación de la vivienda con la hipoteca.

\section{Procedimiento}

El cuestionario diseñado se ha entregado en los diferentes organismos y entidades, en los que en estos momentos se está atendiendo a personas con problemas de desahucio en la ciudad de Málaga, en concreto se ha coordinado su distribución a través de la Oficina de Intermediación Hipotecaria de la Junta de Andalucía, trabajadores sociales de los Servicios Sociales Comunitarios de la provincia, Cáritas Diocesana, Cruz Roja y la Plataforma de Afectados por la Hipoteca (PAH). La recogida de datos se ha realizado de forma directa en la PAH de Málaga, participando en sus asambleas a lo largo de siete semanas. En el resto de entidades durante el mismo periodo, se ha contado con la colaboración de los técnicos y/o personas que atienden a los afectados para la aplicación del cuestionario. En todos los casos, se ha informado de la confidencialidad de los datos, así como del procedimiento voluntario para la participación en el estudio.

El porcentaje mayor de cuestionarios se ha obtenido a través de la $\mathrm{PAH}$, en concreto el $76,4 \%$, lo que puede estar explicado tanto por la recogida directa, como por ser dicha plataforma el mayor referente actual para la realidad de los desahucios en Málaga.

\section{Resultados}

Composición de la unidad familiar, datos económicos y sociodemográficos

Los resultados muestran que las familias que se encuentran actualmente en procesos de desahucios, están compuestas por dos adultos, con una media de edad de 40 años, y en un 59,1\% de los casos, con un menor de 9 años a su cargo.

El 89,1\% de dichas familias son de nacionalidad española.

15. Anexo 1 
Figura I. Familias en procesos de desahucios según nacionalidad
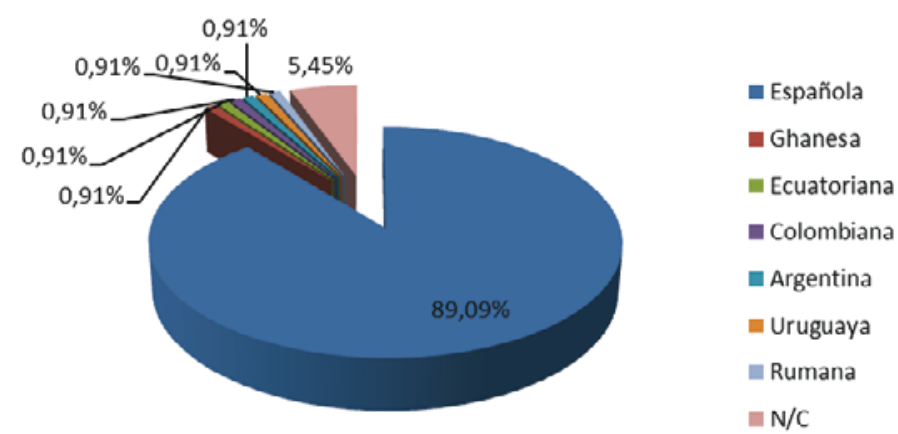

Para el 63,6\% de estas familias, la situación de desempleo es lo que está impidiendo hacer frente al pago de la hipoteca, seguidas por un 15,5\% de casos en los que tenían un negocio que se han visto obligados a cerrar.

Figura II. Circunstancia principal por la que no puede hacer frente a la cuota hipotecaria

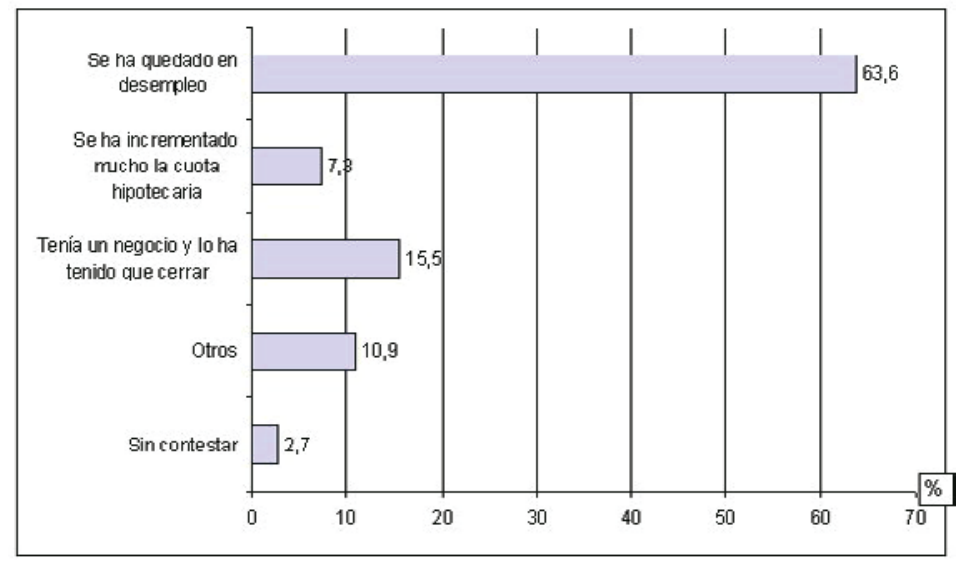

El 37,3\% de los participantes, en el momento de solicitar su hipoteca se encontraban trabajando en la construcción y en empresas auxiliares, en la hostelería y comercio un 32,4\%. La relación laboral que mantenían respondía en un $38,8 \%$ de los casos a un contrato temporal, seguido por un $36,9 \%$ en los que existía un contrato fijo y por un $19,4 \%$ que se encontraban de alta como autónomos. 
Figura III. Tipo de relación laboral que mantenía cuando le concedieron la hipoteca

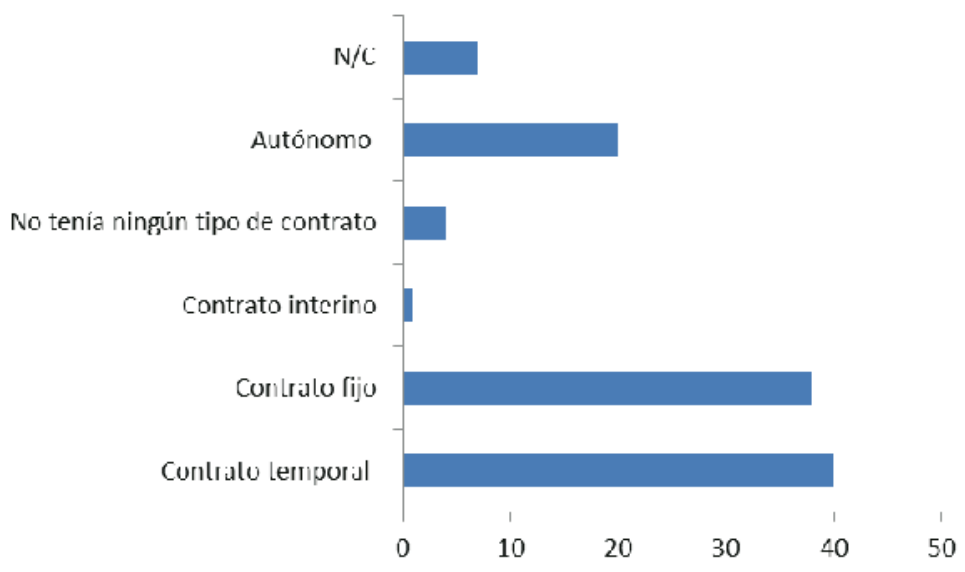

En el 35,1\% de las familias analizadas, los miembros que solicitaron la hipoteca llevaban más de diez años trabajando cuando se la concedieron, seguidos de entre 3 y 6 años en un 27,8\% de los casos, y con menos de un año en el $7,2 \%$ de ellos. En dichas familias se encontraban trabajando sólo un miembro de la unidad familiar, en ese momento, en el 49,5\% de los casos, y dos miembros en el $47,5 \%$.

Los ingresos mensuales que percibían cuando le concedieron la hipoteca se sitúan entre los 1.000 y 1.500 euros en un $37,5 \%$, y entre 1.500 y 2.000 euros en un $25 \%$. No superando los 1.000 euros de ingresos en el $16,3 \%$ de los casos.

Cuadro V. Ingresos económicos mensuales cuando le concedieron la hipoteca

\begin{tabular}{|l|r|}
\hline & $\%$ \\
\hline Entre 600 y 1.000 euros & 15.5 \\
\hline Entre 1.000 y 1.500 euros & 35.5 \\
\hline Entre 1.500 y 2000 euros & 23.6 \\
\hline Más de 2.000 euros & 20.0 \\
\hline N/C & 5.5 \\
\hline Total & 100.0 \\
\hline
\end{tabular}


En relación a la intención de adquirir una vivienda pública antes de acceder a una de renta libre vía hipoteca, el $72,1 \%$ de las personas encuestadas manifiestan no haberse planteado dicha opción, fundamentalmente por falta de información y por considerar que no reunían los requisitos exigidos para ello, dadas sus condiciones laborales, familiares y/o económicas. Respecto a si se plantearon el alquiler como una opción mejor que la compra, a través de la hipoteca, el 72,6\% de los participantes respondió que no, motivado principalmente por los precios del alquiler, excesivos y parecidos al de las hipotecas, y por el deseo de seguridad de cara al futuro.

Estado de salud, afrontamiento y actuación ante el problema

Los resultados muestran que, ante la imposibilidad de hacer frente al pago de la cuota hipotecaria, todos los participantes han experimentado sentimientos de miedo, ansiedad, culpa o la combinación entre ellos. Un 59,6\% de ellos, ha expresado que ha utilizado fármacos o consumido otras sustancias a raíz de no poder pagar la cuota hipotecaria. Y un $66,7 \%$ ha indicado que ha tenido problemas de salud, cuando tuvo conocimiento del desahucio, siendo principalmente éstos de ansiedad y depresión.

Figura IV. Problemas de salud presentados al tener conocimiento del desahucio

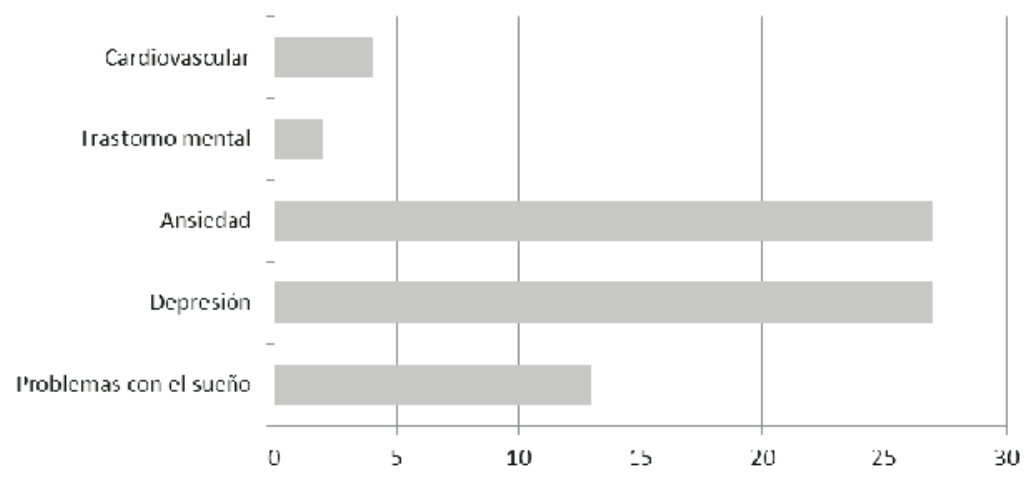

Así mismo, el 65,2\% de las familias reconocen haber experimentado cambios en su relación familiar tras la imposibilidad de hacer frente a la hipoteca. Éstos, en un 32,65\% de las situaciones, son definidos por ellos mismos como incremento de la agresividad, enfrentamientos y discusiones. 
Figura V. Cambios en la relación familiar ante la imposibilidad de hacer frente a la hipoteca

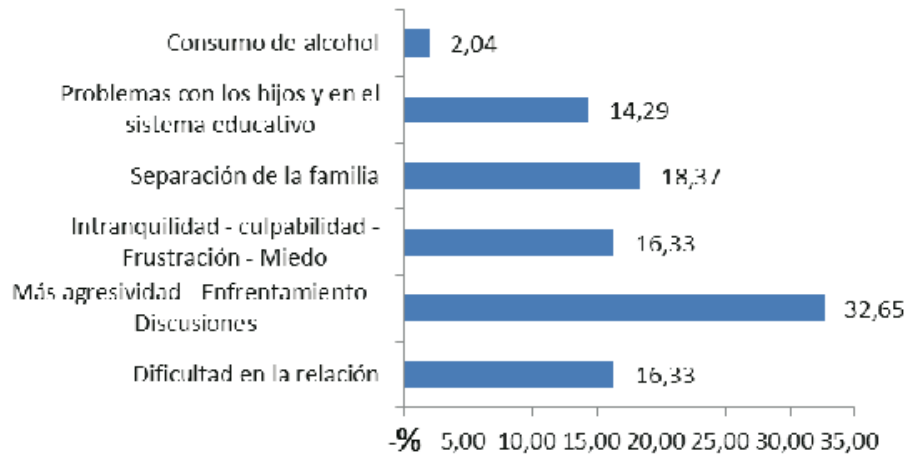

De cara a la actuación ante el problema, en un $43 \%$ de los casos, los participantes han acudido a los Servicios Sociales cuando han tenido dificultades para hacer frente a la cuota hipotecaria. También la familia, en un 36,4\% de las situaciones ha sido la primera opción en la que pensaron para solicitar su ayuda, encontrándose además un $28,3 \%$ de los casos, que no pensaron en nadie.

Hipoteca de la vivienda y relación con la entidad bancaria

El importe de la hipoteca solicitado se elevó a más de 200.000 euros en el $22,2 \%$ de los participantes, seguido de entre 100.000 y 125.000 euros en el $21,2 \%$. La media de años en que se encuentran financiadas estas hipotecas alcanza los 30,22 años. Estas hipotecas, en el 63,9\% de los casos no fueron avaladas por nadie, y entre quienes sí necesitaron aval, los madres/padres actuaron de avalista en el $56,4 \%$ de ellos y los hermanos en el $17,9 \%$.

En el 44,8\% de los casos, las entidades bancarias concedieron más importe en la hipoteca del solicitado previamente, manifestando el 68,3\% de los participantes haber dedicado dicho excedente a adquirir otros bienes de consumo o servicios, tales como reformar la vivienda o adquirir un automóvil. Tras la concesión de la hipoteca, en el 63,5\% de los casos, no se ha producido ampliación de la misma, ni a más años ni a más importe, mientras que en el $16,7 \%$ de los mismos, sí que se ha producido el incremento a más importe, en el $14,6 \%$ a más años y en el 5,2\%, tanto a más años como a más importe.

El 39,8\% de estas familias, indican que la actitud de la entidad financiera cuando se ha producido una cuota devuelta, o cuando se le ha informado de que no se iba a poder pagar la cuota hipotecaria, ha sido autoritaria, junto a 
un $26,9 \%$ de los casos, en los que no han obtenido ninguna respuesta. Según los resultados, el $68,8 \%$ de las familias en procesos de desahucios, se han sentido acosadas por la entidad financiera o por otras empresas que actúan en su nombre. Situación ésta, que si la ponemos en relación con aquellas personas que han indicado que tuvieron necesidad de tomar fármacos o consumir algún tipo de sustancias, a raíz de no poder hacer frente a la hipoteca, obtenemos que son las que más han consumido, un $77,77 \%$, siendo por el contrario las que no se han sentido acosadas las que menos han consumido.

Figura VI. Relación entre personas que se han sentido acosada y las que expresan que han consumido algún fármaco o sustancia

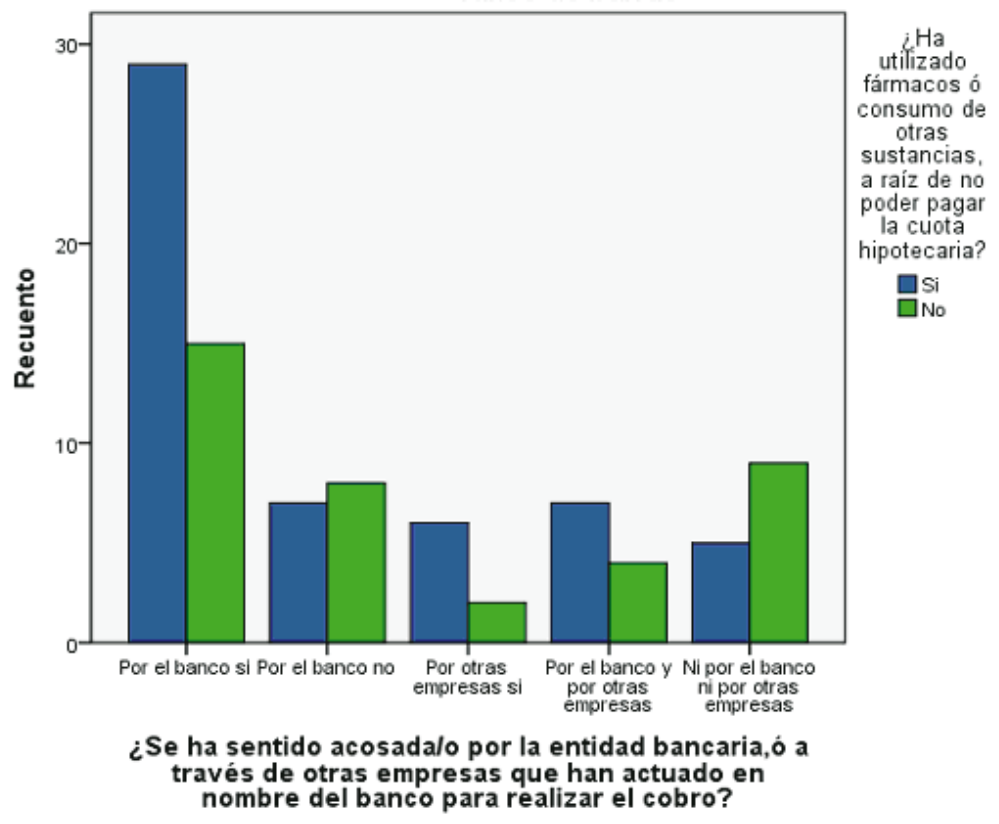

\section{Discusión}

El modelo de crecimiento planteado desde los años 50 en nuestro país, ha estado marcado por el peso específico de la construcción de vivienda privada por encima de la pública, así como por el cambio respecto al régimen de tenencia de la vivienda, pasando de la tendencia a la residencia en formato de alquiler a la vivienda en propiedad. Todo ello llega a su cenit con el llamado «boom inmobiliario». En este escenario, se ha ido originando un perfil de ciudadanos, cuya gran mayoría ha dirigido su actividad hacia la construcción 
o empresas auxiliares. A la vez, las entidades financieras han ido focalizando su negocio principal en todo lo relacionado con el sector inmobiliario, en muchos de los casos sin tener en cuenta medidas preventivas, y asumiendo un riesgo excesivo a la hora de conceder hipotecas a las familias españolas. De igual forma, las entidades locales se han sumado a este modelo, viendo en ello una fuente casi «inagotable» de ingresos financieros.

Con el inicio de la crisis financiera, como un castillo de naipes, este modelo de crecimiento ha caído en picado. La historia no sólo nos debiera de servir para conocer hechos y acontecimientos ocurridos, sino también para aprender de los aciertos y errores pasados, de cara a continuar o no en la realización de los mismos.

Por los datos obtenidos en este estudio, el hecho de que miles de ciudadanos se hayan quedado y se sigan quedando en desempleo y/o viéndose obligados a cerrar sus negocios, está provocando que en la gran mayoría de los casos analizados, éstos no puedan hacer frente al pago de la hipoteca.

Según los datos facilitados por el gobierno español, y remitidos a la comunidad europea a través de la «Actualización del Programa de Estabilidad 2013-2016» ${ }^{16}$, no se prevé que a corto plazo estas circunstancias vayan a ser modificadas. En este informe, se indica que la tasa de paro podrá alcanzar este año el $27,1 \%$, y podrá situarse para el año 2015 en un $25,8 \%$, superando la del año 2012 que fue del $25 \%$.

Tal como además ha reflejado esta investigación, y muy unido a lo anterior, nos encontramos ante un perfil de personas que no pueden hacer frente al pago de su hipoteca, por circunstancias de índole laboral. Ciudadanos que principalmente trabajaban en empresas de la construcción y auxiliares, y en los que primaba la contratación temporal cuando le concedieron la hipoteca. Estos datos y la pérdida del empleo, refleja las características de inseguridad que esta situación ha supuesto para las familias con hipotecas. De ahí que el cien por cien de ellos, expresaran que han sentido miedo, ansiedad o culpa cuando no han podido hacer frente a la cuota hipotecaria.

De igual forma, los resultados han reflejado el riesgo asumido por las entidades financieras, así como el esfuerzo económico que ha supuesto para las familias el que los ingresos previos a la hipoteca procedieran sólo de un miembro de la unidad familiar, con ingresos entre 1.500 y 2.000 euros, y el préstamo hipotecario medio haya oscilado entre los 150.000 y $200.000 \mathrm{eu}-$ ros. Esto fue suficiente para que las entidades financieras concedieran dichos

16. http://www.lamoncloa.gob.es/NR/rdonlyres/EFC55817-6964-4425-BB57B263B2351558/234921/ActualizacinProgramaEstabilidad201316ECONOMA.pdf 
préstamos, incluso sin avalista, en la gran mayoría de los casos. Ha quedado comprobado que estas familias asumieron un alto riesgo, agravado aun más por la ampliación, en muchos casos, del importe solicitado. El número medio de años contratado en las hipotecas se ha establecido en 30, en un mercado laboral cada vez más inestable, con la revisión actual del sistema de pensiones que apuesta por alternativas de alargar la edad de jubilación, y disminuir el importe a cobrar, y con una tasa nacional de paro juvenil del $57,22 \%$, según la EPA. Todo ello hará que se perpetúen situaciones de inviabilidad, tanto del acceso a la vivienda como del pago de la misma.

En relación al perfil de las familias con problemas en el pago de sus hipotecas, según los datos del presente estudio, nos encontramos con familias compuestas por 3 miembros, con una edad media de 40 años y con un menor de unos 9 años en la mayoría de los casos. Este perfil está en relación con los datos facilitados por las últimas encuestas del INE, que establecen la edad media de la maternidad en los 32 años, con un número de hijos por mujer de 1,3 , lo que refleja que las familias con problemas en el pago de la hipoteca ahora, son familias que iniciaban un proceso de desarrollo personal cuando optaron por la contratación de la misma. Además, no intentaron adquirir una vivienda pública por falta de información, y tampoco optaron por la opción del alquiler ya que los precios eran parecidos, y les generaba mayor seguridad de cara al futuro tener una vivienda de propiedad.

Las familias se tienen que enfrentar a situaciones nuevas para las que no están preparadas, como es el hecho de no poder hacer frente a un compromiso hipotecario contraído. Esta situación se vive como un acto reprobable socialmente, que conlleva a su vez a un enfrentamiento ante las entidades financieras. Generando en las familias sensación de impotencia, incapacidad y miedo, ocasionándoles no sólo problemas de salud sino también inestabilidad en las relaciones familiares. Es preocupante, que la principal circunstancia de conflicto familiar sea el incremento de la agresividad, los enfrentamientos y las discusiones en familias, como ya se ha indicado, en las que en la mayoría de los casos existen menores con no más de 9 años, con el riesgo que ello conlleva de cara a su desarrollo personal y educativo.

En toda esta realidad, según nos indica la investigación, sigue siendo la familia el mayor colchón social ante la que se acude en los momentos de crisis, bien sea a la más cercana padres y madres como a la de su entorno.

La falta de estudios previos de estas características, sitúa a este trabajo como un primer acercamiento a una realidad visibilizada a raíz de la crisis financiera, pero que ya existía antes para todas aquellas familias que eran desalojadas de sus viviendas. Estas situaciones venían siendo atendidas por los 
Servicios Sociales, los cuáles facilitaban en la mayoría de los casos una ayuda económica de emergencia. En estos momentos, tanto por el volumen como por las características de las personas que están siendo objeto de desahucio, las respuestas ofrecidas no pueden seguir siendo las mismas.

Esta investigación presenta limitaciones metodológicas que han de ser tenidas en cuenta en futuros estudios, en la dirección de obtener una mayor implicación y coordinación en el análisis de esta realidad, por parte del conjunto de las administraciones que atienden a personas con problemas para hacer frente a la cuota hipotecaria, lo que permitirá un incremento de la muestra, que mejore los índices de error.

\section{Conclusiones}

Los resultados aquí expuestos nos indican que urge intervenir en el problema del desempleo que sufren estas familias, ofreciendo no sólo alternativas a la vivienda, sino también recursos suficientes y válidos ante su situación de desempleo. De lo contrario, se estará generando una doble vulnerabilidad, la falta de una vivienda y la falta de recursos suficientes para satisfacer sus necesidades básicas y/o primarias.

De acuerdo con el informe del Defensor del Pueblo «Crisis económica y deudores hipotecarios: actuaciones y propuestas del Defensor del Pueblo», es necesario que las entidades financieras asuman una actitud negociadora, donde la mediación y el diálogo superen las circunstancias sobrevenidas por parte de las familias, y se puedan renegociar nuevas condiciones que mejoren las prácticas mantenidas de falta de información, agotando previo a las ejecuciones hipotecarias, la vía extrajudicial de la mediación. A la vez que están obligadas a la eliminación de las llamadas cláusulas abusivas.

Por otro lado, tanto ellas, como las administraciones públicas, debieran de establecer mecanismos novedosos y alternativos, para facilitar el acceso a la vivienda, más allá de alargar el número de años en que se concede el préstamo hipotecario, ya que es un riesgo ante la inseguridad del mercado laboral y sus perspectivas futuras.

La información que se facilite tanto por las administraciones públicas como por parte de las entidades financieras, debe ser correcta, suficiente y rigurosa, en cuanto a la adquisición de vivienda. Ya que no ha primado el interés general de los ciudadanos, y si por el contrario, el interés comercial y empresarial de cara a obtener beneficios a costa de un derecho, como es el disponer de una vivienda.

Es necesario hacer un seguimiento de las familias que se ven afectadas por un problema de desahucio, ofreciendo apoyo psicosocial no sólo a las 
personas afectadas sino también a su red familiar, abordando la intervención con los menores existentes. Siendo necesario por parte de los Servicios Sociales, que se establezcan líneas de intervención diferencias y actualizadas a una nueva realidad.

A la vez es fundamental contar con estadísticas periódicas y específicas, no sólo sobre los desahucios-lanzamientos que se producen, sino sobre el conjunto de las circunstancias que les rodea.

Y unido a todo ello, se evidencia la necesidad de que se realicen las modificaciones legislativas oportunas, para que se garantice el derecho a la vivienda como un derecho fundamental.

\section{Referencias}

Alguacil, A., Alguacil, J., Arasanz, J., Fernández, G., Paniagua, J.L., Olea, S. y RENES, V. (2013). La vivienda en España en el siglo XXI. Madrid: Fundación FOESSA. Cáritas.

Colau, A. y Alemany, A. (2012). Vidas hipotecadas. Barcelona: Cuadrilátero de libros.

- Empobrecimiento y desigualdad social. (2013).

- VIII Informe del Observatorio de la Realidad Social. (2013) Madrid: Cáritas Española.

Laparra, M., Obradors, A., Pérez, B., Pérez, M., Renes, V., Sarasa, S., Subirats, J. y TRujillo, M. (2007). Una propuesta de consenso sobre el concepto de exclusión. Implicaciones metodológicas. Revista Española del Tercer Sector, 5, $15-57$.

MiRA, Fco. J., (2001). Territorio, hábitat y vivienda frente a la exclusión social. Alternativas. Cuadernos de Trabajo Social, 9, 241-262.

Naciones Unidas. Consejo de Derechos Humanos. (2008) Promoción y protección de todos los derechos humanos, civiles, políticos, económicos, sociales y culturales incluidos el derecho al desarrollo. New York.

NAVARRO, C. (2005). Indicadores de Vivienda y exclusión. Documentación Social, 138, 173-190.

TRABADA, E. (2012). El problema de la vivienda en una sociedad que se dualiza. Documentación Social, 165, 165-188.

Ayuntamiento de Málaga. Presupuesto 2013. Estado Consolidado. Recuperado el 18 de mayo de $2013 \mathrm{http}: / /$ presupuestos2013.malaga.eu/export/sites/default/ economia/presupuestos2013/portal/menu/seccion_0001/documentos/estado_consolidado.pdf

Banco de España. Nota informativa sobre la presentación de una nueva estadística de procesos de ejecución hipotecaria sobre viviendas. Recuperado el 12 de 
mayo de 2013 http://www.bde.es/f/webbde/GAP/Secciones/SalaPrensa/NotasInformativas/Briefing_notes/es/notabe10-05-13.pdf

Boletín Oficial de la Junta de Andalucía. Decreto-ley 6/2013, de 9 de abril, de medidas para asegurar el cumplimiento de la Función Social de la Vivienda. Recuperado el 15 de mayo de 2013 http://www.juntadeandalucia.es/boja/2013/69/BOJA13-069-00026-6120-01_00025059.pdf

Boletín Oficial del Estado. Real Decreto-ley 27/2012, de 15 de noviembre, de medidas urgentes para reforzar la protección a los deudores hipotecarios. Recuperado el 15 de mayo de 2013 http://www.boe.es/boe/dias/2012/11/16/pdfs/ BOE-A-2012-14115.pdf

Boletín Oficial del Estado. Real Decreto-ley 6/2012, de 9 de marzo, de medidas urgentes de protección de deudores hipotecarios sin recursos. Recuperado el 15 de mayo de 2013 http://www.boe.es/boe/dias/2012/03/10/pdfs/BOEA-2012-3394.pdf

Boletín Oficial del Estado. Real Decreto 233/2013, de 5 de abril, por el que se regula el Plan Estatal de fomento del alquiler de viviendas, la rehabilitación edificatoria, y la regeneración y renovación urbana, 2013-2016. Recuperado el 12 de mayo de 2013 http://www.boe.es/boe/dias/2013/04/10/pdfs/BOEA-2013-3780.pdf

Boletín Oficial del Estado. Resolución de 23 de abril de 2013, de la Secretaría de

Estado de Servicios Sociales e Igualdad. http://www.boe.es/boe/dias/2013/05/16/ pdfs/BOE-A-2013-5163.pdf

Centro de Investigaciones Sociológicas (CIS). Barómetro de abril. Avance de resultados. Recuperado el 15 de mayo de 2013 http://datos.cis.es/pdf/ Es2984mar_A.pdf

Ciudades para un futuro más sostenible. Ayudas a 71 familias: Red Igloo Barcelona. Recuperado el 13 de octubre de 2013 http://habitat.aq.upm.es/bpes/ che00/bpes343.es.html

Colegio de Registradores de la Propiedad, Bienes Muebles y Mercantiles de España. Panorama Registral de Impagos Hipotecarios de Vivienda. Recuperado el 12 de mayo de 2013 http://www.registradores.org/get?DS=6\&file=/Estadisticas/Panorama_registral_de_impagos_hipotecarios_de_vivienda_en_2012. pdf

Consejo General del Poder Judicial. Informes periódicos. Efecto de la crisis en los órganos judiciales. Recuperado el 12 de mayo de 2013 http://www.poderjudicial.es/cgpj/es/Temas/Estadistica_Judicial/Informes_estadisticos/ Informes_periodicos

Consejo General del Poder Judicial. La Justicia dato a dato. Recuperado el 07 de julio de 2013 http://www.poderjudicial.es/cgpj/es/Temas/Estadistica Judicial/ Analisis estadistico/La Justicia dato a dato/ 
Defensor del Pueblo. Crisis económica y deudores hipotecarios: actuaciones y propuestas del Defensor del Pueblo. Recuperado el 26 de mayo de 2013 http://www.defensordelpueblo.es/es/Documentacion/Publicaciones/monografico/Documentacion/Crisis_Hipotecas_2012.pdf

Instituto Nacional de Estadística. Censo de población y vivienda 2011. Edificios y viviendas. Datos provisionales. Recuperado el 12 de mayo de 2013 http:// www.ine.es/prensa/np775.pdf

Instituto Nacional de Estadística. Construcción de vivienda según calificación. Recuperado el 12 de mayo de 2013 http://www.ine.es/jaxi/tabla.do?path=/t38/ bme2/t07/a081/10/\&file=1300007.px\&type=pcaxis $\& \mathrm{~L}=0$

Instituto Nacional de Estadística. Encuesta de condiciones de vida 2012. Resultados provisionales. Recuperado el 12 de mayo de 2013 http://www.ine.es/jaxi/ tabla.do?path=/t25/p453/provi/l0/\&file=01002.px\&type=pcaxis\&L=0

Instituto Nacional de Estadística. Encuesta de Población Activa. Recuperado el 12 de mayo de $2013 \mathrm{http} / /$ www.ine.es/jaxi/menu.do? $\mathrm{L}=0 \&$ type=pcaxis\&path= $\% 2 \mathrm{Ft} 22 \% 2 \mathrm{Fe} 308 \_m n u \& f i l e=i n e b a s e$

La Moncloa. Gobierno de España. Programa Nacional de Reformas y actualización del Programa de Estabilidad. Recuperado el 26 de mayo de 2013 http://www.lamoncloa.gob.es/NR/rdonlyres/EFC55817-6964-4425-BB57B263B2351558/234921/ActualizacinProgramaEstabilidad201316ECONOMA.pdf

Ministerio de Fomento. Precios de la vivienda. Recuperado el 22 de mayo de 2013 http://www.fomento.gob.es/BE2/?nivel=2\&orden=35000000

Naciones Unidas Derechos Humanos. El derecho a una vivienda adecuada. Recuperado el 22 de mayo de 2013 http://www.ohchr.org/Documents/Issues/ Housing/A-67-286_sp.pdf

Tribunal de Justicia Europeo. Conclusiones de la abogada general Sra. Juliane Kokott. Asunto C-445/11. Mohamed Aziz contra Catalunyacaixa. Recuperado el 10 de octubre de 2013 http://curia.europa.eu/juris/document/document.jsf? text $=\&$ docid $=129481 \&$ pageIndex $=0 \&$ doclang $=$ es $\&$ mode $=$ req $\&$ dir $=\&$ \&occ $=$ first $\&$ part $=1 \&$ cid $=172995$

\section{Anexo 1. Cuestionario}

El presente cuestionario forma parte de un trabajo de investigación que se está realizando en el Máster de Investigación e Intervención Social y Comunitaria de la Universidad de Málaga.

La información aquí facilitada es total y absolutamente anónima. Su contestación no le llevará más de 15 minutos, sólo tendrá que marcar con una X la respuesta que considere oportuna. Agradeciendo su interés en participar contestando las siguientes preguntas. 
Número de personas que componen la Unidad Familiar

Edad de las personas de la Unidad Familiar
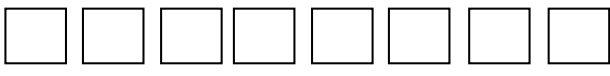

Nacionalidad

1) Ante la imposibilidad de hacer frente al pago de la cuota hipotecaria, ¿experimentó sentimientos de?

\begin{tabular}{|l|l|l|l|l|l|l|l|}
\hline Miedo & & Ansiedad & & Indiferencia & & Culpa & \\
\hline
\end{tabular}

Otros, indicar cuales

2) ¿Ha utilizado fármacos ó consumo de otras sustancias, a raíz de no poder pagar la cuota hipotecaria?

En caso afirmativo ¿cuáles?

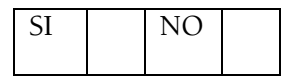

\begin{tabular}{|l|l|l|l|l|l|}
\hline Antidepresivos & Tranquilizantes & & Alcohol & Consumo excesivo de café & \\
\hline
\end{tabular}

Otros, indicar cuales

3) ¿Le avalo algún familiar y/o amigo para la concesión de la hipoteca?

En caso afirmativo ¿quién?

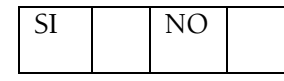

\begin{tabular}{|c|c|c|c|}
\hline Madres/padres & Hermana/o & \begin{tabular}{|l} 
Suegra/o \\
\end{tabular} & Amiga/o \\
\hline
\end{tabular}

Otros, indicar cuales

4) ¿La circunstancia principal por la que no puede hacer frente a la cuota hipotecaria es?

\begin{tabular}{|c|c|c|c|c|}
\hline $\begin{array}{c}\text { Se ha quedado en } \\
\text { desempleo }\end{array}$ & $\begin{array}{c}\text { Se ha incrementado } \\
\text { mucho la cuota }\end{array}$ & $\begin{array}{c}\text { Tenía un negocio y lo } \\
\text { ha tenido que cerrar }\end{array}$ \\
\hline
\end{tabular}

Otros, indicar cual 
5) ¿En que trabajaba cuando solicitó la hipoteca?

6) ¿Qué tipo de relación laboral mantenía cuando le concedieron la hipoteca?

\begin{tabular}{|c|c|c|c|c|c|c|c|c|}
\hline $\begin{array}{c}\text { Contrato } \\
\text { temporal }\end{array}$ & Contrato fijo & $\begin{array}{c}\text { Contrato } \\
\text { interino }\end{array}$ & $\begin{array}{c}\text { No tenía ningún } \\
\text { tipo de contrato }\end{array}$ & $\begin{array}{c}\text { Era } \\
\text { autónomo }\end{array}$ & \\
\hline
\end{tabular}

7) ¿Cuántos años llevaba trabajando cuando le concedieron la hipoteca?

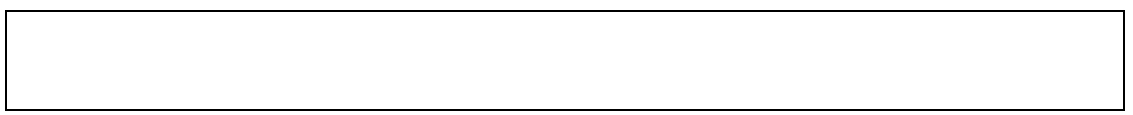

8) ¿Cuántos miembros de la unidad familiar trabajaban cuando le concedieron la hipoteca?

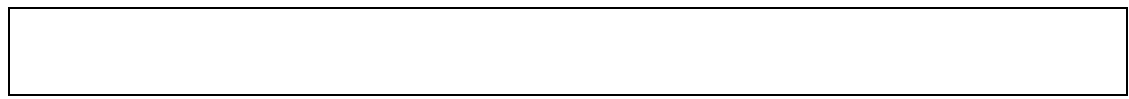

9) ¿Cuáles eran sus ingresos económicos mensuales cuando le concedieron la hipoteca?

\begin{tabular}{|c|c|c|c|c|c|c|}
\hline $\begin{array}{c}\text { Entre } 600 \mathrm{y} 1.000 \\
\text { euros }\end{array}$ & $\begin{array}{c}\text { Entre } 1.000 \mathrm{y} \\
1.500 \text { euros }\end{array}$ & $\begin{array}{c}\text { Entre } 1.500 \mathrm{y} \\
2.000 \text { euros }\end{array}$ & $\begin{array}{c}\text { Más de } 2.000 \\
\text { euros }\end{array}$ & \\
\hline
\end{tabular}

10) ¿Intentó adquirir una vivienda pública antes de adquirir una de renta libre vía hipoteca?

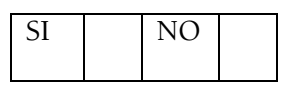

En caso de que la respuesta sea negativa, puede indicar el motivo

En caso de que la respuesta sea afirmativa, ¿por qué optó al final por la de renta libre?

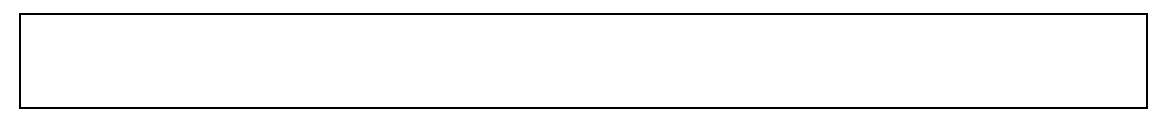


11) ¿Se planteó el alquiler como una opción mejor que la compra a través de una hipoteca?

\begin{tabular}{|l|l|l|l|}
\hline SI & & NO & \\
\hline
\end{tabular}

En caso de que la respuesta sea afirmativa, ¿por qué no lo hizo?

12) ¿Una vez que tuvo conocimiento del desahucio ha tenido problemas de salud provocados por ésta situación?

\begin{tabular}{|l|l|l|l|}
\hline SI & & NO & \\
\hline
\end{tabular}

En caso de que la respuesta sea afirmativa, puede indicar cuáles

13) ¿Se ha producido algún cambio en la relación familiar, de los miembros que conviven en el domicilio, tras la imposibilidad de hacer frente a la hipoteca?

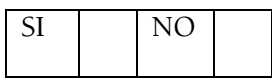

En caso de que la respuesta sea afirmativa, ¿puede indicar que cambios en la relación familiar son los que han ocurrido?

14) El comportamiento de la entidad bancaria, ante una cuota devuelta o cuando usted le ha informado que no iba a poder pagarla, ¿ha sido de?

\begin{tabular}{|l|l|c|c|c|c|c|c|c|}
\hline Comprensión & $\begin{array}{c}\text { Facilitadora } \\
\text { de soluciones }\end{array}$ & Negociadora & $\begin{array}{c}\text { No ha tenido } \\
\text { respuesta }\end{array}$ & Autoritaria & \\
\hline
\end{tabular}

Otro, indicar cual 
15) ¿Se ha sentido acosada/o por la entidad bancaria, ó a través de otras empresas que han actuado en nombre del banco para realizar el cobro?

\begin{tabular}{|l|l|l|l|l|l|l|l|l|l|}
\hline Por el banco & SI & & NO & & Por otras empresas & SI & & NO & \\
\hline
\end{tabular}

16) ¿Cuándo solicitó el préstamo hipotecario le dieron el importe económico mínimo necesario para comprar la vivienda o más, del que usted necesitaba?

\begin{tabular}{|l|l|l|l|}
\hline Me dieron el Importe mínimo & & Me dieron más de lo que necesitaba & \\
\hline
\end{tabular}

17) ¿Adquirió algún otro bien de consumo: coche, TV... o servicio: hizo un viaje, una obra... al adquirir el préstamo hipotecario que se incorporó a la hipoteca?

\begin{tabular}{|l|l|l|l|}
\hline SI & & NO & \\
\hline
\end{tabular}

En caso de ser afirmativo, podría indicar ¿cuál?

18) ¿Recuerda cuántos años firmó de hipoteca?

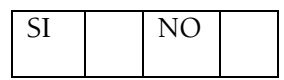

En caso afirmativo puede indicar ¿cuántos?

19) ¿Qué cantidad solicitó de hipoteca?

\begin{tabular}{|c|c|c|c|c|c|c|c|c|}
\hline $\begin{array}{c}\text { Menos de } \\
100.000 \\
\text { euros }\end{array}$ & $\begin{array}{c}\text { Entre } \\
100.000 \mathrm{y} \\
125.000 \\
\text { euros }\end{array}$ & $\begin{array}{c}\text { Entre } \\
125.000 \mathrm{y} \\
150.000 \\
\text { euros }\end{array}$ & $\begin{array}{c}\text { Entre } \\
150.000 \mathrm{y} \\
175.000 \\
\text { euros }\end{array}$ & $\begin{array}{c}\text { Entre } \\
175.000 \mathrm{y} \\
200.000 \\
\text { euros }\end{array}$ & $\begin{array}{c}\text { Más de } \\
200.00 \\
\text { euros }\end{array}$ \\
& & & & & \\
\hline
\end{tabular}

20) ¿Ha realizado alguna ampliación de la hipoteca en más años o a más importe?

\begin{tabular}{|l|l|l|l|l|}
\hline Si a más años & Si a más importe & & No ni a más años ni a más importe & \\
\hline
\end{tabular}

21) ¿Ha acudido a los servicios sociales de su Ayuntamiento, cuando no ha podido hacer frente a la cuota hipotecaria?

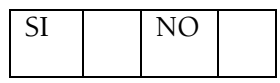


En caso de que la respuesta sea negativa, puede indicar ¿por qué?

En caso afirmativo ¿qué respuesta le han dado?

22) ¿Quién pensó primeramente que le podía ayudar cuando no pudo hacer frente al pago de la cuota hipotecaria?

23) ¿Se encuentra inscrita/o en el Registro de demandante de vivienda de su ayuntamiento?

\begin{tabular}{|l|l|l|l|}
\hline SI & & NO & \\
\hline
\end{tabular}

En caso de que la respuesta sea negativa puede indicar ¿por qué?

24) ¿Cuál cree que podría ser una solución para no tener que ser desahuciada/o?

MUCHAS GRACIAS POR SU TIEMPO Y SUS RESPUESTAS

Alternativas, 20, 2013, pp. 113-140 - ISSN 1133-0473 - DOI: 10.14198/ALTERN2013.20.07 


\title{
IMPACTO DE LA CRISIS ECONÓMICA Y LOS CAMBIOS EN LAS POLÍTICAS SOCIALES EN EL PERFIL, NECESIDADES Y PRESTACIONES DE LAS PERSONAS USUARIAS DE LOS SERVICIOS SOCIALES MUNICIPALES. ANÁLISIS DE CASO LOCAL EN LA REGIÓN DE MURCIA (ESPAÑA)
}

\author{
Economic crisis impact and social policy changes in the profile, needs \\ and benefits of municipal social services' users. A local case study in the \\ region of Murcia (Spain)
}

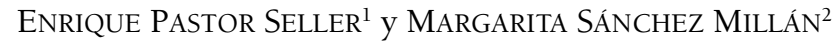

\section{Resumen}

El artículo presenta los resultados de una investigación empírica orientada a conocer y analizar el impacto de la crisis económica y los cambios normativos en las necesidades y prestaciones de las personas usuarias del sistema de servicios sociales de atención primaria. Para su consecución se ha realizado una investigación longitudinal de necesidades y prestaciones en un municipio de la Comarca Oriental de la Región de Murcia durante el período comprendido entre 1996 y 2011, comparando sus resultados con investigaciones similares de ámbito regional y estatal. Así mismo se presenta un análisis transversal (2012) y de tendencias. La metodología empleada se ha basado en la diversidad de técnicas y fuentes de recolección y análisis de datos a partir del análisis del universo de personas usuarias, concretamente 4.562 personas y 3.325 unidades familiares, lo que proporciona a la investigación unos resultados fiables, contrastables y transferibles. Los resultados obtenidos permiten verificar la hipótesis de partida de que los cambios en el perfil de las personas usuarias, las necesidades y los servicios / recursos aplicados por la estructura básica de los servicios sociales municipales están directamente relacionados con las dinámicas de la crisis social y económica y el desarrollo de las políticas/normativas de bienestar social relacionadas directa e indirectamente con los servicios sociales.

Palabras clave: crisis, servicios sociales, políticas sociales, necesidades sociales, bienestar social.

\begin{abstract}
This article presents the results of empirical research with the objective of discovering and analyzing the impact of the economic crisis and regulatory changes in needs and benefits of the primary care social services system users. To this end, a longitudinal study on the needs and benefits in a municipality in the eastern region of Murcia have been conducted from 1996 to 2011, comparing their results with similar regional and state investigations. It also presents a cross-sectional and trends analysis (2012). The methodology used is based on a diversity of techniques, pickup sources and data analysis of the users' universe, specifically 4,562 individuals and 3,325 households, thereby providing a transferable and contrastable reliable research result. The obtained results verify the hypothesis that changes in the profile of the users, needs and services/resources applied by the basic structure of the municipal social services is directly related to the dynamics of social and economic crisis and policy development/welfare regulations related directly and indirectly to social services.
\end{abstract}

Key words: crisis, social services, social policies, social needs, social welfare.

\begin{tabular}{lll}
\hline Recibido: 21/10/2013 & Aceptado: 07/11/2013 & Publicado: 03/12/2013 \\
\hline
\end{tabular}

1. Profesor Titular de Universidad. Decano de la Facultad de Trabajo Social de la Universidad de Murcia. IP Grupo de Investigación Trabajo Social y Servicios Sociales. epastor@um.es

2. Graduada en Trabajo Social y Responsable Servicios Sociales de Beniel (Murcia). 


\section{Introducción}

El Sistema Público de Servicios Sociales en España lo conforman el conjunto de servicios y prestaciones cuya finalidad es la promoción del desarrollo pleno y libre de la persona dentro de la sociedad para la obtención de un mayor bienestar social y mejor calidad de vida, así como la prevención y eliminación de las causas que conducen a la marginación social; estando integrado por todas las estructuras y servicios públicos. Un sistema basado en los principios de universalidad, responsabilidad pública, igualdad, equidad, prevención y dimensión comunitaria, promoción de la autonomía personal, atención personalizada e integral, inserción y normalización, proximidad, solidaridad, calidad, participación y cooperación y colaboración (Ministerio de Sanidad, Servicios Sociales e Igualdad, 2013). Por consiguiente, sus elementos de identidad son: ámbito específico de necesidades sociales de referencia (derechos sociales que garantiza); oferta específica y estructurada de prestaciones sociales; red de equipamientos; normativa, planificación y presupuestos propios.

Son numerosas las definiciones existentes respecto de los servicios sociales de atención primaria, por las distintas leyes autonómicas y autores/as. Sin ser el objeto de este artículo entrar en una disertación al respecto, podemos partir de entenderlos como aquellas estructuras y equipamientos básicos del Sistema Público de Servicios Sociales, diseñados sobre espacios poblacionales dimensionados que garantizan las Prestaciones Básicas del Sistema a los ciudadanos, mediante atenciones de carácter individual, familiar y/o colectivo, a través de recursos propios o como cauce de acceso a otros Servicios Sociales o de Bienestar Social. Se organizan territorialmente por medio de los Centros de Servicios Sociales y unidades zonales, los cuales tienen un carácter universal y polivalente en el ámbito más próximo al ciudadano (ámbito local) y constituyen la estructura básica.

El sistema encuentra su primera referencia en un ámbito específico de necesidades sociales a las que debe dar respuesta: información y orientación sobre el acceso a recursos; convivencia personal y familiar; integración social; cobertura de necesidades básicas y participación social. Para su atención se dota de recursos o prestaciones técnicas, económicas y materiales para la gestión de las prestaciones básicas de información y orientación, apoyo a la unidad convivencial y ayuda a domicilio; alojamiento alternativo, prevención e inserción social y fomento de la solidaridad social y la cooperación social.

La Constitución, a pesar de la indefinición del término servicios sociales, otorga a las Comunidades Autónomas las competencias en materia de servicios sociales, las cuales son asumidas en las Leyes Orgánicas de los Estatutos de las diferentes Comunidades Autónomas y desarrolladas a través de 
las Leyes de Servicios Sociales y de otras vinculadas con la protección social. A partir de 2006 y como consecuencia, fundamentalmente, de la promulgación de la Ley 39/2006, de 14 de diciembre, de Promoción de la Autonomía Personal y Atención a las personas en situación de Dependencia ${ }^{3}$, surgen las denominadas leyes de servicios sociales de «tercera generación $»^{4}$ caracterizadas, entre otras, por: el derecho subjetivo a las prestaciones y servicios; la ampliación y consolidación de derechos y deberes de las personas usuarias; la importancia de la calidad; la introducción del derecho subjetivo y la elaboración de catálogos / carteras de las prestaciones y servicios (Casado, 2010; Pastor 2012a; Vila, 2012). La mencionada Ley ha sufrido recientemente modificaciones ${ }^{5}$ sustanciales $^{6}$ repercutiendo de manera desfavorable en los derechos y prestaciones inicialmente regulados (Ramírez, 2012, García, Barriga, Ramírez y Santos, 2013).

La Ley 7/1985, de 2 de abril, Reguladora de las Bases del Régimen Local ${ }^{7}$, actualmente en proceso de revisión en razón del proyecto de Ley aprobado por el Consejo de Ministros del 22 de febrero de 2013, establece la competencia de los municipios en la prestación de los servicios sociales (arts. $25.2 \mathrm{~K}$

3. Publicada en B.O.E. núm.: 299 de 15 de diciembre de 2006.

4. Ley Foral 15/2006, de 14 de diciembre, de servicios sociales B.O.E. núm.: 27 de 31 de enero. Ley de Cantabria 2/2007, de 27 de marzo de Derechos y Servicios Sociales B.O.C. núm.: 66 de 3 de abril. Ley 12/2007, de 11 de octubre de Cataluña B.O.E. núm.: 266 de 6 de noviembre. Ley 13/2008, de 3 de diciembre, de servicios sociales de Galicia D.O.G. núm.: 245 de 18 de diciembre. Ley 12/2008, de 5 de diciembre, de servicios sociales del País Vasco B.O.P.V. núm: 246 de 24 de diciembre. Ley 4/2009, de 11 de junio, de servicios sociales de las Illes Baleares B.O.B.B núm.: 89 de 18 de junio. Ley 5/2009, de 30 de junio, de servicios sociales de Aragón B.O.A. núm.: 132 de 10 de julio. Ley 7/2009, de 22 de diciembre, de Servicios Sociales de la Rioja B.O.R. .de 28 de diciembre. Ley 14/2010, de 16 de diciembre, de servicios sociales de Castilla-La Mancha B.O.E. núm.: 38 de 14 de febrero de 2011. Ley 16/2010, de 20 de diciembre, de servicios sociales de Castilla y León - B.O.E. núm.: 7 de 8 de enero de 2011. BOCYL. núm.: 244 de 21 de diciembre de 2010 y corrección de errores en BOCYL, núm.: 23 de 3 de febrero de 2011.

5. Modificada por Real Decreto-ley 20/2012, de 30 de diciembre, de medidas urgentes en materia presupuestaria, tributaria y financiera para la corrección del déficit público B.O.E. núm.: de 31 de diciembre de 2011, Real Decreto-ley 20/2012, de 13 de julio, de medidas para garantizar la estabilidad presupuestaria y de fomento de la competitividad - B.O.E. núm.: de 14 de julio de 2012 y la Ley de Presupuestos Generales del Estado.

6. Concretamente en el ámbito de: efectividad del derecho a las prestaciones, régimen de incompatibilidad de las mismas, calendario de protección de grado, reconocimiento de grado, intensidad de protección de los servicios del catálogo, cuantías, retroactividad en la prestación, régimen de los convenios especiales en el sistema de la Seguridad Social de los cuidadores no profesionales, asignación presupuestaria de la Administración General del Estado, entre otras.

7. Modificado por Ley 57/2003, de 16 de diciembre de medidas para la modernización del gobierno local. 
y 26.1.c), regulando la creación de Comarcas u otras entidades que agrupen varios Municipios para la prestación de servicios.

El proyecto de ley de Racionalización y Sostenibilidad de la Administración Local a pesar del enorme rechazo del arco parlamentario político, así como de múltiples y diversos agentes sociales, económicos y sindicales, superó el 18 de octubre de 2013 las enmiendas de devolución al Gobierno continuando así su tramitación de manera ordinaria. En este proyecto de ley se modifica la denominación de «servicios sociales» por «evaluación e información de situaciones de necesidad social y la atención inmediata a personas en situación o riesgo de exclusión social» ( $\operatorname{art}^{\circ}$. 25.2 e del Anteproyecto de Ley), omitiéndose la prevención y la promoción.

La implantación del Plan Concertado para el Desarrollo de Prestaciones Básicas de Servicios Sociales de Corporaciones Locales en 1988 contribuyó a la ampliación de las prestaciones de los servicios sociales municipales y a la progresiva universalización de los servicios sociales de atención primaria en España (Gutiérrez, 2001, Las Heras, 2002, Subirats, 2007, Roldan et. al., 2006, Alemán, 2010) tanto desde una perspectiva territorial municipal como de personas usuarias atendidas (en 2011 se atendieron a 6.930 .978 personas, lo que supone un $15.8 \%$ de la población española), aunque en la actualidad observamos una demolición/degradación del mismo, especialmente desde 2012, atendiendo a su progresiva reducción presupuestaria, la cual para el año 2013 se sitúa en $27.593 .000 €$ representando un $2 \%{ }^{8}$ respecto de la financiación que precisa el sistema.

\section{Material y métodos}

La investigación, cuyos resultados son objeto del presente artículo, analiza de manera sistemática la evolución, estructura y dinámica del sistema de servicios sociales de atención primaria en un municipio rural situado en la Comarca Oriental de la Región de Murcia desde una perspectiva longitudinal (1996-2011), transversal (2012) y de tendencias, contrastando sus resultados con investigaciones similares en el ámbito regional y nacional.

Las unidades de análisis han sido el universo total de ciudadanos del municipio de Beniel que han sido sujetos de atención por parte de los servicios sociales municipales en el periodo comprendido entre 1996 y 2011 y que asciende a 4.562 personas distintas Este dato representa al 40,7 \% de la

8. Supone una disminución de un $58.34 \%$ respecto de 2012 y de un $68 \%$ respecto de 2011 (ver informes recientes en Asociación Estatal de Directoras y Gerentes de Servicios Sociales. http://www.directoressociales.com/index.php Consulta 15/09/2013) 
población actual del municipio, el cual cuenta con 11.198 habitantes (INE 2013) ${ }^{9}$. El conjunto de personas atendidas pertenecen a un total de 3.325 unidades familiares. En la investigación se han analizado las necesidades que han presentado las personas usuarias durante dicho período mencionado, lo que ha supuesto el análisis de 6.035 informes diagnósticos y 8.894 intervenciones sociales profesionales. Por consiguiente, la investigación se vincula con la totalidad del censo, siendo las unidades de análisis tanto las personas usuarias como las unidades familiares, las atenciones recibidas y las respuestas ofrecidas por los servicios sociales municipales a las mismas.

Tabla 1.Distribución relacional de las dimensiones objeto de estudio y sujetos

\begin{tabular}{|l|c|c|c|c|c|}
\hline \multirow{2}{*}{ DIMENSIONES } & \multicolumn{5}{|c|}{ PERSONAS USUARIAS } \\
\cline { 2 - 6 } & $1996-1999$ & $2000-2003$ & $2004-2007$ & $2008-2011$ & TOTAL \\
\hline USUARIOS & $683(15 \%)$ & $814(18 \%)$ & $970(21 \%)$ & $\begin{array}{c}2095 \\
(46 \%)\end{array}$ & $\begin{array}{c}4562 \\
(100 \%)\end{array}$ \\
\hline NECESIDADES & $850(14 \%)$ & $1075(18 \%)$ & $\begin{array}{c}1306 \\
(22 \%)\end{array}$ & $\begin{array}{c}2804 \\
(46 \%)\end{array}$ & $\begin{array}{c}6035 \\
(100 \%)\end{array}$ \\
\hline RECURSOS & $1066(12 \%)$ & $1295(14 \%)$ & $\begin{array}{c}1572 \\
(18 \%)\end{array}$ & $\begin{array}{c}4961 \\
(56 \%)\end{array}$ & $\begin{array}{c}8894 \\
(100 \%)\end{array}$ \\
\hline
\end{tabular}

Fuente: Elaboración propia.

La investigación parte de la hipótesis de que el perfil y necesidades de las personas usuarias y los recursos aplicados a éstas por parte de la estructura básica de los servicios sociales municipales durante los últimos dieciséis años se ha ido modificando en razón del contexto social e institucional, el desarrollo normativo de las políticas sociales y la crisis. Tiene, por tanto, una doble finalidad, conocer la evolución y tendencias del perfil y necesidades de las personas usuarias y analizar las respuestas «dinámicas» institucionales ofrecidas a éstas desde los servicios sociales municipales. Ambos objetivos son vertientes inseparables de una misma línea discursiva y de investigación

9. El municipio de Beniel se encuentra situado al este de la región y forma parte de la denominada Comarca Oriental de la Región de Murcia, cuenta con 11.198 habitantes y una densidad de 1.108,7 habitantes/ $\mathrm{km}^{2}$ (INE 2013). Los servicios sociales se implantaron en 1989, aunque es en 1991 cuando se integra en el Centro de Servicios Sociales de la Comarca citada, la cual desarrolla su acción en cuatro municipios con una población cercana a los 30.000 habitantes. 
analítica al encontrarse dialécticamente relacionadas con los contextos sociales, estructurales e institucionales de cada momento.

Los objetivos especificos que orientaron la investigación, son los siguientes:

1. Caracterizar la evolución del perfil socio demográfico de las personas usuarias.

2. Analizar la evolución de las necesidades sociales de las personas usuarias y de los recursos aplicados.

3. Describir el perfil, necesidades y recursos actuales y su proyección futura en el contexto local de estudio.

Con el fin de dotar a la investigación de un marco ordenado de acercamiento a la realidad objeto de estudio se identificaron como dimensiones de análisis, las siguientes:

- Perfil de los usuarios de los servicios sociales de atención primaria: sexo; edad; nacionalidad y zona de residencia.

- Evolución de las necesidades sociales de las personas usuarias: número - evolución cuatrienal - distribución por tipologías a partir de identificación necesidad principal dictaminada.

- Evolución de los recursos aplicados: número de usuarios que se han beneficiado de prestaciones - evolución cuatrienal - distribución por tipologías.

- Situación actual y percepciones desde sus actores.

- Tendencias percibidas de los servicios sociales desde los actores estratégicos del municipio.

Considerando la amplitud y complejidad del fenómeno a estudiar, se han empleado diversas técnicas de recogida de datos con el fin de incrementar la eficiencia de las mismas, concretamente la ficha social al universo de unidades de análisis y la entrevista en profundidad a informantes estratégicos para el análisis transversal y de proyección/tendencias.

Se ha considerado la ficha social como el instrumento más idóneo como fuente para la recogida de datos al encontrarse validado y disponer de la información fehaciente de todas y cada una de las unidades del universo de análisis, dimensiones y variables objeto de estudio. Ofrece datos uniformes, homogéneos y verificados, por lo que su uso ha permitido cumplir los objetivos de conocimiento con la máxima fiabilidad y validez científica, al utilizar toda la información de dicha fuente y coincidir su objeto con el propio de la presente investigación. Considerando la amplitud temporal (16 años) se ha 
considerado oportuno agrupar los datos por estratos cuatrienales (96-99 / 0003 / 04-07 / 08-11) con el fin de que cada intervalo tenga la misma longitud temporal, siendo, además, una decisión que se vincula con cortes temporales donde acontecen cambios sustanciales en el contexto social y normativo que afecta a las políticas sociales (Ley de Extranjería, Ley de Dependencia, la crisis económica) y, por tanto, vinculado a la hipótesis de estudio.

Por otra parte, las entrevistas en profundidad se han orientado a conocer los aspectos más valorativos y dinámicos tales como la situación actual y tendencias de los servicios sociales (perfil necesidades y recursos) desde los actores estratégicos en dicha área en el municipio. El universo de actores estratégicos vinculados directamente con el área específica de los servicios sociales del municipio ascendía a 13. Con el fin de garantizar la inclusión en la muestra de los diversos elementos de la población (políticos, técnicos y asociativos) en proporciones lo más cercanas posibles a la realidad, el diseño muestral adoptado ha sido el estratégico por cuotas/estratificado atendiendo a las diferentes categorías/características del universo. Concretamente se entrevistó al único responsable político, a 5 técnicos representativos de todas las áreas (servicios sociales generales, especializados e inserción laboral) y 3 asociaciones representativas del sector de iniciativa social (atención general, mujer y personas mayores).

Para el análisis de los datos se utilizó el análisis multivariable y técnicas cuantitativas y comparativas estadísticas descriptivas tales como: tablas de distribución de frecuencias y porcentajes y medidas de tendencia central y de dispersión. Para el análisis de la información reunida por entrevistas en profundidad se utilizaron técnicas cualitativas que han permitido un análisis de contenido mediante la identificación de similitudes y diferencias entre los grupos de interés (entre todos y por categorías).

\section{Resultados}

Durante el periodo comprendido entre 1996-2011 se atendieron a 4.562 personas (distintas) representando al 40,7\% del total de habitantes del municipio (considerando para el ello el dato de población de 2013). Las personas usuarias pertenecen a 3.325 unidades familiares, lo que representa un ratio de 1.4 persona usuaria/familia atendida, mostrándose constante su media en todo el periodo de estudio. El análisis longitudinal nos muestra una desigual distribución temporal destacando que el $46 \%$ de las personas atendidas entre 1996-2011 han sido usuarias entre 2008-2011, incrementándose en 22 puntos respecto del periodo inmediatamente anterior 2004-2007. En igual sentido sucede con las unidades familiares con el $44 \%$ (diferencial del $22 \%$ 
respecto del anterior período). Por otra parte, señalar que en 2011 el número de personas usuarias atendidas ascendió a 961 y conforman un total de 708 unidades familiares, representando al $21 \%$ del total de personas usuarias y unidades familiares atendidas durante el período 1996-2011. Pero si lo relacionamos con respecto al último período comprendido entre 2008-2011 representaría el $46 \%$ y $48 \%$, respectivamente. De esta manera podemos afirmar que el año 2011 representa casi el 50\% de dicho período (4 años) lo que constata la intensidad de personas usuarias y familias atendidas y, por consiguiente, el elevado número de personas en situación de necesidad que empiezan a detectarse a partir de 2011.

Gráfica 1. Distribución de unidades familiares y personas usuarias de Servicios Sociales en el periodo $1996-2011$

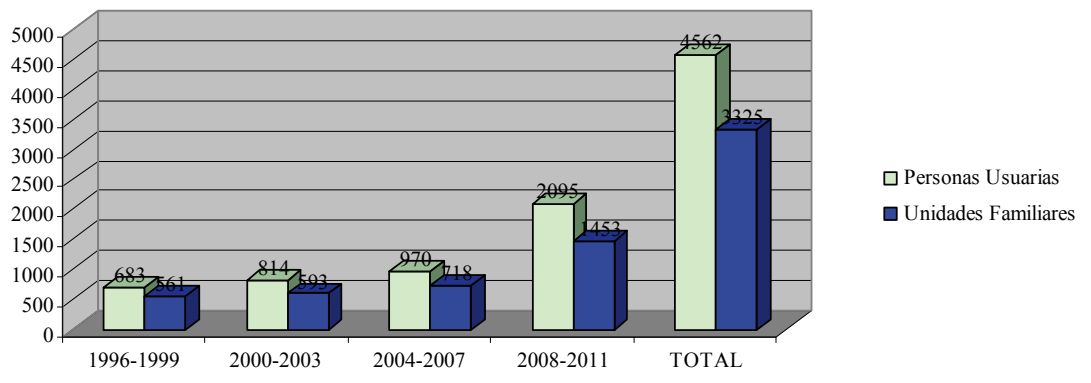

Fuente: Elaboración propia.

\subsection{Perfil de las personas y familias}

El $61 \%$ de las personas atendidas son mujeres y el 39\% son varones; una distribución constante en el periodo de estudio (1996-2011) a excepción del intervalo 2008-2011 donde se observa una reducción del 5\% de mujeres mostrando así un cambio de tendencia en el perfil de género de las personas usuarias de los servicios sociales, aunque muy incipiente. Esta tendencia se encuentra en consonancia con la información procedente de las entrevistas en profundidad que nos informan que es la mujer el sexo predominante como persona usuaria en el presente y en el futuro, pero a su vez existe la percepción de que con mayor frecuencia los hombres se van incorporando como personas usuarias al sistema.

«Mayoritariamente, y en un primer momento, suelen ser mujeres, [...], las que acuden [...], bien con una demanda propia, o de algún miembro de la familia $[\ldots] »(\mathrm{E} 9)$ 
«[... nos encontramos, aunque en menor grado, hombres [...] que han perdido su empleo.» (E7)

En cuanto a la edad el $26 \%$ de las personas beneficiarias se encuentran entre 30-44 años, el 18\% tiene 75 o más años; el 15\% son menores de 14 años o entre 45-59 (cada intervalo); el 14\% entre $15-29$ y el $12 \%$ entre $60-74$. Relacionando este dato con la estratificación de los habitantes del municipio, encontramos similitudes en torno a los grupos de edad, con la excepción de 75 o más años que representa en las personas usuarios el 18\% mientras que supone el $6 \%$ de la población total. Esta dispersión viene determinada porque dicho grupo de edad feminizado se encuentra especialmente vulnerable $y$, por tanto, necesitado de las prestaciones que ofrece el sistema de servicios sociales. Los informantes clave señalan que son las personas en edad adulta (en los tramos comprendidos entre 30 y 60 años) y los jóvenes, los grupos que preferentemente son personas usuarias en la actualidad y en el futuro, debido a las peculiares circunstancias que les afectan. Destaca la coincidencia de los informantes respecto de la percepción de una mayor presencia de los jóvenes como personas usuarias. Este dato es relevante, en tanto en cuanto, es un sector «invisible» en los servicios sociales y que a pesar de ser un colectivo en situaciones de necesidad (altos índices de desempleo y/o precariedad laboral, quiebra económica, etc.) objeto del sistema no acuden al mismo en la misma intensidad.

«Ha aumentado el número de jóvenes que necesitan ayuda.» (E2)

«Además creo que acudirán más jóvenes [...] sin formación académica ni cualificación profesional.» (E8)

En cuanto a la nacionalidad se constata a partir de 2004 que las personas usuarias de nacionalidad española descienden y se incrementa de manera exponencial (cuadruplicado) la población procedente de Marruecos, Ecuador y Ucrania. Pero este dato es relativo, dado que al analizarlo de manera comparativa con el total de población española y extranjera residente en el municipio atendiendo al último Padrón Municipal de Habitantes, se constata que se está atendiendo al 38\% de la población con nacionalidad española y al 37\% de la población con otras nacionalidades, lo que nos lleva a afirmar que el incremento se encuentra directamente relacionado con el universo de residentes y su normalización en el acceso a los servicios sociales.

Por su parte, los informantes clave señalan que son las personas inmigrantes las que fundamentalmente acceden y usan de los servicios sociales municipales tanto en la actualidad como en el futuro.

«Lo que pienso es que son [...] extranjeras [...].» (E3) 
«La población inmigrante tiene una presencia importante.»(E6)

«La diferencia será que vendrán más españolas si sigue la cosa como va.» (E5)

Esta percepción contrasta con los datos objetivos de personas usuarias atendidas al seguir siendo predominante las personas de nacionalidad española frente a las extranjeras.

Como conclusión del perfil de las personas usuarias, las entrevistas en profundidad muestran la coincidencia mayoritaria de que si se mantiene el contexto actual de recesión económica junto a los cambios estructurales previstos desde las distintas administraciones que llevan implícito un descenso en el gasto social se va a producir un cambio en el número y, por tanto, en el perfil de las personas usuarias del sistema, lo que se ha venido a denominar la «democratización de la pobreza».

"Creo que personas que hoy no están en la cola de los servicios sociales tendrán que ir. No se le ve salida a la crisis. [...] Va a haber más pobres.» (E3)

"[...], pero si la situación actual no mejora, es posible que los sectores de población atendidos se amplien a personas y familias que hasta el momento no han sido usuarios de servicios sociales.» (E6)

"Creo que personas que hoy no están en la cola de servicios sociales tendrán que ir.» (E3)

\subsection{Demandas y necesidades sociales}

En el periodo de estudio (1996-2011) el número de personas usuarias que han precisado de un diagnóstico profesional ante situaciones de necesidad ha ascendido a 6.035 (1,32 diagnóstico/usuario/a). Se constata que entre 20082011 se produce la mayor concentración de las necesidades $(46,5 \%)$ de todo el período.

Durante todo el período el 33\% de las personas usuarias atendidas han presentado una necesidad principal relacionada con el sector de referencia de personas mayores, seguido del 30\% de personas con discapacidad, el 14\% familia, el 10\% inmigrantes y el 5\% mujer. Del análisis longitudinal comprobamos que el sector de personas con discapacidad se incrementa significativamente en el período 2000-2003, el de personas mayores entre 20042007 y el de inmigrantes 2008-2011, situándose este último en tercer lugar en 2008-2011, inmediatamente después de las personas con discapacidad. Este especial incremento de las necesidades vinculadas con la migración marca una tendencia en sintonía con el perfil analizado anteriormente. Asimismo constatar que el incremento de necesidades vinculadas con las personas con discapacidad en 2000-2003 coincide con la implantación, entre otras, de la 
Tabla 2. Distribución de personas usuarias según sector de referencia en el periodo $1996-2011$

\begin{tabular}{|c|c|c|c|c|c|}
\hline \multirow{2}{*}{$\begin{array}{c}\text { SECTOR DE } \\
\text { REFERENCIA }\end{array}$} & \multicolumn{5}{|c|}{ PERSONAS USUARIAS } \\
\hline & 1996-1999 & $2000-2003$ & 2004-2007 & $2008-2011$ & TOTAL \\
\hline Familia & $159(23,4 \%)$ & $133(16,3 \%)$ & $90(9,3 \%)$ & $253(12,1 \%)$ & $635(13,9 \%)$ \\
\hline Infancia & $19(2,8 \%)$ & $92(11,3 \%)$ & $64(6,6 \%)$ & $30(1,4 \%)$ & $205(4,5 \%)$ \\
\hline Juventud & $0(0,0 \%)$ & $5(0,6 \%)$ & $1(0,1 \%)$ & $14(0,7 \%)$ & $20(0,4 \%)$ \\
\hline Mujer & $13(1,9 \%)$ & $39(4,8 \%)$ & $31(3,2 \%)$ & $134(6,4 \%)$ & $217(4,8 \%)$ \\
\hline Personas mayores & $194(28,5 \%)$ & $168(20,6 \%)$ & $411(42,4 \%)$ & $725(34,6 \%)$ & $1498(32,8 \%)$ \\
\hline Personas discapacidad & $241(35,3 \%)$ & $341(41,9 \%)$ & $338(34,8 \%)$ & $466(22,3 \%)$ & $1386(30,4 \%)$ \\
\hline $\begin{array}{l}\text { Reclusos y ex- } \\
\text { reclusos }\end{array}$ & $1(0,1 \%)$ & $1(0,1 \%)$ & $1(0,1 \%)$ & $2(0,1 \%)$ & $5(0,1 \%)$ \\
\hline Minorías étnicas & $2(0,3 \%)$ & $0(0,0 \%)$ & $1(0,1 \%)$ & $1(0,0 \%)$ & $4(0,1 \%)$ \\
\hline $\begin{array}{l}\text { Marginados/ } \\
\text { transeúntes }\end{array}$ & $26(3,8 \%)$ & $15(1,9 \%)$ & $0(0,0 \%)$ & $0(0,0 \%)$ & $41(1,0 \%)$ \\
\hline Toxicómanos & $7(1,0 \%)$ & $10(1,2 \%)$ & $6(0,6 \%)$ & $4(0,2 \%)$ & $27(0,6 \%)$ \\
\hline Refugiados y asilados & $1(0,1 \%)$ & $0(0,0 \%)$ & $0(0,0 \%)$ & $0(0,0 \%)$ & $1(0,0 \%)$ \\
\hline Emigrantes & $1(0,1 \%)$ & $1(0,1 \%)$ & $1(0,1 \%)$ & $1(0,0 \%)$ & $4(0,1 \%)$ \\
\hline Enfermos mentales & $1(0,1 \%)$ & $1(0,1 \%)$ & $0(0,0 \%)$ & $0(0,0 \%)$ & $2(0,0 \%)$ \\
\hline Enfermos terminales & $1(0,1 \%)$ & $2(0,3 \%)$ & $1(0,1 \%)$ & $0(0,0 \%)$ & $4(0,1 \%)$ \\
\hline Otros & $17(2,5 \%)$ & $4(0,5 \%)$ & $1(0,1 \%)$ & $11(0,5 \%)$ & $33(0,7 \%)$ \\
\hline Inmigrantes & $0(0,0 \%)$ & $2(0,3 \%)$ & $24(2,5 \%)$ & $454(21,7 \%)$ & $480(10,5 \%)$ \\
\hline TOTAL & $683(100 \%)$ & $814(100 \%)$ & $970(100 \%)$ & $2095(100 \%)$ & $4562(100 \%)$ \\
\hline
\end{tabular}

Fuente: Elaboración propia.

prestación familiar por hijo a cargo y el incremento relacionado con personas mayores en el período 2004-2007 (duplicado) está relacionado con la implantación de la Ley 39/2006.

En cuanto a tendencias, la información obtenida de las entrevistas en profundidad es la relativa a la incorporación al sistema de nuevas personas usuarias en situación de necesidad social que precisen por primera vez de una intervención profesional de los servicios sociales, procedentes de los sectores de población de personas mayores, jóvenes e inmigrantes.

«[...] se incorporarán como colectivo los pensionistas que cobran pensión y que por la situación del pago de medicamentos y de las subidas, en general, necesitarán ayuda económica de los servicios sociales.» (E3)

«[...] en los próximos dos años los sectores de población que se verán más afectados serán juventud, debido a la dificultad para encontrar un primer empleo, así como los inmigrantes [...] algunos trabajan sin contrato y no podrán pedir prestación por desempleo [...].» (E4) 
Atendiendo a la categorización de necesidades el 68\% de las personas usuarias atendidas han presentado una necesidad relacionada con una adecuada información sobre el acceso a recursos, el 17\% con una adecuada convivencia personal, el $9 \%$ falta de medios para la cobertura de las necesidades básicas y el $6 \%$ restante con integración social.

Tabla 3. Distribución de personas usuarias según necesidades sociales en el periodo $1996-2011$

\begin{tabular}{|c|c|c|c|c|c|}
\hline \multirow[t]{2}{*}{ NECESIDADES } & \multicolumn{5}{|c|}{ PERSONAS USUARIAS } \\
\hline & 1996-1999 & $2000-2003$ & $2004-2007$ & $2008-2011$ & TOTAL \\
\hline $\begin{array}{l}\text { Información sobre el } \\
\text { acceso a recursos }\end{array}$ & $678(79,8 \%)$ & $767(71,3 \%)$ & $742(56,8 \%)$ & $1894(67,5 \%)$ & $4081(67,6 \%)$ \\
\hline $\begin{array}{l}\text { Adecuada } \\
\text { convivencia } \\
\text { personal / familiar }\end{array}$ & $89(10,5 \%)$ & $185(17,2 \%)$ & $393(30,1 \%)$ & $345(12,3 \%)$ & $1012(16,8 \%)$ \\
\hline Integración social & $58(6,8 \%)$ & $45(4,2 \%)$ & $46(3,5 \%)$ & $212(7,6 \%)$ & $361(6,0 \%)$ \\
\hline $\begin{array}{l}\text { Falta de medios para } \\
\text { cubrir nec. básicas }\end{array}$ & $25(2,9 \%)$ & $78(7,3 \%)$ & $125(9,6 \%)$ & $353(12,6 \%)$ & $581(9,6 \%)$ \\
\hline TOTAL & $850(100 \%)$ & $1075(100 \%)$ & $1306(100 \%)$ & $2804(100 \%)$ & $6035(100 \%)$ \\
\hline
\end{tabular}

Fuente: Elaboración propia.

Tal y como se constata las necesidades relacionadas con la falta de medios para la cobertura de las necesidades básicas y de integración social son las que se sitúan por encima de la media en el período comprendido entre 2008-2011, en consonancia con las dificultades económicas que atraviesan las personas y familias a raíz de la crisis económica y financiera y que precisan de la atención de los servicios sociales. Este incremento en dichas necesidades se relaciona, a su vez, con el incremento de las situaciones de desempleo, quiebra económica e incremento de la exclusión social (Pastor, 2013), entre otros.

En cuanto a la evolución de las necesidades sociales de manera más específica el 54\% de las personas usuarias atendidas han presentado una necesidad relacionada con información sobre el acceso a recursos del sistema de servicios sociales, el 14\% con otros sistemas, el 10\% con una adecuada convivencia personal/familiar motivada por desajustes convivenciales; el 9,4\% ante la falta de medios para la cobertura de las necesidades básicas y el 7\% por limitación de autonomía personal y/o situaciones de dependencia.

Respecto a las necesidades específicas se vuelve a constatar que son las necesidades relacionadas con la falta de medios para la cobertura de las necesidades básicas y de integración social, laboral y escolar las que se sitúan por encima de la media en el período 2008-2011, destacando, de un análisis 
más desagregado, que las necesidades de integración escolar se incrementan especialmente a partir de 2004 motivado, entre otros, por las reagrupaciones familiares.

Tabla 4. Distribución personas usuarias según necesidades sociales específicas en el periodo $1996-2011$.

\begin{tabular}{|c|c|c|c|c|c|}
\hline \multirow[t]{2}{*}{ NECESIDADES } & \multicolumn{5}{|c|}{ PERSONAS USUARIAS } \\
\hline & 1996-1999 & 2000-2003 & 2004-2007 & $2008-2011$ & TOTAL \\
\hline $\begin{array}{l}\text { Información para } \\
\text { acceso al Sistema de } \\
\text { SS. SS. }\end{array}$ & $455(53,6 \%)$ & $579(53,9 \%)$ & $639(48,9 \%)$ & $1576(56,2 \%)$ & $3249(53,8 \%)$ \\
\hline $\begin{array}{l}\text { Información otros } \\
\text { Sist. Protección } \\
\text { Social }\end{array}$ & $223(26,2 \%)$ & $188(17,5 \%)$ & $103(7,9 \%)$ & $318(11,3 \%)$ & $832(13.8 \%)$ \\
\hline $\begin{array}{l}\text { Adecuada } \\
\text { convivencia } \\
\text { familiar: desajustes }\end{array}$ & $47(5,5 \%)$ & $98(9,1 \%)$ & $187(14,3 \%)$ & $245(8,8 \%)$ & $577(9,6 \%)$ \\
\hline $\begin{array}{l}\text { Adecuada } \\
\text { convivencia: } \\
\text { (limitación } \\
\text { autonomía personal/ } \\
\text { dependencia)) }\end{array}$ & $42(5,0 \%)$ & $878,1 \%)$ & $206(15,8 \%)$ & $100(3,5 \%)$ & $435(7,2 \%)$ \\
\hline Integración social & $52(6,1 \%)$ & $33(3,1 \%)$ & $20(1,6 \%)$ & $159(5,7 \%)$ & $264(4,4 \%)$ \\
\hline Integración laboral & $4(0,5 \%)$ & $4(0,3 \%)$ & $7(0,5 \%)$ & $21(0,8 \%)$ & $36(0,6 \%)$ \\
\hline Integración escolar & $2(0,2 \%)$ & $8(0,8 \%)$ & $19(1,5 \%)$ & $32(1,1 \%)$ & $61(1,0 \%)$ \\
\hline $\begin{array}{l}\text { Falta de medios } \\
\text { para cobertura nec. } \\
\text { básicas }\end{array}$ & $23(2,7 \%)$ & $71(6,6 \%)$ & $123(9,4 \%)$ & $353(12,6 \%)$ & $570(9,4 \%)$ \\
\hline $\begin{array}{l}\text { Falta de medios por } \\
\text { emergencias }\end{array}$ & $2(0,2 \%)$ & $7(0,6 \%)$ & $2(0,1 \%)$ & $0(0,0 \%)$ & $11(0,2 \%)$ \\
\hline TOTAL & $850(100 \%)$ & $1075(100 \%)$ & $1306(100 \%)$ & $2804(100 \%)$ & $6035(100 \%)$ \\
\hline
\end{tabular}

Fuente: Elaboración propia.

Los informantes clave identifican como principales las necesidades relacionadas con: falta de recursos propios para cobertura de necesidades básicas (fundamentalmente recursos económicos), adecuada convivencia personal/ familiar (principalmente situaciones de dependencia) e integración (fundamentalmente laboral).

«En la actualidad, las familias y la población en general del municipio están teniendo serias dificultades para la cobertura de necesidades básicas de sus miembros y, sobre todo, de los menores.» (E7) 
«En general, la mayor parte de las personas que acuden a servicios sociales demandan ayudas económicas, dada la situación actual y poder hablar con la profesional de su situación.» (E6)

\subsection{Beneficios / recursos / sistema de respuestas a las necesidades sociales}

Durante el periodo de referencia del estudio se ha aplicado un total de 8.894 recursos/prestaciones, constatándose que en el intervalo 2008-2011 se concentra la aplicación de los recursos (56\%) de todo el período, ascendiendo a un ratio de 2.4 recurso aplicado/usuario/a. Al analizar el año 2011 se constata que la proporción aplicada de recurso/usuario se reduce en 0.6 puntos de la media en el periodo 2008-2011 (1.75), lo que confirma una reducción de los recursos disponibles / aplicados en el sistema de servicios sociales en sintonía con el progresivo recorte en los servicios sociales en España. En igual sentido se manifiestan a su vez los informantes clave.

«[...] tenemos serias dificultades para articular recursos sociales que palien esas carencias y dificultades, sobre todo si nos referimos a prestaciones de tipo económico.» (E7)

"[...] ha habido recortes importantes en materia de recursos sociales.» (E1)

«Supongo que las situaciones de crisis [...] harán que se produzca una sobrecarga en el sistema de servicios sociales, habiendo una mayor demanda [... y si se mantiene la tónica general de un recorte en servicios, se acabará dejando a la UTS como gestora de recursos sin posibilidad real de intervención.» (E9)

«La situación actual no da garantías de mantener las coberturas actuales» (E6)

Como se muestra en la siguiente tabla (5), en el periodo 1996-2011, el 40,3 $\%$ de los recursos aplicados son prestaciones de información, orientación, valoración y movilización; el 26,1 \% de apoyo a la unidad convivencial y ayuda a domicilio, el $19,4 \%$ son recursos complementarios para la cobertura de necesidades básicas y el 13,5 \% de prevención e inserción social. Destacar que las prestaciones relacionadas con el alojamiento alternativo en todo el período no alcanzan el $1 \%$.

Las prestaciones de prevención e inserción social y de apoyo a la unidad convivencial son las que se sitúan por encima de la media en el periodo 2008-2011, llegando a duplicarse en el primer caso. Contrasta la disminución de casi un $50 \%$ entre la media del período total y la del comprendido entre 2008-2011 de las prestaciones relacionadas con la cobertura de necesidades básicas cuando anteriormente hemos constatado que dichas necesidades han aumentado en ese mismo periodo en un tercio. De esta manera podemos afirmar que las necesidades de cobertura de necesidades básicas 
Tabla 5. Distribución personas usuarias según prestaciones básicas en periodo 1996- 2011

\begin{tabular}{|l|r|r|r|r|r|}
\hline \multirow{2}{*}{ PRESTACIONES } & \multicolumn{5}{|c|}{ PERSONAS USUARIAS } \\
\cline { 2 - 6 } & $1996-1999$ & $2000-2003$ & $2004-2007$ & \multicolumn{1}{|c|}{$2008-2011$} & \multicolumn{1}{c|}{ TOTAL } \\
\hline $\begin{array}{l}\text { Información/ } \\
\text { orientación/ } \\
\text { valoración/ } \\
\text { movilización. }\end{array}$ & $560(52,5 \%)$ & $509(39,3 \%)$ & $633(40,3 \%)$ & $1883(38,0 \%)$ & $3585(40,3 \%)$ \\
\hline $\begin{array}{l}\text { Apoyo a unidad } \\
\text { convivencial / ayuda } \\
\text { a dom. }\end{array}$ & $105(9,8 \%)$ & $298(23,0 \%)$ & $548(34,9 \%)$ & $1371(27,6 \%)$ & $2322(26,1 \%)$ \\
\hline $\begin{array}{l}\text { Actuaciones y } \\
\text { medidas alojamiento } \\
\text { alternativo }\end{array}$ & $6(0,6 \%)$ & $13(1,0 \%)$ & $29(1,8 \%)$ & $11(0,2 \%)$ & $59(0,7 \%)$ \\
\hline $\begin{array}{l}\text { Prevención e } \\
\text { inserción social }\end{array}$ & $8(0,8 \%)$ & $12(0,9 \%)$ & $15(0,9 \%)$ & $1164(23,5 \%)$ & $1199(13,5 \%)$ \\
\hline $\begin{array}{l}\text { Recursos compl. } \\
\text { para cobertura nec. } \\
\text { básicas }\end{array}$ & $387(36,3 \%)$ & $463(35,8 \%)$ & $347(22,1 \%)$ & $532(10,7 \%)$ & $1729(19,4 \%)$ \\
\hline TOTAL & $1066(100 \%)$ & $1295(100 \%)$ & $1572(100 \%)$ & $4961(100 \%)$ & $8894(100 \%)$ \\
\hline
\end{tabular}

Fuente: Elaboración propia.

no encuentran una respuesta en cuanto a aplicación de recursos vinculados a dichas necesidades.

De un análisis más desagregado y en cuanto a las prestaciones de información, orientación, valoración y movilización se refiere, el 63\% de las personas usuarias han sido beneficiarias de la prestación de información y orientación de recursos del sistema de servicios sociales y el 37\% de otros sistemas de protección. Así mismo, en el análisis longitudinal se comprueba que mientras la información y orientación sobre reconocimiento del grado de discapacidad se incrementa a lo largo del período, la información sobre prestaciones económicas de la Comunidad Autónoma y de pensiones no contributivas sufre un progresivo descenso desde 2004.

Por otra parte, a lo largo de todo el periodo, el 26,1\% de las personas usuarias del sistema han sido beneficiarias de la prestación de apoyo a la unidad convivencial y ayuda a domicilio, aunque la entrada en vigor de la Ley 39/2006 incide directamente en los recursos que contiene esta prestación. Cabe destacar que del análisis longitudinal se constata un incremento de las actuaciones de inserción social a partir de 2011, con lo que se constata, de nuevo, el incremento de situaciones de dificultad social que precisan de la valoración e intervención profesional orientada a la integración/inserción social, 
situación en sintonía con el contexto actual de exclusión social como muestran diferentes estudios (Amnistía Internacional, 2011; Laparra y Pérez, 2011; García y Ramírez, 2012, FOESSA, 2013, García, Barriga, Ramírez y Santos, 2013). En igual sentido se manifiestan los informantes clave, que destacan como importantes ahora y en el futuro los recursos destinados a la inserción laboral y prevén un incremento en las personas beneficiarias de los mismos.

«Debido a la falta de empleo las personas necesitarán más recursos a nivel de inserción y formación laboral.» (E4)

\section{Discusión}

Los resultados del trabajo empírico realizado constatan la hipótesis que ha orientado la investigación, concretamente, que la evolución y tendencias del perfil y necesidades de las personas usuarias y las respuestas institucionales actuales y futuras de la estructura básica de los servicios sociales en el municipio se han ido modificando en razón del contexto social e institucional y del desarrollo normativo de las políticas sociales vinculadas a los servicios sociales, con un claro impacto de la crisis y los recortes en el sistema y las personas.

La investigación muestra que el número de personas que precisan de la atención y prestaciones de los servicios sociales ha ido ascendiendo progresivamente, constatándose un incremento exponencial a partir de la crisis económica. Así solo en un año, concretamente en el 2011 se atendió a un 21\% del total de personas usuarias atendidas en 16 años y al 50\% de los últimos 4 años. Este dato es representativo de la repercusión que ha tenido la crisis en la ciudadanía del municipio, pero esta realidad no es particular, todo lo contrario, se trata de una situación que está sucediendo en los servicios sociales en el contexto nacional conforme a los estudios específicos sobre la materia (Lima, 2011; Barriga, 2012; Gallego y Subirats, 2012; Gustavo y Ramírez, 2012; Roldan y Castañer, 2012; Pastor, 2012a; Asociación de Directores y Gerentes de Servicios Sociales, 2012; Alguacil, 2012; Fundación FOESSA, 2013, García, Barriga, Ramírez y Santos, 2013). De esta manera, se constata que el incremento de personas usuarias ha aumentado a consecuencia y en consonancia temporal a la crisis económica y financiera.

El perfil de las personas usuarias se caracteriza por ser mayoritariamente mujer, de nacionalidad española, residente en el casco urbano y en edades comprendidas entre 30 y 60 años. Un perfil que lejos de ser estático se nos muestra dinámico y cambiante con una tendencia a una progresiva, aunque lenta, equiparación de género (López, 2012) en el acceso, uso y disfrute de las prestaciones sociales y que encuentra múltiples causas, entre otras, en el incremento en el número de personas inmigrantes (mayoritariamente hombres) 
usuarias y el aumento de hombres que precisan, en ambos casos, atención personalizada para la resolución de los problemas que les afecta directamente (desempleo, cobertura necesidades básicas, etc.). Además de estos factores debemos añadir que los hombres se han visto más afectados por las situaciones de desempleo que las mujeres, por lo que son ellos los que deben acudir a los servicios sociales para solicitar las prestaciones y ayudas que precisa la unidad convivencial al encontrarse la mujer trabajando. De manera más particular, las características del empleo femenino en el municipio (industria agroalimentaria) se ha visto menos afectado por la situación de crisis por lo que sus ingresos han pasado de ser subsidiarios a ser principales, siendo el hombre el que debe ocuparse de algunas tareas tradicionalmente vinculadas a las mujeres como es el de acudir a los servicios sociales. Por otra parte y como se ha señalado anteriormente, la progresiva normalización de los servicios sociales contribuye a que éstos no sean percibidos como «degradantes», «vergonzosos» o «marginales» para quien los «usa» sino como un recurso más del municipio al que cualquier ciudadano puede acudir ante situaciones concretas. Este cambio de imaginario incide en que progresivamente el hombre se convierta en persona usuaria. No debemos olvidar que, habitualmente, la persona usuaria es únicamente aquella que presenta una necesidad social y que en muchas ocasiones dicha situación de dificultad no se vincula directamente con ella individualmente, sino con la unidad familiar o incluso con algún miembro distinto del que accede como usuario/a y, en cualquier caso, siempre con efectos en la unidad convivencial.

La investigación también nos muestra que el número de necesidades presentadas ha ascendido de manera diferencial a partir de la crisis económica, donde se constata un aumento sustancial. Pero profundizando en el ámbito de las necesidades, comprobamos que la necesidad principal que motiva la intervención se ha ido modificando en el tiempo. Las personas inmigrantes, mayores y discapacitados son los sectores de referencia que han orientado mayoritariamente y de manera constante el diagnóstico y la intervención de los servicios sociales, variando en el tiempo su prelación. Los datos señalan, que las personas inmigrantes son el colectivo fundamentalmente afectado y precisado de los servicios sociales, lo que se relaciona con el actual contexto, dado que son los que están sufriendo con mayor intensidad los efectos de la crisis económica al encontrarse en situaciones previas de mayor vulnerabilidad (precariedad laboral, insuficientes apoyos familiares, déficits en hábitat, ingresos inestables, etc.) y en las fronteras de los sistemas de protección social.

En la actual situación de crisis económica y progresiva descapitalización de los sistemas de protección, las personas situadas en los márgenes se 
encuentran abocadas al abismo de la pobreza, la exclusión y la desprotección social. Esta situación se constata, a su vez, al comprobar que son las necesidades relacionadas con la falta de medios para la cobertura de las necesidades básicas y de integración social las fundamentales en la actualidad; acordes al incremento de las situaciones de desempleo, quiebra económica de las personas y exclusión social. Por otra parte, el análisis longitudinal del sector de referencia nos muestra, además, una relación directa de éste respecto de la implantación de servicios y prestaciones dirigidas a los mismos, lo que constata su relación con el desarrollo normativo.

Se constata que en el actual contexto de crisis se ha producido un progresivo descenso en la oferta de prestaciones que se ofrecen de manera efectiva a las personas usuarias. Las demandas relacionadas con prestaciones de prevención e inserción social y de cobertura de necesidades básicas son las que han sufrido un considerable incremento en la actualidad en coherencia con la actual situación de crisis. Tanto las prestaciones de carácter técnico como económico se han visto sustancialmente mermadas.

La crisis se encuentra afectando doblemente a las personas, por una parte, al encontrarse en situaciones de exclusión y, por otra, al no disponer de políticas de protección ante tales situaciones, lo que ocasiona situaciones de «abismo»y «violencia estructural». Por tanto, nos encontramos con un sistema dotado de capital humano pero infradotado en la actualidad en relación a las necesidades sociales actuales y futuras. Esta situación de descapitalización del sistema público y de aumento galopante de necesidades está ocasionando que el sistema deba acudir a la iniciativa de organizaciones no gubernamentales para conseguir que las personas puedan cubrir sus necesidades de subsistencia más básicas a través de prestaciones en especie, lo que nos vincula con escenarios de graciabilidad, asistencialismo, caridad, limosna, etc. que creíamos superados. Esta situación revela un sistema que se va debilitando muy rápidamente por los recortes del gasto público y que éstos afectan muy negativamente al desarrollo de los servicios sociales, poniendo en riesgo la sostenibilidad del sistema.

Pero esta situación no solo afecta al sistema de servicios sociales del municipio sino que se vincula a un contexto de degradación del sistema público de servicios sociales de la misma Comunidad Autónoma de la Región de Murcia. Así, los dos últimos Informes sobre Desarrollo de Servicios Sociales (García y Ramírez, 2012 y García, Barriga, Ramírez y Santos, 2013) señalan que ésta ocupa la posición número 14 (respecto de las 17 comunidades autónomas) en el desarrollo de los servicios sociales, con una calificación de «irrelevantes» y una puntuación global de 3.6 (2012) y 2.8 (2013) sobre 10. 
Entre los indicadores resaltar: falta de un catálogo de derechos, carencia de instrumentos de planificación y ordenación del sector, gasto por habitante inferior a la media nacional, etc. Esta situación de marcada debilidad del sistema regional de servicios sociales nos sitúa en una situación muy precaria en un contexto de recortes del gasto público en los sistemas de protección social en general y de los servicios sociales en particular.

Pero lejos de cifras, lo cierto es que la inadecuada/insuficiente satisfacción de las necesidades presentes redundará de manera negativa en la calidad de vida de las generaciones futuras y repercutirá en el propio desarrollo social del territorio y del sistema de servicios sociales. Analizando la aplicación de las prestaciones en el tiempo se vuelve a constatar que se encuentra estrechamente vinculado con la implantación especifica de las mismas y los sectores de población destinatarios; siendo especialmente significativo lo relacionado con el Sistema para la Autonomía y Atención a la Dependencia. Estas prestaciones han experimentado un crecimiento al mismo tiempo que han sufrido un decrecimiento las pertenecientes al propio sistema de servicios sociales. Se constata, al igual que en los estudios relativos a la aplicación de la Ley 39/2006, de Promoción de la Autonomía Personal y Atención a las personas en situación de dependencia (Rodríguez, 2011; Asociación Estatal de Directores y Gerentes de Servicios Sociales, 2012; Observatorio de la Dependencia, Ramírez, 2012) que la mayor parte de los recursos aplicados del sistema corresponden a la prestación económica de cuidados en el entorno en detrimento de los servicios de ayuda a domicilio y/o residenciales; siendo una tónica general en la aplicación de la citada ley. En este sentido, los cambios introducidos por leyes de índole presupuestaria en los dos último años (2012 y 2013) están incidiendo directamente en la mencionada Ley y está repercutiendo directamente en las economías familiares.

En resumen, los resultados de la investigación constatan la hipótesis de partida y se confirma que la evolución y tendencias del perfil y necesidades de las personas usuarias y las respuestas institucionales actuales y futuras de la estructura básica de los Servicios Sociales en el municipio se ha ido modificando en razón del contexto social e institucional y del desarrollo normativo de las políticas sociales vinculadas a los servicios sociales.

Por ello y ante la actual situación de crisis y de recortes del gasto público es preciso revitalizar el sistema mediante una promulgación de una ley de servicios sociales que otorgue derechos de ciudadanía-subjetivos; luchar por mantener e incrementar el esfuerzo presupuestario, incrementar la cobertura y cuantía de las prestaciones vinculadas con la cobertura de las necesidades básicas. En el ámbito local dichas propuestas son también de aplicación en 
su micro-desarrollo y en la propia organización más eficiente de los escasos recursos existentes.

\section{Bibliografía}

Alemán, C. (2010). Fundamentos de Servicios Sociales. Valencia: Tirant Lo Blanch AlguACIL, J. (2012). La quiebra del incompleto sistema de Servicios Sociales en España. Cuadernos de Trabajo Social, 25 (1), 63-74

Amnistía Internacional (2011). Derechos a la intemperie. Obstáculos para hacer valer los derechos económicos, sociales y culturales en España. Madrid: Amnistía Internacional

Asociación Estatal de Directores y Gerentes de Servicios Sociales (2012). Informe sobre el Estado Social de la Nación. Asociación Estatal de Directores y Gerentes de Servicios Sociales. Madrid: Roneo. (http://www.directoressociales.com/ documentos/novedades-en-discusi\%C3\%B3n.html Consultado 30/11/2012)

BARRIGA, L. (2012). La protección a las situaciones de quiebra económica de particulares. Un desafío para los Servicios Sociales en España. AZARBE Revista Internacional de Trabajo Social y Bienestar, 1, 21-38

CASAdo, D. (Coord.) (2010). Leyes de Servicios Sociales del siglo XXI. Cáritas. Fundación Fomento de Estudios Sociales y de Sociología Aplicada FOESSA.

Fundación FOESSA (2013): Desigualdad y derechos sociales. Análisis y perspectivas. Cáritas. http://www.caritas.es/noticias_tags_noticiaInfo.aspx?Id=6475

GAllEGO, R. y SubiRATS, J. (2011). Autonomies i desigualtatas a Espanya: percepcions, evolució social i politiques de benestar. (Con)textos. Barcelona: Institut d’Estudis Autonómics. Generalitat de Catalunya.

García, G. y RAmírez, J.M. (2012). Índice de desarrollo de los Servicios Sociales 2012. Asociación Estatal de Directores y Gerentes de Servicios Sociales. Madrid. Roneo. http://www.directoressociales.com/documentos/novedades-endiscusi\%C3\%B3n.html (Consultado 30/11/2012)

García, G., Barriga, L, Ramírez, J.M. y SAntos, J. (2013). Índice de desarrollo de los Servicios Sociales 2013. Asociación Estatal de Directores y Gerentes de Servicios Sociales. Madrid. Roneo. http://www.directoressociales.com/documentos/novedades-en-discusi\%C3\%B3n.html (Consultado 30/09/2013)

Gutiérrez, A. (2001). El Plan Concertado de prestaciones básicas de Servicios Sociales en España (once años del Plan Concertado). REIS, 93, 89-130

LAPARRA, M. y PÉREZ, B. (2011). El primer impacto de la crisis en la cohesión social en España. Madrid: Fundación FOESSA

Las Heras, M. P. (2002). El Sistema Público de Servicios Sociales: contribución del Trabajo Social, desafíos, oportunidades y estrategias. Revista Trabajo Social Hoy Monográfico, 9-80. 
LiMA, A. I. (2012) Trabajo social, nuevos contexto, nuevos compromisos. AZARBE Revista Internacional de Trabajo Social y Bienestar, 1, 73-86.

LÓPEZ, A. (2012). Jóvenes y Trabajo Social. Revista de Estudios de Juventud. Madrid: INJUVE. Ministerio de Sanidad, Servicios Sociales e Igualdad.

Ministerio de Sanidad, Servicios Sociales e Igualdad (2013): Catalogo de referencia de Servicios Sociales. Roneo. http://www.msc.es//ssi/familiasInfancia/ inclusionSocial/serviciosSociales/Catalogo_Servicios_Sociales/docs/Catalogo_SSSS.pdf (Consultado 30/07/2013)

PASTOR, E. (2011): Impact, effectiveness and sustainability of social policies and local democracy through the social involvement. Revista de Cercetare si Interventie Sociala (RCIS), 35, 7- 27.

- (2012a). Gobernanza de los Servicios Sociales municipales: dar voz y salida a las aspiraciones ciudadanas. Cuadernos de Trabajo Social, 25(1),143-148

- (2012b). Trabajo social, capital social, inteligencia cooperativa y diálogo significante en el ámbito local. Portularia, 12, 91-99

RAmíREZ, J. M. (2012). Informe de evaluación de la Ley de Dependencia. Una mirada a la realidad de la Región de Murcia. AZARBE Revista Internacional de Trabajo Social y Bienestar, 1, 97-109

RodríGuez, C. G. (2011). Políticas de atención a la dependencia en los regímenes de bienestar de la Unión Europea. Ponencia presentada en el Encuentro de Intervención y Políticas Sociales de Caja Madrid y X Jornadas de SIPOSO: Protección a la dependencia y leyes de servicios sociales del siglo XXI. Madrid, 3 de junio de 2011. Roneo

Roldán, E. y García, T. (2006). Políticas de Servicios Sociales. Madrid: SINTESIS

Roldán, E. y CASTAÑar, M. (2012). Servicios Sociales en tiempos de crisis. Cuadernos de Trabajo Social, 25 (1), 13-17

Subirats, J. (Dir.) (2007). Los Servicios Sociales de Atención Primaria ante el cambio social. Madrid: Ministerio de Trabajo y Asuntos Sociales

VILÀ, A. (2012). La nueva generación de leyes autonómicas de servicios sociales (2006-2011): análisis comparativo. AZARBE Revista Internacional de Trabajo Social y Bienestar, 1, 143-157. 



\title{
APLICACIÓN DEL SISTEMA DE PROMOCIÓN DE LA AUTONOMÍA PERSONAL Y ATENCIÓN A PERSONAS EN SITUACIÓN DE DEPENDENCIA EN LA COMUNITAT VALENCIANA: EFECTOS SOBRE EL EJERCICIO DEL DERECHO SOCIAL
}

\author{
Promotional implementation of the personal autonomy and care for \\ dependent situations in the Valencian Community: effects on the exercise \\ of the social right
}

CARMEN MONTALBÁ OCAÑA ${ }^{1}$

\section{Resumen}

Este artículo presenta el estudio de caso realizado sobre el ciclo de vida de la Ley de Promoción de la autonomía personal y atención a situaciones de dependencia (LAPAD) en la Comunitat Valenciana durante el periodo 2006-2012.

El objetivo de esta investigación ha sido identificar las razones que han contribuido a incrementar la brecha entre la formulación legal y su efectiva implementación. La hipótesis de partida, sometida a contraste mediante método etnográfico, propone que la citada ley no puede representar un avance en la afirmación de derechos sociales en el contexto de una débil cultura de la legalidad, como representa el caso valenciano.

La metodología cualitativa y el método etnográfico han guiado el procedimiento de investigación, empleando múltiples técnicas que transitan desde las «narrativas individuales» de informantes clave a los «discursos colectivos» representativos de los diferentes actores considerados (sindicatos, patronal, movimientos sociales, etc.).

Los resultados obtenidos han fijado la atención sobre aquellas dimensiones que remiten al modelo institucional que acoge el derecho social y aquellas condiciones que posibilitan o dificultan su pleno ejercicio, confirmando la hipótesis planteada a partir de la identificación de los siguientes obstáculos en el reconocimiento y ejercicio del derecho: la relación público-privado en la política social valenciana, la relación de la administración y la ciudadanía valenciana (rendición de cuentas y transparencia), el conflicto competencial y los mecanismos de defensa del derecho que conducen a la judicialización de la política.

Palabras clave: políticas públicas, derechos sociales, situación de dependencia y cultura de la legalidad.

\begin{abstract}
This paper presents a case study made along the life cycle of the Law for Promotion of Personal Autonomy and Care for Dependent Situations (LAPAD) in the Valencian Community during the period 2006-2012.

The objective of this research was to identify the reasons that have contributed to increase the gap between the legal formulation and its effective implementation. The initial hypothesis, subjected to contrast by the ethnographic method, proposes that the Act can not represent a breakthrough in the assertion of rights in the context of a weak culture of legality, as it is the case of Valencia.

The qualitative methodology and the ethnographic methodology have guided this research process, using multiple techniques: from the «single narrative» of key informants to the «collective discourses» represented by different actors (trade unions, employers, social movements, etc.).

The results have pointed out those dimensions that refer to the institutional model that welcomes social law and the conditions that enable or impede its full exercise. In the recognition and exercise of the law, these results have confirmed the initial hypothesis from the following clear identification of obstacles: the public-private relationship in Valencian social policy, the ratio among the public administration and Valencian citizenship (accountability and transparency), and the conflict and jurisdictional law defense mechanisms that lead to criminalization of politics.
\end{abstract}

Keywords: public policy, social rights, dependency and culture of legality.

Recibido: 02/09/2013

Aceptado: 11/11/2013

Publicado: 03/12/2013

1. Dpto. Trabajo Social y Servicios Sociales. Facultad de Ciencias Sociales. Universitat de València. Despacho D.09. Primera planta. Tfno. 9638288 07. Carmen.Montalba@uv.es. 


\section{Introducción}

El presente artículo sintetiza un trabajo de más de cinco años de estudio sobre el ciclo de vida de la Ley de promoción de autonomía personal y atención a personas en situación de dependencia (LAPAD) en la Comunitat Valenciana.

El objeto de estudio ha evolucionado en estos años pudiendo distinguir dos fases en el proceso de investigación: una exploratoria, centrada en el interés por conocer el proceso de gestación de la ley y la negociación de alternativas y una segunda fase, de estudio de caso, coincidente con la etapa de implementación y puesta en marcha de la misma en el territorio valenciano.

La investigación se ha ido enfocando sobre las variables que han intercedido como obstáculos en el reconocimiento y ejercicio del derecho social en el marco de la relación administración-ciudadanía.

Para la historia de la Política Social desarrollada en democracia, esta ley se presenta como un gran avance, con la aspiración de convertir al sistema de servicios sociales en el cuarto pilar de bienestar social. De esta manera, tal y como en su propia exposición de motivos se expresa «configurar un nuevo desarrollo de los Servicios Sociales del país que amplíe y complemente la acción protectora de este sistema, potenciando el avance del modelo de Estado social que consagra la Constitución Española, potenciando el compromiso de todos los poderes públicos en promover y dotar los recursos necesarios para hacer efectivo un sistema de Servicios Sociales de calidad, garantistas y plenamente universales».

La LAPAD encarnaba, por tanto, la posibilidad de reforzar al Estado Social con el reconocimiento de un nuevo derecho social y, sobre todo, la posibilidad de reforzar el papel de los poderes públicos como garantes del mismo. Pero, paradójicamente, se ha ido fraguando en un contexto histórico adverso en el que han coincidido la crisis del Estado de Bienestar junto a cambios sociodemográficos (envejecimiento y cambios en los modelos de familia), crisis económica, flexibilización del mercado de trabajo, pérdida de poder de negociación y representación de los agentes sociales, transferencia creciente de algunas competencias a las comunidades autónomas a la par que la recentralización de otras, etc. En este contexto, y tal y como lo expresa Roldán (2001: 2): «(...) se está produciendo una restructuración institucional del mismo y una reorientación ideológica como la privatización de los servicios sociales, un aumento significativo de las organizaciones altruistas, la ruptura del ideal universalista de protección social y el auge de la exclusión social (o «desafiliación», dificultades de acceso a los mecanismos básicos de integración social)».

En definitiva, esta coyuntura ambivalente ha sido capaz de acoger e impulsar una ley con pretensiones para configurar un nuevo sistema de protección 
basado en principios de igualdad, universalidad y el carácter público de las prestaciones y servicios aunque los coletazos de los últimos años han dado claro testimonio que tales principios se reducen a un mero espejismo.

La fase de implementación pone en evidencia, en mayor medida, la paradoja o falta de coherencia entre el nivel normativo o formal y los hechos, con una especial atención a la relación que establecen los diferentes agentes presentes en este escenario. Esto invita a verificar la siguiente hipótesis: la LAPAD no puede representar un avance en la afirmación de los derechos sociales en el marco de una débil cultura de la legalidad ${ }^{3}$, como representa el caso valenciano.

En este sentido, la LAPAD se concreta en un sistema (sistema para la promoción de la autonomía personal y atención a personas en situación de dependencia - SAAD) que cuenta con la colaboración y participación de todas las Administraciones Públicas (Administración General del Estado - AGE, administración autonómica y administración local) aunque también reconoce la participación de la iniciativa privada ${ }^{4}$ y del tercer sector.

Pese a que el objeto de estudio reconoce la relación entre todos estos agentes, hay uno destacado dado el ordenamiento actual de los servicios sociales: la administración autonómica. Por tanto, la propia naturaleza del presente objeto impulsa al estudio de caso centrando la atención en la realidad valenciana y la elección de la etnografía como método y metodologías capaces de aprehender todo el proceso de gestación e implantación de una política en un territorio.

\section{Método y metodología}

El objetivo central de la presente investigación ha sido identificar las razones que nutren la brecha existente entre el texto legal y su efectiva implementación a partir del contraste de la hipótesis ya enunciada, siendo un escenario privilegiado para emprender este análisis la relación administración-ciudadanía.

En la consecución de dicho objetivo, bajo un diseño de investigación abierto, se ha evolucionado desde la citada fase exploratoria (de junio a noviembre de 2006), de carácter descriptiva, en la que se aborda las fases de la política pública relativas a la formulación del problema (problematización de

3. El concepto de «cultura de la legalidad» empleado remite a un sistema coherente entre el plano formal, vinculado al derecho y a las leyes, y el plano real de la implementación de las políticas públicas, concepto incluido en el de calidad democrática y buen gobierno, que a su vez acoge a otros términos como rendición de cuentas y transparencia.

4. El artículo 6.2 dice el «Sistema se configura como una red de utilización pública que integra, de forma coordinada, centros y servicios, públicos y privados». 
la «situación de dependencia») y la negociación de alternativas (gestación de la LAPAD), a una fase de estudio de caso (de diciembre de 2006 a diciembre de 2010), con un mayor carácter interpretativo, en la que se analiza la implementación de la ley y se contrasta la hipótesis.

Las dimensiones de descripción y análisis en la fase exploratoria han gravitado sobre:

a. La problematización de la situación de dependencia: qué es y cómo se reconoce.

b. Negociación de alternativas, cómo se despliegan las respuestas al problema: marco normativo, procedimiento de reconocimiento del derecho (agentes que intervienen), e implantación del catálogo de servicios y prestaciones.

En la fase de estudio de caso se profundiza en lo enunciado y se intenta dar cuenta mayormente de la implementación de la ley a través de:

- El análisis longitudinal y comparativo (entre diferentes territorios) a partir de los datos que proporciona el Sistema de Información del SAAD mensualmente que evidencian el grado de implantación y, por tanto, la cobertura y atención al derecho. Entre otros, los indicadores estadísticos analizados han sido: la evolución de las solicitudes, las solicitudes efectivamente valoradas frente a las prestaciones reconocidas, el régimen de compatibilidades mediante la ratio prestaciones por persona beneficiaria, el peso de las prestaciones económicas frente a los servicios, el peso de la prestación de cuidados en el entorno familiar, etc.

- Elementos de carácter institucional que inciden en el reconocimiento y ejercicio del derecho (qué actores, en base a qué reglas del juego, qué valores y qué cultura alimentan), siendo dimensiones de análisis básicas: los niveles de protección y financiación; sistema de información; estructura de coordinación interadministrativa; gobernabilidad; acreditación de centros y servicios; intensidad y compatibilidad de los mismos; así como el procedimiento desplegado en el reconocimiento del derecho en la Comunitat Valenciana.

- El grado de formalidad jurídica de las actividades administrativas y, por tanto, las garantías de protección jurídica de la ciudadanía frente a sus actos a partir de la busqueda de indicadores de rendición de cuentas legal y administrativa, tales como: la transparencia, la responsabilidad pública, cumplimiento del procedimiento administrativo, 
etc. así como las estrategias desplegadas en la defensa del derecho: rendición de cuentas societal y horizontal.

Para poder abordar todas estas aristas que dan forma al objeto de estudio, la estrategia metodológica ha evolucionado en paralelo: desde la fase exploratoria con mayor peso de las metodologías cualitativas guiadas por paradigmas comprensivos e interpretativos con el protagonismo de entrevistas semiestructuradas (individuales y grupales) (ver tabla 1 y 2) a la fase de estudio de caso con la aplicación del método etnográfico, orientado por paradigmas críticos, en la que se amplía y diversifica la utilización de técnicas, entre otras: el análisis del discurso de diferentes registros etnográficos, observación y análisis del discurso en comunidades virtuales, auto-observación, observación

Tabla 1: Técnicas de la Fase Exploratoria, 14 entrevistas semiestructuradas

\begin{tabular}{|c|c|}
\hline $\begin{array}{l}\text { INFORMANTES } \\
\text { CLAVE ÁMBITO } \\
\text { PÚBLICO }\end{array}$ & ENTIDAD \\
\hline 3 & $\begin{array}{l}\text { Direcciones territoriales: } \\
\text { - Jefatura de Acción Social de Alicante } \\
\text { - Jefatura de Mayores de Valencia } \\
\text { - Jefatura de Discapacitados/as de Castellón }\end{array}$ \\
\hline 1 & IVADIS \\
\hline 2 & Residencia Pública Mayores y discapacitados/as \\
\hline 1 & Administración local con SAD propio \\
\hline 1 & Centro de Día, CRIS. \\
\hline $\begin{array}{l}\text { INFORMANTES } \\
\text { CLAVE ÁMBITO } \\
\text { PRIVADO } \\
\end{array}$ & ENTIDAD \\
\hline 2 & $\begin{array}{l}\text { - Empresa representativa ámbito privado residencial que opera a } \\
\text { nivel autonómico con mayores. } \\
\text { - Entidad sin ánimo de lucro representativa del ámbito } \\
\text { residencial que opera a nivel autonómico con personas } \\
\text { discapacitadas. }\end{array}$ \\
\hline 2 & $\begin{array}{l}\text { - Empresa representativa del ámbito privado, SAD que opera a } \\
\text { nivel provincial (Valencia, Castellón y Alicante). } \\
\text { - Entidad sin ánimo de lucro del SAD que opera a nivel } \\
\text { provincial (Valencia, Castellón y Alicante). }\end{array}$ \\
\hline 1 & $\begin{array}{l}\text { Empresa y/o entidad sin ánimo de lucro representativa a nivel } \\
\text { comarcal o local-centro de día o CRIS. }\end{array}$ \\
\hline 1 & $\begin{array}{l}\text { Empresa y/o entidad sin ánimo de lucro representativa a nivel } \\
\text { comarcal o local - Teleasistencia. }\end{array}$ \\
\hline
\end{tabular}

Fuente: Elaboración propia 
Tabla 2: Técnicas de la Fase Exploratoria, 2 entrevistas grupales

\begin{tabular}{|c|c|}
\hline $\begin{array}{l}\text { GRUPO FOCALIZADO A } \\
\text { PROFESIONALES } \\
\text { CRITERIOS DE SELECCIÓN: } \\
\text { Conocimientos profesionales } \\
\text { sobre el presente de la atención } \\
\text { a situación de dependencia y } \\
\text { su análisis o reflexión sobre la } \\
\text { futura ley. }\end{array}$ & $\begin{array}{l}\text { - Colegio profesional de Trabajadores Sociales (2 } \\
\text { representantes) } \\
\text { - Asociación de directores y gerentes de SS.SS. (1 } \\
\text { representante) } \\
\text { - Sindicato/s mayoritarios - UGT y CCOO } \\
\text { (Federación de Sanidad, Enseñanza y } \\
\text { Administración Pública) (3 representantes) }\end{array}$ \\
\hline $\begin{array}{l}\text { GRUPO FOCALIZADO A } \\
\text { EMPRESAS } \\
\text { CRITERIOS DE SELECCIÓN: Su } \\
\text { presencia en el mercado vinculado } \\
\text { a la atención de personas en } \\
\text { situación de dependencia, y su rol } \\
\text { de agentes social protagonista en } \\
\text { espacios de negociación. }\end{array}$ & $\begin{array}{l}\text { - Patronales de cooperativas, FEVECTA. } \\
\text { - Asociación de Empresarios de Economía Social de } \\
\text { SS.SS. de la C.V. AEES } \\
\text { - Gesmed } \\
\text { - Secopsa } \\
\text { - Asociación Empresarial de Residencias y Servicios } \\
\text { Sociales de la Comunitat Valenciana (AERTE) } \\
\text { - Asociación de Residencias no Lucrativas C.V. } \\
\text { (Lares Comunitat Valenciana) } \\
\text { - Patronal de discapacitados psíquicos FEAPS }\end{array}$ \\
\hline
\end{tabular}

Fuente: Elaboración propia

Tabla 3: Técnicas de la Fase estudio de caso, 8 entrevistas semiestructuradas a expertos/as juristas

\begin{tabular}{|c|l|}
\hline $\begin{array}{c}\text { NÚM.INFORMANTES } \\
\text { CLAVE }\end{array}$ & \multicolumn{1}{|c|}{ ENTIDAD } \\
\hline 1 & $\begin{array}{l}\text { Organizaciones legalmente constituidas para la defensa de } \\
\text { los derechos ciudadanos: Sindicatura de Greuges y Colegios } \\
\text { de Abogados (turnos de oficios). }\end{array}$ \\
\hline 4 & $\begin{array}{l}\text { Abogados de organizaciones sindicales y ONGs que están } \\
\text { prestando servicios en este ámbito. }\end{array}$ \\
\hline 2 & Expertos/as juristas del ámbito académico. \\
\hline 1 & Magistrados del Tribunal Superior Justicia. \\
\hline
\end{tabular}

Fuente: Elaboración propia

participante, entrevistas informales, entrevistas semiestructuradas (orientadas a agentes sociales y a profesionales), entrevistas a expertos/as juristas que asesoran en la defensa del derecho y talleres grupales aplicando la técnica del tetralema (ver tabla 3 y 4 ). 
Tabla 4: Técnicas de la Fase estudio de caso, 2 talleres grupales aplicando la técnica del Tetralema

\begin{tabular}{|c|l|}
\hline Objetivo & $\begin{array}{l}\text { Profundizar en los significados que se atribuyen a aquello que se } \\
\text { calificaba de «público» y de «privado»: qué prácticas y sentidos } \\
\text { aglutinan estos términos y cómo interfieren dichos significados en el } \\
\text { ejercicio del derecho }\end{array}$ \\
\hline $\begin{array}{l}\text { Taller de } \\
\text { Valencia }\end{array}$ & $\begin{array}{l}\text { Plataforma Valenciana en defensa de la LAPAD, constituido por un total de } \\
\text { ocho personas, fundamentalmente profesionales del sector y algún familiar } \\
\text { de persona afectada. }\end{array}$ \\
\hline Taller de & $\begin{array}{l}\text { Plataforma Alicante en defensa de la LAPAD, con una participación } \\
\text { de cuatro personas pertenecientes a colectivos de enfermos crónicos y } \\
\text { personas discapacitadas. }\end{array}$ \\
\hline
\end{tabular}

Fuente: Elaboración propia

\section{Resultados}

En este epígrafe se presentan los resultados destacados de cada una de las fases del ciclo de vida de la ley analizadas:

\subsection{Resultados de la fase de formulación y de alternativas: problematización de la dependencia y respuesta institucional}

En esta fase se ha analizado cómo se construye como problema la «situación de dependencia», su legitimación y la respuesta desde las políticas públicas. Así, en términos discursivos, dado que la ley remite a una "situación» (enfoque situacional) y no a un colectivo, se puede afirmar que se ha manejado una definición próxima al denominado modelo social, no prestando atención a los rasgos que sirven para identificar a la persona con «discapacidad o diversidad funcional» sino a las circunstancias en las que la persona se encuentra y que limitan sus posibilidades de autonomía, en definitiva, las razones de su construcción social.

Sin embargo, la investigación realizada demuestra que la operativización del concepto a través de los instrumentos de valoración de la dependencia ha seguido enmarcándola en el denominado modelo médico-rehabilitador. Como afirman Pié (2012) y Romañach (2012), la ley genera una categoría que filtra a la población entre quienes pueden o no pueden acceder al sistema de distribución basado en las necesidades. De esta manera, el concepto empleado estaría, en la práctica, huyendo de una visión antropológica y ontológica de las situaciones de dependencia como condiciones consustanciales al ser humano, con su expresión más evidente en la infancia y en la vejez. 
En la construcción social del problema y su legitimación también ha interesado identificar qué tipos de respuestas se articulan. En este sentido, la aprobación de la LAPAD ha supuesto el paso fundamental para ofrecer una intervención desde la esfera pública. Tradicionalmente, la actividad del cuidado y la atención a situaciones de dependencia quedaban relegadas al ámbito privado, fruto también de una división sexual del trabajo en la cual se hacía a la mujer responsable de la prestación del socorro y cuidado de sus seres queridos y familiares. La intervención pública en España se ha sostenido en una asistencia social vinculada a situaciones de emergencia y carencia, prestada con cierto carácter arbitrario y siempre sujeta a la prueba de suficiencia de recursos.

La LAPAD reconoce como derecho subjetivo la atención a las situaciones de dependencia y, de esta forma, les otorga un nuevo valor o carácter a través de su consideración como derecho, desplazando la obligación al ámbito público, gubernamental.

Finalmente, un efecto no previsto en la formulación de la política pública pero real en sus consecuencias ha sido la conversión de la situación de dependencia como paradigma de la «autonomía». La ideología liberal siempre ha sido temerosa del intervencionismo estatal, entre otros argumentos, porque es generador de dependencias, de ciudadanías pasivas, en condición permanente de súplica y demanda a la administración para que ésta le resuelva los problemas. Sin embargo, la LAPAD ha conseguido el efecto contrario en las personas que padecen una situación de dependencia, gracias al reconocimiento del derecho y a la asunción de éste por parte de la ciudadanía.

Un ejemplo de cómo la deficiente aplicación de esta ley ha conseguido recuperar la identidad republicana de la ciudadanía activa ${ }^{5}$ es la conformación de múltiples plataformas que reivindican el derecho social a la atención y la responsabilidad pública. El movimiento social rompe con la idea liberal de

5. «(...) Los ciudadanos pasivos son aquéllos que se limitan a cumplir con un mínimo de obligaciones, aunque en momentos efímeros de emoción colectiva puedan manifestarse públicamente. Para ellos el ejercicio de la virtud cívica consiste en la obediencia rutinaria a la autoridad legítima, es decir, el pago de contribuciones sin evasión fiscal detectable, el relativo buen comportamiento en la vía pública, y demás expresiones de buena conducta cívica aceptable, amén de su presencia en las urnas. Los ciudadanos activos, por su parte, son aquéllos que, sin ser profesionales de la política, intervienen en la esfera pública para mejorar las condiciones de la vida democrática, ejercer su propia libertad y, sobre todo, cultivar la virtud suprema de la república, la fraternidad. Los ciudadanos activos son, esencialmente, proactivos, es decir, toman iniciativas para cumplir estos fines, al margen o más allá de situaciones que les hayan perjudicado o dañado» (Giner, 2005: 19). 
una ciudadanía pasiva, hace frente a la tesis de la infantilización ${ }^{6}$ donde lo que se pretende es amamantarse del Estado, la «dependencia de la ayuda social»y, por el contrario, se comporta como el adulto que se ha atrevido a saber (aude sapere), que ha tomado conciencia crítica de lo que esta ley presupone y ha activado dispositivos de reivindicación para poder ejercer el nuevo derecho que se les reconoce así como mecanismos pedagógicos para su divulgación.

En definitiva, una situación personal de dependencia en las actividades de la vida cotidiana no se traduce en una situación de dependencia/pasividad frente a la administración en el sentido liberal sino más bien de la ciudadanía activa como sujeto político, que reivindica su posición en el espacio público y da un paso importante hacia la gobernabilidad del Estado de Bienestar: «Nunca esta tradición pudo hacer ver de qué manera era posible trasladar al ámbito público las lecciones que en privado se aprenden sobre el carácter y enriquecer así la política con peso psicológico real» (Sennett, 2003: 132).

Este aspecto, identificado en la fase de legitimación del problema, constituirá un factor importante en la conformación de una fuerte rendición de cuentas societal.

Por su parte, en la fase de alternativas se ha analizado el proceso de negociación y debate acontecido en la gestación de la ley y el desarrollo de una política de atención a situaciones de dependencia. El centro de la discusión se situó en su encuadramiento institucional, competencial y de financiación para asegurar el derecho. Las discusiones académicas, políticas y tecnocráticas pivotaban alrededor de: financiación mediante Seguridad Social o por vía impositiva, demarcación sectorial en el sistema de servicios sociales o en el sistema sanitario, configuración como Ley Básica o su asunción autonómica, y predominio de un sistema público frente a un sistema mixto.

El proceso de negociación se inició con la recomendación que el Defensor del Pueblo emitió en el año 2000 aludiendo a la «oportunidad de implantar en España un sistema de protección a la dependencia en el marco de la Seguridad Social» (Rodríguez; Arriba; Marban y Salido, 2005). A partir de este momento surgen toda una serie de declaraciones y acuerdos, fruto de la negociación política en la que se enmarca el debate: la Comisión Parlamentaria de seguimiento del Pacto de Toledo (mayo de 2000), el Acuerdo para la Mejora y Desarrollo del Sistema de Protección Social (3 de abril de 2001), la renovación del Pacto de Toledo (2003), el Acuerdo Competitividad, Empleo y Cohesión Social (julio de 2004), la publicación del Libro Blanco de la Dependencia (2005) hasta

6. «Los pensadores liberales han supuesto que la dependencia, en particular la dependencia de los poderes públicos, hace que los adultos se comporten como niños» (Sennett, 2003: 111). 
llegar, finalmente, al Acuerdo de la situación protectora: Sistema Nacional de Dependencia (diciembre de 2005). Será en este último donde se plantea el modelo que acogerá al sistema mediante una ley que tenga la condición de norma básica, que promueva la autonomía personal y garantice el derecho a ser atendido en situaciones de dependencia, y en la que se establecerán las condiciones básicas y los requisitos de acceso a los servicios y prestaciones en condiciones de equidad en todo el territorio del Estado. El Sistema Nacional de la Dependencia ${ }^{7}$ se configuraría como una nueva modalidad de protección social, que debería regir bajo los siguientes principios: carácter universal y público de las prestaciones; acceso a las prestaciones de dependencia en condiciones de igualdad y no discriminación; equidad en la distribución territorial de los recursos; carácter universal y público de las prestaciones; acceso a las prestaciones de dependencia en condiciones de igualdad y no discriminación y la equidad en la distribución territorial de los recursos. Estos principios sirvieron para alimentar la expectativa de lo que algunos/as llamarían cuarto pilar del Estado de Bienestar.

En los pasos posteriores que correspondieron al trámite parlamentario, de discusión y participación, que discurrieron desde el Consejo de Ministros (23 de diciembre de 2005) hasta la publicación en el Boletín Oficial del Estado en diciembre de 2006, la cuestión competencial apareció como un tema central en el debate político, produciéndose diferentes enmiendas ${ }^{8}$ a la totalidad del proyecto de ley que gravitaban sobre la injerencia del Estado al establecer una norma básica en un ámbito competencial autonómico.

La legitimidad competencial se arrastrará hasta nuestros días como un obstáculo evidente en la implementación de esta ley.

Finalmente, con el acuerdo de un sistema de protección universal e igualitario, con la aspiración por parte de la AGE de regular las condiciones básicas y el contenido mínimo que además debería someterse al marco de cooperación interadministrativa con la constitución del Consejo Territorial, se gestó una ley que ha representado el paso de un modelo de protección asistencial a un modelo de carácter universalista o continental ya que compartía con éstos, al menos sobre el papel: el carácter universal, el sistema de copago, la

7. Denominación que tras el proceso de alegaciones pasó a ser Sistema de Promoción de la Autonomía y Atención a las situaciones de dependencia (SAAD).

8. Se presentaron las enmiendas a la totalidad del Grupo Parlamentario Vasco (PNV-EAJ), CIU y Eusko Alkartasuna (Grupo Mixto) siendo la invasión de competencias autonómicas exclusivas en servicios sociales la razón aducida para votar en contra de la LAPAD cuando ésta se aprobó por el Pleno del Congreso de los Diputados el 30 de noviembre de 2006 (Diario de Sesiones del Congreso de los Diputados n 219, 30 Noviembre de 2006). 
responsabilidad pública, la preferencia de servicios y la orientación a dignificar la figura de la persona cuidadora.

\subsection{Resultados de la fase de implementación}

Resulta complejo sintetizar los resultados principales de esta fase dado que se ha analizado un amplio espectro de factores que tienen incidencia directa sobre el reconocimiento y ejercicio del derecho social, siendo éstos: la financiación, el sistema de información, la estructura institucional de coordinación y gestión, la intensidad y compatibilidad entre servicios y prestaciones, la relación público-privada y, finalmente, el procedimiento relativo al reconocimiento del derecho. A continuación se señalan sólo algunos de los resultados que se considera que tienen una incidencia más notable en el reconocimiento y ejercicio del derecho, pues además convergen en cada una de las dimensiones analizadas.

a) El débil papel de tutela y garante del derecho de la Administración General del Estado

Todos los diagnósticos ${ }^{9}$ realizados en torno a la desigual aplicación territorial de la ley apuntan a una misma dirección: falta de coordinación interadministrativa y la necesidad de un mayor protagonismo de la administración central para asegurar la necesaria homogeneidad. Esta demanda es como pedirle "peras al olmo» porque si la AGE cumple su papel de tutela y liderazgo puede ser acusada de inconstitucionalidad por interferir en el espacio de competencia autonómica mientras que, por otro lado, debe garantizar condiciones de «igualdad» en todo el territorio.

La fórmula innovadora del Consejo Territorial (C.T.), el cual pretendía lograr la co-implicación de todas las administraciones, ha desempeñado un rol paradójico y claramente inoperante. Esta fórmula no ha conducido al éxito porque el interés general no ha coincidido siempre con el interés de todas las administraciones representadas y de todo el espectro partidista que las gobernaba.

9. El informe encargado a la Agencia Estatal de Evaluación de las Políticas Públicas y la Calidad de los Servicios (2009), el I Dictamen de la Asociación Estatal de Directores y Gerentes de SS.SS. (2008), Estudio de la Fundación Alternativas (Kahale, 2009), Informe balance realizado por CC.OO. (2009), Estudio comparativo autonómico sobre los desarrollos normativos promovido por el CERMI (2009), Informe de Gobierno para estos cinco años de aplicación de la LAPAD (VV.AA., 2011: 583). 
De la misma manera, las autonomías interpretaban de formas múltiples su responsabilidad con el impulso de la ley según el partido que las gobernaba, según el peso histórico de los servicios sociales o según la estructura institucional que se deseara desplegar en torno a la misma, entre otros factores. Nos situábamos pues ante un problema de difícil solución y que debe trascender el debate formulado en términos simplistas de «centralismo vs autonomismo» como si tomar posición por uno u otro de los modelos de estado y gobierno resolviera el problema de fondo.

Si el Consejo Territorial hubiera sido capaz de concretar al máximo los acuerdos de los que era responsable y de comprometer a todas las administraciones en la mutua supervisión y vigilancia, hubiéramos estado ante una nueva fórmula madura para superar el centralismo del gobierno central y los particularismos autonómicos en pro de la igualdad. En definitiva, se trataba de experimentar una nueva fórmula que requería de la convicción y esfuerzo de las diferentes administraciones y gobiernos implicados, tal y como lo expresa el Informe de la Comisión de Expertos (Cervera, Herce, López, Rodríguez y Sosvilla, 2009): «El objetivo del Consejo Territorial es robustecer la coordinación en un sistema descentralizado y, como tal, hay que contemplar su desarrollo en el futuro de forma que el SAAD no sea un conjunto de diecinueve subsistemas, sino un único sistema, coherente en su diversidad, que garantice en todo el territorio los principios básicos de la ley: universalidad, igualdad, transparencia, cooperación y eficacia. En este sentido, sería deseable el perfeccionamiento de los mecanismos de un gobierno cooperativo que conjugue diversidad y armonización en aras de la creación de un marco global de acción integrada».

En conclusión, la mejor manera de aumentar el control suponía ampliar las exigencias en rendición de cuentas, acordando mecanismos comunes de auditoría y sanciones ante los incumplimientos. Incluso si el Comité Consultivo estuviera ampliado por organizaciones y plataformas ciudadanas, el control sobre las administraciones también podría ejercerse desde abajo. Para ello resultaba necesario seguir mejorando los mecanismos de información y transparencia respecto a la gestión concreta realizada por las diferentes administraciones, siendo necesaria la mejora y ampliación de los indicadores ofrecidos en las estadísticas mensuales del SISAAD. Entre los más reivindicados por colectivos y profesionales figuran los propios plazos de tramitación y espera así como los mecanismos de sanción frente a las desviaciones como parte de la rendición de cuentas. 
b) La financiación

Uno de los aspectos que ha debilitado la tutela del derecho por parte de la AGE es la propia estructura de financiación que debía acogerle. La LAPAD caracteriza el modelo de financiación como estable, suficiente, sostenido en el tiempo y equitativo pero ninguna de estas condiciones se ha confirmado en su efectiva implementación.

La investigación realizada ha demostrado que lo que ha tenido graves efectos sobre el derecho no es sólo el cuánto sino también el cómo la ingeniería de financiación desplegada ha sido sometida a cambios permanentes.

Con el fin de realizar una aproximación esclarecedora del galimatías que supone la citada ingeniería financiera, ha resultado necesario centrarse en tres cuestiones mutuamente imbricadas: la totalidad del dinero aportado (fondos), las responsabilidades contributivas que debían o podían asumir las diversas administraciones públicas por niveles territoriales (niveles de protección) y, por último, la asignación distributiva que con carácter autonómico se hacía de parte de los fondos estatales, conforme a una serie de criterios, en continua y cambiante evolución.

En la LAPAD se denomina nivel mínimo de protección a los fondos que son garantizados por la AGE. Al margen de cualquier otra aportación financiera que pudiera realizarse, como mínimo, la administración central se comprometía a la fijación de una cantidad económica mensual por cada una de las personas beneficiarias reconocidas según su grado y nivel de dependencia valorado. En la ley se determina que la liquidación de estos fondos se realizaría mensualmente, en función de los datos de reconocimiento efectivo del derecho a las prestaciones que cada comunidad autónoma registrara. Quizás fue ésta la razón que motivó que algunas autonomías realizaran «valoraciones de oficio», viendo de esta manera incrementar sus estadísticas y percibiendo, consecuentemente, la oportuna financiación estatal.

Otra de las perversiones que el sistema consentía es el desfase entre la recepción del dinero por parte de las autonomías y la transmisión del mismo a sus legítimos/as destinatarios/as. Ya se ha mencionado que los pagos de la AGE se realizan mensualmente por cada persona que ha sido valorada como dependiente, aunque esta última aún no haya recibido ninguna prestación o servicio. Por lo tanto, las administraciones autonómicas podrían disponer de crédito sin intereses para poder acometer otros pagos u obras. Es más, estos entes públicos periféricos podían tener la tentación de demorar los trámites para otorgar la prestación o servicio correspondiente pues, de esta manera, conseguían seguir disponiendo libremente de una financiación adicional sin 
coste financiero en momentos donde disponer de liquidez para las arcas públicas ha supuesto un grave problema.

Posiblemente por este motivo se aprobó el R.D. 99/2009 que junto a que el procedimiento debía ser iniciado a solicitud de la persona interesada, proponía cierta aclaración respecto de cómo se habría de justificar la valoración de las personas en situación de dependencia para poder recibir las transferencias monetarias del nivel mínimo, así como que sólo se abonarían las resoluciones de reconocimiento que incluyeran el Programa Individual de Atención (PIA).

Es necesario destacar lo difícil que ha resultado investigar cuáles han sido las transferencias exactas que ha realizado la AGE a cada comunidad autónoma por este concepto, dada la falta de transparencia informativa por parte de ambas instituciones, emisora y receptora.

Por su parte, el nivel de protección acordado, que teóricamente debía ser determinado entre la administración central y las administraciones autonómicas a través de los convenios bilaterales previstos en la ley, plantea dos claras restricciones unilaterales: en primer lugar, la contribución estatal venía predeterminada y, en segundo lugar, se le exigía a cada comunidad autónoma que debía contribuir a la financiación «acordada» con una cantidad al menos igual a la aportada por la AGE incluyendo los fondos del nivel mínimo que fueran otorgados.

Sin embargo, no ha existido equilibrio entre la aportación de las administraciones (central y autonómicas). La explicación residía en diferenciar el denominado como Gasto Consolidado frente al Gasto Nuevo (VV.AA., 2011: 185, 196-199): «En la LAPAD se establece que la aportación de las comunidades autónomas será para cada año, al menos igual a la de la Administración General del Estado en concepto de nivel mínimo y nivel acordado (Art. 32), entendiéndose que esta «nueva financiación» debe ir destinada para el gasto "nuevo", necesario para cumplir los objetivos de la Ley. En consecuencia se trata de fondos nuevos tanto para el Estado como para las comunidades, que deberían añadirlo al gasto que ya venían realizando antes de la Ley». Ese gasto ya realizado, que tenía sus vías de financiación, es el denominado Gasto Consolidado. De hecho, cuando la ley daba sus primeros pasos, las comunidades autónomas presentaban sus tremendos logros que en ciertos casos solamente respondían a hacer aflorar como gasto nuevo lo que realmente era gasto consolidado ${ }^{10}$.

10. Los primeros años de aplicación, según calendario fijado en la ley, se debía reconocer a la población Gran Dependiente, que en su gran mayoría ya estaba siendo objeto de atención por algún recurso del sistema de servicios sociales. 
Los criterios de distribución autonómica del nivel acordado han de ser fijados, mediante acuerdo del Consejo Territorial, a través de los denominados como Marco de Cooperación Interadministrativa (MCI). Es evidente que los MCI se fueron estableciendo para ir acompañando la aplicación de la ley, aportando dinero antes del cumplimiento de objetivos. La antelación en el desembolso se justificaba por el compromiso adquirido por las autonomías. No obstante, la ejecución de la LAPAD ya señalaba algo con claridad: la voluntad de desarrollar la ley no era la misma en todos los territorios del estado español. Parecía atisbarse entonces que el MCI debía pasar de ser una mera comparsa en la ejecución de la ley a una brújula que estableciera cuáles son las razones que justifican la recepción de los fondos y, por tanto, que obligara a hacer cambios de rumbo importantes a determinadas autonomías que parecían claramente «desorientadas«.

Tras varios anuncios sobre una gran reforma de los MCIs, se pospuso ésta al mismo tiempo que se aprobaba un programa de carácter plurianual (2010-2013), publicado en el BOE de 21/07/201011 el cual incorporaba los cambios en los criterios como consecuencia, además, de la aprobación de una nueva ley de financiación de las autonomías. Esta reforma modificaba uno de los ítems que más pesaba en el Fondo General y, por tanto, en el conjunto total del nivel acordado: el volumen de población potencialmente dependiente (PPD). El reparto de Fondos entre las CC.AA. correlacionaba positivamente con esta variable: a más población potencialmente dependiente, más financiación (independientemente del esfuerzo que estuviera realizando en el efectivo reconocimiento del derecho). Sin embargo, mediante los cambios del nuevo marco se intentaba ligar más la financiación a su efectivo cumplimiento, incrementando el pago en función de los Planes Individuales de Atención aprobados, como se expresa en las ponderaciones de los diferentes criterios de la Tabla 5.

Estos cambios sí que han logrado que el MCI sea esa brújula que desea marcar el rumbo y el ritmo para lograr una plena implantación de la ley. Aquellas comunidades que no habían sabido o querido enderezar el timón son fácilmente identificables en la siguiente tabla, expresando el poco esfuerzo realizado con el consiguiente sufrimiento de sus ciudadanos/as en situación de dependencia.

11. Resolución de 15 de julio de 2010, del Instituto de Mayores y Servicios Sociales, por la que se publica el Acuerdo de Consejo de Ministros de 9 de julio de 2010, por el que se aprueba el marco de cooperación interadministrativa y criterios de reparto de créditos de la AGE para la financiación durante 2010-2013 del nivel acordado. 
Tabla 5: Criterios de reparto de los fondos destinados al nivel acordado en el MCI de 2010

\begin{tabular}{|c|c|c|c|c|c|c|}
\hline & CRITERIOS & FONDOS 2010 & 2010 & 2011 & 2012 & 2013 \\
\hline & Población potencialmente protegible & \multirow{7}{*}{$\begin{array}{l}\text { FONDO GENERAL } \\
226.557 .936 € \\
80 \%\end{array}$} & $55,00 \%$ & $35,00 \%$ & $25,00 \%$ & $0,00 \%$ \\
\hline \multirow{12}{*}{$\begin{array}{c}\text { CRITERIOS } \\
\text { CORRECTORES }\end{array}$} & Dispersión geográficc & & $0,60 \%$ & $0,60 \%$ & $0,60 \%$ & $0,60 \%$ \\
\hline & Insularidad & & $0,60 \%$ & $0,60 \%$ & $0,60 \%$ & $0,60 \%$ \\
\hline & Superficie & & $1,80 \%$ & $1,80 \%$ & $1,80 \%$ & $1,80 \%$ \\
\hline & $\begin{array}{c}\text { Beneficiarios reconocidos como } \\
\text { dependientes con derecho a prestación } \\
\text { y registrados en el SISAAD }\end{array}$ & & $63 \%$ & $63 \%$ & $63 \%$ & $63 \%$ \\
\hline & PIAs & & $189 \%$ & $38,90 \%$ & $48,90 \%$ & $73,90 \%$ \\
\hline & Prestaciones de Servicios & & $168 \%$ & $168 \%$ & $168 \%$ & $168 \%$ \\
\hline & $\begin{array}{c}\text { Rento per cápito disponible y pensión } \\
\text { media de jubilación }\end{array}$ & \multirow{3}{*}{$\begin{array}{c}\text { FONDO COMPENSACION } \\
28.319 .742 € \\
10 \%\end{array}$} & $49,00 \%$ & $49,00 \%$ & $49,00 \%$ & $49,00 \%$ \\
\hline & Coste de Servicios & & $49,00 \%$ & $49,00 \%$ & $49,00 \%$ & $49,00 \%$ \\
\hline & Emigrantes retomados & & $2,00 \%$ & $2,00 \%$ & $2,00 \%$ & $2,00 \%$ \\
\hline & $\begin{array}{l}\text { Formacion de Cuidadores No } \\
\text { Profesionales }\end{array}$ & \multirow{2}{*}{$\begin{array}{l}\text { FONDO CUMPLIMMENTO DE } \\
\text { ACUERDOS } \\
28.319 .742 € \\
10 \%\end{array}$} & $85 \%$ & $85 \%$ & $85 \%$ & $85 \%$ \\
\hline & $\begin{array}{c}\text { Transposicion de acuerdos a normativa } \\
\text { autonomica }\end{array}$ & & $15 \%$ & $15 \%$ & $15 \%$ & $15 \%$ \\
\hline & TOTAL & $283.197 .420 €$ & & & & \\
\hline
\end{tabular}

Fuente: Elaboración propia

Tabla 6: Comparación de índices de reparto del nivel acordado por CC.AA. (2007 a 2010)

COMPARACIÓN

\begin{tabular}{l} 
Andalucía \\
\hline Aragón \\
\hline Asturias (Principado de) \\
Balears (Illes) \\
Canarias \\
Cantabria \\
Castilla y León \\
Castilla-La Mancha \\
Cataluña \\
\hline Comunidad Valenciana \\
Extremadura \\
Galicia \\
Madrid (Comunidad de) \\
Murcia (Región de) \\
Navarra \\
\hline País Vasco \\
Rioja (La) \\
Ceuła y Melilla
\end{tabular}

\begin{tabular}{|c|c|c|c|}
\hline \multicolumn{4}{|c|}{ Índice de Distribución Resultante } \\
\hline 2007 & 2010 & 2010-2007 & Crec. \\
\hline 7.4918 & 21,6560 & 4,1642 & 20,0110 \\
\hline 4,0442 & 3,8480 & $-0,1962$ & $-4,85 \%$ \\
\hline 3,4610 & 2,8826 & $-0,5784$ & $-16,71 \%$ \\
\hline 2,1260 & 1,9630 & $-0,1631$ & $-7,67 \%$ \\
\hline 3.7205 & 3,1035 & & \\
\hline 1,6333 & 1,7670 & 1337 &, 17 \\
\hline 8,5900 & 7,9942 & $-0,5958$ & $-6,94^{\circ} \%$ \\
\hline 5,6196 & 5,5857 & $-0,0340$ & $-0,609$ \\
\hline 5.6324 & 17.4402 & 1,8078 & $11,56 \%$ \\
\hline 0.2682 & 8,9319 & $-1,3364$ & $-13,01 \%$ \\
\hline 3,2038 & 2,9635 & $-0,2402$ & $-7,50 \%$ \\
\hline 9,0498 & 7,1405 & $-1,9093$ & $-21,10 \%$ \\
\hline 11.2942 & 10,3759 & $-0,9183$ & $-8,13 \%$ \\
\hline 2,8280 & 2.9888 & 0.1608 & 5,69 \\
\hline & & & 2,54 \\
\hline & 0.2357 & -0.0133 & $-5,35$ \\
\hline
\end{tabular}

Fuente: Elaboración propia sobre información publicada en los BOE correspondientes a cada MCI 
c) La implementación en la Comunitat Valenciana (CV)

La singularidad en la aplicación de la ley en la CV se puede identificar con el confuso escenario institucional: múltiples agentes con competencias, con nuevas fórmulas de relación público-privadas, con una estructura institucional confusa y sometida a continuos cambios y regulaciones, y con el polémico papel en el procedimiento de reconocimiento del derecho de una empresa pública con forma jurídica mercantil, la Agencia Valenciana de Prestaciones Sociales S.A. (AVAPSA).

La información que se deriva del trabajo de campo etnográfico ha resultado coincidente con fuentes secundarias como los principales informes y estudios que realizaron un balance de la aplicación de la ley durante el marco temporal en el que se ha desarrollado dicho trabajo de campo ya fueran informes solicitados por las propias instancias gubernamentales, tales como el estudio realizado por la Comisión de Expertos (Cervera et al., 2009) nombrada por el pleno del Congreso de los Diputados a tal efecto y el informe que desde el Ministerio de Sanidad y Política Social se solicitó a la Agencia de Evaluación de Políticas Públicas (AEVAL, 2009) así como los promovidos desde organizaciones profesionales y afectados, siendo especialmente reveladores los Dictámenes que elabora la Asociación de Directores y Gerentes de SS.SS., los informes de los sindicatos por su condición de promotores de la ley e interlocutores en su desarrollo así como los informes que ha realizado el CERMI por su condición de representante de personas afectadas. Las memorias anuales de la Sindicatura de Greuges y del Defensor del Pueblo también se han considerado como valioso barómetro para medir la presión ciudadana sobre los incumplimientos así como la cantidad y cualidad de los mismos.

A diferentes niveles, y con diferentes enfoques, las fuentes secundarias analizadas y el testimonio de profesionales, ciudadanos/as y abogados, así como los datos primarios que ha publicado el SISAAD, han dado cuenta de la deficiente aplicación de la LAPAD en la CV remitiendo a factores como: un procedimiento largo y tortuoso con su expresión en la demora en la tramitación de los expedientes y en la percepción de las prestaciones; el no reconocimiento de la retroactividad; la paralización de expedientes por cualquier motivo (por no tener grado o nivel suficiente; por falta de documentación; por no haber elegido una prestación antes de hacer el PIA); cambios continuos en la regulación; baja proporción de solicitudes en función de la población potencialmente dependiente; régimen estricto de incompatibilidades; modelo de atención basado en el predominio de la prestación de cuidados en el entorno familiar y las residencias; desviaciones de la norma en lo relativo al silencio administrativo o los órganos responsables de la valoración; la falta de 
información sobre el procedimiento y el estado de tramitación; confusión y falta de una visión global del los/as profesionales de los servicios municipales de atención a la dependencia; en caso de errores en el procedimiento, pérdida de documentación o paralización de la tramitación, la ciudadanía ha tenido dificultades para identificar a los/as responsables dada la compleja maraña de instancias que participan, generándoles una importante indefensión

El problema de implementación de la ley en la Comunitat Valenciana no ha remitido sólo al conflicto competencial o a la estructura de financiación desplegada sino que se han añadido tres ingredientes más como claros obstáculos en el efectivo cumplimiento de la ley, los cuales vienen a verificar la hipótesis planteada puesto que son evidencias de una débil cultura de la legalidad: el modelo de política social desarrollado desde el que se articulaba la relación público-privado, la relación administración-ciudadanía (rendición de cuentas y transparencia) y la defensa del derecho en virtud a su judicialización. A continuación se profundiza en los mismos como expresión de la quiebra entre el plano formal del derecho y el real de la práctica política y administrativa.

\section{Débil cultura de la legalidad: razones de la disonancia entre el texto legal y la experiencia cotidiana en el ejercicio del derecho}

Una de las razones que ha tenido un impacto central en la contribución o menoscabo de la cultura de la legalidad ha sido la rendición de cuentas. Según Villoria y Wences (2010: 14), la rendición de cuentas podría definirse como un proceso a través del cual gobernantes, representantes y servidores públicos, informan, responden y justifican sus actos, sus decisiones y sus planes de acción a gobernados/as y se sujetan a las sanciones y recompensas. Durante este proceso, la ciudadanía observa, analiza, verifica y juzga su reconocimiento, critica o rechaza la actuación de la persona representante, gobernante o funcionaria pública haciendo uso de mecanismos e instrumentos de control institucional, electoral y/o social.

Así, la responsabilidad de rendir cuentas y solicitarla no se refiere únicamente a la acción de gobierno sino también a la acción administrativa. Algunos de los múltiples «fallos» de la administración valenciana en el procedimiento, que pueden calificarse como problemas de rendición de cuentas, han sido de carácter legal y administrativos.

Retomando las definiciones de estos conceptos, podremos afirmar que un gobierno y una administración que velen por una rendición de cuentas legal deben mostrar comportamientos acordes con los procedimientos legales y éstos contribuirán a una rendición de cuentas administrativa cuando los actos 
burocráticos (eficaces, eficientes, equitativos y transparentes) sean responsables y respetuosos con dichos procedimientos.

No tanto lo que la propia administración autonómica ha declarado, respondido, informado o justificado resultan ser evidencias de una débil o nula rendición de cuentas administrativa y legal como los datos revelados en el trabajo etnográfico referentes a las preocupaciones que tanto la ciudadanía como los/as profesionales, agentes sociales e incluso instituciones como el Defensor del Pueblo y el Síndic de Greuges han mostrado, generando preguntas, denuncias públicas o reivindicaciones, evidenciando además la ausencia de control ciudadano frente a los hechos relatados.

En definitiva, el trabajo etnográfico descubre que la ciudadanía se ha enfrentado a un complejo deambular, de «idas y venidas» entre diferentes organizaciones (especialmente AVAPSA) ${ }^{12}$ y administraciones, con largos plazos de espera y con exigua, confusa y cambiante información, tal y como muestra la siguiente síntesis:

A. Para valorar la rendición de cuentas administrativa se han identificado los siguientes fallos que se han mostrado como claros indicadores de su débil presencia:

a.1. Parte del proceso ha discurrido con irregularidades en la forma de proceder (por ejemplo, las notificaciones vía teléfono o email).

a.2. Se detectan irregularidades como la petición reiterada de la misma documentación, la pérdida de la misma y la paralización del procedimiento ante la falta de instrucciones claras.

a.3. Dilaciones en la resolución, paralización del procedimiento.

a.4. Silencio por respuesta: se ha impuesto el silencio administrativo negativo y, como consecuencia, la ciudadanía se ha mostrado insegura, desconcertada e indefensa.

a.5. Estructura fundamental de carácter local (Servicios Municipales de Atención a la Dependencia - SMAD) dependiente de una orden de ayudas sujeta a convocatorias de subvención anuales pudiéndose dar el caso de periodos en los que desaparece el servicio que debe dar respuesta a un derecho subjetivo hasta la renovación de la misma.

a.6. Múltiples agentes con competencias en el procedimiento (AVAPSA, SMADs y Conselleria) con directrices confusas, falta de coordinación y desconcierto de los/as profesionales.

12. AVAPSA constituye la empresa pública de gestión privada con forma jurídica de sociedad anónima que ha intervenido en alguna de las partes del procedimiento en el reconocimiento del derecho en la Comunidad Valenciana. 
a.7. Implantación limitada del catálogo de prestaciones y servicios. Protagonismo de la prestación del cuidador familiar y residencias.

B. Para valorar la rendición de cuentas legal se han encontrado los siguientes fallos que resultan ser indicadores de su débil presencia:

b.1. Generación de un sistema de provisión «híbrido» (público + privado) que ha intervenido en el espacio de gestión y que ha dado lugar al incumplimiento de normativa básica, aspecto éste que remitía al debate jurídico sobre si la empresa pública AVAPSA podía, o no, desempeñar funciones que suponen autoridad pública.

b.2. La participación de la mercantil AVAPSA ha implicado el no control sobre los procesos de contratación de personal para asegurar las condiciones básicas de «capacidad, mérito y publicidad».

b.3. Se ha incurrido en procesos de contratación que diluían, aún más, la responsabilidad pública.

b.4. Fuerte producción normativa a nivel central y autonómico que ha provocado cambios continuos en la estructura institucional, competencias, procedimientos, etc.

b.5. Desviaciones e irregularidades respecto a la norma: valoraciones de oficio y fuera del entorno habitual de la persona.

b.6. Disparidad territorial en la aplicación de los acuerdos que se han derivado del Consejo Territorial.

b.7. Indefensión jurídica: agotada la vía de la reclamación administrativa sin respuesta alguna, se ha de efectuar un recurso contencioso- administrativo, sometiéndose a un proceso aplazado en el tiempo y asumiendo costas judiciales que no todo el mundo puede afrontar.

b.8. Estricto régimen de incompatibilidades con otras prestaciones o servicios ya concedidos que incluso suponen un retroceso en derechos.

En definitiva, estos «fallos» en la relación administración - ciudadanía han servido para medir y operativizar la rendición de cuentas (legal y administrativa), revelando la debilidad de los siguientes componentes:

- La ausencia de transparencia sobre la información relevante: escasa divulgación de la ley, falta de información sobre el procedimiento, dificultad en el acceso a la información que consta en los expedientes y la no información pública sobre la función que ejerce AVAPSA en el sistema. La referencia a la escasa o nula información relativa al procedimiento y a los criterios que la administración ha empleado en el 
mismo ha sido redundante en el discurso de los juristas que trabajan en la defensa y garantía de este derecho en diferentes organizaciones.

- La ausencia de participación y nula capacidad de influir en las decisiones: débil responsabilidad pública que, a su vez, debilita el estatus de ciudadanía generando indefensión frente al silencio de la administración y escasa capacidad real de elección o desacuerdo con la prescripción profesional. También, en el mismo sentido y de manera contundente se han pronunciado todos/as los/as juristas entrevistados/as, haciendo énfasis en el silencio como respuesta habitual de la administración y los graves perjuicios que conlleva esta forma de proceder sobre el derecho (inseguridad, incertidumbre, menosprecio y falta de garantías al derecho).

La aplicación de la LAPAD en la Comunitat Valenciana ha resultado ser ejemplo de cómo los avances en el marco jurídico no necesariamente se materializan incluso cuando se refiere a derechos de obligado cumplimiento por parte de las administraciones.

Los colectivos de profesionales, la ciudadanía, las organizaciones de personas discapacitadas y mayores así como los agentes sociales han insistido en las ineficiencias propias de su puesta en marcha: los procedimientos empleados, las dificultades que se plantean en el ejercicio del derecho y las garantías de equidad según territorio de residencia.

La acción reivindicativa y propositiva de las plataformas ciudadanas, organizaciones de profesionales y sindicatos han dado muestras de una viva y rica rendición de cuentas societal pero sus posibilidades de injerencia en la acción gubernamental han sido mínimas, inclusive en el caso de aquellas organizaciones, como ocurre en el caso de los sindicatos, que forman parte de órganos como el Comité Consultivo. Las alegaciones a la norma valenciana, la recogida de firmas, las manifestaciones o concentraciones y los intentos de interlocución con la administración no han resultado efectivos al igual que tampoco lo han sido los organismos que velan por la rendición de cuentas horizontal.

Pese al escaso poder sancionador, sí que ha existido una contribución importante en términos de «información, respuestas y exigencia de responsabilidades» que no ha acabado sólo en el terreno judicial sino en el plano de la política y la acción democrática de la ciudadanía, siendo elementos imprescindibles para alimentar no sólo la cultura de la legalidad sino, fundamentalmente, la cultura democrática. En este sentido, se puede concluir que frente a una débil rendición de cuentas legal y administrativa se ha logrado una fuerte 
rendición de cuentas societal ${ }^{13}$ y horizontal ${ }^{14}$, con un importante papel de las plataformas ciudadanas, defensores del pueblo así como el propio tribunal de cuentas.

Por otro lado, la LAPAD, al reconocer un derecho subjetivo, ha motivado la defensa judicial de éste, siendo muchas personas quienes han emprendido su vía de reivindicación de manera individualizada y por la vía de los Tribunales. Si bien ésta es una respuesta legítima y necesaria, no se puede reducir la defensa del derecho a la misma y ni siquiera representa una vía interesante para alimentar la cultura de la legalidad y democrática.

La garantía de los derechos sociales no puede dirimirse únicamente en el terreno judicial porque, como plantea Pisarello (2007: 90), éste puede convertirse en un "factor de erosión de la propia participación política, puesto que generaría en los ciudadanos una «ilusión de tutela» que lo llevaría a remplazar la lucha electoral y la movilización social por la imposición de acciones judiciales». Por tanto, también deben ser responsables de su tutela órganos legislativos, ejecutivos incluso órganos independientes como los tribunales de cuentas o los defensores del pueblo. En conclusión, se trata, como plantea este autor, de una reconstrucción compleja de las garantías a través tanto de mecanismos institucionales como extrainstitucionales o sociales, facilitando la organización colectiva y la participación como mecanismos de autotutela.

Las referencias a los diferentes mecanismos de garantía y tutela de los derechos remiten inevitablemente a los diferentes niveles de rendición de cuentas reconocidos. Si éstos no se dan, se debilitan los mecanismos administrativos y políticos responsables de garantizar los derechos sociales.

Tras la investigación realizada, las respuestas apuntan a la escasa o nula cultura de la legalidad y al mal gobierno, manifestadas con claridad en la relación administración-ciudadanía. Se trata de buscar las razones estructurales que dan origen a estas situaciones y que, a modo de pescadilla que se muerde la cola, son a su vez causa y consecuencia: la desmaterialización del Estado de Bienestar estaría en la base de la frágil cultura de la legalidad con la que opera la administración pero, a su vez, ésta débil cultura contribuye a la desmaterialización del anterior. Como plantean Pisarello y Asens (2012: 142) «Si no se podía obligar a un gobierno a satisfacer todos los derechos sociales de la

13. La rendición de cuentas societal es un mecanismo no electoral, vertical, de control de las autoridades políticas que descansa en las acciones de un múltiple conjunto de asociaciones de ciudadanos y movimientos sociales.

14. La rendición de cuentas horizontal supone la relación entre el gobierno, la administración y los órganos independientes de la misma pero de carácter institucional, controlando su labor con auditorías, defensores, tribunales de cuentas, fiscalías, inspectores. 
noche al día, si cabía, en cambio, imponerle la obligación de no generar retrocesos arbitrarios en relación con las conquistas adquiridas».

\section{Bibliografía}

Agencia Estatal de Evaluación de las Políticas Públicas y la Calidad de los Servicios (2009). La participación de la Administración General del Estado en el Sistema para la Autonomía y Atención a situaciones de Dependencia. http://www. aeval.es/comun/pdf/evaluaciones/E13.pdf (12 de julio de 2013).

Asociación Estatal de Directores y Gerentes de Servicios Sociales (2009). II Dictamen del Observatorio. Análisis y evaluación del proceso de implantación de la Ley de promoción de autonomía personal y atención a situaciones de dependencia. Ed. Ayuntamiento de Alcorcón.

Asociación Estatal de Directores y Gerentes de Servicios Sociales (2010a). IV Dictamen del Observatorio. Análisis y evaluación del proceso de implantación de la Ley de promoción de autonomía personal y atención a situaciones de dependencia. Enero. Ed. Ayuntamiento de Alcázar de San Juan.

Asociación Estatal de Directores y Gerentes de Servicios Sociales (2010b). V Dictamen del Observatorio. Análisis y evaluación del proceso de implantación de la Ley de promoción de autonomía personal y atención a situaciones de dependencia. Junio. Ed. Ayuntamiento de Alcorcón.

Asociación Estatal de Directores y Gerentes de Servicios Sociales (2011). VI Dictamen del Observatorio. Análisis y evaluación del proceso de implantación de la Ley de promoción de autonomía personal y atención a situaciones de dependencia. Ed. Colexio Oficial de Traballo Social de Galicia.

Asociación Estatal de Directores y Gerentes de SS.SS. (2008). I Dictamen del Observatorio. Evaluación y análisis de los procesos de implantación de la Ley de Promoción de autonomía personal y atención a situaciones de dependencia. Síntesis de las Jornadas celebradas en Alcázar de San Juan. Ed. Diputación de Ciudad Real.

Asociación Estatal de Directores y Gerentes de SS.SS. (2009b). III Dictamen del Observatorio. Desarrollo e implantación de la Ley de promoción de la autonomía y atención a personas en situaciones de dependencia. Junio 2009. Síntesis de las jornadas celebradas el 22 y 23 de mayo de 2009.

Cervera, M., Herce, J. A., López, G., Rodríguez, G. y Sosvilla, S. (2009). Informe final del grupo de expertos para la evaluación del desarrollo y efectiva aplicación de la ley 39/2006 de promoción de la autonomía personal y atención a las personas en situación de dependencia. Ministerio de Sanidad y Política Social. http://www.imserso.es/InterPresent1/groups/imserso/documents/binario/informesaadgexpertos.pdf (19 de julio de 2013). 
GINER, S. (2005). Ciudadanía pública y sociedad civil republicana. Documentación Social, $n^{\circ} 139,13-34$.

KAHALE, D. T. (2009). La cobertura de la situación de dependencia. Madrid: Fundación Alternativas.

PIÉ, A. (2012). Fundamentos de la educación para la autonomía: los Disability Studies. En Pié, A. (coord.): Deconstruyendo la dependencia. Propuesta para una vida independiente (pp. 21-46). Barcelona: Editorial UOC.

PIÉ, A. (coord.) (2012). Deconstruyendo la dependencia. Propuestas para una vida independiente. Barcelona: Editorial UOC.

Pisarello, G. (2007). Los derechos sociales y sus garantías. Madrid: Trotta.

PisArello, G. y Asens, J. (2012). No hay derecho(s). La ilegalidad del poder en tiempos de crisis. Barcelona: Icaria.

ROLDÁN, E. (2001). ¿Hacia un sistema mixto del bienestar social? La evolución de los servicios sociales en España. Madrid: Editorial Complutense.

ROMAÑACH, J (2012). Ética y derechos en la práctica diaria de la atención a la dependencia: autonomía moral vs autonomía física. En A. Pié (coord.). Deconstruyendo la dependencia. Propuesta para una vida independiente (pp. 47-74). Barcelona: Editorial UOC.

SENNETT, R. (2003). El respeto. Madrid: Anagrama.

Vidriales, R., DE ARAOZ, I., BeOtAS, J. L., LÓPEZ, J. M., MARrero, R. y RodríGuez, A. (2009). Análisis de los desarrollos normativos del SAAD. Colección Cermi. es, $n^{\circ}$ 40. Madrid: Cinca. http://www.cermi.es/es-ES/ColeccionesCermi/Cermi.es/Lists/Coleccion/Attachments/65/AnalisisdelosdesarrollosnormativosdelSAAD.pdf (10 de febrero de 2010).

VILLORIA, M. y WenCES, M. I. (2010). Cultura de la legalidad. Madrid: Catarata.

VV.AA. (2011). Informe del Gobierno para la evaluación de la Ley de promoción de autonomía personal y atención a situaciones de dependencia. Ministerio de Sanidad y Política Social.

Young, I. M. (2000). Inclusion and Democracy. Oxford: Oxford University Press. 


\title{
PROCESO DE SELECCIÓN DE LOS CENTROS DE PRÁCTICAS DE TRABAJO SOCIAL ${ }^{1}$. INSTRUMENTO DE SISTEMATIZACIÓN Y OBJETIVACIÓN
}

\author{
Selection process for centres hosting social work student interns ${ }^{2}$. \\ Instrument to ensure systematic objective results
}

Amaia Mosteiro Pascual ${ }^{3}$, Usue Beloki Marañón ${ }^{3}$, Emma Sobremonte Mendicuti $^{4}$

\section{Resumen}

En este artículo se presenta el instrumento diseñado por el equipo responsable de Prácticas Externas del grado en Trabajo Social de la Universidad de Deusto para la valoración de la idoneidad de los centros de prácticas como receptores de nuestro alumnado. La construcción del instrumento se ha llevado a cabo a través de grupos de discusión entre docentes de trabajo social y profesionales con amplia experiencia en la formación de alumnado en prácticas en sus centros. Su diseño se inicia con el objetivo de identificar los elementos clave para asegurar la calidad en la elección de los centros de prácticas. Tomando como referencia el conocimiento y la experiencia acumulada de los agentes implicados en la formación práctica del alumnado, el instrumento incorpora y pondera las dimensiones identificadas a fin de reducir la variabilidad que conlleva su valoración subjetiva. Pretende igualmente ser una herramienta útil para la toma de decisiones en situaciones en las que se ha de valorar un eventual cambio de centro. Consideramos que el diseño de instrumentos de esta naturaleza permitirá mejorar la praxis docente $y$, en definitiva, incrementar la calidad de las prácticas externas mediante el trabajo conjunto con los centros de prácticas.

Palabras clave: Prácticas Externas, Trabajo Social, instrumento de valoración, calidad, centros de prácticas.

\begin{abstract}
This article presents the instrument designed by the team coordinating internships in the undergraduate degree in Social Work at the University of Deusto. The purpose is to evaluate the suitability of centres hosting our students as interns. Discussion groups made up of Social Work lecturers and practising professionals with long experience training student interns at their centres held discussion groups to build the instrument. Design of the instrument focused on identifying the key aspects to ensure quality when choosing a centre to host interns. The instrument is based on knowledge and experience gained by agents involved in students' practical training. It includes and assigns weight to the dimensions identified in order to reduce the variability implied by subjective evaluation. It also aims to be a useful tool when making decisions concerning possible changes to another centre. We believe that designing instruments of this type will improve teaching praxis and ultimately enhance the quality of external internships through joint work with centres hosting the interns.
\end{abstract}

Keywords: External internships, social work, assessment tool, quality, internship centres.

1. El contenido de este artículo fue presentado parcialmente como comunicación para su debate en el XII Symposium Intenacional sobre el Prácticum y las Prácticas en empresas en la formación universitaria. Celebrado en Poio (Pontevedra) del 26 al 28 de junio de 2013.

2. A communication consisting of parts of this article was submitted for debate at the 12th International Symposium on Practicums and Internships in University Education held in Poio (Pontevedra) from 26 to 28 June 2013.

3. Universidad de Deusto. Departamento de Trabajo Social y Sociología.

4. Responsable de la correspondencia. Universidad de Deusto. Facultad de Ciencias Sociales y Humanas. Departamento de Trabajo Social y Sociología. Avda. Universidades, 24. 48007. Bilbao. emma.sobremonte@deusto.es. 


\section{Introducción}

La implementación de los nuevos grados en las universidades españolas como consecuencia de la incorporación al Espacio Europeo de Educación Superior (EEES) ha propiciado un creciente interés por la formación teórico-práctica del alumnado de las diversas titulaciones incorporándose las prácticas externas por primera vez en algunas de ellas y, en otras, otorgándoles un peso mayor. En el caso del Trabajo social, este proceso ha reforzado su filosofía y planteamiento de enseñanza-aprendizaje y ha fomentado la mejora continua y la innovación. Fortalecer la integración teórico-práctica del alumnado a través de la prácticas externas ha sido una constante en los planes de estudio universitarios de Trabajo Social, de ahí que sus objetivos formativos, su estructura y organización, los agentes implicados o la supervisión hayan sido tratados en diversos foros científicos y objeto de numerosas publicaciones.

En los últimos años, esta importancia dada al vínculo teórico- práctico de la formación en Trabajo Social ha sido reconocida en el Libro Blanco de Trabajo Social, aprobado en 2004 por la Agencia Nacional de Evaluación de la Calidad y Acreditación (ANECA, 2004), así como en el documento Criterios para el diseño de planes de estudio de los grados en Trabajo Social aprobado conjuntamente por la Conferencia Española de Decanos/as y Directores/as de Centros y Departamentos de Trabajo Social y el Consejo General de Diplomados en Trabajo Social y Asistentes Sociales, en 2007 (Conferencia de Directores y Directoras de Centros y Departamentos de Trabajo Social, 2007)

De ambos documentos se desprende la centralidad de las prácticas externas en el proyecto formativo del grado en Trabajo Social y se plasma la necesidad de disponer de un programa específico que cuente con la colaboración de profesionales de centros externos. En este sentido, el documento Criterios para el diseño de planes de estudio es un poco más preciso cuando señala que las prácticas externas deben desarrollarse en servicios y entidades desde las que se prestan servicios de Trabajo Social reconocidos como centros colaboradores para la formación en prácticas por las universidades. (Conferencia de Directores y Directoras de Centros y Departamentos de Trabajo Social, 2007) (en adelante CDTS). En la encuesta pasada por parte de la CDTS a todas las universidades que imparten el título de Trabajo Social también se han abordado cuestiones directamente relacionadas con la calidad de los centros de prácticas (Ovejas, C. et al, 2012). Con los resultados de esta encuesta la CDTS decide elaborar el documento sobre Estándares de calidad en las prácticas curriculares externas del título de grado en Trabajo Social, aprobado por la Conferencia de Directores/ as de Centros y Departamentos de Trabajo Social en 2013. Este documento es un claro exponente del compromiso de la comunidad universitaria con la 
calidad de las prácticas. Se trata de un documento de recomendaciones cuyo objetivo es orientar a las universidades respecto a los mínimos universalizables en torno a los aspectos que configuran las prácticas (Conferencia de Directores/as de Centros y Departamentos de Trabajo Social, 2013) y en donde se recogen detalladamente los aspectos esenciales de las mismas señalándose, a propósito de la elección de los centros colaboradores, la necesidad de definir criterios de selección teniendo en cuenta las características y/o requisitos que deben cumplir, de modo que garanticen el desarrollo del proceso formativo (Conferencia de Directores/as de Centros y Departamentos de Trabajo Social, 2013) Por tanto, la elección del centro de prácticas resulta fundamental dentro del proceso formativo.

La importancia dada a este elemento se ha hecho explícita a través de diversos foros de prácticas y documentos específicos de Trabajo Social. Miguel Zabalza (2011), en su ponencia presentada en el XI Symposium Internacional sobre el practicum y las prácticas en empresas, destaca como criterio específico de calidad de las prácticas externas la propuesta de contenidos formativos vinculados a las mismas y afirma que su implementación condicionará, entre otros aspectos, la elección de los centros de prácticas y de tutores. De forma más concreta, Leandra Pérez (1998) defiende dentro del proceso organizativo de las prácticas externas la importancia de la fase de selección de los centros como pieza clave en el aprendizaje del alumnado. Señala que el área en que se desarrolle la actividad profesional del centro ha de estar directamente relacionada con las actividades propias del Trabajo Social. Otros autores como Sergio Fernández (2008) y Enrique Pastor (2010) destacan el importante papel de los centros de prácticas y del tutor/a de los mismos en la formación práctica del alumnado, poniendo de manifiesto la necesaria vinculación entre la persona encargada de la supervisión de las prácticas en la universidad con estos agentes, de tal forma que se amplíe y actualice el conocimiento y que se tenga presente el papel que juega el marco contextual y organizacional para la práctica profesional. Todos estos elementos inciden en el proceso de selección de centros como punto de partida para garantizar un aprendizaje de calidad. Otroa autores como Mingun Lee y Anne E. Fortune se han referido en diversos artículos a las actividades que se desarrollan en los centros y a reflexionar cómo contribuyen a la adquisición de las competencias profesionales y a la satisfacción del alumnado. (Fortune, y Kaye, 2002; Lee y Fortune, 2013)

Sin embargo, la importancia dada a este proceso no se ha traducido en la elaboración de trabajos en los que se sistematicen y ponderen de forma objetiva las diversas dimensiones susceptibles de ser valoradas en el momento de seleccionar la idoneidad de los centros. Por ello, el desarrollo del nuevo título de grado en Trabajo Social ha resultado una excelente oportunidad para reflexionar sobre esta cuestión e intentar plasmar el conocimiento acumulado 
a través de instrumentos que permitan, por un lado, asegurar la calidad del aprendizaje y, por el otro, incorporarlo a los procesos de garantía de calidad que las universidades españolas están desarrollando.

Por las razones expuestas el equipo responsable de las prácticas externas de Trabajo Social de la Universidad de Deusto ha estado trabajando en la elaboración de un instrumento de valoración de los centros de prácticas, que permita:

a. Seleccionar aquellos centros que posibiliten el desarrollo del proyecto formativo y por tanto, garanticen la adquisición de las competencias de la asignatura «Prácticas de Trabajo Social». Esta selección exige sistematizar todas las dimensiones implicadas en el proceso formativo. Por ejemplo, qué profesionales de los centros colaboradores pueden o deben tutelar al alumnado, qué posibilidades ofrecen para el desempeño de las diversas actividades del proyecto formativo o cuáles son las condiciones contextuales de los centros.

b. Jerarquizar los centros en función del mayor o menor grado de adecuación al conjunto de dimensiones que condicionan y configuran el proyecto formativo. Ciertamente, el abanico de centros donde el alumnado puede desarrollar sus prácticas es rico y diverso, por tanto, los matices y singularidades de cada uno de ellos deberán ser tenidos en cuenta a la hora de valorar su idoneidad global. El hecho de tratar de establecer una jerarquía que ayude a conocer qué centros o servicios cubren en mayor medida las necesidades de aprendizaje del alumnado contribuye a establecer un punto de corte como umbral por debajo del cual habría que plantearse la posibilidad de eliminarlo del catálogo de centros de prácticas o, por el contrario, de revisar su oferta formativa.

c. Asegurar la continuidad de los criterios de calidad utilizados en la selección de los centros en el tiempo, así como preservar hasta donde sea posible, la objetividad en su aplicación, independientemente de las personas que asuman esta responsabilidad en cada momento. No es ningún secreto que factores como el cambio de los agentes implicados en la gestión de las prácticas, su formación o concepción del trabajo social, así como otros factores coyunturales como la disponibilidad de centros en un momento dado pueden influir en la evaluación de su idoneidad para recibir estudiantes en prácticas. Sin negar el peso que tienen dichos factores, consideramos que disponer de un instrumento que valore y pondere los diferentes aspectos implicados en la selección puede contribuir a mejorar el proceso de aprendizaje y a homogeneizar los criterios dentro de nuestra comunidad científica 
respondiendo así tanto a las exigencias normativas como a la ética de las buenas prácticas en el aprendizaje universitario.

d. Constituirse en una herramienta eficaz para la toma de decisiones relativas a cambios de centro de prácticas solicitados tanto por el alumnado como por la persona que lleva su tutela o supervisión académica. Se sabe que la propuesta de cambio de centro es una dificultad que sobreviene durante el desarrollo de las prácticas por diferentes razones, por eso, se considera que el disponer de criterios objetivables permite dar una respuesta adecuada a esta eventualidad minimizando, en la medida de lo posible, la subjetividad inherente a la toma la decisiones que conlleva el cambio de centro.

\section{Método}

El instrumento que se presenta se ha elaborado a través de grupos de discusión. Los criterios de selección de los/as participantes han sido, por un lado, la experiencia en la formación del alumnado en prácticas del Grado en Trabajo Social y, por otro, el perfil profesional de Trabajo Social. Así, y de cara a garantizar heterogeneidad en el grupo, este ha quedado conformado por 10 participantes: 5 docentes del Departamento de Trabajo Social y Sociología de la Universidad de Deusto y 5 profesionales del Trabajo Social, de distintos ámbitos de intervención: 4 profesionales del ámbito público de servicios sociales, dos de atención primaria y dos de atención especializada, y un profesional perteneciente al ámbito del tercer sector.

El trabajo se ha desarrollado a lo largo de ocho meses, con una sesión mensual. Este proceso se ha realizado a través de las siguientes fases:

- Clarificación conceptual de los términos esenciales asociados a las prácticas.

- Identificación de las dimensiones clave para la selección de los centros de prácticas y de los factores de exclusión.

- Clasificación de las dimensiones en factores, en función del tipo de contribución que aportan al proceso de aprendizaje en el prácticas.

- Descomposición de cada factor debidamente clasificado en indicadores que valoren las diferentes dimensiones que contiene cada factor.

- Ponderación, a través de puntuaciones, del peso específico de cada factor y dimensión, en función de su incidencia en el proceso de aprendizaje.

- Aplicación piloto del instrumento al conjunto de centros receptores de alumnado del Grado de Trabajo Social del curso 2012-2013. 
3. Descripción del proceso de construcción de la herramienta de selección de centros

\subsection{Identificación de las dimensiones clave y de los factores de exclusión}

La identificación de las dimensiones clave para la idoneidad de los centros de prácticas por parte del equipo de trabajo tiene su base en la experiencia acumulada durante veinte años, tanto del profesorado como de los profesionales de los centros de prácticas, en la asignación y recepción de alumnado en prácticas.

Las dimensiones clave a la hora de valorar la idoneidad de un centro que acoge y forma al alumnado de prácticas son las siguientes: perfil profesional del tutor/a externo de las prácticas; actividades que el estudiante puede realizar en el centro de prácticas; condiciones contextuales de realización de las prácticas; inserción laboral; idioma de comunicación en el centro; trasferencia del conocimiento y perfiles de usuarios.

\section{Dimensión 1. Perfil profesional}

Esta dimensión hace referencia a la titulación de base de la persona encargada de la tutela del alumnado en el centro de prácticas. El Trabajador/a Social es competente, tanto en sentido normativo como profesional, en el desempeño de unas intervenciones y técnicas específicas dentro del campo de la intervención social. Éstas están dirigidas a los fines propios del Trabajo Social recogidos en el Código Deontológico Profesional (2012). En la identificación de esta dimensión se han tenido en cuenta las consideraciones surgidas del debate sobre la idoneidad de que alumnado en prácticas pueda ser formado por perfiles profesionales diferentes al de trabajo social. Aunque la mayoría de los miembros del grupo de discusión defendía que la tutela en el centro debía ser desempeñada por un/a profesional del Trabajo Social, quedó claro que era preciso considerar excepciones siempre y cuando esta carencia fuera compensada por otras dimensiones asociadas al aprendizaje práctico como por ejemplo la participación en un proyecto de interés social o innovador en el que alumnado se encuentre acompañado por profesionales de disciplinas afines y donde tenga la oportunidad de realizar actividades propias del Trabajo Social. En estos casos y otros similares, la supervisión de la universidad tendrá que ser mucho más estrecha y llevada a cabo por un/a profesional del Trabajo Social. Sin embargo, a efectos de valorar esta dimensión, existe unanimidad en otorgar un mayor peso al tutelaje realizado por los/as profesionales del Trabajo Social. La preocupación que suscitó el hecho de que proyectos innovadores pudieran verse afectados al obtener menos puntuación en esta dimensión, se disipó al tener presente que este déficit podía ser no sólo compensarse sino superase por un mayor peso en el resto de las dimensiones. 


\section{Dimensión 2. Actividades del proyecto formativo}

El reconocimiento de la idoneidad de un centro de prácticas como receptor de alumnado depende, tanto de las oportunidades que ofrece para la adquisición de competencias genéricas y específicas, como de la diligencia y pericia del profesional en el seguimiento y supervisión de las responsabilidades asumidas por el estudiante. La adquisición de las competencias asignadas a la asignatura de prácticas externas y que se recogen en el programa y guía de aprendizaje de la misma, se concreta en las actividades de formación plasmadas en el proyecto formativo de cada estudiante.

El equipo responsable de las prácticas del Grado en Trabajo Social de la Universidad de Deusto ha elaborado un catálogo sintético de actividades y técnicas propias de la profesión que posibilitan la adquisición de las competencias asignadas a las prácticas. Dado que la elaboración del catálogo suscitó un intenso debate conceptual en torno a la clasificación de las intervenciones y técnicas de la profesión, hubo que dirimir la cuestión de una forma pragmática atendiendo a la finalidad para la cual se estaba elaborando el catálogo. Y la finalidad era, en primer lugar, conocer qué tipo de actividades podía desarrollar el alumnado en cada uno de los centros de prácticas que garantizaran la obtención de los resultados de aprendizaje relativos al conjunto de competencias asignadas a las prácticas en nuestro centro.

En segundo lugar, establecer un compromiso de formación individualizado para cada estudiante en base a la selección de las actividades catalogadas que ofrece el centro y entendiendo que los caminos para obtener los resultados de aprendizaje pueden ser variados. Esto significa que la adquisición de las competencias se deriva de combinaciones múltiples y diversas de las actividades del catálogo no siendo necesaria la realización de todas ellas para adquirir las competencias. En este sentido, la selección de actividades se adecua a las posibilidades y riqueza que ofrecen los centros.

Por otra parte, el catálogo debía ser sencillo, claro y conciso, de tal manera que facilitara su comprensión por parte de todos los agentes implicados en las prácticas externas. Así que, tras contrastar el catálogo inicial con diferentes profesionales de los centros de prácticas, optamos por la versión que presentamos a continuación inspirada en la clasificación de las intervenciones de Cristina de Robertis (De Robertis, 1988), aun siendo conscientes de que desde un punto de vista estrictamente metodológico el catálogo no se corresponde con la tradicional diferenciación entre técnicas e intervenciones de Trabajo Social. Teniendo en cuenta que en la negociación con los centros se pueden dar simultáneamente intervenciones individuales, familiares, grupales y comunitarias, el siguiente catálogo trata de recoger una oferta amplia de actividades que pueden darse en una y otra modalidad. 
Tabla 1. Catálogo de actividades

\begin{tabular}{|c|c|c|}
\hline \multicolumn{3}{|c|}{ ACTIVIDADES A DESARROLLAR EN EL CENTRO } \\
\hline $\begin{array}{l}\text { ATENCIÓN DIRECTA } \\
\text { (participación o } \\
\text { realización de las } \\
\text { mismas) }\end{array}$ & \multicolumn{2}{|c|}{$\begin{array}{l}\text { - Observación directa. } \\
\text { - Entrevistas individuales } \\
\text { - Entrevistas familiares } \\
\text { - Acompañamiento a visitas domiciliarias } \\
\text { - Acompañamiento a recursos sociales } \\
\text { - Sesiones grupales } \\
\text { - Sesiones o charlas comunitarias } \\
\text { - Seguimiento de casos objeto de intervención. } \\
\text { - Aplicación de herramientas de valoración social } \\
\text { - ......................................... (otras) }\end{array}$} \\
\hline \multirow{3}{*}{$\begin{array}{l}\text { ATENCIÓN } \\
\text { INDIRECTA } \\
\text { (participación o } \\
\text { realización de las } \\
\text { mismas) }\end{array}$} & $\begin{array}{l}\text { Coordinación y } \\
\text { gestión }\end{array}$ & $\begin{array}{l}\text { - Actividades de coordinación interna } \\
\text { y externa con otros/as profesionales: } \\
\text { entrevistas, reuniones, etc. } \\
\text { - Participación en derivaciones activas } \\
\text { o pasivas } \\
\text { - Asistencia a reuniones de equipo } \\
\text { - Propuesta de recursos y/o tramitación } \\
\text { de los mismos. } \\
\text { - Otras................................. }\end{array}$ \\
\hline & $\begin{array}{l}\text { Planificación y } \\
\text { evaluación }\end{array}$ & 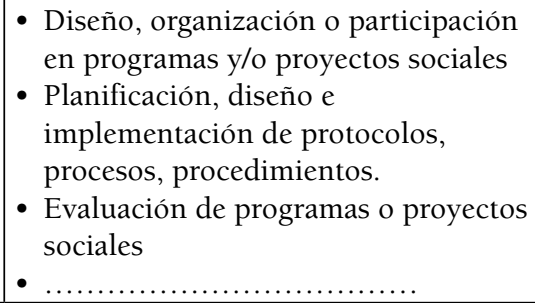 \\
\hline & $\begin{array}{l}\text { Documentación y } \\
\text { registros }\end{array}$ & $\begin{array}{l}\text { - Revisiones documentales } \\
\text { - Registros de T.S.: } \\
\text { - Genograma } \\
\text { - Registro de entrevistas individuales } \\
\text { y/o familiares } \\
\text { - Registro de visita } \\
\text { - Historia Social. } \\
\text { - Ficha social. } \\
\text { - Informe Social. } \\
\text { - Hoja de seguimiento: registro de } \\
\text { actividades y seguimiento } \\
\text { - Registros o crónicas de sesiones } \\
\quad \text { grupales o colectivas } \\
\text { - Manejo de aplicaciones informáticas } \\
\text { - Otras.......................... }\end{array}$ \\
\hline
\end{tabular}




\begin{tabular}{|l|l|}
\hline \multicolumn{2}{|c|}{ ACTIVIDADES A DESARROLLAR EN EL CENTRO } \\
\hline INVESTIGACIÓN & $\begin{array}{l}\text { - Estudio/ análisis de la realidad } \\
\text { - Diseño o desarrollo de proyecto de investigación } \\
\text { - Aplicación de técnicas de investigación social }\end{array}$ \\
\hline FORMACIÓN & $\begin{array}{l}\text { - Asistencia a cursos, jornadas, congresos u otro tipo de } \\
\text { actividades científicas }\end{array}$ \\
\hline
\end{tabular}

Al inicio del curso, la Universidad acuerda con cada centro de prácticas las actividades que el/la estudiante en prácticas tendrá la posibilidad de realizar. Durante el curso, y en dos momentos, el centro informa al equipo de las actividades y técnicas en las que el alumnado participa junto al profesional y de aquéllas que realiza por sí mismo. Asimismo, el estudiante identifica su participación en las actividades del catálogo.

\section{Dimensión 3. Condiciones contextuales del centro de prácticas}

Las condiciones del Centro de prácticas deberán respetar la normativa vigente y facilitar el aprendizaje por parte del alumnado. En este factor se ha tenido especialmente en cuenta todo lo relativo a los derechos y deberes de los estudiantes en prácticas que se recogen en el Estatuto del Estudiante Universitario. Consideramos condiciones contextuales aspectos tales como las oportunidades de formación y de integración en la organización de prácticas que facilitan el aprendizaje. Nos referimos al proceso de acogida, a la disponibilidad de espacios adecuados para el desempeño de su trabajo, a las oportunidades de relación con otros profesionales y a al compromiso con la igualdad de oportunidades, la no discriminación y la accesibilidad universal.

\section{Dimensión 4. Inserción laboral}

En esta dimensión se recoge la importancia de tener en cuenta aquellos centros de prácticas en los que el equipo responsable de la universidad detecte que hay una posibilidad a corto plazo de inserción laboral para el alumnado en prácticas, así como aquellos que desarrollan su labor en un área estratégica de creación de empleo.

\section{Dimensión 5. Idioma vehicular}

Dada la realidad socio-lingüística de la Comunidad Autónoma Vasca, la oferta de plazas bilingües (euskera-castellano) se considera un aspecto importante que incrementa la calidad de la oferta al servicio del alumnado. Asimismo, 
se considera un criterio de calidad la posibilidad de usar otros idiomas en el centro de prácticas.

Dimensión 6. Trasferencia del conocimiento

La importancia de esta dimensión radica en el valor añadido que aporta la creación de redes de colaboración entre los centros de prácticas y la universidad para el diseño y desarrollo conjunto de proyectos de investigación, formación e innovación social.

Dimensión 7. Perfiles de usuarios

El equipo responsable considera que los centros de atención primaria, en la medida en que trabajan con perfiles de usuarios diversos, dan la posibilidad al estudiante de conocer múltiples realidades y situaciones-problema. Ello permite al alumnado realizar una valoración de sus propios intereses y capacidades, lo que le será de gran ayuda para la mejora continua y para orientar su futuro profesional hacia un ámbito concreto de intervención, ya sea en la formación especializada de postgrado o en la búsqueda activa de empleo. Se considera además que los centros de atención especializada ofrecen una experiencia de aprendizaje práctico que se aprovecha en mayor medida por los estudiantes de postgrado. Este tema ha dado lugar a la apertura del debate relativo a los elementos diferenciadores de la formación práctica de grado y la de postgrado, cuestión que dada la nueva ordenación de titulaciones universitarias constituye un gran desafío para nuestra disciplina.

Por último, hay que destacar que de la identificación de las dimensiones clave para establecer la idoneidad de los centros de prácticas, surgieron ciertos aspectos no contemplados que por sí mismos, dada su importancia y trascendencia, podían conllevar la exclusión del catálogo de centros de prácticas. Nos referimos a aquellos centros cuyos fines no sean acordes con los principios y valores del trabajo social y lo establecido en el Código Deontológico del Trabajo Social. La reflexión sobre este factor ha recogido una rica discusión sobre las cuestiones éticas y su sentido dentro de la formación del trabajo social teniendo en cuenta la conjunción de factores profesionales, factores institucionales y la defensa de las libertades y los derechos humanos. Nos referimos, por ejemplo, a casos excepcionales en los que alguna organización o empresa ha solicitado alumnado en prácticas para intentar utilizar técnicas y actividades propias del Trabajo Social con fines lucrativos ajenos al mismo de manera velada. Asimismo, constituye un factor de exclusión la 
incompatibilidad horaria de las prácticas con las actividades docentes en la universidad y otras establecidas en el Estatuto del Estudiante Universitario.

\subsection{Clasificación de las dimensiones clave e indicadores}

En un segundo momento, se ha procedido a agrupar las dimensiones en factores en función del tipo de contribución que aportan al proceso de aprendizaje en las prácticas. Son tres los factores que resultan de esta agrupación: a)factores determinantes del aprendizaje, b)factores posibilitadores del desempeño pre-profesional y c)factores promotores del conocimiento.

Factor determinante del aprendizaje

Este factor está formado por las dimensiones 1 y 2 y sus correspondientes indicadores:

- D.1. Perfil profesional del supervisor de las prácticas: Titulación en Trabajo Social, titulaciones del ámbito de la intervención social y otras titulaciones.

- D.2. Actividades propias del Trabajo Social: actividades y técnicas de atención directa, indirecta y de gestión y documentación, de carácter individual, familiar, grupal y comunitario. En esta dimensión se valora también la congruencia entre las actividades planificadas y las efectuadas por el alumnado. Se contrasta también el ajuste entre la percepción que de dicha realización tiene e/la tutor/a del centro y el/la estudiante. Asimismo, se incluyen como indicadores el grado de consecución de las competencias del alumnado durante el curso anterior y la supervisión y seguimiento por parte del tutor/a del centro.

Estas dimensiones se consideran esenciales para la adquisición de las competencias genéricas y específicas profesionales que aseguran el desempeño del perfil profesional del trabajador/a social.

Factor posibilitador del desempeño pre-profesional

Este factor incluye las dimensiones 3, 4 y 5 y sus correspondientes indicadores

- D.3. Condiciones contextuales del centro de prácticas: oportunidades de formación complementaria (cursos, jornadas, etc.); integración física y organizativa del alumnado en el equipo de profesionales; facilitación de documentación relativa al ámbito de las prácticas; condiciones de 
accesibilidad para estudiantes con discapacidad que aseguren la igualdad de oportunidades.

- D.4. Inserción laboral: oportunidad previsible de contrato del estudiante en el centro de prácticas dentro del año siguiente a la finalización de las prácticas; ámbito de intervención identificado como de alta empleabilidad por el equipo responsable.

- D.5. Idioma vehicular: bilingüe euskera castellano; otros idiomas; otros sistemas de comunicación (lengua de signos, etc.)

Las dimensiones de este factor además de asegurar un desempeño pre-profesional adecuado, dotan al estudiante de mayores posibilidades de empleabilidad.

Factor promotor del conocimiento

Este factor incluye las dimensiones 6 y 7 , con sus correspondientes indicadores.

- D.6. Trasferencia del conocimiento: participación conjunta en proyectos de investigación, formación e innovación social.

- D.7. Perfiles de usuarios: servicios sociales y sanitarios de atención primaria; servicios sociales y sanitarios en el ámbito de la exclusión social; servicios sociales de atención secundaria o especializados.

En este factor se han incluido dos dimensiones que enfatizan por un lado, y amplían por otro, las posibilidades de generación y trasferencia del conocimiento.

\subsection{Ponderación de cada factor y dimensión en función de su incidencia en el} proceso de aprendizaje

Por último, se han ponderado los factores y las dimensiones tal y como se muestra en la tabla siguiente. 
Tabla 2. Instrumento de valoración de los centros de prácticas externas

\begin{tabular}{|c|c|c|c|c|c|}
\hline FACTOR & POND & DIMENSION & INDICADORES & POND & $\begin{array}{l}\text { PUNT. } \\
\text { MÍN/MÁX }\end{array}$ \\
\hline \multirow{8}{*}{$\begin{array}{c}\text { Factor } \\
\text { determinante } \\
\text { del aprendizaje }\end{array}$} & \multirow{8}{*}{$60 \%$} & \multirow{3}{*}{$\begin{array}{l}\text { Perfil profesional } \\
\text { del supervisor de } \\
\text { las prácticas }\end{array}$} & Titulación en Trabajo Social & \multirow{3}{*}{$20 \%$} & \multirow{3}{*}{$0-20$} \\
\hline & & & $\begin{array}{l}\text { Titulaciones intervención } \\
\text { social }\end{array}$ & & \\
\hline & & & Otras titulaciones & & \\
\hline & & \multirow{5}{*}{$\begin{array}{l}\text { Actividades } \\
\text { propias del } \\
\text { Trabajo Social }\end{array}$} & $\begin{array}{l}\text { Actividades y técnicas } \\
\text { planificadas }\end{array}$ & \multirow{5}{*}{$40 \%$} & \multirow{5}{*}{$0-40$} \\
\hline & & & $\begin{array}{l}\text { Actividades y técnicas } \\
\text { realizadas }\end{array}$ & & \\
\hline & & & $\begin{array}{c}\text { Percepción del estudiante } \\
\text { de la realización de las } \\
\text { actividades }\end{array}$ & & \\
\hline & & & Supervisión y seguimiento & & \\
\hline & & & $\begin{array}{l}\text { Consecución de } \\
\text { competencias }\end{array}$ & & \\
\hline \multirow{10}{*}{$\begin{array}{c}\text { Factor } \\
\text { posibilitador } \\
\text { del desempeño } \\
\text { pre-profesional }\end{array}$} & \multirow{10}{*}{$30 \%$} & \multirow{5}{*}{$\begin{array}{c}\text { Condiciones } \\
\text { contextuales } \\
\text { del centro de } \\
\text { prácticas }\end{array}$} & $\begin{array}{l}\text { Oportunidades de } \\
\text { formación }\end{array}$ & \multirow{5}{*}{$10 \%$} & \multirow{5}{*}{$0-10$} \\
\hline & & & Integración física & & \\
\hline & & & Integración organizativa & & \\
\hline & & & $\begin{array}{l}\text { Facilitación de } \\
\text { documentación }\end{array}$ & & \\
\hline & & & Accesibilidad & & \\
\hline & & \multirow[b]{2}{*}{ Inserción laboral } & Oportunidades de empleo & \multirow[b]{2}{*}{$10 \%$} & \multirow[b]{2}{*}{$0-10$} \\
\hline & & & $\begin{array}{c}\text { Ámbito de alta } \\
\text { empleabilidad }\end{array}$ & & \\
\hline & & \multirow{3}{*}{ Idioma vehicular } & Bilingüe: euskera castellano & \multirow{3}{*}{$10 \%$} & \multirow{3}{*}{$0-10$} \\
\hline & & & Otros idiomas & & \\
\hline & & & $\begin{array}{l}\text { Otros sistemas de } \\
\text { comunicación }\end{array}$ & & \\
\hline \multirow{4}{*}{$\begin{array}{l}\text { Factores } \\
\text { promotores del } \\
\text { conocimiento }\end{array}$} & \multirow[t]{4}{*}{$10 \%$} & $\begin{array}{l}\text { Trasferencia del } \\
\text { conocimiento }\end{array}$ & $\begin{array}{c}\text { Participación conjunta en } \\
\text { proyectos de investigación, } \\
\text { formación e innovación } \\
\text { social. } \\
\end{array}$ & $5 \%$ & $0-5$ \\
\hline & & \multirow{3}{*}{$\begin{array}{l}\text { Perfiles de } \\
\text { usuarios }\end{array}$} & Atención primaria & \multirow{3}{*}{$5 \%$} & \multirow{3}{*}{$0-5$} \\
\hline & & & Exclusión social & & \\
\hline & & & Atención especializada & & \\
\hline TOTALES & $100 \%$ & & & $100 \%$ & 100 \\
\hline
\end{tabular}

\section{Aportaciones}

Tras la aplicación provisional del instrumento con la información disponible en el 2012-2013 se ha podido verificar que las dimensiones consideradas a priori para la selección de los centros de prácticas así como el peso otorgado 
a las mismas coincide con la valoración que hasta la fecha el equipo responsable de prácticas hacía de los centros. Sin embargo, ha modificado también el grado de idoneidad atribuido a algunos de ellos, por lo que el hecho de utilizar este tipo de instrumentos objetivos reduce los sesgos y la variabilidad que subyace en toda valoración y contribuye a focalizarla en las oportunidades objetivables que ofrece el centro para la adquisición del conjunto de las competencias asignadas a las prácticas y evitar la sobrevaloración de algunas o la minimización de otras. Asimismo el instrumento ha resultado eficaz para dirimir algunas discusiones sobre situaciones en las que existían posiciones encontradas sobre la adecuación de algunos centros. Consideramos que el diseño y la validación de instrumentos de esta naturaleza permitirán mejorar la praxis docente y, en definitiva, incrementar la calidad de las prácticas externas mediante el trabajo conjunto con los centros de prácticas en la identificación de los aspectos susceptibles de mejora.

\section{Referencias bibliográficas}

ANECA (2004) Libro blanco del título de grado en Trabajo Social.

Disponibleen:http://www.aneca.es/var/media/150376/libroblanco_trbjsocial_ def.pdf (13/02/13)

Código deontológico de trabajo social (2012) Disponible en: http://www.cgtrabajosocial.com/consejo/codigo_deontologico (20/02/13)

Conferencia Española de Decanos/as y Directores/as de Centros y Departamentos de Trabajo Social y el Consejo General de Trabajo Social (2007) Criterios para el diseño de planes de estudio de los grados en Trabajo Social. No publicado.

Conferencia Española de Decanos/as y Directores/as de Centros y Departamentos de Trabajo Social (2013). Estándares de calidad en las prácticas curriculares externas del título de grado en Trabajo Social. Disponible en: https://www.dropbox.com/s/bd9x6h2d8z7haq5/EstCalPraTS230713.pdf (03/09/13)

De RoberTis, C. (1988). Metodología del Trabajo Social. El Ateneo. Argentina.

FERNÁNDEZ, S. (2008) Identidad y formación en el trabajo social: desafíos corporativos del prácticum para la docencia y el ejercicio profesional. Portularia. Vol. 3. $\mathrm{N}^{\circ}$ 2. Pp 153-164

FORTUNE, A. E., \& KAYE, L. (2002). Leaming opportunities in field practica: Identifying skills and activities associated with MSW students' self-evaluation of skill performance and satisfaction. Clinical Supervisor, 27(1), 5-28.

LeE, M. y Fortune, A. (2013) Do we need more « doing» activities» or « thinking» activities in the field practicum?. Journal of Social Work Education, 49. 646-660.

Ovejas, C., Fernández, J., Rosa, De la Rosa, P., Facal, T., Raya, E. y SobremonTE, E. (2012) Encuesta sobre prácticas externas y Trabajo Fin de Grado en 
Trabajo Social - 2012. Alternativas. Cuadernos de trabajo social. Vol. 19. Pp 93-111.

PASTOR, E. (coord.) (2010). Supervisión y prácticas en trabajo social: organización, metodología e instrumentos para el proceso de construcción del conocimiento desde la práctica profesional. Diego Marín. Murcia

PÉREZ, L. (1998) Metodología de organización de las prácticas de Trabajo Social. Cuadernos de Trabajo Social. Vol. 11. Pp. 57-67.

Real Decreto 1791/2010, de 30 de diciembre, por el que se aprueba el Estatuto del Estudiante Universitario. BOE. Num. 318, de 31 de diciembre de 2010.

ZABAlZA, M. (2011) Evaluar la calidad del prácticum: una propuesta. En Raposo, M., Martínez, M.E., Muñoz, P.C., Pérez, A, y Otero, J.C. (coord.) Evaluación y supervisión del prácticum: el compromiso con la calidad de las prácticas. Santiago de Compostela: Andavira. pp. 101-128. Disponible en: http://redaberta. usc.es/poio/documentos/actas/actas_poio_2011.pdf (19/04/13) 



\section{RESEÑAS}

Título: Vivienda y exclusión residencial

Autor: Manuel Hernández Pedreño (coord.)

Edita: Editum. Murcia. 2013. 317 pp.

ISBN: 978-84-15463-72-6

La vivienda se ha convertido en España en uno de los principales problemas sociales, siendo un elemento esencial para que cualquier ciudadano se integre con normalidad en la sociedad. Actualmente muchos procesos de exclusión social se inician a partir de problemas vinculados con la vivienda y la carencia de sus funciones integradoras. Existe una situación de exclusión residencial cuando las condiciones que articulan la construcción social de las necesidades de alojamiento no se cumplen adecuadamente.

En el estudio y análisis de la vivienda convergen numerosas disciplinas (Derecho, Economía, Sociología, Arquitectura, Educación, Trabajo Social,....). Así lo pone de manifiesto la obra colectiva Vivienda y exclusión residencial, coordinada por Manuel Hernández Pedreño y elaborada por los integrantes del Grupo de Investigación Exclusión Social y Desigualdad de la Universidad de Murcia, participando además algunos colaboradores externos.

El libro se compone de 11 capítulos estructurados en tres bloques: Políticas de vivienda; Aproximación a la realidad de la exclusión residencial y Colectivos en desventaja residencial.

En el capítulo 1, El derecho a la vivienda, Teresa Vicente Giménez, Eva Rubio Fernández y José Martínez Coy denuncian la falta de realización del derecho a la vivienda, a pesar de estar sólidamente fundamentado a nivel jurídico, y reclaman la necesidad de adoptar políticas gubernamentales que garanticen la plena realización de este derecho humano básico.

El capítulo 2, Políticas de vivienda en España y la Región de Murcia, escrito por $M^{a}$ Isabel Sánchez-Mora Molina, Esther Clavero Mira y Salvador 
Manzanera Román ofrece un análisis de las normativas y recomendaciones que a nivel mundial, europeo y estatal se han desarrollado en materia de vivienda y su aplicación en nuestro país, a través de los distintos planes de vivienda aprobados y puestos en marcha, tanto en España como en la Región de Murcia.

En el capítulo 3, El mercado de la vivienda en España y la Región de Murcia, Ángel Olaz Capitán y Ana Belén Fernández Casado analizan la evolución del parque de viviendas, poniendo especial atención a las peculiares características de la Región de Murcia. Se detallan algunos aspectos relacionados con el precio, renta necesaria y, en definitiva, el esfuerzo necesario para poder acceder y mantener la vivienda por parte de los usuarios, sin olvidar de un modo más concreto cuestiones asociadas al comportamiento de algunos colectivos más vulnerables al problema de la vivienda.

El capítulo 4, Exclusión residencial, firmado por Manuel Hernández Pedreño ofrece la evolución de las distintas ramas sociológicas que estudian los fenómenos sociales vinculados con la vivienda, a la vez que se revisan sus bases teóricas y las principales aportaciones realizadas por diversos autores (clásicos y contemporáneos). Asimismo, describe el contexto estructural donde se desarrolla la exclusión residencial, las causas que explican su configuración como proceso social, y por último, sus características.

En el capítulo 5, Análisis y medición de la exclusión residencial, Gaspar Brändle Señán y Olga García Luque tratando de dar cobertura al estudio de cualquier situación de exclusión residencial, realizan una minuciosa revisión de la tipología ETHOS elaborada por la Federación Europea de Organizaciones Nacionales que trabajan con Personas sin Hogar (FEANTSA), ofreciendo una serie de nuevos indicadores que complementan y amplían dicha tipología.

La atención residencial a personas sin hogar es el título del capítulo 6 que firman Isabel Serrano Rodríguez y Antonio Ripoll Spiteri. Este capítulo trata de identificar a las personas con más dificultades en el acceso a una vivienda: las personas sin hogar; analizando cuáles son sus características sociales, a partir de la información que proporciona el INE desde la Encuesta a personas sin hogar (personas-2005 y centros-2010), así como a través de una encuesta a las distintas ONG que ofrecen apoyo residencial en la Región de Murcia.

El capítulo 7, Zonas desfavorecidas residencialmente en el municipio de Murcia, realizado por Isabel Serrano Rodríguez y Nicolás Martínez Valero identifica las características, indicadores más significativos y se acerca a la localización de los barrios desfavorecidos del municipio de Murcia, con el fin de demostrar la estrecha relación que existe entre las situaciones de exclusión y desigualdad social y el espacio urbano donde se vive. 
En el capítulo 8, Vivienda y personas mayores, Juan Benito Martínez y Juan Benito Lozano abordan la relación entre vivienda, personas mayores, exclusión social y residencial, ya que vincula a las personas mayores con ciudadanía activa y con su derecho a una vida digna e independiente, lo que necesariamente incluye el derecho a una vivienda digna.

En Jóvenes vulnerables y exclusión residencial, capítulo 9 (Diego Pascual López Carmona), se revisan aspectos de los jóvenes como su evolución demográfica, las principales teorías que, en ciencias sociales, han abordado los estudios de juventud, la evolución del mercado de trabajo y las condiciones residenciales de los jóvenes. A la vez que identifican los obstáculos que dificultan el estudio de los problemas residenciales de los jóvenes y se realizan algunas propuestas que permitan superar dichas limitaciones.

En el capítulo 10, Vivienda y pueblo gitano, José Francisco Caselles Pérez realiza una breve aproximación histórica y demográfica del pueblo gitano y una revisión de los estudios más recientes sobre su situación social general y residencial. Asimismo, analiza la Estrategia Nacional para la Inclusión Social de la Población Gitana en España 2012-2020 surgida del marco europeo.

Por último, en el capítulo 11 , Condición inmigrante y exclusión residencial, Manuel Hernández Pedreño y Diego Pascual López Carmona analizan las principales dificultades asociadas a la condición inmigrante, centrando la atención en el estudio de los factores vinculados al ámbito residencial de este colectivo y cómo éste ha evolucionado desde el comienzo de la crisis económica actual. Asimismo, plantean una reflexión iexiste en España un modelo de integración residencial para los inmigrantes? Finalmente realizan algunas propuestas que permitan conocer con mayor precisión la situación residencial de este colectivo en España y la Región de Murcia.

Dra. María Teresa Martínez Fuentes

Profesora Titular de Universidad

Facultad de Trabajo Social

Universidad de Murcia 

Título: Trabajo Social, Concepto y Metodología

Autora: María José Aguilar Idañez

Edita: Ediciones Paraninfo y Consejo General del Trabajo Social, Madrid, 2013, $435 \mathrm{p}$.

ISBN: 978-84-283-3485-3

El Manual «Trabajo Social, Concepto y Metodología» es una obra ambiciosa que se publica en un contexto histórico de crisis global que está afectando a millones de personas en todo el mundo. Las políticas públicas están erosionando o rompiendo la cohesión social hasta niveles hasta ahora impensables en algunos países. Y el trabajo social se encuentra inmerso en esta coyuntura, la crisis no le es ajena y tiene que afrontar la injusticia social que presenta a veces nuevas caras pero persistiendo el eje central que es la desigualdad de oportunidades en el ejercicio de los derechos humanos.

La autora nos proporciona la oportunidad de reflexionar sobre modos de actuación profesional que promueven la justicia social, bien diferenciados de otras modalidades que contribuyen a mantener la desigualdad. No hay que olvidar el trabajo de Natividad de la Red en el Prólogo, que reflexionando sobre la situación histórica que estamos viviendo destaca la necesidad de una formación sólida básica y continuada. Y es una obra ambiciosa porque en realidad son dos libros en uno (o un dos por uno) y así queda claro en la estructura que gira alrededor de dos partes. La primera parte se titula «Conceptualización del Trabajo Social» y la segunda «Metodología del Trabajo Social». Cada parte es una sistematización de conocimientos, prácticas sociales y vivencias personales que denotan un trabajo intelectual riguroso y un historial formativo y docente poco convencional.

En la primera parte, encontramos una sistematización de las posiciones de diversos autores en torno al objeto del trabajo social, objetivos y funciones, principios y valores, naturaleza y definición del trabajo social, el marco de referencia contextual y la base teórica del trabajo social. Es una secuencia sobre qué es el trabajo social, qué hacen las trabajadoras (es) sociales, en qué 
principios y valores se basan. Es particularmente ilustrativa la descripción y comparación entre teorías y modelos que sustentan la práctica profesional destacando la importancia de conocerlos pero sin olvidar que «el camino a recorrer [...] es el de constituir una sólida base teórica para el trabajo social profundizando en los modelos ya elaborados y delineando otros nuevos para utilizar en la práctica, a medida que se transforma a través de una continua búsqueda y teorización de la práctica misma». Ese camino a recorrer no puede realizarse sin avances en la teoría y modelos aplicados (o no aplicados) en la práctica profesional basados en la investigación sobre la misma práctica.

En la segunda parte, tras recorrer la evolución histórica del trabajo social se plantea la situación actual de la metodología del trabajo social, la estructura y características del proceso metodológico, con un enfoque operativo destacando algunas de las que la autora denomina «Acciones-Clave del proceso de intervención social»: el diagnóstico social, el diseño de proyectos de intervención, la ejecución del proyecto y la evaluación. Pero la metodología del trabajo social no concierne únicamente a las trabajadoras sociales y esto es algo que sucede con frecuencia. No hay que olvidar el rol de la entidad o institución y el de las personas usuarias que son sujetos de las intervenciones sociales. En especial hay que tener en cuenta a las personas que son los sujetos de las acciones, si hablamos de empoderar a las personas no se trata de un sentido restringido sino el sentido más amplio de ser dueños de sus propias vidas y esto se incluye en la relación profesional con las trabajadores sociales.

Globalmente considerado este Manual presenta una serie de ideas fuerza entre las que cabe destacar las siguientes: el compromiso por la justicia social y los derechos humanos con el convencimiento de que otro mundo es posible; la interdependencia entre la práctica y la disciplina del trabajo social para seguir avanzando, con enfoque multidisciplinar; la investigación sobre la práctica, en retroalimentación con la teoría; un trabajo social que promueva la emancipación y la participación no solo de las personas, grupos y comunidades sino, también, de las propias trabajadoras sociales.

$\mathrm{Y}$ algo muy importante, como señala la autora, es tener presente en todo momento el código deontológico teniendo en cuenta los principios de la profesión. La mejor actuación profesional no es la que utiliza determinados métodos y técnicas sino la que se basa en dichos principios generales. En estos momentos de crisis es buen momento para recuperar esos principios con frecuencia ignorados y enterrados por la burocratización. Los recursos son las potencialidades de las personas y sus entornos, así como los de la trabajadora social. La relación de ayuda es esencial, la escucha activa, la individualización, la promoción de la autonomía, etc. Cuando los derechos humanos no 
se respetan, es importante la información y el empoderamiento para poder exigirlos. Y el trabajo social, además de informar y asesorar, tiene ente sus funciones hacer visibles las situaciones injustas de vulneración de derechos de las personas y acompañarlas en la exigencia del ejercicio de los derechos. Según Johan Galtung ${ }^{1}$ la injusticia social es una violencia estructural porque es evitable, por ello son necesarias políticas públicas que promuevan la justicia social y las trabajadoras sociales tienen como función incidir en las políticas para promover cambios. Así el Código Deontológico de Trabajo Social², en el Preámbulo, señala como funciones profesionales «planificar, proyectar, calcular, aplicar, evaluar y modificar los servicios y políticas sociales para los grupos y comunidades» y en relación con las instituciones el en su artículo 46 señala: «El/la profesional del trabajo social desde su responsabilidad principal hacía la persona usuaria proponga los necesarios cambios de política, procedimientos y actuaciones mediante los canales apropiados con los que cuentan las entidades y organizaciones. En el caso de que éstas limitaran la responsabilidad en su actuación y persistan lesiones y vulneración grave de los derechos de la persona usuaria, si se agotan las vías de soluciones adecuadas, recúrrase a instancias superiores o a la más amplia comunidad de intereses»

En definitiva, esta obra es un Manual elaborado desde una perspectiva amplia y plural que ofrece información relevante y comparada de diversos autores, con análisis de la autora basados en su experiencia docente. Su lectura ofrece numerosas pistas para reflexionar no solo a estudiantes sino, también, a docentes del trabajo social, profesionales e investigadores.

María Asunción Martínez Román

Departamento de Trabajo Social y Servicios Sociales. Instituto Interuniversitario «Desarrollo Social y Paz». Universidad de Alicante

1. Galtung, J. (1969) Violence, Peace and Peace Research, Journal of Peace Research, 6, p. 167-191.

2. Consejo General del Trabajo Social (2012) Código Deontológico de Trabajo Social. Madrid: CGTS. 

Título: Presente y futuro de la formación en Trabajo Social. III Congreso Andaluz de Centros Universitarios de Trabajo Social (Málaga, junio de 2011) Autoras: Gallego Fontalba, C. (Coord.) y Palma García, M.O. Edita: Colegio Profesional de Trabajo Social de Málaga, 2013 ISBN: 978-84-695-8643-3

Se trata de la publicación electrónica donde se recogen los trabajos que se expusieron y presentaron en el III Congreso Andaluz de Centros Universitarios de Trabajo Social, que se celebró en la Facultad de Estudios Sociales y del Trabajo de la Universidad de Málaga en junio de 2011. Esta iniciativa responde a la preocupación por coordinar nuestras acciones para conseguir resultados lo más eficientes posible y que permitieran homogeneizar respuestas en el espacio universitario andaluz de docencia en Trabajo Social.

En el congreso, partiendo del análisis de la realidad actual en cada uno de los centros en la implantación del grado, se abordaron cuestiones relacionadas con los cursos puente, los idiomas y la internacionalización, las prácticas, la investigación, la evaluación de las competencias y los másteres y la formación de postgrado.

El congreso que estuvo dirigido a los docentes de Andalucía y pretendía conectar con las inquietudes que se plantean en el ejercicio profesional y en la formación de los futuros graduados en Trabajo Social permitió conocer iniciativas de gran interés que se proponían o se llevaban a cabo por parte de los componentes de los centros andaluces o de otros lugares. 



\section{INSTRUCCIONES PARA LOS AUTORES ${ }^{1}$}

\section{Información general}

La Revista Alternativas. Cuadernos de Trabajo Social con ISSN 1133-0473 es una publicación de Departamento de Trabajo Social y Servicios Sociales de la Universidad de Alicante. Fundada con el mismo título en 1992 por la Escuela Universitaria de Trabajo Social de la Universidad de Alicante, se publica desde el 2009 por el Departamento de Trabajo Social y Servicios Sociales de dicha universidad. Su periodicidad es anual. Se edita en el mes de diciembre.

Se trata de una revista arbitrada que utiliza el sistema de revisión externa por expertos (peer-review) en el conocimiento de los objetos investigados y en las metodologías utilizadas en las investigaciones. Adopta y se adhiere a las normas de publicación establecidas en el Manual de la $\mathrm{APA}^{2}$. Es preciso recordar que el cumplimiento de los requisitos del Manual de la APA facilita la indización de la revista en las principales bases de datos de la especialidad, con lo que ello supone de beneficio para los autores y sus centros por la mayor difusión que alcanzan los trabajos publicados.

Cada uno de sus números se edita tanto en versión impresa como en versión electrónica, ésta disponible en el Repositorio Institucional de la Universidad de Alicante (http://rua.ua.es/dspace/handle/10045/5269).

Alternativas. Cuadernos de Trabajo Social está abierta a intercambios con otras publicaciones.

1. De acuerdo con lo elaborado para FECYT por Rafael Ruiz-Pérez, Emilio Delgado LópezCózar, Evaristo Jiménez Contreras. Grupo de Investigación EC3, Universidad de Granada, http://ec3.ugr.es/.

2. American Psychological Association, [en línea], http://books.apa.org/books.cfm?id= 4200061 \& toc=yes). 


\section{Alcance y Cobertura}

Alternativas. Cuadernos de Trabajo Social tiene como objeto fundamental contribuir a la difusión de investigaciones, experiencias, trabajos teóricos y metodológicos, tanto de carácter académico como profesional, que se realizan en nuestro país y en el ámbito internacional, relativos al Trabajo Social, a la política social y a los Servicios Sociales, así como a otras disciplinas y profesiones que, desde un punto de vista multi e interdisciplinar, enriquecen y complementan la disciplina y la acción profesional del Trabajo Social en el ámbito de las Ciencias Sociales.

Los trabajos deben ser originales, no publicados ni estar siendo considerados en otra revista para su publicación, escritos en español, inglés, francés o portugués. El autor es el único responsable de las afirmaciones sostenidas en su artículo. De manera excepcional, los artículos que no sean inéditos se publicarán bajo la valoración del Comité Editorial y en función de: que su difusión haya sido en algún medio de difícil acceso y de que se consideren de particular relevancia e interés científico profesional.

Serán considerados para su publicación los siguientes tipos de trabajos: investigaciones originales, trabajos teóricos, experiencias prácticas, reseñas bibliográficas y notas técnicas.

Investigaciones originales: estarán estructuradas de la siguiente manera: resumen, palabras clave, texto (introducción, material y métodos, resultados y discusión), agradecimientos y bibliografía. La extensión máxima del texto será de 6.000 palabras (en formato Word), escritas a doble espacio, cuerpo de letra 12, tipo Times New Roman, admitiéndose 4 figuras y 6 tablas. Las tablas y figuras deberán presentarse en hoja aparte, numerándose correlativamente e indicando el lugar de colocación en el artículo. Si se utilizan, han de ser aquellas que, por su relevancia, sean necesarias para apoyar los argumentos recogidos en el texto. Es aconsejable que el número de autores no sobrepase los seis.

Trabajos teóricos y experiencias prácticas: los trabajos teóricos consistirán en un análisis crítico de temáticas relevantes para el Trabajo Social, la política social y los servicios sociales. Las experiencias prácticas consistirán en una sistematización rigurosa del proceso y resultados de las mismas. Ambas, revisiones y experiencias, deberán incluir un apartado con aportaciones o propuesta de aplicación o transferencia al Trabajo Social, la política social, los servicios sociales o la intervención social. Los textos tendrán una extensión máxima de 4.000 palabras en formato Word, escritas a doble espacio, cuerpo de letra 12 y tipo Times New Roman. Opcionalmente el trabajo podrá incluir tablas y figuras. 
Reseñas bibliográficas: tendrán una extensión máxima de 1.000 palabras (en formato Word), escritas a doble espacio, cuerpo de letra 12 y tipo Times New Roman. Deberán estar precedidas del título de la obra, autores, editorial, lugar de edición, año de publicación, número de páginas e ISBN.

Notas técnicas: describirán de forma resumida normativas o políticas, investigaciones en curso, así como crónicas de congresos, seminarios o jornadas relevantes para el Trabajo Social, la política social y los servicios sociales. Tendrán una extensión máxima de 1.000 palabras (en formato Word), escritas a doble espacio, cuerpo de letra 12 y tipo Times New Roman.

\section{Presentación y estructura de los trabajos}

Las siguientes normas de publicación están basadas en Manual de la APA:

a) Los manuscritos deben ser enviados por correo electrónico a la Redacción de la revista Alternativas. Cuadernos de Trabajo Social del Departamento de Trabajo Social y Servicios Sociales, a la dirección dtsss@ua.es con copia a masun.martinez@ua.es, a doble espacio, márgenes amplios y con sus páginas numeradas correlativamente en el ángulo superior derecho. Deberán ir acompañados de una carta de presentación (ver modelo facilitado por la revista) pidiendo la consideración del manuscrito, en la que además el autor explicará en 4-5 líneas cuál es la aportación original del trabajo que presenta y sus novedades, la declaración de que no ha sido publicado anteriormente y que no se ha enviado simultáneamente a otras revistas, así como la confirmación de las autorías firmantes. En esta carta también figurará la cesión de derechos al editor. El autor debe conservar una copia del original para evitar irreparables pérdidas o daños del material.

b) Las citas bibliográficas deben reseñarse en forma de referencias a continuación de la discusión o de los agradecimientos, si los hubiere. Las citas bibliográficas, cuyo número ha de ser el suficiente y necesario, se presentarán según el orden de aparición en el texto con la correspondiente numeración correlativa y serán identificadas por autor y año entre paréntesis y separados por una coma (ejemplo: Coob, 1989), con inclusión del número de página o páginas en el caso de citas textuales (ejemplo: Coob, 1989: 25-27). 
Los manuscritos se presentarán según el siguiente orden y estructura

Página de título. Primera página del manuscrito

A modo de portada del manuscrito, esta primera página contendrá:

a) Título del artículo (conciso pero informativo), en español e inglés, conformado con el mayor número de términos significativos posibles (a ser posible tomados de un vocabulario controlado de la especialidad). Si es necesario, se añadirá un subtítulo no superior a 40 letras y espacios, en español e inglés.

b) Nombre y dos apellidos de cada uno de los autores teniendo en cuenta la forma de firma para indexación en bases de datos internacionales (véanse en la sección "¿Sabes qué tienes que hacer para identificar tus publicaciones científicas?" las recomendaciones formuladas en http://www.accesowok.fecyt.es/).

c) Nombre completo del centro de trabajo de cada uno de los autores, el cual tendrá su referencia al lado del nombre del autor con números arábigos entre paréntesis (o en superíndice).

d) Nombre y dirección completa del responsable del trabajo o del primer autor como responsable de correspondencia, incluyendo número de teléfono y del telefax en su caso, así como dirección de correo electrónico si se dispone de ella.

e) Información sobre becas, ayudas o soporte financiero con el que se ha contado (Proyectos de Investigación) para la subvención del trabajo y otras especificaciones, cuando sea el caso.

Para una mejor elaboración de esta página, véase modelo adjunto a estas instrucciones sobre cómo elaborar la hoja de identificación del manuscrito

Páginas de resumen y palabras-clave. Segunda página del manuscrito

Una segunda página independiente deberá contener los nombres y apellidos de los autores, el título del artículo y de la revista, un resumen del contenido del artículo en español y el listado de palabras clave. Tanto el resumen como las palabras clave tendrán una versión en inglés.

a) El resumen del trabajo tendrá una extensión de 150-250 palabras. En el caso de los artículos originales, el contenido del mismo se dividirá en cuatro apartados (resumen estructurado): introducción, material y métodos, resultados y discusión. En cada uno de ellos se describirá, de forma concisa, respectivamente, el motivo y el objetivo de la investigación, la metodología 
empleada, los resultados más destacados y las principales conclusiones. Se enfatizarán los aspectos novedosos y relevantes del trabajo. En el caso de las colaboraciones especiales, se resumirá el trabajo sin dividirlo en estos cuatro apartados.

b) Palabras clave: a continuación del resumen se especificarán cinco palabras clave o frases cortas que identifiquen el contenido del trabajo para su inclusión en los repertorios y bases de datos nacionales e internacionales. Se procurará poner el mayor número posible hasta un máximo de cinco. Deberán utilizarse términos controlados de referencia.

Texto del manuscrito. Tercera página, que será la del arranque del texto del manuscrito

La tercera página y siguientes serán las que se dediquen al texto del manuscrito, que se ajustará a las especificaciones de las instrucciones indicadas para cada tipo de trabajo. En el caso de los Trabajos teóricos y Notas técnicas podrá figurar el manuscrito estructurado en los apartados convenientes para facilitar así su compresión. Sin embargo, los trabajos originales deben ajustarse en la medida de lo posible a los siguientes apartados: introducción, materiales y métodos, resultados y discusión:

Introducción: debe incluir los fundamentos y el propósito del estudio, utilizando las citas bibliográficas estrictamente necesarias. No incluirá datos o conclusiones del trabajo presentado. No debe realizarse una revisión bibliográfica detallada.

Material y métodos: será presentado con la precisión que sea conveniente para que el lector comprenda y confirme el desarrollo de la investigación. Fuentes y métodos previamente publicados deben describirse solo brevemente y aportar las correspondientes citas, excepto si se han realizado modificaciones en los mismos. Se describirá el cálculo del tamaño de la muestra y la forma de muestreo utilizada en cada caso. Se hará referencia al tipo de análisis documental, crítico, estadístico, etc. empleado. Si se trata de una metodología original, será necesario exponer las razones que han conducido a su empleo y describir sus posibles limitaciones.

Cuando se trate de trabajos experimentales en los que se hayan utilizado grupos humanos, se indicará si se han tenido en cuenta los criterios éticos correspondientes. No deben utilizarse los nombres ni las iniciales de las personas que hayan participado formando parte de la muestra estudiada.

Resultados: aparecerán en una secuencia lógica en el texto, tablas o figuras, no debiendo repetirse en todas ellas los mismos datos. Se procurará resaltar las observaciones importantes. Se describirán, sin interpretar ni 
hacer juicios de valor, las observaciones efectuadas con el material y métodos empleados.

Discusión: resumirán los hallazgos, relacionando las propias observaciones con otros estudios de interés y señalando las aportaciones y limitaciones de unos y otros. No deben repetirse con detalle los datos u otro material ya comentado en otros apartados. Se mencionarán las inferencias de los hallazgos y sus limitaciones, incluyendo las deducciones para una investigación futura. Se enlazarán las conclusiones con los objetivos del estudio, evitando las afirmaciones gratuitas y las conclusiones no apoyadas completamente por los datos del trabajo.

Agradecimientos: únicamente se agradecerá su colaboración a aquellas personas que hayan hecho contribuciones sustanciales al estudio pero sin llegar a merecer la calificación de autor, debiendo disponer el autor de su consentimiento por escrito. Asimismo, el Council Science Editors (CSE) recomienda a los autores, en su caso, una declaración explícita de la fuente de financiación de la investigación, y que ésta se encuentre en los agradecimientos (CSE, 2000) (Conflicts of Interest and the Peer Review Process. Draft for CSE member review, del 03/31/00. http://www.cbe.org/services_DraftPolicies. shtml).

Bibliografía: la bibliografía debe reseñarse a continuación de la discusión o de los agradecimientos si los hubiere, y en la forma antes indicada según el orden alfabético de autores.

Para las referencias bibliográficas se recomienda seguir el estilo que se detallará más adelante como ejemplo, basado en las normas de la APA.

- Los nombres de las revistas deben abreviarse según consenso existente en el área de conocimiento, y siempre que exista una lista de referencia.

- Se mencionarán todos los autores hasta seis, o los seis primeros, y et al. cuando sean siete o más.

La bibliografía debe ser corregida por el autor, comparándola con la copia en su poder. Se evitará utilizar frases imprecisas como citas bibliográficas. No pueden emplearse como tales las que precisen de aclaraciones del tipo "observaciones no publicadas", ni "comunicación personal", aunque sí podrán citarse dentro del texto entre paréntesis. Los trabajos aceptados, pero aún no publicados, se incluirán en las citas bibliográficas especificando el nombre de la revista, seguido por la expresión "en prensa".

Las citas bibliográficas deberán extraerse de los documentos originales, indicando siempre la página inicial y final del trabajo del que proceden. A fin de asegurar la coherencia, en cualquier momento del proceso editorial, la 
dirección de la revista podrá requerir a los autores el envío de la primera página (fotocopia) de cada uno de los artículos citados en la bibliografía.

Para las revistas, dada su trascendencia para los índices de citas y los cálculos de los factores de impacto, se citarán: a) autor(es), con su(s) apellido(s) e inicial(es) de nombre(s), separando los apellidos del nombre con una coma. Si hay más de un autor, entre ellos se pondrá una coma. Todos hasta un máximo de seis, y cuando sean más de seis se pondrán sólo los seis primeros y se añadirá et al. Tras el último autor se pondrá el año entre paréntesis y un punto; b) título del artículo en su lengua original, y con su grafía y acentos propios. Tras el título se pondrá un punto; c) nombre correcto de la revista; d) número de volumen $\left(\mathrm{n}^{\circ}\right)$ (la separación entre este apartado y el siguiente se hará con coma); y e) páginas primera y última, separadas por un guión.

A continuación se dan ejemplos de citas bibliográficas correctamente referenciadas.

\section{Publicaciones periódicas}

Artículo de revista, un autor

Bekerian, D. A. (1992). In search of the typical eyewitness. American Psychologist, 48, 574-576.

Artículo de revista, dos autores

Klimowski, R., Palmer, S. (1993). The ADA and the hiring process in organizations. Consulting Psychology Journal: Practice and Research, 45(2), 10-36.

Artículo de revista, de tres a cinco autores

Borman, W. C., Hanson, M. A., Oppler, S. H., Pulakos, E. D., y White, L. A. (1993). Role of early supervisory experience in supervisor performance. Journal of Applied Psychology, 78, 443-449.

Artículo de revista, seis autores

Kneip, R. C., Delamater, A. M., Ismond, T., Milford, C., Salvia, L., y Schwartz, D. (1992). Self- and spouse ratings of anger and hostility as predictors of coronary heart disease. Health Psychology, 12, 301-307.

Artículo de revista, en prensa

Bekerian, D. A. (en prensa). In search of the typical eyewitness. American Psychologist. 
Bekerian, D. A. (en prensa-a). Role of early supervisory experience in supervisor performance. American Psychologist.

Bekerian, D. A. (en prensa-b). Self- and spouse ratings of anger and hostility as predictors of coronary heart disease. American Psychologist.

Artículo de revista no inglesa, con el título traducido al inglés

Zajonc, R. B. (1992). Bischofs gefühlvolle Verwirrunggen über die Gefühlle [Bischof's emotional fluster over the emotions]. Psychologische Rundschau, 40, 574-576.

\section{Libros y capítulos de libro}

Referencias a libros completos

Bekerian, D. A. (1992). People in organizations: An introduction to organizational behavior ( $3^{\mathrm{a}}$ ed.). New York: McGraw-Hill.

Libro, autor en grupo (agencia gubernamental) como editor

Australian Bureau of Statistics (1992). Estimated resident population by age and sex in statistical local areas, New South Wales, June 1990 (No 3209.1). Australian Capital Territory: ABS

Libro editado

Bekerian, D. A. (Ed.). (1992). People in organizations: An introduction to organizational behavior. New York: McGraw-Hill.

Libro sin autor o editor

Merriam-Webster's Collegiate Dictionary (10 $0^{\mathrm{a}}$ ed.). Springfield, MA: Merriam-Webster.

Enciclopedia o diccionario

Bekerian, D. A. (1992). The new Grove dictionary of music and musicians (3 ed., Vols. 1-20). New York: McGraw-Hill.

Traducción inglesa de un libro

Laplace, P. -S. (1951). A philosophical essay on probabilities (Trads., F. W. Truscott y F. L. Emory). New York: McGraw-Hill. (Trabajo original publicado en 1814). 
Capítulo en un volumen de una serie

Maccoby, E. E. (1992). Socialization in the context of the family. En P. M. Musen (Ed. Serie) y M. J. Martin (Ed. Vol.). Handbook of child psychology: Vol. 4. Socialization, personality, and social development ( $3^{\mathrm{a}} \mathrm{ed} ., \mathrm{pp} .1-101$ ). New York: McGraw-Hill.

\section{Informes técnicos y de investigación}

Informe disponible en la GPO (Government Printing Office), instituto gubernamental como autor

National Institute of Mental Health (1992). Clinical training in serious mental illnes (Publicación DHHS No ADM 90-1679). Washington, DC: Government Printing Office.

Reuniones científicas (congresos, simposios, etc.)

Actas de congreso publicadas, contribución publicada a un simposio, artículo o capítulo en libro editado

Bekerian, D. A. (1992). A motivational approach to the self. En R. DeMaier (Ed.), Nebraska Symposium of Motivation: Vol. 38. Perspectives on motivation (pp. 574-596). Lincoln: University of Nebraska Press.

Actas publicadas regularmente

Bekerian, D. A. (1992). In search of the typical eyewitness. Proceedings of the National Academy of Sciences, USA, 89, 574-576.

Trabajo no publicado presentado a un congreso

Bekerian, D. A. (1992, Enero). Early data on the Trauma Symptom Checklist for Children (TSC-C). Comunicación presentada al Congreso de la American Professional Society on the Abuse of Children, San Diego, CA.

\section{Tesis doctorales y de máster}

Tesis doctoral no publicada

Bower, D. L. (1993). Employee assistant programs supervisory referrals: Characteristics of referring and nonreferring supervisors. Tesis doctoral no publicada. University of Missouri, Columbia.

Tesis de máster no publicada, universidad no estadounidense Saldaña, P. (1992). Actitudes de los padres hacia la integración escolar. Tesis de master no publicada, Universidad de Salamanca, Salamanca, España. 


\section{Revisiones}

Revisión de un libro

Baumeister, R. F. (1993). Exposing the self-knowledge myth [Revisión del libro The self-knower: A hero under control]. Contemporary Psychology, 38, 466-467.

\section{Medios audiovisuales}

Película, circulación limitada

Bekerian, D. A. (Productor), y Smith, J. N. (Director). (1992). Changing our minds [Película]. (Disponible en Changing Our Minds, Inc., 170 West End Avenue, Suite 35R, New York, NY 10023).

\section{Medios electrónicos}

Artículo de revista on-line, acceso limitado a suscriptores

Central Vein Occlusion Study Group. (1993, 2 Octubre). Central vein occlusion study of photocoagulation: Manual of operations [675 párrafos]. Online Journal of Current Clinical Trials [Serie on-line]. Disponible en: Doc. $\mathrm{N}^{\circ} 92$.

\section{Referencias de fuentes electrónicas (internet)}

Sitios web

Tilton, J. (1995). Composing good HTML (Vers. 2.0.6). http://www.cs.cmu. edu/ tilt/cgh/ (13 Jan. 1997).

Tablas: deben presentarse en hojas independientes numeradas según su orden de aparición en el texto con números arábigos. Se emplearán para clarificar puntos importantes no aceptándose la doble documentación bajo la forma de tablas y figuras. Los títulos o pies que las acompañen deben explicar perfectamente el contenido de las mismas.

Figuras: serán consideradas figuras todo tipo de fotografías, gráficas o dibujos. Se les asignará un número arábigo según orden de aparición en el texto, siendo identificadas por el término abreviado fig.(s). Los pies o leyendas de cada una deberán ir mecanografiados y con el número correspondiente en una hoja aparte. El texto en las figuras irá en mayúsculas. Deben ser diseñadas presentando un buen contraste, de forma que no pierdan calidad con la reducción. Las microfotografías presentarán también un buen contraste de forma que puedan ser publicadas sin reducción.

La publicación con figuras a color debe especificarse previamente, corriendo los gastos de fotomecánica a cargo del autor. 
Las figuras deben clarificar de forma importante el texto y su número estará reducido al mínimo necesario.

Abreviaturas: solo deberán ser empleadas abreviaturas estándar universalmente aceptadas (consultar Units Symbols and Abbreviations). Cuando se pretenda acortar un término empleado frecuentemente en el texto, su abreviatura, entre paréntesis, deberá acompañarse la primera vez que aparezca. No serán usados los números romanos en el texto, empleándose para los decimales el punto a la derecha del cero en lugar de la coma. Los nombres comerciales no serán utilizados salvo necesidad, en cuyo caso la primera vez que se empleen irán acompañados del símbolo.

\section{Proceso editorial}

Los trabajos se remitirán acompañados de una carta de presentación, en la que se solicitará la evaluación de los mismos para su publicación en alguna de las secciones de la revista, con indicación expresa de tratarse de un trabajo que no ha sido difundido ni publicado anteriormente, ser enviado únicamente a la revista Alternativas. Cuadernos de Trabajo Social para su evaluación y publicación si procede, así como las aportaciones en cuanto a originalidad y novedad que, a juicio de los autores, plantea el trabajo.

La carta de presentación deberá ir firmada por todos los autores. Es responsabilidad de los autores el cumplimiento de los principios éticos, incluyendo, en su caso, la autorización escrita de todas las personas que aparezcan en los agradecimientos o de aquellas que hayan sido estudiadas durante la investigación y cuya identificación sea esencial para presentar los resultados. Asimismo, se declarará aceptar, si procede, la introducción de cambios en el manuscrito por parte de la Redacción de la revista.

La Redacción de la revista acusará recibo a los autores de los trabajos que le lleguen y, posteriormente, informará de su aceptación o rechazo.

La Redacción pasará a considerar el trabajo para su publicación por el Comité Editorial, comprobando si se adecua a la cobertura de la revista y cumple las normas de publicación. En tal caso, se procederá a su revisión externa.

Los manuscritos serán revisados de forma anónima (ciego o doble ciego) por dos expertos en el objeto de estudio y/o metodología empleada. La Redacción de la revista, a la vista de los informes externos, se reserva el derecho de aceptar/rechazar los artículos para su publicación, así como el de introducir modificaciones de estilo y/o acortar los textos que sobrepasen la extensión permitida, comprometiéndose a respetar el contenido del original. El protocolo utilizado por los revisores de la revista se hace público como anexo a estas normas y está publicado en la web de la Revista en el Departamento 
de Trabajo Social y Servicios Sociales (http://dtsss.ua.es/es/alternativascuadernostrabajosocial/normas-de-edicion.html).

En el caso de juicios dispares entre los dos evaluadores, los trabajos se remitirán a un tercer evaluador. Serán sometidos a revisión pareada externa las investigaciones, los trabajos teóricos y las experiencias. Los trabajos que sean revisados y pudieran ser considerados para publicación previa modificación, deberán ser devueltos en el plazo de 30 días tanto si se solicitan correcciones menores como mayores. Cuando sea necesario, la nueva versión del texto será enviada otra vez a los revisores externos, procedimiento que se seguirá hasta la aceptación definitiva del trabajo por la revista. Los autores recibirán los informes de evaluación de los revisores (de acuerdo con el protocolo de evaluación de la revista) de forma anónima, para que éstos puedan realizar (en su caso) las correcciones o réplicas oportunas.

En general, una vez vistos los informes externos, los factores en los que se funda la decisión sobre la aceptación-rechazo de los trabajos por parte de la Redacción de la revista son los siguientes: a) originalidad: totalmente original, información valiosa, repetición de resultados conocidos; b) actualidad y novedad; c) relevancia: aplicabilidad de los resultados para la resolución de problemas concretos; d) significación: avance del conocimiento científico; e) fiabilidad y validez científica: calidad metodológica contrastada; y f) presentación: buena redacción, organización (coherencia lógica y presentación material).

Los autores/as de artículos aceptados recibirán las pruebas de imprenta para su corrección por correo electrónico en formato PDF. Deberán devolverlas corregidas a la Redacción de la revista mediante fax o PDF dentro de las 72 horas siguientes a su recepción. Únicamente se pueden realizar mínimas correcciones sobre el contenido del manuscrito original sin incurrir en un coste extra.

En su caso, el autor o primer firmante recibirá un ejemplar de la revista en papel después de su publicación.

\section{Responsabilidades éticas}

Es responsabilidad y deber de la Redacción de la revista Alternativas. Cuadernos de Trabajo Social recordar a sus colaboradores los siguientes extremos:

- Cuando se describen experimentos realizados en seres humanos debe indicarse si los procedimientos seguidos son conformes a las normas éticas del comité de experimentación humana responsable (institucional o regional) y a la Declaración de Helsinki de 1975 revisada en el 2000. No se deben utilizar nombres, iniciales u otros datos de identificación de los centros donde se ha realizado. 
- Contar con permiso de publicación por parte de la institución financiadora de la investigación, cuando proceda.

- La revista no acepta material previamente publicado. Los autores son responsables de obtener los oportunos permisos para reproducir parcialmente material (texto, tablas o figuras) de otras publicaciones y de citar su procedencia correctamente.

Conflicto de Intereses: la revista espera que los autores declaren cualquier asociación comercial que pueda suponer un conflicto de intereses en conexión con el artículo remitido.

Autoría: en la lista de autores firmantes deben figurar únicamente aquellas personas que han contribuido intelectualmente al desarrollo del trabajo. Haber ayudado en la colección de datos o haber participado en alguna técnica no son, por sí mismos, criterios suficientes para figurar como autor. En general, para figurar como autor deben cumplirse los siguientes requisitos: a) haber participado en la concepción y realización del trabajo que ha dado como resultado el artículo en cuestión, b) haber participado en la redacción del texto y en las posibles revisiones del mismo y c) haber aprobado la versión que finalmente va a ser publicada.

La revista declina cualquier responsabilidad sobre posibles conflictos derivados de la autoría de los trabajos a publicar.

Consentimiento informado: los autores deben mencionar, en la sección de métodos, que los procedimientos utilizados con los participantes han sido realizados tras obtención de un consentimiento informado.

Transmisión de derechos de autor: se incluirá junto al manuscrito, o formando parte de la carta de presentación, una Hoja de Identificación y Cesión de Derechos (facilitada por la revista) firmada por todos los autores.

\section{Información Adicional}

La revista acusa recepción de todos los trámites realizados para tener informados a los autores de la situación en la que se encuentra su manuscrito.

Los juicios y opiniones expresados en los artículos y comunicaciones publicados en la revista son del autor(es) y no necesariamente del Comité Editorial.

Tanto el Comité Editorial como la empresa editora declinan cualquier responsabilidad sobre el material publicado. Ni el Comité Editorial ni la empresa editora garantizan o apoyan ningún producto que se anuncie en la revista, ni garantizan las afirmaciones realizadas por el fabricante sobre dicho producto o servicio. 


\section{Protocolos destinados a los autores ${ }^{3}$}

\section{Listado de comprobaciones}

Tiene por objeto el exigir al autor una revisión final del manuscrito en cuanto a sus aspectos fundamentales de carácter formal y metodológico.

\section{Listado de comprobaciones}

Para facilitar la labor del Comité de Lectura, la entrada en proceso de su manuscrito y la rapidez en su posible publicación, se exige que el autor realice una revisión final del manuscrito, comprobando las cuestiones enumeradas en la presente lista que, una vez marcadas, será remitida junto al manuscrito. Se recuerda que el incumplimiento de alguno de los ítems puede ser motivo de devolución del manuscrito.

1. Se envía el manuscrito vía correo electrónico, en ficheros en formato Word, escritos a doble espacio, incluidas las citas bibliográficas, tablas y figuras.

2. Se incluye el título completo del manuscrito en español e inglés.

3. Se incluye el resumen del manuscrito y las palabras clave, en español e inglés.

4. El resumen se ajusta a las normas de publicación en cuanto a número de palabras, y en él constan objetivos, diseño o material y métodos, resultados, conclusiones y/o discusión.

5. Se envía el resumen y las palabras clave traducidos al inglés y, a ser posible, revisados por un experto en este idioma.

6. Se incluyen las filiaciones institucionales y/o profesionales de cada uno de los autores.

7. Se incluye la dirección del autor principal o responsable de correspondencia, número de teléfono, fax y dirección de correo electrónico.

8. En su caso, se declaran becas, ayudas o soporte financiero y su procedencia.

9. El manuscrito responde a la estructura exigida en las normas de publicación y a las especificaciones de la sección a la que se dirige.

10. El manuscrito describe todas las fuentes, materiales, equipo y elementos usados, tanto en términos de grupos investigados como la globalidad del estudio.

11. Un experto en el contenido del manuscrito podría reproducir su estudio, experimento, análisis, etc., a partir de la metodología descrita.

12. Las conclusiones se apoyan en los resultados obtenidos.

13. En su caso, se han utilizado análisis estadísticos, y estos han sido revisados por un experto en la materia.

14. Se han revisado las referencias bibliográficas, y se ajustan en su estilo y formato a las normas internacionales exigidas por la revista.

15. En su caso, las figuras y tablas aportan información adicional y no repetida en el texto.

16. En su caso, se ha revisado el sistema de unidades empleado.

3. De acuerdo con lo elaborado para FECYT por Rafael Ruiz-Pérez, Emilio Delgado López-Cózar y Evaristo Jiménez Contreras. Grupo de Investigación EC3, Universidad de Granada (http://ec3.ugr.es/). 


\begin{tabular}{|l|c|}
\hline 1. Listado de comprobaciones \\
\hline 17. Se detallan las abreviaturas tras su primera cita en el texto. & $\bullet$ \\
\hline 18. En su caso, se citan las normas éticas utilizadas. & $\bullet$ \\
\hline $\begin{array}{l}\text { 19. En su caso, se adjuntan o se da fe en el manuscrito del consentimiento de } \\
\text { los informados de experimentación con personas, así como de los permisos de } \\
\text { reproducción. }\end{array}$ & $\bullet$ \\
\hline $\begin{array}{l}\text { 20. Se adjunta lista de comprobación y carta de presentación indicando } \\
\text { originalidad, novedad del trabajo y sección de la revista a la que se dirige. }\end{array}$ & $\bullet$ \\
\hline $\begin{array}{l}\text { 21. La carta de presentación debe incluir un anexo firmado por los autores } \\
\text { responsabilizándose de la autoría y cediendo los derechos de autor al editor. }\end{array}$ & $\bullet$ \\
\hline
\end{tabular}

\section{Cómo confeccionar la primera página del manuscrito}

También llamada hoja de identificación o página de título. Este protocolo tiene la intención de facilitar al autor el formato adecuado para la elaboración de los datos de identificación del manuscrito. Estos datos no solo son importantes para la propia versión del manuscrito que finalmente será publicada, sino también para la indexación en las bases de datos.

\section{Cómo confeccionar una hoja de identificación}

Dada la importancia de los datos de identificación del manuscrito (primera página del manuscrito o página de título), debe seguirse la estructura del siguiente modelo:

TÍTULO:

COMPETENCIA PROFESIONAL EN TRABAJO SOCIAL...

PROFESSIONAL COMPETENCE IN SOCIAL WORK...

\section{AUTORES:}

Roberto A. XXXX-XXXX ${ }^{1}$, Luis A. DE XXX-XXXX², José XXXXX-XXXX

FILIACIÓN PROFESIONAL/INSTITUCIONAL

1. Universidad XXXXX, Dpto. de XXXXXXX, Madrid, España

2. Consejo Superior de Investigaciones Científicas, Instituto de XXX, Granada, España

3. Hospital XXX, Servicio de XXX, Unidad de XXX, Madrid, España

(No hacer referencia a la condición de «residente», «profesor», «catedrático», etc.)

\section{RESPONSABLE CORRESPONDENCIA}

Roberto A. XXXX-XXXX

Universidad XXXXX, Dpto. de XXXXXXX, Madrid, España

Av. MMMMMMM, 273

28007 Madrid, España

E-mail: xxx@internet.com

INSTITUCIÓN RESPONSABLE QUE SOPORTA LA INVESTIGACIÓN Y/O SOPOR-

TE FINANCIERO (en su caso)

Instituto Oftalmológico XXX, Universidad de XXXXXXXX, Madrid, España

Proyecto subvencionado FIS-78/2-1993 del Ministerio de Sanidad

ANTECEDENTES DE DIFUSIÓN (en su caso)

Presentado parcialmente como comunicación al «XX Congreso XXXXXXXX»,

Helsinki, Finlandia, celebrado el XXXXXXXX 
2. Cómo confeccionar una hoja de identificación

SECCIÓN A LA QUE SE DIRIGE EL ARTÍCULO

(especificar)

3. Carta de presentación, de cesión de derechos y de declaración de conflicto de intereses

La carta de presentación tiene la finalidad de ayudar a que el proceso de revisión del manuscrito y la toma de decisiones sobre el mismo sea más rápida y eficiente, y ello en la medida en que informa y adelanta aquellos aspectos y detalles más importantes requeridos por la revista para la toma en consideración de un trabajo, tales como justificación de la elección de la revista, aportaciones del trabajo, declaración de autoría y originalidad, responsabilidades éticas y conflictos de interés, etc.

\begin{tabular}{l}
\hline 3. Carta de presentación y transferencia de derechos de copyright \\
\hline Sr./Sra. director/a de la Revista Alternativas. Cuadernos de Trabajo Social \\
Leídas atentamente las instrucciones a autores, y analizada la cobertura de la revista, \\
considero que la publicación que Vd. dirige es la adecuada para la difusión de nuestro \\
trabajo, por lo que le ruego someta a la consideración de su posible publicación en la \\
sección de \\
el manuscrito que adjunto le remito titulado \\
cuyos autores son \\
de los cuales \\
será el encargado de correspondencia. \\
Las aportaciones originales y novedades que en nuestra opinión el referido manuscrito \\
aporta al estudio de \\
son, en síntesis, las siguientes: \\
\hline \\
\hline Los autores certifican que este trabajo no ha sido publicado ni en todo ni en parte por \\
cualquier otro medio, ni está en vías de consideración para publicación en otra revista. \\
Los autores se responsabilizan de su contenido y de haber contribuido a la concepción, \\
diseño y realización del trabajo, análisis e interpretación de datos, y de haber participado \\
en la redacción del texto y sus revisiones así como en la aprobación de la versión que \\
finalmente se remite. \\
Asimismo, aceptamos la introducción de cambios en el contenido si hubiere lugar tras la \\
revisión y de cambios en el estilo del manuscrito por parte de la redacción de la revista.
\end{tabular}


3. Carta de presentación y transferencia de derechos de copyright

Cesión de derechos y declaración de conflicto de intereses

Los autores abajo firmantes transfieren los derechos de propiedad (copyright) del presente trabajo al Servicio de Publicaciones de la Universidad de Alicante, como organización editora patrocinadora de la revista Alternativas. Cuadernos de Trabajo Social. Declaramos además estar libres de cualquier asociación personal o comercial que pueda suponer un conflicto de intereses en conexión con el artículo remitido, así como el haber respetado los principios éticos de investigación.

Firmado:

Roberto A. XXX-XXX

Luís A. de XXX

José XXX-XXX

Alternativas, 20, 2013, pp. 213-229 - ISSN 1133-0473 



\section{INSTRUCTIONS FOR THE AUTHORS ${ }^{1}$}

\section{General Information}

The Journal Alternativas. Cuadernos de Trabajo Social, ISSN 1133-0473, is a publication of the Department of Social Work and Social Services at the University of Alicante. Originally founded under the same title in 1992 by the University School of Social Work at the University of Alicante, since 2009 the journal has been published by the Department of Social Work and Social Services at the same University. The journal is published annually.

It is a refereed journal, using the peer-review system for external revision by experts in the field and methodology of the research. The publication standards adopted and applied are those detailed in the APA Publication Manual $^{2}$.

It should be noted that indexing of the journal in the leading social work databases is facilitated by compliance with the requirements of the APA Manual; such compliance is therefore of benefit to authors and their centers as it ensures widespread dissemination of the research published.

Each issue of the journal is published in both a printed version and an electronic version; the latter is available on RUA at the University of Alicante (http://rua.ua.es/dspace/handle/10045/5269)

The journal is open to collaboration with other publications.

\section{Scope and Policy}

The primary objective of the Journal Alternativas. Cuadernos de Trabajo Social is to contribute towards the dissemination of research, experiences, and theoretical and methodological studies, of both an academic and professional

1. FECYT Rafael Ruiz-Pérez, Emilio Delgado López-Cózar, Evaristo Jiménez Contreras. Granada University. http://ec3.ugr.es/t.

2. APA (American Psychological Association http://books.apa.org/books.cfm?id= $4200061 \&$ toc $=$ yes $)$ 
practice nature, carried out in Spain or internationally. Such studies may deal specifically with social work, social policies and the social services or come from other disciplines and professions in the area of the Social Sciences, which from a multi- or interdisciplinary perspective serve to enrich and complement the discipline and professional practice of social work.

Submissions must represent original, previously unpublished work which is not being considered for publication in another journal, written in Spanish, English, French or Portuguese. The author bears sole responsibility for the claims made in the article. Under special circumstances, previously published research may be published following consideration by the Editorial Board, when the following condition applies: publication has been through channels which are not easy to access, and the article is of particular professional relevance or scientific interest.

The following are considered for publication: original research, concept papers, practical experience, book reviews and technical notes.

Original. They must have the following structure: summary, key words, text (introduction, material and methods, results and discussion), thanks and bibliography. The maximum length of the text will be 6.000 words, (in Word format), double-spaced, font size 12, font Times New Roman, with a maximum of 4 figures and 6 tables. Tables and Figures must be submitted on a separate page, numbered sequentially and indicating where they are to be inserted in the article. Only those Tables and Figures necessary to support the arguments presented in the text should be included. It is recommended that the number of authors does not exceed six.

Concept papers and practical experience. Concept papers should comprise a critical analysis of subjects relevant to social work, social policy and the social services. Practical experiences should consist of a rigorous systemization of the process and corresponding results. Both concept papers and practical experiences should include a section detailing the contribution made, or a proposal for application or transfer to social work, social policy the social services or social intervention. Texts will be no longer than 4.000 words in Word format, and should be double spaced in Times New Roman font size 12. Optionally, the text may include Tables and Figures.

Book reviews. These will be no longer than 1000 words in Word format, and should be double spaced in Times New Roman Font size 12. The heading should include the book title, authors, publishing house, place of publication, year of publication, number of pages and ISBN.

Technical notes: These should comprise a brief description of regulations or policies, research in progress, or reports of conferences, seminars or study 
days of relevance to social work, social policy or the social services. They will be no longer than 1.000 words in Word format, and should be double spaced in Times New Roman font size 12.

\section{Paper presentation and structure}

The following publication standards are based on APA http://books.apa.org/ books.cfm?id=4200061\&toc=yes

a) The manuscripts must be sent to the Department of Social Work and Social Services (dtsss@ua.es) with a copy to masun.martinez@ua.es, double-spaced, wide margins and with the pages numbered sequentially in the upper right-hand corner. The manuscript shall be accompanied by a cover letter (use the template provided by the journal) asking for the manuscript to be taken into consideration, with the author explaining in 4-5 lines what the original contribution of the work presented is and its new developments, a statement of non-simultaneous submission to other journals and confirmation of the undersigned authors. This letter must also transfer the copyright to the publisher. The author must keep a copy of the original to avoid irreparable loss or damage to the material.

b) Bibliographic quotations must be marked as references following the discussion or thanks, if any. An adequate number of relevant references should be used, and these should be listed in order of appearance in the text, with the corresponding reference number. References should be given as author and year between brackets, separated by a comma (for example, Coob, 1989). Page number or numbers should be included for textual quotes (for example, Coob, 1989: 25-27).

The manuscripts must be presented according to the following order and structure:

Title Page. First page of the manuscript

As the cover of the manuscript, this first must contain:

a) Title of the article (concise, yet informative), in Spanish and English, made up of the greatest number of significant terms possible (taken when possible from a controlled specialty glossary). If necessary, a subtitle may be added, not to exceed 40 letters and spaces, in Spanish and English.

b) First name and two last names of each of the authors, taking into account the signature format for indexing in international databases (see section 
"Do you know how to reference scientific publications?" the recommendations provided in http://www.accesowok.fecyt.es/)

c) Full name of the work center of each of the authors, which is referenced beside the name of the author with Arabic numerals in parentheses (or superscript).

d) Name and full address of the person responsible for the work of the lead author as responsible for correspondence, including the phone number and fax number, when appropriate, as well as the e-mail address, if any.

e) Information on grants, aid or financial support provided (Research Projects) to subsidize the work and other specifications, when applicable.

To better prepare this page, see the template (provided by the journal) attached to these instructions on how to prepare the manuscript identification sheet.

\section{Abstract and Key-Word Pages. Second page of the manuscript}

A second, separate page must contain the first and last names of the authors, the title of the article and the abbreviated title of the journal, article content summary in Spanish and the list of key words. Both the abstract and the key words must have an English version.

- The Abstract of the work must be between 150 and 250 words. In case of the original articles, the content shall be divided into four sections (structured abstract): Introduction, Material and Methods, Results and Discussion. Each of them must describe, concisely, the purpose and objective of the research, the methodology used, the most important results and the main conclusions, respectively. The innovative and relevant aspects of the work must be emphasized. In the case of Special Collaborations, the work will be summarized, without dividing it into these four sections.

- Key words: Below the abstract, 5 key words or short phrases shall be specified to indicate the content of the work, for inclusion in collections of national and international databases. As many as possible should be provided, up to a maximum of five. The controlled reference terms must be used.

Manuscript text. Third page, which is where the manuscript text begins

The third and following pages are dedicated to the manuscript text, which will comply with the specifications detailed in the instructions above for all 
submissions. In the case of concept papers and notes, the structured manuscript may be included in the appropriate sections to facilitate comprehension. However, the Original papers must include, to the extent possible, the following sections: Introduction, Material and Methods, Results and Discussion.

Introduction: You must include the foundation and purpose of the study, using the bibliographic citations that are strictly necessary. Do not include data or conclusions of the work presented. Do not provide a detailed bibliographic review.

Material and Methods: It must presented with sufficient precision so that the reader can understand and confirm the development of the research. Sources and methods published previously should be described just briefly, providing the corresponding quotes, except when they have been modified. The sample size calculation and the sampling method used must be described, when appropriate. Reference must be made to the type of documentary, critical and statistical analysis, etc. used. If it is an original methodology, the reasons for using it must be explained, describing any possible limitations.

When dealing with experimental papers in which groups of humans have been used, indicate whether the ethical criteria has been approved. Neither the names nor the initials of the people participating in the study sample must be used.

Results: These shall appear in a logic sequence in the text, tables or figures, without repeating the same data included in each of them. Try to highlight the important observations. Describe, without interpreting or judging, the observations made with the material and methods used.

Discussion: Summarize the findings, relating the observations of this study with those of other studies of interest, highlighting the contributions and limitations of each. Do not repeat the data or other material already commented in other sections in detail. Mention the inferences from the findings and their limitations, including the deductions for future research. Link the conclusions to the study objectives, avoiding gratuitous affirmations and conclusions that are not fully supported by the study data.

Thanks: Thank only those who have made substantial contributions to the study, but who do not warrant the status of author; the author must obtain their consent in writing. Likewise, the Council Science Editors (CSE) recommend that authors, when appropriate, provide an explicit statement of the source of their research funding, placing it among the thanks (CSE 2000) (Conflicts of Interest and the Peer Review Process. Draft for CSE member review, posted 3/31/00. http://www.cbe.org/services_DraftPolicies.shtml). 
Bibliography: The bibliography must be placed after the discussion or the thanks, if any, in the format indicated above, based on the alphabetical order of authors.

The recommended style for the references is indicated below in the examples; it is based on the APA standards.

- The names of the journals must be abbreviated in accordance with the consensus reached in the area of knowledge, whenever there is a reference list.

- All authors must be mentioned, up to six, or the first six plus "et al" when there are seven or more.

The bibliography must be corrected by the author, correcting it with the copy in his or her possession. Avoid using vague phrases as bibliographical quotations. Do not use those that require clarifications such as "unpublished observations" or "personnel correspondence", although they may be cited in the text in parentheses. Papers that have been accepted, but not yet published, shall be included in the bibliography, specifying the name of the journal, followed by the expression "pending publication".

The bibliographic quotes must be taken from the original documents, always indicating the starting and ending page number of the work from which they are taken. To ensure consistency, at any time during the publishing process, the journal editors may require authors to send the first page (photocopy) of each of the articles quoted in the bibliography.

For journals, given the importance for quotation indexes and Impact Factor calculations, the following shall be cited: a) author(s), with their last name(s) and first name(s). If there is more than one author, they must be separated by a comma. All of them, up to a maximum of six; if there are more than six, the first six shall be indicated, followed by "et al". Place the year, in parentheses and a period after the final author; b) title of the article in the original language, with the appropriate spelling and accents. Place a period after the title; c) correct name of the journal; d) issue number (no.). A comma shall be used to separate this section and section f; and e) first and last pages, separated by a hyphen.

The following are examples of properly referenced bibliographic quotations:

\section{Periodical Publications}

Journal article, one author

Bekerian, D. A. (1992). In search of the typical eyewitness. American Psychologist, 48, 574-576. 
Journal article, two authors

Klimowski, R., Palmer, S. (1993). The ADA and the hiring process in organizations. Consulting Psychology Journal: Practice and Research, 45(2), 10-36.

Journal article, three to five authors

Borman, W. C., Hanson, M. A., Oppler, S. H., Pulakos, E. D., and White, L. A. (1993). Role of early supervisory experience in supervisor performance. Journal of Applied Psychology, 78, 443-449.

Journal article, six authors

Kneip, R. C., Delamater, A. M., Ismond, T., Milford, C., Salvia, L., and Schwartz, D. (1992). Self- and spouse ratings of anger and hostility as predictors of coronary heart disease. Health Psychology, 12, 301-307.

Journal article, pending publication

Bekerian, D. A. (pending publication). In search of the typical eyewitness. American Psychologist.

Bekerian, D. A. (pending publication-a). Role of early supervisory experience in supervisor performance. American Psychologist.

Bekerian, D. A. (pending publication-b). Self- and spouse ratings of anger and hostility as predictors of coronary heart disease. American Psychologist.

Non-English journal article, with the title translated into English

Zajonc, R. B. (1992). Bischofs gefühlvolle Verwirrunggen über die Gefühlle [Bischof's emotional fluster over the emotions]. Psychologische Rundschau, 40, 574-576.

\section{Books and Book Chapters}

References to entire books

Bekerian, D. A. (1992). People in organizations: An introduction to organizational behavior (3rd ed.). New York: McGraw-Hill.

Book, group authorship (governmental agency) as publisher

Australian Bureau of Statistics (1992). Estimated resident population by age and sex in statistical local areas, New South Wales, June 1990 (No. 3209.1). Australian Capital Territory: ABS

Published book

Bekerian, D. A. (Ed.). (1992). People in organizations: An introduction to organizational behavior. New York: McGraw-Hill. 
Book without author or publisher

Merriam-Webster's Collegiate Dictionary (10th ed.). Springfield, MA: Merriam-Webster.

Encyclopedia or dictionary

Bekerian, D. A. (1992). The new Grove dictionary of music and musicians (3rd ed., Vols. 1-20). New York: McGraw-Hill.

English translation of a book

Laplace, P. -S. (1951). A philosophical essay on probabilities (Trans., F. W. Truscott and F. L. Emory). New York: McGraw-Hill. (Original work published in 1814).

Chapter in one volume of a series

Maccoby, E. E. (1992). Socialization in the context of the family. En P. M. Musen (Ed. Serie) and M. J. Martin (Ed. Vol.). Handbook of child psychology: Vol. 4. Socialization, personality, and social development (3rd ed., pgs. 1-101). New York: McGraw-Hill.

\section{Technical and Research Reports}

Report available in the GPO (Government Printing Office), governmental institution as author

National Institute of Mental Health (1992). Clinical training in serious mental illness (Publication DHHS No. ADM 90-1679). Washington, DC: Government Printing Office.

Scientific Meetings (Congresses, symposiums, etc.)

Published congress minutes, contribution published in a symposium, article or chapter in published book

Bekerian, D. A. (1992). A motivational approach to the self. En R. DeMaier

(Ed.), Nebraska Symposium of Motivation: Vol. 38. Perspectives on motivation (pgs. 574-596). Lincoln: University of Nebraska Press.

Regularly published minutes

Bekerian, D. A. (1992). In search of the typical eyewitness. Proceedings of the National Academy of Sciences, USA, 89, 574-576. 
Unpublished work presented at a congress

Bekerian, D. A. (1992, January). Early data on the Trauma Symptom Checklist for Children (TSC-C). Presentation given at the Congress of the American Professional Society on the Abuse of Children, San Diego, CA.

\section{Doctoral and Master's Theses}

Unpublished doctoral thesis

Bower, D. L. (1993). Employee assistant programs supervisory referrals: Characteristics of referring and nonreferring supervisors. Unpublished doctoral thesis. University of Missouri, Columbia.

Unpublished Master's thesis, non-American university

Saldaña, P. (1992). Actitudes de los padres hacia la integración escolar. Unpublished Master's thesis, Universidad de Salamanca, Salamanca, Spain.

\section{Reviews}

Review of a book

Baumeister, R. F. (1993). Exposing the self-knowledge myth [Review of the book The self-knower: A hero under control]. Contemporary Psychology, $38,466-467$.

\section{Audiovisual Media}

Film, limited distribution

Bekerian, D. A. (Producer), and Smith, J. N. (Director). (1992). Changing our minds [Film]. (Available from Changing Our Minds, Inc., 170 West End Avenue, Suite 35R, New York, NY 10023).

\section{Electronic Media}

Online journal article, access limited to subscribers

Central Vein Occlusion Study Group. (1993, 2 October). Central vein occlusion study of photocoagulation: Manual of operations [675 paragraphs]. Online Journal of Current Clinical Trials [Online series]. Available in: Doc. No. 92. 


\section{References to electronic sources (INTERNET)}

WWW sites

Tilton, J. (1995). Composing good HTML (Vers. 2.0.6). http://www.cs.cmu. edu/ tilt/cgh/ (13 Jan. 1997).

Tables: These must be presented on separate pages, numbered according to their order of appearance in the text with Arabic numerals. They are used to clarify important points; double documentation by means of tables and figures shall not be accepted. The titles or footers that accompany them must perfectly explain their content.

Figures: All types of photographs, graphs or drawings are considered figures. They are assigned an Arabic numeral according to their order of appearance in the text, identified by the abbreviated term fig.(s). The legend of each one must be typed, with the corresponding number on a separate sheet. The text in the figures must be in uppercase. They must be designed and presented with good contrast so that quality is not lost in the reduction. Micro-photographs will be accepted in these proportions for publication without reduction.

The publication of figures in color must be specified in advance. The author shall be responsible for the photomechanical expenses.

The figures must clarify the text in a major way, and they must be used in the minimum amount necessary.

Abbreviation: Only standard, universally accepted abbreviations shall be used. See Units, Symbols and Abbreviations. When a term that is used frequently in the text is to be shortened, the corresponding abbreviation must accompany it (in parentheses) the first time it appears. No Roman numerals shall be used in the text; periods shall be used to the right of the zero for decimals, not commas. Trademarks shall not be used except as needed, in which case the first time they are used they shall be accompanied by the symbol.

\section{Editorial process}

Papers shall be submitted together with a cover letter which requests evaluation of the same for publication in one of the sections of the Journal, expressly indicating that it is a work that has not been disseminated or published previously, sent only to the Journal Alternativas. Cuadernos de Trabajo Social for evaluation and publication, if appropriate, as well as the contributions regarding originality and novelty that, according to the authors, the paper contains.

The cover letter must be signed by all authors. The authors are responsible for and must comply with ethical principles, including (if it is the case), 
authorization from all people appearing in the section of thanks or from those studied during the research whose identification is essential in presenting the results. It shall also include a statement, when appropriate, accepting the introduction of changes to the manuscript by the journal editors.

The Journal's editorial staff shall acknowledge receipt to the authors of the articles they receive, subsequently notifying them of their acceptance or rejection.

The editorial staff shall pass the work under consideration for publication to the Editorial Board, verifying that it suits the journal's coverage and complies with the publication standards. If it does, it will be reviewed externally.

The manuscripts shall be reviewed anonymously (blind or double blind) by two experts in the study subject and/or methodology used. Based on the external reports, the Journal's editorial staff reserves the right to accept / reject the articles for publication, as well as to make style modifications and/or shorten texts that surpass the established limit, respecting the original content. The protocol used by the journal reviewers shall be made public as annexes to these standards published on the journal's website: http://dtsss.ua.es/ en/alternativascuadernostrabajosocial/editing-rules.html

In the event of differences of opinion between the two evaluators, the article shall be sent to a third evaluator. External paired review will be applied to research, concept papers, and practical experiences. Papers that are reviewed and considered for publication following modification shall be returned within a period of 30 days regardless of whether minor or major corrections are requested. Where necessary, the new version of the text will be submitted again for an external review, and this process will be repeated until the text is definitively accepted by the Journal. The authors will receive the evaluation reports from the reviewers, anonymously, so that they may make (when appropriate) any necessary corrections or replies.

In general, once the external reports have been seen, the factors on which the Journal's editorial staff bases its decision on accepting/rejecting the paper are the following: a) originality: completely original, valuable information, repetition of known results; b) timeliness and novelty; c) relevance: applicability of the results in resolving specific problems; d) significance: advancement of scientific knowledge; e) reliability and scientific validity: verified methodological quality; f) presentation: good writing, organization (logical coherence and material presentation).

The author(s) of accepted articles will receive printing proofs for correction by e-mail in PDF format. These must be returned corrected to the editorial staff of the journal by fax or PDF within 72 hours of receipt. Only minimal 
corrections may be made to the content of the original manuscript without an extra charge applying.

The author or the lead signatory will receive 1 copy of the Journal after it has been published.

\section{Ethical responsibility}

It is the responsibility and duty of the editorial staff of the Journal Alternativas. Cuadernos de Trabajo Social to remind its collaborators of the following:

- When describing the experiments carried out on human beings, indicate whether the procedures followed are in compliance with the ethical standards of the responsible human experimentation committee (institutional or regional) and the 1975 Declaration of Helsinki, revised in 2000. No names, initials or other information should identify the centers where the research was conducted.

- The institution financing the research must grant permission for publication.

- The journal does not accept previously published material. The authors are responsible for obtaining the appropriate permission for partially reproducing material (text, tables or figures) from other publications and for citing their source correctly.

Conflict of Interest. The Journal expects the authors to declare any commercial association that may represent a conflict of interest as regards the article submitted.

Authorship. The list of signing authors must include only those who have contributed intellectually to the development of the work. Having assisted in the collection of data or participated in a technique are not in and of themselves sufficient criteria for listing as an author. In general, being listed as an author requires fulfilling the following requirements: a) Participation in the conception and drafting of the work leading to the article in question, b) Participation in drafting the text and in any revisions, c) Having approved the final version to be published.

The Journal waives any liability due to possible conflicts derived from the authorship of the works published in the Journal.

Informed Consent. The authors must mention, in the methods section, that the procedures and controls used with participants were carried out after obtaining an informed consent form.

Copyright Transfer. The manuscript or the cover letter shall include a Rights Identification and Transfer Sheet (provided by the journal) signed by all authors. 


\section{Additional Information}

The Journal confirms receipt all formalities carried out to keep the authors abreast of the status of their manuscript.

The judgments and opinions expressed in the articles and notices published in the Journal are those of the authors and not necessarily of the Editorial Board.

Both the Editorial Board and the publishing company waive all liability for the material published. Neither the Editorial Board nor the publishing company guarantee or support any product advertised in the Journal, nor do they guarantee the claims made by the manufacturer of said product or service.

\section{Protocols for the authors ${ }^{3}$}

\section{Checklist}

(Its purpose is to require the author(s) to review the manuscript one last time as regards its fundamental formal and methodological aspects.)

\section{CHECKLIST}

To facilitate the Reading Committee's work, acceptance of the manuscript for processing and speeding up its possible publication, the author(s) must carry out a final review of the manuscript, verifying the issues included on this list. Once completed, the list must be submitted together with the manuscript. Remember that failure to complete any of the items may be cause for the manuscript to be returned.

1. Attached is a complete copy of the manuscript by e-mail files, in word format, double-spaced, including the bibliographic quotations, and figures.

2. The full title of the manuscript is included in Spanish and English.

3. The abbreviated title of the manuscript and the key words are included in Spanish and English.

4. The summary complies with the publication standards as regards the number of words, and it includes objectives, design or material and methods, results, conclusions and/or discussion.

5. The summary and key words has been translated into English or Spanish and, when possible, reviewed by an expert in that language.

6. The institutional and/or professional affiliations of each author are included

7. The address, telephone number, fax number and e-mail address of the main author or the person responsible for correspondence are included.

8. When applicable, grants, aid or financial support have been stated. Source.

3. (C) Drafted for FECYT by Rafael Ruiz-Pérez, Emilio Delgado López-Cózar, Evaristo Jiménez Contreras. EC3 Research Group. University of Granada. http://ec3.ugr.es/ 


\begin{tabular}{|l|l|}
\hline 1. CHECKLIST \\
\hline $\begin{array}{l}\text { 9. The manuscript follows the structured required in the publication standards and } \\
\text { the specifications from the section to which it is addressed. }\end{array}$ & $\bullet$ \\
\hline $\begin{array}{l}\text { 10. The manuscript describes all sources, materials, equipment and elements used, } \\
\text { both in terms of research groups and in the whole of the study. }\end{array}$ & $\bullet$ \\
\hline $\begin{array}{l}\text { 11. An expert in the subject matter covered by the manuscript could reproduce the } \\
\text { study, experiment, analysis, etc. based on the methodology described. }\end{array}$ & $\bullet$ \\
\hline 12. The conclusions are based on the results obtained. & $\bullet$ \\
\hline 13. When appropriate, statistical analyses were used, reviewed by an expert. & $\bullet$ \\
\hline $\begin{array}{l}\text { 14. The Bibliographic References have been reviewed and they comply with the style } \\
\text { and format in the international standards required by the journal. }\end{array}$ & $\bullet$ \\
\hline $\begin{array}{l}\text { 15. When applicable, the figures and tables provide additional information, not } \\
\text { repeated in the text. Their graphical quality has been verified. }\end{array}$ & $\bullet$ \\
\hline $\begin{array}{l}\text { 16. When appropriate, the units system used has been reviewed. } \\
\text { 17. Abbreviations are detailed the first time they are mentioned in the text. }\end{array}$ & $\bullet$ \\
\hline 18. When appropriate, the ethical standards used are cited. & $\bullet$ \\
\hline $\begin{array}{l}\text { 19. When appropriate, the informed consent forms for experimentation with humans } \\
\text { or animals, as well as reproduction permission, are attached to the manuscript. }\end{array}$ & $\bullet$ \\
\hline $\begin{array}{l}\text { 20. The checklist and cover letter are attached, indicating originality, novelty of the } \\
\text { work and the section of the journal to which it is addressed. }\end{array}$ & $\bullet$ \\
\hline $\begin{array}{l}\text { 21. The cover letter includes an annex signed by the authors, taking responsibility } \\
\text { for authorship and transferring the copyright to the publisher. }\end{array}$ & $\bullet$ \\
\hline
\end{tabular}

\section{Writing the first page of the manuscript}

Also known as the Identification Sheet or Title Page, this protocol provides the author with the appropriate format for providing the manuscript identification data. These data are important not only for the final version of the manuscript that is to be published, but also for indexing in the databases.

\section{PREPARING AN IDENTIFICATION SHEET}

Given the importance of the identification data for the manuscript (First page of the manuscript or Title Page), follow the structure in the following template.

TITLE: spanish and english

COMPETENCIA PROFESIONAL EN TRABAJO SOCIAL...

PROFESSIONAL COMPETENCE IN SOCIAL WORK...

AUTHORS:

Roberto A. XXX-XXX11, Luís A. de XXX-XXX², José XXX-XXX

PROFESSIONAL/INSTITUTIONAL AFFILIATION

1. XXX University. XXX Dept., Madrid, Spain

2. Higher Council for Scientific Research. Institute of XXX, Granada, Spain

3. XXX Hospital. XXX Service. XXX Unit, Madrid, Spain

(Do not reference status as «resident», «professor», «department head», etc.) 


\begin{tabular}{|l|}
\hline 2. PREPARING AN IDENTIFICATION SHEET \\
\hline CORRESPONDENCE COORDINATOR \\
Roberto A. XXX-XXX \\
XXX University. XXX Dept., Madrid, Spain \\
Av. MMMMMMM 273 \\
28007 Madrid, Spain \\
$\quad$ E-mail: xxx@internet.com \\
\hline INSTITUTION RESPONSIBLE FOR RESEARCH SUPPORT AND/OR FINANCIAL \\
SUPPORT (when applicable) \\
XXX Ophthalmology Institute, XXX University, Madrid, Spain. \\
Subsidized project FIS-78/2-1993 by the Ministry of Health \\
\hline DISSEMINATION HISTORY (when applicable) \\
Presented in part as a speech to the "20th XXXXXXX Congress", Helsinki, Finland, held \\
on XXX \\
\hline SECTION TO WHICH THE ARTICLE IS ADDRESSED \\
Original Articles \\
\hline
\end{tabular}

3. Cover letter, rights transfer and conflict of interests statement

The purpose of the Cover Letter is to help make the manuscript review and decision-making process as quick and efficient as possible, in that it provides information and summarizes the most important aspects and details, required by the journal to take the work into consideration, such as justification for choosing the journal, work contributions, authorship and originality statement, ethical and conflict of interest responsibilities, etc. 


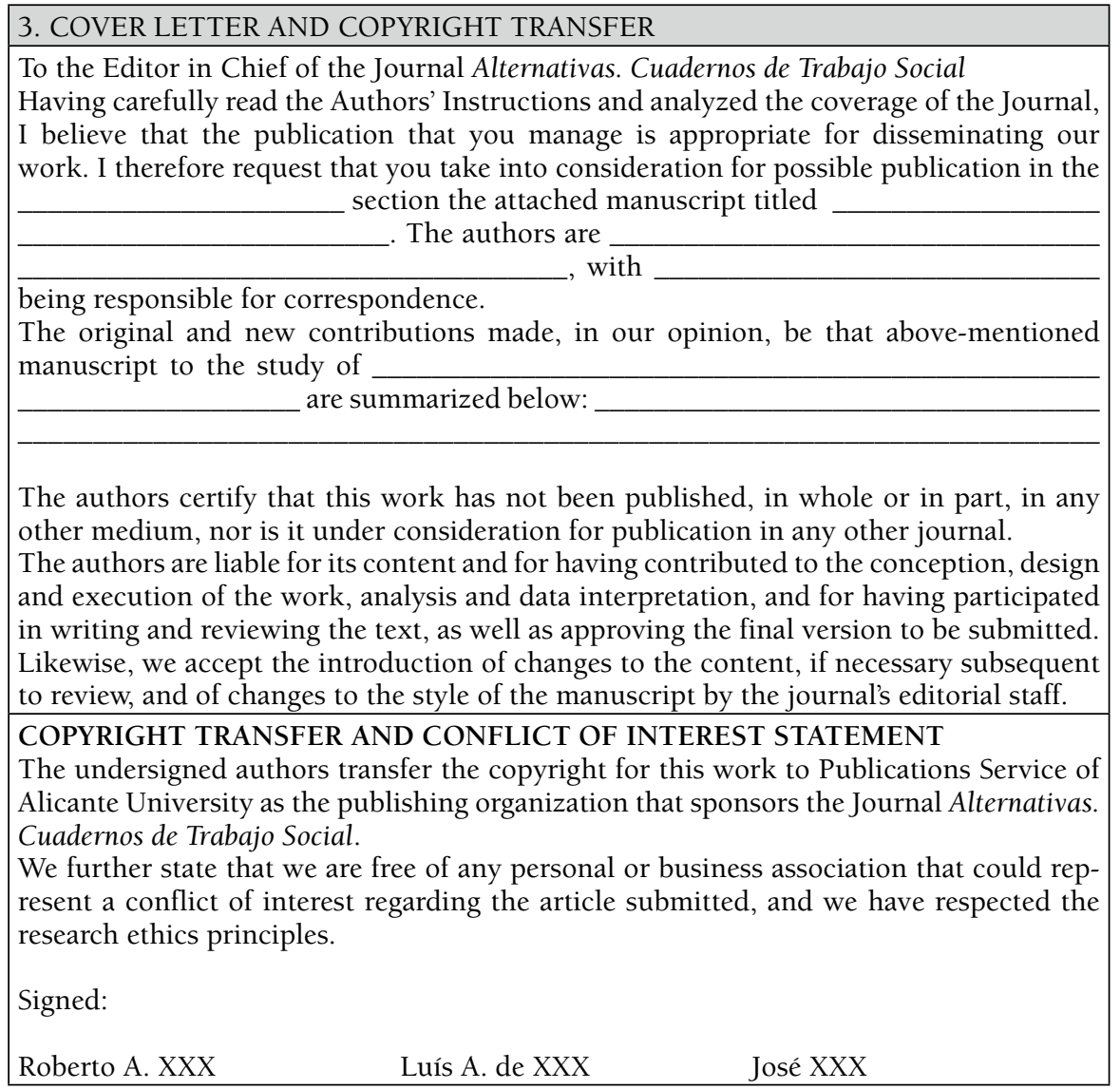




\section{PROTOCOLO REVISORES EXTERNOS}

Estimado revisor:

El modelo que se adjunta pretende ser una ayuda orientada para la realización de su valoración, y no una limitación a la misma. A este protocolo el evaluador puede añadir aquellos aspectos que considere oportunos, a ser posible, en la línea de uno de los fundamentos del Peer Review (revisión por pares), esto es, mejorar la presentación formal y los contenidos científicos del manuscrito cuando éste le merezca una valoración favorable.

Junto a este protocolo, se le remiten las instrucciones para los autores de la revista, si bien, también podrá localizarlas en http://www.ua.es/dpto/dtsss/ publicaciones.htm.

Una vez realizada la evaluación, remitir vía e-mail a Yolanda Doménech López(dtsss@ua.es),con copia a masun.martinez@ua.es.

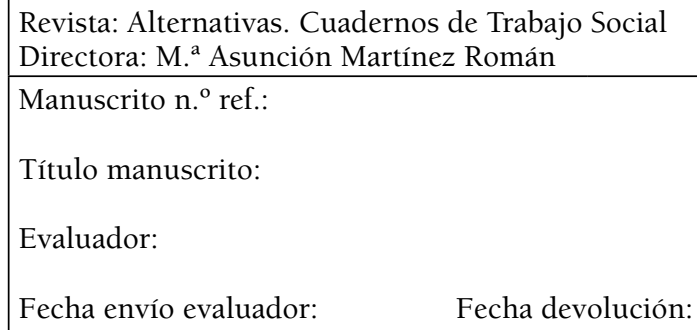




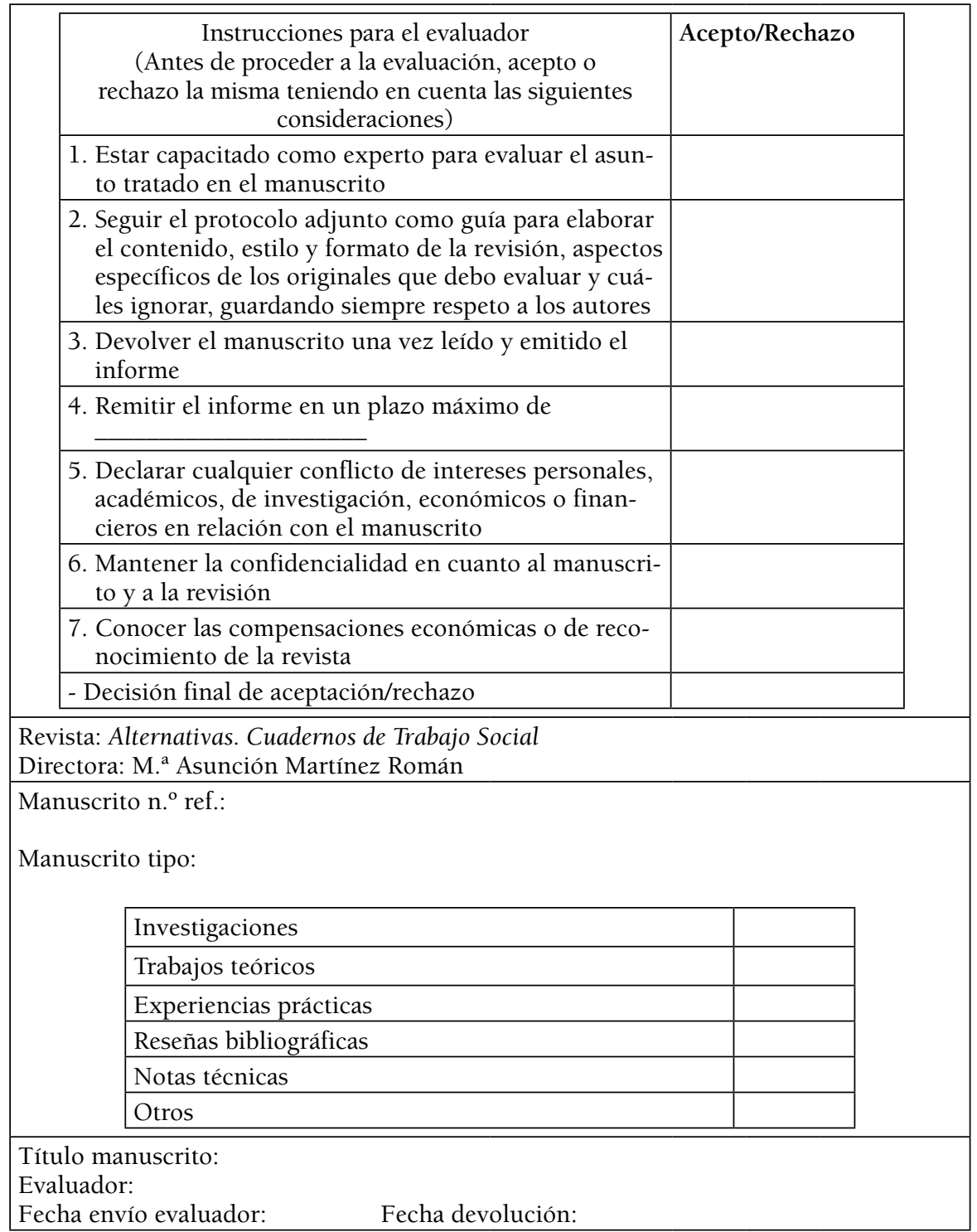




\section{Cumplimentar como conclusión final de la evaluación}

1. Recomendación:

\begin{tabular}{|l|l|}
\hline Aceptar & \\
\hline Aceptar con correcciones menores & \\
\hline $\begin{array}{l}\text { Aceptar con correcciones mayores } \\
\text { (Nuevo proceso de revisión) }\end{array}$ & \\
\hline Rechazar & \\
\hline Prioridad de publicación & \\
\hline
\end{tabular}

2. Valoración global de la calidad del trabajo

\begin{tabular}{|l|l|}
\hline Máxima & \\
\hline Buena & \\
\hline Media & \\
\hline Baja & \\
\hline
\end{tabular}

3. Valoración de originalidad y relevancia (respecto de la información científica que contiene el artículo: a) nueva y valiosa, b) resultados ya conocidos, c) irrelevante)

\begin{tabular}{|l|l|}
\hline Máxima & \\
\hline Media & \\
\hline Baja & \\
\hline
\end{tabular}

4. Aspectos técnicos y científicos:

\begin{tabular}{|l|l|l|l|}
\hline 4.1. Estructura y estilo: & Sí & No & $\begin{array}{c}\text { Mejorar o } \\
\text { cambiar }\end{array}$ \\
\hline 4.1.1. Título adecuado (claro, conciso e informativo) & & & \\
\hline Español & & & \\
\hline Inglés & & & \\
\hline $\begin{array}{l}\text { 4.1.2. Resumen correcto (es claro e incluye los objetivos, } \\
\text { el diseño, los métodos, las variables consideradas, } \\
\text { los principales resultados y las conclusiones más } \\
\text { relevantes) }\end{array}$ & & & \\
\hline Español & & & \\
\hline Inglés & & & No \\
\hline $\begin{array}{l}\text { 4.1.3. La estructura del discurso es adecuada } \\
\text { 4.1.4. El estilo es apropiado (claro, conciso y sigue una se- } \\
\text { cuencia lógica) }\end{array}$ & & & \\
\hline $\begin{array}{l}\text { 4.2. Fundamentación, metodología, } \\
\text { resultados y discusión }\end{array}$ & & & \\
\hline $\begin{array}{l}\text { 4.2.1. El tema, asunto o problema general ise identifica de } \\
\text { forma inmediata y clara? }\end{array}$ & & & \\
\hline $\begin{array}{l}\text { 4.2.2. El tema(s), asunto o problema específico ise delimita } \\
\text { y define con claridad? }\end{array}$ & & & \\
\hline
\end{tabular}




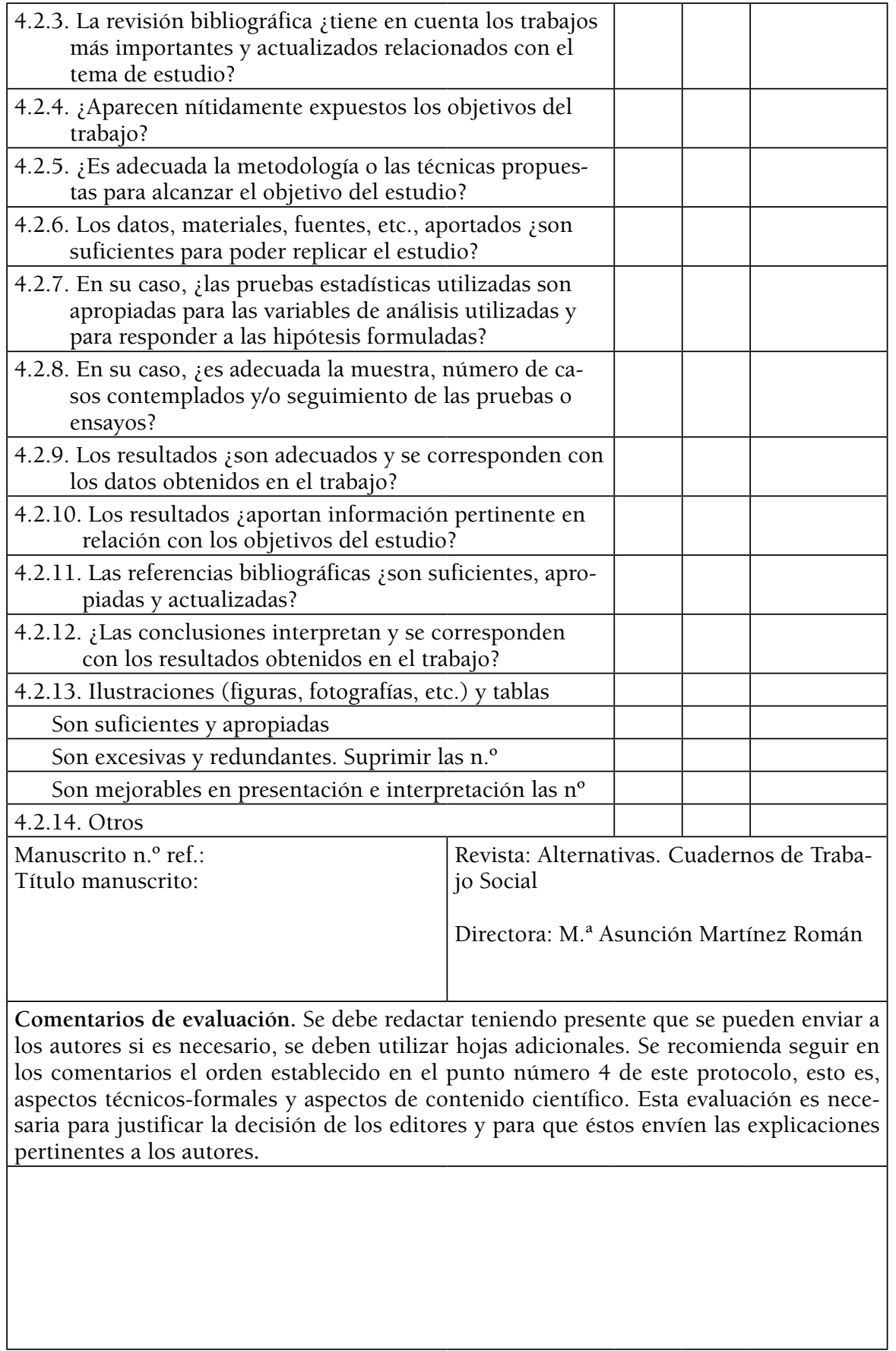




\begin{tabular}{|l|l|}
\hline $\begin{array}{l}\text { Manuscrito } \mathrm{n}^{\circ} \text { : } \\
\text { Manuscrito Título: }\end{array}$ & $\begin{array}{l}\text { Revista: Alternativas. Cuadernos de Traba- } \\
\text { jo Social }\end{array}$ \\
Evaluador: & Directora: Ma Asunción Martínez Román \\
\hline $\begin{array}{l}\text { Comentarios confidenciales (Comentarios sólo con respecto a la aceptabilidad del ma- } \\
\text { nuscrito, sólo para el editor) }\end{array}$ & \\
\hline
\end{tabular}

Tras revisar el artículo, declaro: Que no tengo interés financiero ni intelectual, ni personal en relación con el mismo y que no difundiré la información obtenida a través de su revisión previamente a su publicación

Nombre y apellidos:

Lugar y fecha:

Firmado: 



\section{EXTERNAL REVIEWERS' PROTOCOL}

Dear reviewer, The attached template is intended as a guideline for conducting the assessment, but not a limitation to the same. The evaluator may add any aspects to this protocol deemed to be appropriate, in line, when possible, with one of the principles of the Peer Review; that is, to improve the formal presentation and scientific content of the manuscript when it is worthy of a favorable assessment.

The Instructions for the Authors for the journal are also included, although they can also be found on the website http://www.ua.es/dpto/dtsss/ publicaciones.htm

Once completed, send the evaluation by e-mail to Yolanda Domenech López(dtsss@ua.es),with copy to masun.martinez@ua.es

Journal: Alternativas. Cuadernos de Trabajo Social

Editor in Chief: M. ${ }^{a}$ Asunción Martínez Román

Manuscript Ref. No.:

Manuscript Title:

Evaluator:

Date sent to evaluator: Date returned: 


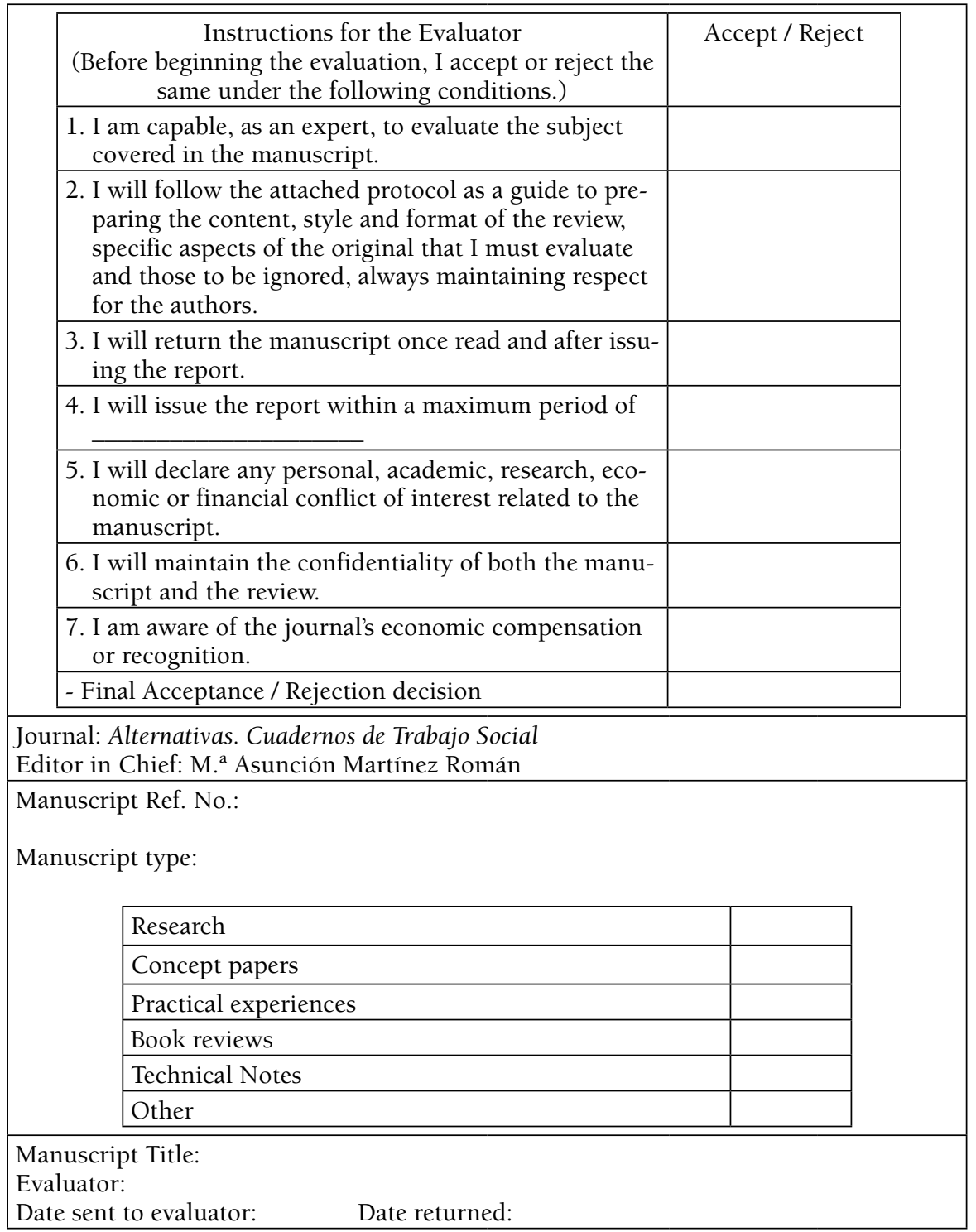




\section{Complete as final evaluation conclusion}

1. Recommendation:

\begin{tabular}{|l|l|}
\hline Accept & \\
\hline Accept with minor corrections & \\
\hline $\begin{array}{l}\text { Accept with major corrections } \\
\text { (New review process) }\end{array}$ & \\
\hline Reject & \\
\hline Publication priority & \\
\hline
\end{tabular}

2. Overall assessment of the quality of the work:

\begin{tabular}{|l|l|}
\hline Highest & \\
\hline Good & \\
\hline Average & \\
\hline Low & \\
\hline
\end{tabular}

3. Originality and relevance assessment (regarding the scientific information contained in the article: -new and valuable, -results already known, - irrelevant):

\begin{tabular}{|l|l|}
\hline Highest & \\
\hline Average & \\
\hline Low & \\
\hline
\end{tabular}

4. Technical and scientific aspects:

\begin{tabular}{|c|c|c|c|}
\hline 4.1. Structure and style & Yes & No & $\begin{array}{c}\text { Improve or } \\
\text { Change }\end{array}$ \\
\hline \multicolumn{4}{|l|}{ 4.1.1. Appropriate title (clear, concise and informative) } \\
\hline \multicolumn{4}{|l|}{ Spanish } \\
\hline \multicolumn{4}{|l|}{ English } \\
\hline \multicolumn{4}{|l|}{$\begin{array}{l}\text { 4.1.2. Correct summary (it is clear and includes the objec- } \\
\text { tives, design, methods, variables considered, primary } \\
\text { results and most relevant conclusions) }\end{array}$} \\
\hline \multicolumn{4}{|l|}{ Spanish } \\
\hline \multicolumn{4}{|l|}{ English } \\
\hline \multicolumn{4}{|l|}{ 4.1.3. The structure of the discussion is appropriate } \\
\hline \multicolumn{4}{|l|}{$\begin{array}{l}\text { 4.1.4. The style is appropriate (clear, concise and following } \\
\text { a logical sequence) }\end{array}$} \\
\hline 4.2. Foundation, methodology, results and discussion & Yes & No & $\begin{array}{c}\text { Improve or } \\
\text { Change }\end{array}$ \\
\hline \multicolumn{4}{|l|}{$\begin{array}{l}\text { 4.2.1. Is the theme, subject or general problem identified } \\
\text { immediately and clearly? }\end{array}$} \\
\hline \multicolumn{4}{|l|}{$\begin{array}{l}\text { 4.2.2. Are the theme(s), subject or specific problem } \\
\text { outlined and defined clearly? }\end{array}$} \\
\hline $\begin{array}{l}\text { 4.2.3. Does the bibliographic review take into consideration } \\
\text { the most important and up-to-date works related to } \\
\text { the study theme? }\end{array}$ & & & \\
\hline
\end{tabular}









\begin{tabular}{|l|l|}
\hline $\begin{array}{l}\text { Manuscript } \mathrm{N}^{\mathrm{o}} .: \\
\text { Manuscript Title: }\end{array}$ & $\begin{array}{l}\text { Journal: Alternativas. Cuadernos de Tra- } \\
\text { bajo Social } \\
\text { Editor in Chief: M. }{ }^{a} \text { Asunción Martínez } \\
\text { Román }\end{array}$ \\
\hline Evaluator: & C (Comments on the acceptability of the manuscript only; for the Editor only). \\
\hline
\end{tabular}

I have reviewed the article and hereby declare: that I have no financial, intellectual or personal interest in this article and that I will not disseminate the information obtained through the review of the article prior to its publication.

Name:

Location and date:

Signed.

Alternativas, 20, 2013, pp. 253-260 - ISSN 1133-0473 



\section{LISTADO DE EVALUADORES 2012-2013}

Alberto Acosta Espinosa

Manuel Aguilar Hendrickson

Ma José Aguilar Idáñez

María Carmen Albert Guardiola

Luis Enrique Alonso Benito

Andrés Arias Astray

José Manuel Barbero García

Carmen Barranco Expósito

Annamaria Campanini

Joan Canimas

Andrea Capilla Pérez

Fernando Casas Mínguez

Yolanda de la Fuente Robles

Natividad De la Red Vega

Pablo De la Rosa Gimeno

Fernando de Lucas y

Murillo de la Cueva

Rosa Ma Díaz Jiménez

Teresa Facal Fondo

Josefina Fernández Barrera

Mona Fransehn

María Paz García-Longoria Serrano

Diana Gil González

Josefa Gómez Moya

Antonio Gorri Goñi

Daniel La Parra Casado

Marta Llobet Estany
Facultad Latinoamericana de Ciencias

Sociales

Universitat de Barcelona

Universidad de Castilla-La Mancha

Universidad de Alicante

Universidad Autónoma de Madrid

Universidad Complutense de Madrid

Universitat de Girona

Universidad de la Laguna

Università degli Studi di

Milano-Bicocca

Unviersitat de Girona

Unviersidad de Huelva

Universidad Castilla La Mancha

Universidad de Jaén

Universidad de Valladolid

Universidad de Valladolid

Universidad Complutense

Universidad Pablo de Olavide

Universidad de Santiago de Compostela

Universitat de Barcelona

Göteborg University

Universidad de Murcia

Universidad de Alicante

Universidad de Valencia

Universidad Pública de Navarra

Universidad de Alicante

Universitat de Barcelona 
Antonio López Peláez

Emilio Martínez Navarro

Miguel Ángel Mateo Pérez

Manuel Enrique Medina Tornero

Ana Belén Méndez Fernández

$\mathrm{M}^{\mathrm{a}}$ Teresa Mira-Perceval Pastor

Rosalía Mota López

Eloísa Nos Aldás

Enrique Pastor Seller

Antía Pérez Caramés

José Vicente Pérez Cosín

Joaquín María Rivera Álvarez

J. Daniel Rueda Estrada

José Luis Sarasola Sánchez-Serrano

$\mathrm{M}^{a}$ Luisa Setién Santamaría

José María Tortosa Blasco

Octavio Vázquez Aguado

Cristina Villalba Quesada

Esther Villegas Castrillo
UNED

Universidad de Murcia

Universidad de Alicante

Universidad de Murcia

Universidad de Vigo

Universidad de Alicante

Universidad de Comillas

Universitat Jaume I

Universidad de Murcia

Universidade da Coruña

Unviersidad de Valencia

Universidad Complutense

Universidad de Valladolid

Universidad Pablo de Olavide

Universidad de Deusto

Universidad de Alicante

Universidad de Huelva

Universidad Pablo de Olavide

Universidad de Alicante 



